ting

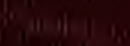




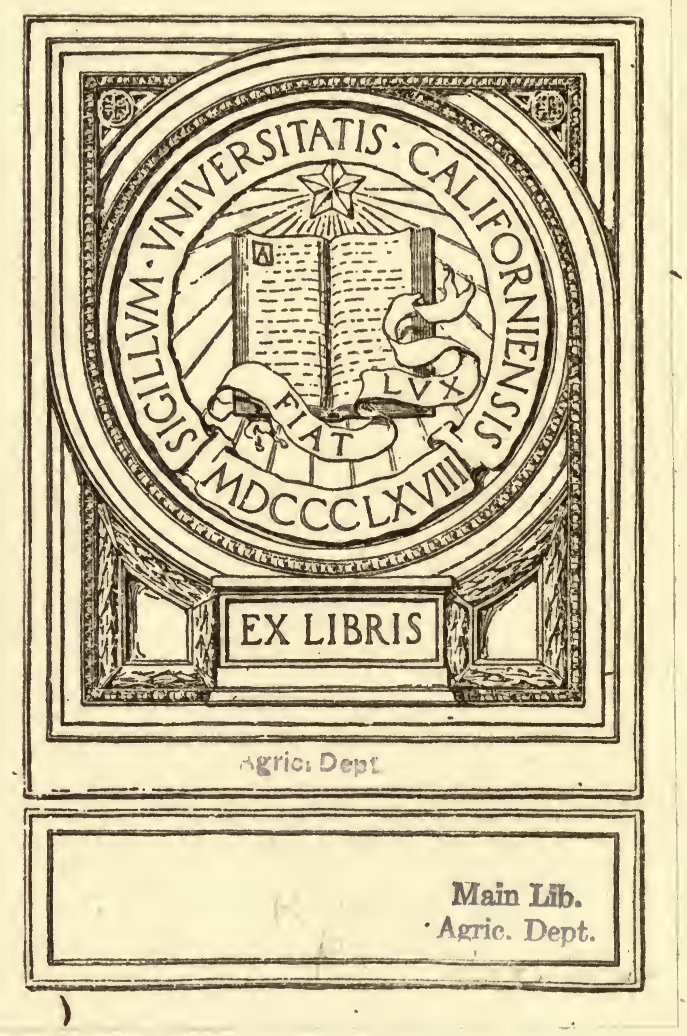








\title{
PRINCIPLES AND PRACTICE OF MILK HYGIENE
}

\author{
BY \\ LOUIS A. KLEIN, V.M.D.
}

PROFESBOR OF PHARMACOLOGY AND VETERINARY HYGIENE IN THE SCHOOL OF VETERINARY MEDICINE AT THE UNIVERSTTY OF PENNGYLVANIA, AND DEAN OF THE FACULTY

41 ILLUSTRATIONS IN THE TEXT

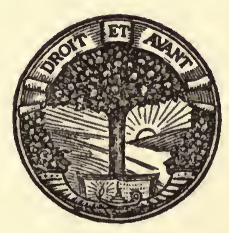

PHILADELPHIA AND LONDON J. B. LIPPINCOTT COMPANY 
$k 5$

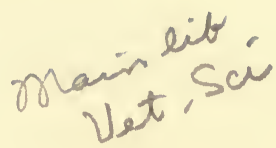

COPYRIGHT, IMIT, BY J. B. LIPPINCOTT COMPANY

Agric Dept (veterinary)

PRINTED BX J. B. LIPPINCOTT COMPANY

AT THE WASHINGTON SQUARE PRESS

PHILADELPHIA, U. s. A. 


\section{PREFACE}

In this book an effort has been made to present systematically, in concise form, the facts and principles which are of importance in the practice of milk hygiene and to describe how they may be applied in the inspection of dairy farms and in the examination of milk. The material has been obtained from various sources. Jensen's " Milk Hygiene," Savage's " Milk and the Public Health," Conn's " Practical Dairy Bacteriology," Swithinbank and Newman's "Bacteriology of Milk," King's "Ventilation," Van Slyke's " Modern Methods of Testing Milk and Milk Products," Grimmer's " Chemie und Physiologie der Milch," Rievel's " Milchkunde," Weigmann's " Mykologie der Milch," Ernst's “ Milchhygiene für Tierärzte," Sommerfeld's "Handbuch der Milchkunde," and Barthel's "Methoden zur Untersuchung von Milch und Molkereiprodukten" have been freely drawn upon, while articles by numerous research workers which have appeared in the various journals and official reports have furnished many important facts. To all of these authors and investigators due acknowledgment is made.

The book is intended primarily as a text for students taking a course in milk hygiene, but it is the hope of the author that it will also prove of service to dairy inspectors, milk examiners, public health officials, dairymen, milk distributers, and others interested in the production of wholesome milk.

Louis A. KLein

Philadelphia, Pa.

September 15, $191 \%$. 



\section{CONTENTS}

CHAPTER

I. Physiology of Mur Steration ..............

Udder Structure and Cell Activity. Stages of

Lactation. Phases of Milk Secretion.

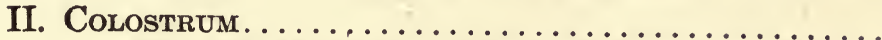

Physical Properties; Chemical Properties; Microscopic Appearance; Ferments or Enzymes; Change from Colostrum to Milk; Judgment of Colostrum as a Food for Man.

III. MrLK

Chemical Properties: Constituents; Variations in Composition; Reaction. Physical Properties: Color; Odor and Taste; Specific Gravity; Refraction; Viscosity; Freezing Point. Microscopical Appearance of Milk and Milk Sediment: Cellular Content; Number of Cells. Biological Properties of Milk: Ferments or Enzymes; Original and Bactcrial Ferments; Diastase; Peroxydase; Catalase; Reductase; Antibodies or Immune Bodies; Germicidal Action of Milk; Toxins; Aggressins. Classes or Grades of Market Milk: Certified Milk; Inspected Milk; Pasteurized Milk; Grade A; Grade B; Grade C.

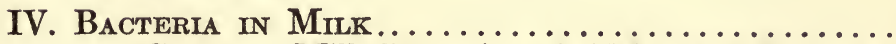

Common Milk Bacteria: Acid-forming Bacteria; Gas-forming Bacteria; Peptonizing or Casease Bacteria; Alkali-forming Bacteria; Inert Bacteria. Variations in Number and Kind of Bacteria: Original Contamination; Temperature; Age of Milk; Proportion of Different Groups of Bacteria.

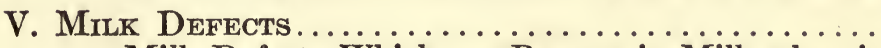

Milk Defects Which are Present in Milk when it Comes from the Udder: Cow-like, or Salty, Cowlike Taste; "Fishy" Milk; Rancid Milk; Slowcreaming Milk; Premature Curdling; "Gritty" or "Sandy" Milk. Milk Defects which Appear After the Milk is Drawn from the Udder: Bitter Milk; Viscid, "Ropy," or "Stringy" Milk; "Soapy" Taste; Failure to Sour and "Butter;" Stable-like, 
Turnip-like and Beet-like Tastes, and a Burnt or Malt-like Taste and Odor; Blue Milk; Red Milk; Yellow- or Orange-colored Spots; Yellowish-green Discoloration; Greenish-Yellow Spots; Violetcolored Spots.

VI. Influence of Disease Upon Milk.............. Diseases of Cattle Transmissible Through Milk: Tuberculosis; Aphthous Fever or Foot and Mouth Disease; Cow-pox; False Cow Pox; Furunculosis of the Udder; Anthrax; Rabies; Actinomycosis; Milk Sickness or Trembles. Diseases of Cattle which may Render Milk Harmful to Man: Inflammation of the Udder (Mastitis); Blood in Milk; OEdema of the Udder; Indigestion; Spoiled Feed; Septic or Hemorrhagic Enteritis; Septic Metritis; Retained Placenta; Infectious Abortion; Other Diseases; Excretion of Medicines Through the Udder. Diseases of Man Transmissible Through Milk: Typhoid Fever; Paratyphoid Fever; Diphtheria; Septic Sore Throat; Scarlet Fever; Tuberculosis.

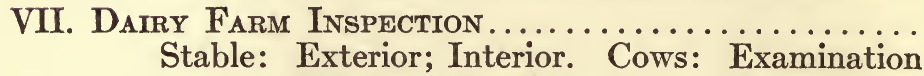
for Cleanliness; Stage of Lactation; Examination for Symptoms of Diseases. Stable Practices: Method of Cleaning the Stable; Cleaning the Cows; Methods of Milking; Feeding; Bedding. Milk House: Location; Construction; Apparatus; Water Supply. Score Cards.

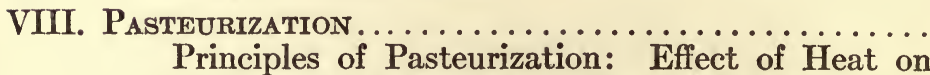
Pathogenic Organisms; Effect of Heat on the Common Milk Bacteria; Toxins and Decomposition Products; Nutritive Properties; Ferments or Enzymes; Taste; Cream Line. Methods of Pasteurization: "Flash" or Continuous Process; "Holder" Process; Pasteurization in the Final Container; Types of Pasteurizers; Biorization; Ultra-violet Rays; Electricity; Ozone.

IX. Methods of Examining MilK.

Collecting Samples; Preserving Samples; Stable or Herd Samples; Individual Samples; Mixing the Milk Sample; Color, Consistency; Odor and Taste. Determination of Specific Gravity; Determination of the Per Cent. of Fat; Determination of Total 
Solids; Determination of Solids Not Fat; Determination of the Specific Gravity of the Solids; Determination of the Per Cent. of Fat in the Total Solids; Determination of the Degree of Adulteration; Tests for Nitrates and Nitrites; Detection of the Usual Adulterations; Determination of the Refraction Number; Determination of the Reaction; Tests for Preservatives; Standard Methods of Counting Bacteria; Examination for Streptococci; Examination for Coli; Examination for Tubercle Bacilli; Fermentation Test; Estimation of the Number of Leucocytes; Boiling Test; Alcohol Test; Catalase Test; Reductase Test; Fermentation Reductase Test; Diastase Test; Tests for Heated Milk; Examination for Dirt; Test for Lactose; Examination for Coloring Matters.

Methods and Standards for the Production and Distribution of "Certified Milk": Organization of Medical Milk Commissions; Hygiene of the Dairy; Transportation; Veterinary Supervision of the Herd; Bacteriological Standards; Chemical Standards and Methods; Methods and Regulations for the Medical Examination of Employees, Their Health and Personal Hygiene. 



\section{ILLUSTRATIONS}

FIG.

HALFTONES

PAGE

1. Alveoli of the Udder in Cross-section............. 2

2. Cross-section of an Alveolus of the Udder at the Time of Parturition......................... 2

3. Involution of the Udder of an Old Cow.......... 3

4. Extremity of the Milk Cistern............... 3

7. Colonies of Coli Aërogenes............... 54

8. Colonies of Proteus Vulgaris................. 54

21. Internal or Double-tube Cooler.............. 186

41. Various Types of Dirt Testers.............. 300

\section{TEXT CUTS}

5. Preparation Showing Streptococcus Lacticus or Bacterium Lactis Acidi. . .........................

6. Preparation from Sediment from a Cow Affected with

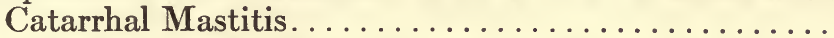

9. Inlet in a Wall Already Constructed; Inlet in a Wall Being Built, and an Outlet Shaft with Two Openings. . 132

10. An Outlet Flue Hinged at the Ceiling........... 134

11. Cross-section of Stable Floor............... 142

12. Window Arranged to Act as Fresh Air Inlet........ 147

13. Open or Uncovered Pail .................. 171

14. Covered-top Pail with Opening Nearly Horizontal. .... 171

15. Covered-top Pail with Vertical Opening.......... 172

16. Another Variety of Covered-top Pail.............. 173

17. Floor Plan of Conveniently Arranged Milk House..... 181

18. Cooler of Conical Type................... 183

19. Corrugated Type of Cooler................ 184

20. Tubular Cooler, with Continuous Surface......... 185

22. Section Showing Relation of Water Table to Surface Irregularities.............................. 194

23. How Springs May be Polluted by Subsurface Drainage. 195

24. A Pasteurizer of Simple Type............... 216

25. Pasteurizer............................. 217 


\section{ILLUSTRATIONS}

26. Pasteurizer.

27. Regenerative Cooler

28. A Simple Holding Tank.

29. Retarder of the Tank Type

30. A Combined Pasteurizer and Holder.

31. Quevenne's Lactometer.

32. Westphal Balance.

33. Modern Type of Babcock Milk-testing Bottle

34. Pipette Used in Babcock Test for Measuring Milk.

35. Cylinder Used in Babcock Test for Measuring Acid.

36. Bottle and Pipettes Used in Gerber Test.

37. Feser's Lactoscope.

38. Zeiss Dipping Refractometer.

39. Sediment Tube Used in the Trommsdorff Test.

40. Gerber-Lobeck Catalase Apparatus. 


\section{PRINCIPLES AND PRACTICE OF MILK HYGIENE}

\section{CHAPTER I \\ PHYSIOLOGY OF MILK SECRETION}

Certain facts concerning the physiology of milk secretion are of importance in milk hygiene. These will, therefore, be briefly presented.

Udder Structure and Cell Activity. -The udder or mammary gland of the cow consists of a large number of alveoli or acini arranged in lobules or groups and held together by connective tissue. The alveoli of each lobule communicate with a common duct which, after emerging from the lobule, continues its course in the interlobular connective tissue toward the milk cistern. The ducts from the several lobules unite to form the larger milk canals. The latter increase in size as they approach the milk cistern, in which they terminate. From the bottom of the milk cistern, a short, narrow canal, called the teat canal, extends through the lower end of the teat to the exterior. The udder of the cow contains four of these glandular systems, one for each teat. Each glandular system is spoken of as a " quarter."

The alveoli are lined with glandular epithelial cells which, in the actively secreting udder, are separated from the capillaries by only a thin basement membrane. These cells select from the blood circulating in the capillaries certain materials which they convert into those substances 
which are peculiar to milk. They also take from th blood, water and other substances which are commo to milk and blood. In histological sections, the milk fa may be observed within the actively secreting cells i the form of small fat droplets (Fig. 1). The other con stituents of milk, being without form, cannot be seer but their presence in the cells is indicated by a granula or turbid condition of the protoplasm. When the cell of an alveolus become filled with secretion, the cell-pro toplasm contracts and the contents is discharged into th lumen of the alveolus, after which secretion again begin The different stages of cell activity do not occur in all c the alveoli at the same time; different alveoli in the sam lobule may show various stages. Secretion continue until the cells are exhausted, and it then ceases unt the cells can recuperate.

In the course of time, after repeated periods of acti ity, exhaustion and rest, the epithelial cells of the alveo are worn out and secretion stops in one alveolus afte another. This change is called involution. In youn cows the worn-out cells are regenerated. The alveo then present the same appearance microscopically a is observed at the time of parturition (see Fig. 2). Th interalveolar connective tissue is increased in volume an contains many leucocytes. Leucocytes are also nume; ous in the alveoli, together with exfoliated epitheli cells, free nuclei, parts of disintegrated cells, fat globule and coagulated casein. Fat droplets may be observe within some of the leucocytes. By their amœboid mov ment the leucocytes migrate from the interalveolar col nective tissue into the interior of the alveoli, passin between the epithelial cells; and the same movemer enables them to take up fat droplets and carry thes 


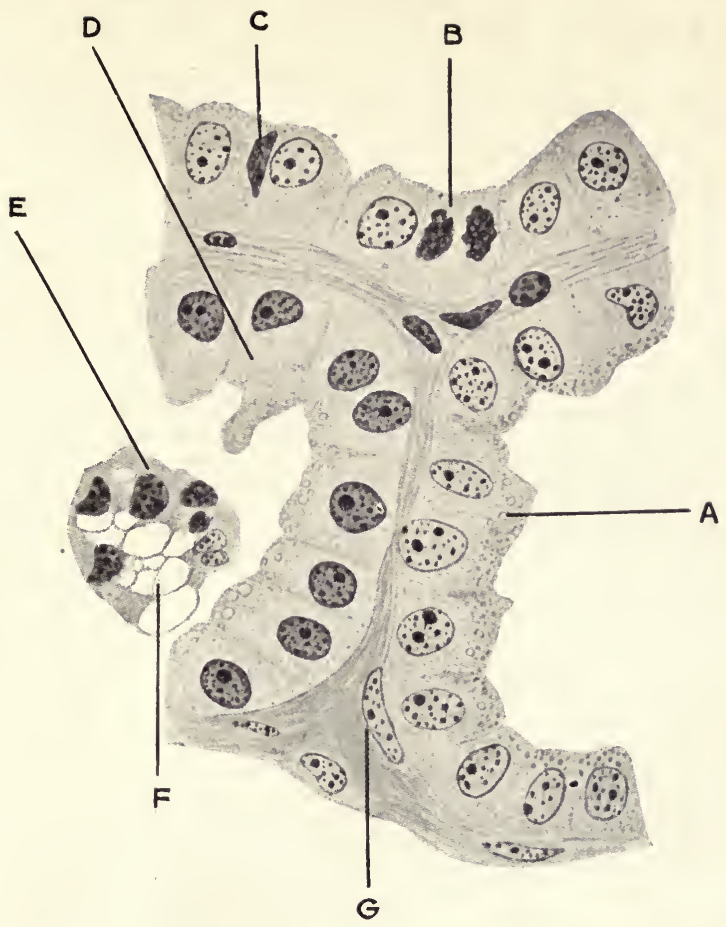

Fra. 1.-Alveoli of the udder in cross-section, showing: (A) fat-droplets in the cpithelial cells, $(B)$ division of the nucleus, $(C)$ a leucocyte in an epithelial cell, $(D)$ epithelial cell with protoplasmic projection, alveolar content with $(E)$ cells and $(F)$ free fat, and $(G)$ interalveolar connective tissue. (From Chemie und Physiologie der Milch, by Dr. W. Grimmer.)

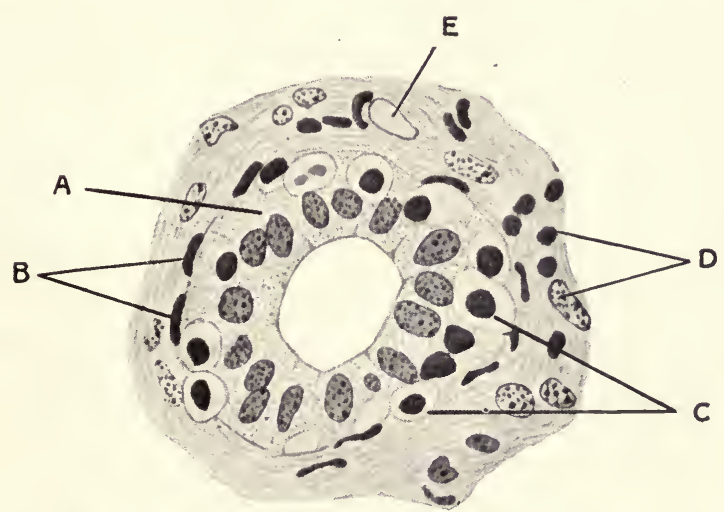

Frg. 2,-Cross-section of an alveolus of the udder at the time of parturition. (A) epithelium, $(B)$ basket cells, $(C)$ leucocytes, $(D)$ nuclei of connective-tissue cells, $\left(E^{\prime}\right)$ blood capillary. (From Chemie und Physiologie der Milch, by Dr. W. Grimmer.) 


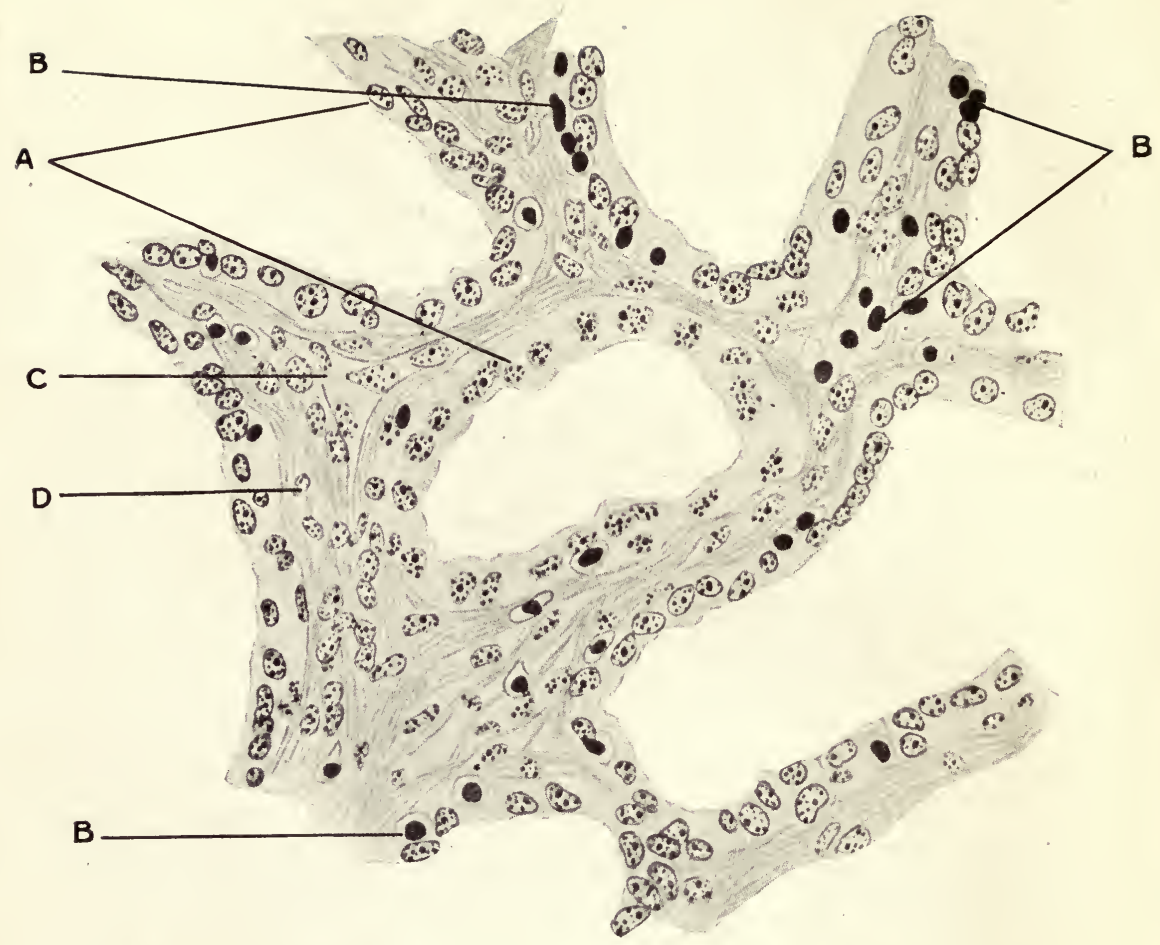

Fig. 3-Involution of the udder of an old cow. (A) epithelium, $(B)$ leucocytes, $(C)$ blood capiliary, $(D)$ interalveolar connective tissue. (From Chemie und Physiologie der Milch, by Dr. W. Grimmer.)

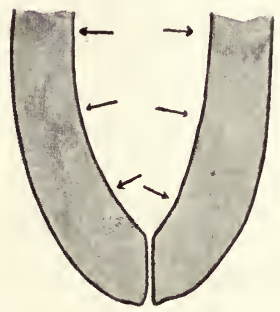

A

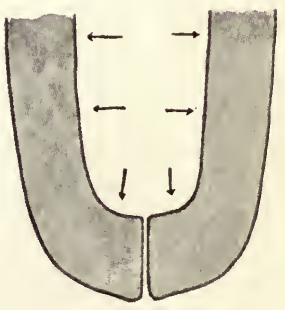

B

Fig. 4.-(A) Funnel-shaped, $(B)$ bell-shaped extremity of the milk cistern. (From Chemie und Physiologie der Milch, by Dr. W. Grimmer.) 
out of the alveoli. An alveolus which has undergone involution and regeneration remains inactive until the next parturition. As the period of the secretory activity of the udder advances, the number of alveoli in this condition increase and the quantity of milk secreted consequently decreases. This change occurs slowly in some cows and rapidly in others, and is commonly spoken of as "going dry." Usually the secretion decreases until it stops altogether; the cow is then said to be "dry." As the termination of secretory activity in the udder approaches, the composition of the milk is considerably changed. Secretion of milk is also called "lactation," and the period during which a cow produces milk is called "a lactation period."

As the cow advances in age, usually beginning with the fifth lactation, some of the worn-out alveoli are not regenerated. With each succeeding lactation an increasing number remain permanently inactive or break down, and the quantity of milk produced is consequently decreased. The interalveolar and interlobular connective tissue gradually increases in volume, while the gland tissue decreases. (See Fig. 3.) Finally the udder becomes firm and hard and is said to be "fleshy." A similar change is sometimes caused by disease in young as well as in old cows.

Stages of Lactation.-The function of milk secretion is intimately related to the function of reproduction. Pregnancy stimulates the development of the gland tissue of the udder and secretion begins a few days before or at the time of parturition. Why the udder begins to secrete at this time is not known. Of the many theories advanced, that of Schein appears to be the most plausible. According to this theory, the blood of the 
pregnant cow contains certain substances called "milkforming substances." During pregnancy the greater portion of these substances is required for the nourishment and development of the fœetus, but sufficient is left over to stimulate the development of the glandular tissue in the udder. When the fœtus is developed, all are available for action upon the udder and secretion is stimulated.

At the time of parturition the udder does not secrete milk, but a substance called colostrum. The alveoli at this period contain many cells, entire and disintegrated, and leucocytes are also numerous in the interalveolar connective tissue. The secretion is therefore rich in cells. It also contains comparatively large, round bodies which have the appearance of masses of fat grobules. These are the so-called colostrum corpuscles, which are regarded by some as leucocytes which have taken up a large number of fat globules, and by others as exfoliated epithelial cells containing masses of fat globules. A cow in this stage of lactation is said to be "fresh."

During the first week the secretion gradually changes to milk. The alveoli of the udder are not all active at this time, but those which are inactive and which have not undergone permanent involution resume their function within the succeeding two or three weeks, when the secretion of milk reaches its highest point. Usually by the end of the first week the leucocytes have disappeared from the alveoli and interalveolar tissue and very few cells are present in the milk. But if milking is delayed or is incomplete at any time, or if stasis of milk occurs from any cause, leucocytes again invade the alveoli and interalveolar tissue in large numbers and become numerous in the milk. Their appearance under these condi- 
tions seems to be for the purpose of preventing stagnation of milk in the alveoli; they take up the fat globules in the alveoli and carry them off to the lymph stream (Czerny). Leucocytes and exfoliated epithelial cells are also present in the milk in large numbers in inflammation of the udder.

Under natural conditions, the secretion of milk continues only until the offspring is able to masticate and digest solid food. But in the highly specialized dairy cow, in which the function of the udder has been greatly developed, lactation may continue for as long as one to two years if reimpregnation does not take place, provided the milk is regularly withdrawn. When the cow is reimpregnated, lactation usually ceases within a few weeks of parturition, but in some individuals it continues without interruption from one parturition to the next. In these latter animals, the secretion changes to colostrum a few days before parturition. Cows in which lactation is about to cease are called "strippers." Near the end of lactation the milk changes very much in composition and the cellular content again increases. Quite frequently it has a salty or bitter taste, or an animal-like taste and odor which are unpleasant. It is considered good practice to give the udder and the organs of digestion an opportunity to rest and recuperate before a new lactation period begins, and "persistent milkers" are frequently "dried off" about a month before the succeeding parturition is due. This can usually be accomplished by reducing the feed and gradually stopping milking. Periodical emptying of the udder is necessary for the continuance of milk secretion, and the opposite effect is produced when milking is incomplete or is omitted. 
Phases of Milk Secretion.-All of the milk obtained from the udder at one milking is not secreted before the withdrawal of the milk is begun. The average volume of the cavities of the udder is 3,000 c.c., or about 3 quarts, while the average yield of milk at one milking is from 4,000 to 6,000 c.c., or about 4 to 6 quarts (Fleischmann). A large part of the milk obtained at a milking is secreted while the cow is being milked. As much milk is secreted in ten to fifteen minutes during milking as is formed during the entire period between milkings. The secretion of milk may be divided into two phases (Zietzschmann).

The first phase occurs during the intervals between milkings. Following the completion of a milking, the gland remains at rest for a short time until the exhausted secretory cells can recuperate; then secretion is resumed, and gradually increases in intensity up to a certain point. The udder gradually becomes larger and firmer, but the teats remain relaxed and pendulous and contain only a small quantity of milk. The greater part of the milk secreted during the first phase remains in the alveoli and the large milk canals. There are two reasons for this: (1) the horizontal direction of the large milk canals does not favor the flow of milk into the cistern, and (2) the inward pressure of the erectile tissue in the teat causes the mucous membrane to project into the cistern in folds, filling up the cavity and opposing the flow of milk into it. When the alveoli and the milk ducts and canals become full, secretion decreases in intensity. Under ordinary conditions the pressure in the alveoli, ducts, and canals does not become sufficient to overcome the counterpressure exerted by the erectile tissue in the teats, 
and consequently the milk cistern remains practically empty.

The second phase of milk secretion begins when the udder is stimulated reflexly by manipulation of the teats. The udder becomes fuller and more tense, the gland substance firmer. The teats lengthen and become rigid and divergent, while the wrinkles disappear from the skin covering them. The udder is distended and the cisterns are full of milk. The milk has been "let down." All these changes are brought about by the downward stroking of the teats, which causes reflexly (1) dilation of the blood vessels and an increased flow of blood to the udder, (2) contraction of the walls of the alveoli and ducts, which forces the milk down into the cisterns, and (3) increased secretion of milk. The same effect may be produced reflexly by an irritation of the internal genital organs such as may result from irrigation of the uterus or vagina, or manual removal of the placenta, and also by psychic influences like the sight of the calf, the clatter of the milk vessels, the sound of milk drawn from another cow into a pail, etc. When the interval between milkings is too long the milk is "let down" spontaneously, but in this case it occurs gradually.

As soon as the milk is sufficiently "let down" the withdrawal of milk may be begun. The descending pressure exerted by the hand upon the contents of the milk cistern in the operation of milking opens the sphincter between the teat canal and the cistern, permitting the milk to escape. This pressure operates perpendicularly to the wall of the cistern, and when the bottom of the cistern is pointed or conical the sphincter is opened more readily than when the bottom is flat (see Fig. 4 ). The 
manipulation of the teats in milking causes the hyperæmia and increased secretion set up by stroking the teats to continue until the secreting cells are exhausted, when the flow of milk ceases and the udder becomes smaller in size and relaxed. The manipulation of one teat produces hyperæmia and stimulates secretion in all four quarters of the udder. The second phase of milk secretion is therefore due to the mechanical stimulation resulting from the manipulation of the teats in milking. The stimulating apparatus is in the teats, but it is not clear how the stimuli are transmitted. The udder is richly supplied with nerves from the sympathetic system and from the lumbar plexus, and yet secretion can go on after the greater part of the nerve apparatus is disconnected.

Three factors are concerned in the second phase of milk secretion: (1) The vasodilator nerves are stimulated reflexly by the mechanical manipulation of the teats in milking, producing a hyperæmia and bringing a rich supply of milk-forming material to the secreting cells. (2) The operation of milking stimulates also the secretory and the motor nerves; stimulation of the secretory nerves accelerating the secretory processes in the cells of the alveoli, and stimulation of the motor nerves causing a contraction of the alveoli and ducts and forcing the milk into the cistern. (3) The " milk-formers," which circulate in the blood, stimulate the secretory cells (Zietzschmann).

Under certain abnormal conditions the secretion of the second phase stops before the usual amount of milk is obtained. This may result from fright, sudden anxiety, and in sensitive animals from unusual manipulation of the teats (strange milkers), from sore teats, etc. The 
distended udder is suddenly reduced in size and becomes relaxed. This is due to a reflex contraction of the blood vessels, which reduces the blood supply, and to the emptying of the milk cisterns. Contraction of the blood-vessels slightly enlarges the alveoli and ducts, creating a vacuum, and the milk in the cisterns is drawn up into the alveoli and ducts. It is then said the cow "draws the milk up," or "will not give down." In these cases the physiological effect of the manipulation of the teats in milking is overcome by a stronger impulse. If these impulses are repeated frequently, or are due to more or less permanent conditions, like chronic sores on the teats, the shortening of the second phase may become habitual or permanent.

The secretion of the first phase is passive and slow. According to Zietzschmann, it is due to the stimulant effect upon the gland cells of the "milk-formers" circulating in the blood.

The secretion of the second phase is active and rapid, and is instituted and continued by the manipulation of the teats in milking.

Within certain limits, increasing the number of milkings, thus shortening the period between milkings, will increase the total daily yield of milk. If milked three times in twenty-four hours, a cow will usually yield a greater total quantity of milk per day than when milked twice in twenty-four hours.

The composition of the milk is different in the first and second phases. The first milk drawn from the udder at any milking will contain a smaller proportion of solids, especially fat, than the succeeding milk. This is not due to the fat rising to the top of the fluid in the udder, nor to the adhesion of the fat globules to the walls 
of the alveoli and ducts, as has been suggested, because when milk is drawn from the udder at the end of the first phase with a milk tube or catheter the composition of the first and last milk is about the same; but as soon as the teats are manipulated, thus beginning the second phase, the per cent. of fat is increased. The milk secreted during the first phase contains a lower per cent. of fat than that formed in the second phase. The per cent. of other solids is nearly the same in the milk of both phases. The original ferments or enzymes, except oxydase, are present in greater quantity in milk of the second phase than in that of the first. The first milk drawn from the udder contains more oxydase than the end milk. 


\section{CHAPTER II}

\section{COLOSTRUM}

Beginning a few days before and continuing for several days after parturition, the udder secretes a substance called "colostrum," which differs in many respects from milk. This fluid is intended for the nourishment of the calf during the first days of life outside of the uterus of the mother. It contains a very high per cent. of albuminous compounds in a form in which they can be readily absorbed from the digestive tract of the young animal. It also contains protective substances from the mother (Engel), which are of value in maintaining health (Immisch), and it has a laxative action upon the bowels of the calf, which results in the removal of the meconium.

Physical Properties.-Colostrum is of a yellowish, reddish-yellow, or brownish color; of a thick, slimy, sticky or "stringy" consistency, with a peculiar unpleasant odor and a salty taste. The yellowish color is due to the presence of fat globules, which are frequently clumped together, while the reddish or brownish tinge is due to the presence of red-blood cells or blood. Containing a much greater per cent. of solids than milk, its specific gravity is naturally much higher, ranging from $\mathbf{1 . 0 4 0}$ to $\mathbf{1 . 0 8 0}$ and even up to $\mathbf{1 . 0 9 0}$.

Chemical Properties.-Albumin and globulin are present in colostrum in considerably greater quantity than in milk. Nuclein compounds are also to be found in larger proportion. There is less casein and sugar, about the same per cent. of extractives, but a greater proportion of mineral salts. The analysis, as given by 
Eugling, is as follows: Casein 2.65 per cent., albumin and globulin 16.55 per cent., sugar 3 per cent., extractives 3.54 per cent., ash 1.18 per cent., and water 73.07 per cent. The high content of albumin and globulin is due to the presence of the colostrum bodies and numerous other cells. The sugar is not lactose, as in milk, but glucose, or perhaps a mixture of glucose and galactose (Tereg). Of the extractives, about 78.2 per cent. is fat, 13.8 per cent. cholesterin, and 8 per cent. lecithin. The fat differs from that of milk and is apparently similar to the fat of the tissues. The mineral salts are rich in magnesia, to which is attributed the laxative effect of colostrum.

The reaction is acid to litmus. For two to four days after parturition the secretion coagulates when boiled (see boiling test), on account of the large quantity of albumin and globulin present, while it curdles for four to twelve days after parturition when mixed with an equal volume of 68 per cent. alcohol (see alcohol test).

Microscopic A ppearance.-Viewed under the microscope, colostrum is seen to contain free fat globules, which are not uniform in size like those seen in milk; colostrum bodies or corpuscles, which are comparatively large, round or mulberry-shaped masses, containing fat globules; leucocytes, some of which contain fat globules, and, in fresh colostrum, show amoboid movement; and epithelial cells, which are more or less disintegrated. The colostrum bodies are cells which contain large masses of fat globules within their protoplasm, but opinions differ as to whether they are leucocytes or epithelial cells.

Ferments or Enzymes.-Catalase and diastase are present in colostrum in greater amount than in milk, but at the end of the first week after parturition they are 
reduced to the amount normally found in milk. Oxydase and peroxydase may be absent for thirty hours or less following parturition, but after that time they are usually present (Gruber).

The bactericidal power of colostrum is greater than that of milk.

Change from Colostrum to Milk. - The secretion of the udder changes gradually in appearance and composition until, in about a week after parturition, it becomes milk. According to Weber, the consistency is changed to that of milk by the second to the fifth day, usually by the third; the color by the third to the eighth day, usually by the fifth, and the reaction by the seventh day, although this is variable. The colostrum bodies persist for variable periods. In some cows they continue to be present indefinitely in small number, while in others they are absent even in the first days of secretion. Shortly before the lactation ceases they again become numerous.

Judgment of Colostrum as a Food for Man.-While colostrum is of great value to the new-born calf, it is not considered desirable as human food. It has not been proven to be injurious to the health of man, but the odor and taste are obnoxious, and its appearance is unappetizing. Regulations of local health authorities for the control of milk supplies, therefore, forbid the sale of the product of a cow for food purposes usually for one week after parturition, and also for fifteen days before. It has been proposed by Weber that the use of the udder secretion be prohibited for general food purposes as long as it coagulates when boiled ( 2 to 4 days), and that its use for children be forbidden as long as it continues to react to the alcohol test (4 to 12 days). 


\section{CHAPTER III}

\section{MILK}

The fluid known as "milk" consists of water and certain solids. The latter are in solution, in suspension, and in emulsion. In order to comprehend the various changes which may occur in milk and to understand the different methods for its examination, it is necessary to have some knowledge of its physical and chemical properties, its microscopic appearance, the ferments or enzymes it contains, and the bacteria with which it may be contaminated. These points will therefore be given consideration.

\section{CHEMICAL PROPERTIES}

Constituents.-The principal chemical constituents are casein, lactalbumin, lactoglobulin, fat, lactose, mineral salts, and water.

Casein is a nucleo-albumin and therefore contains phosphorus. It is insoluble in water when free and uncombined. But in milk it is combined with calcium in the form of dicalcium caseinate. This compound, which is neutral to litmus and acid to phenolphthalein, is responsible for the white color of milk, and in part for its opacity. It is not in solution in milk, but in suspension. When milk is exposed to a low temperature the calcium caseinate forms flakes, which, when the temperature is sufficiently low, are visible to the eye; it is also more readily precipitated. This must be kept in mind when the alcohol test is used (page 285).

If an acid is added to milk the casein is precipitated. 
The same thing occurs when the lactose in the milk is fermented by bacteria and a sufficient quantity of acid is produced. The calcium caseinate is split up. The acid combines with the calcium, while the free casein, being insoluble, is precipitated in the form of a firm, jelly-like white curd. Subsequently this curd contracts and expresses a fluid called whey, which contains some of the milk fat, the albumin and globulin, the milk sugar, the mineral salts, and the calcium salt formed by the combination of the acid with the calcium. Most of the fat remains in the curd with the casein. This is the common sour curdling of milk. If lime water or a dilute solution of an alkali is added, the casein will be redissolved and the acidity reduced.

Rennet or chymosin also causes curdling of milk. In this case the calcium caseinate is split up by the rennet into calcium paracaseinate and a substance known as whey-proteid. Calcium paracaseinate, being insoluble, is precipitated and forms a curd, while the whey-proteid is held in solution in the whey. Certain bacteria produce a rennet-like ferment, which splits up the casein compound of milk in the same manner. This is the sweet curdling of milk, so called because the milk curdles without souring. The curd produced in this way cannot be redissolved by lime water or a dilute solution of an alkali. Curdling of milk may occur from the joint action of acids and the rennet-like ferment. The blood contains a ferment, called anti-rennet, which inhibits the action of rennet. This ferment is not present in normal milk, but when inflammation occurs in the udder and there is a transudation of serum from the blood-vessels into the udder tissue the anti-rennet ferment is present in the udder secretion, which is then not coagulated by rennet 
at all, or only after several times the usual amount of rennet is added. A method based upon these facts has been proposed by Schern for detecting milk from cows affected with mastitis, but the test has not come into very general use, because it has not been found possible to obtain a standardized rennet solution which will not deteriorate.

Fresh milk may be heated to boiling without coagulation occurring. A thin membrane, which consists principally of casein, forms on the surface, but real coagulation does not take place. After a certain degree of acidity has been reached a temperature of $75^{\circ} \mathrm{C}$. $\left(167^{\circ} \mathrm{F}\right.$.) is sufficient to coagulate the casein.

Casein is formed by the secreting cells of the alveoli of the udder from the circulating albumin of the blood (Rievel).

Lactalbumin.-The albumin of milk is in solution. It is similar to the albumin of the blood, but differs slightly in its chemical composition and polarization. It begins to coagulate at $65.6^{\circ} \mathrm{C} .\left(150^{\circ} \mathrm{F}\right.$. $)$, and the coagulation increases with the temperature (Rupp). Whether the albumin originates from the breaking down of cells or is derived from the blood is not known.

Lactoglobulin.-The globulin of milk originates from the disintegration of cells, and is present in milk in solution. It coagulates at $75^{\circ} \mathrm{C} .\left(167^{\circ} \mathrm{F}\right.$.).

Fat.-The fat is present in milk in an extremely finely divided condition-i.e., in an emulsion. Under the microscope it can be observed in the form of small globules. The specific gravity of the fat is lighter than that of any of the other milk constituents, including the water, being only 0.93 . Consequently the fat globules in milk are buoyant, and when the milk is permitted 
to stand undisturbed they rise to the top and in a very short time form a layer on the top of the fluid, which is known as the cream layer or the cream line. By many consumers the quality of milk is judged solely by the thickness of the cream layer. When the cream is removed the remaining fluid is called skim milk; or it is called separator milk when the cream is removed by a centrifugal apparatus known as a separator.

The fat globules vary in size with the breed, the stage of lactation, the feed, at different periods of the same milking, and with the individual. In the milk of Jersey and Guernsey cows the fat globules are larger than they are in the milk of Holsteins and Ayrshires. The cream rises more rapidly when the globules are large than when they are small.

Moderately high temperatures also favor the separation of the fat globules from the remainder of the milk; therefore when milk is to be run through a separator it is usually warmed to $32^{\circ} \mathrm{C}$. $\left(90^{\circ} \mathrm{F}\right.$.). On the other hand, higher temperatures delay or entirely prevent the formation of a cream layer. Temperatures above $70^{\circ} \mathrm{C}$. $\left(158^{\circ} \mathrm{F}\right.$.) destroy the cream line entirely. A temperature of $65^{\circ} \mathrm{C}$. $\left(149^{\circ} \mathrm{F}\right.$.) for ten minutes has no effect, but as the time of exposure at this temperature is increased the formation of the cream layer is delayed more and more, until finally, after forty minutes' exposure, it does not form at all. Milk may be heated at $63^{\circ} \mathrm{C}$. $\left(145.4^{\circ} \mathrm{F}\right.$.) for thirty minutes and at $60^{\circ} \mathrm{C}$. $\left(140^{\circ} \mathrm{F}\right.$.) for as long as fifty minutes without affecting the cream line. The cream does not rise in homogenized milk because the fat globules have been broken up into fine particles. Such milk is said to be more palatable and more digestible than ordinary milk, 
but these advantages are overbalanced by the expense of the process.

When milk is shaken or agitated the fat globules gradually unite and form flakes or lumps-i.e., butter. Small clumps of butter fat may form in milk during transportation when the container is not full. This change may affect the test for fat. If milk or cream is slightly acid and warm, the clumping of the fat globules is facilitated. Hence cream is usually churned after it has attained an acidity 0.4 per cent., and at a temperature of $21^{\circ}$ C. $\left(70^{\circ}\right.$ F. $)$. Cream from a cow near the end of lactation may not "butter" because of its alkalinity.

The fat of milk differs in its chemical and physical properties from both the fat of the tissues and the fat of the food. It consists of a mixture of fats, principally olein, stearin, and palmatin, together with some butyrin and other fats. Its composition varies, being influenced by the breed, feed, external conditions, etc. Cotton-seed meal, for example, increases the olein and raises the melting point. When milk fat decomposes, butyric acid is liberated and produces a rancid odor and taste. The color of the milk fat is more or less yellow. The fat globules, by reflecting the light, are partly responsible for the opacity of milk.

In regard to the origin of the milk fat, it appears most probable that it is derived in part from the splitting up of albuminous compounds in the udder or in another part of the body, or in both places. It may also be formed from the carbohydrates which are carried to the udder by the blood (Rievel).

Lactose.-This substance, also known as "milk sugar," is in solution in milk. It is a disaccharid and 
may undergo different varieties of fermentation when acted on by microörganisms. Certain bacteria split up lactose into lactic acid and certain by-products (carbon dioxide, hydrogen, formic acid, butyric acid, etc.). These organisms are the cause of the common "souring" and curdling of milk. The bacteria of the coli-aerogenes group ferment lactose and form acids and gases (lactic, acetic, and succinic acids, carbon dioxide, carburetted hydrogen, oxygen, and nitrogen).

Under normal conditions, lactose is found only in the milk. If milk is retained in the udder from any cause, as incomplete milking, omission of milking, udder disease, etc., then lactose appears in the urine. When a secreting udder is completely extirpated, glucose is temporarily present in excess in the blood and appears in the urine, while lactose appears in the urine if the udder tissue is not completely removed. These latter facts are taken to indicate that milk sugar is formed in the udder from the glucose carried to it by the blood.

Salts.-The salts of milk, which are in solution, are very largely inorganic. Calcium, potassium, and sodium, together with small quantities of magnesia and oxide of iron, are present in combination with phosphoric acid, sulphuric acid, chlorine, and carbonic acid. "A small portion of the basic substances is in combination with citric acid and probably with other organic acids.

Water. - The water of milk is derived from the blood. The milk constituents, except the water, are referred to as the milk solids, total solids, or dry matter. The casein, albumin, globulin, lactose, and salts are designated as solids not fat.

Variations in Composition.-While normal milk always contains the same chemical constituents, the proportions 
in which they are present vary very much. The fat shows a greater variation than the other solids. In milk rich in total solids, the fat content is frequently considerably above the average, while the per cent. of solids not fat only slightly exceeds the average. On the other hand, in thin, poor milk the fat per cent. may be far below the average, while the per cent. of solids not fat is not very far from the average. Milk from individual cows shows a greater variation in composition than different samples of market milk, which is a mixture of the milk from a number of cows.

Individual milk may show the following variations in the proportion of the different constituents: fat, 2.5 to 7.5 per cent.; lactose, 4 to 5.8 per cent.; casein, 2 to 5 per cent.; albumin, 0.39 to 0.95 per cent.; globulin, a trace; salts, 0.35 to 1.21 per cent.; water, 83 to 89 per cent.

The fat content shows the greatest range of variation and the lactose the least. These variations must be taken into consideration in collecting samples of milk for certain tests and in judging the results of tests for adulteration and skimming. They are due to a number of causes.

Some of these causes, such as the breed, individuality, and stage of lactation, are more or less regular and constant in their operation. As a rule, cows of the Jersey and Guernsey breeds give milk richer in fat than Holsteins and Ayrshires, but some individuals of the Holstein and Ayrshire breeds give milk with a higher fat content than some Jerseys and Guernseys. Early in the stage of lactation, when the milk flow is most abundant, the proportion of solids, especially the fat, is less than it is later, when the milk flow has decreased. Instances 
are known where the addition of several "fresh" cows to a small herd at the same time has reduced the fat per cent. of the mixed milk below the standard formerly maintained. In the last month of lactation, when the secretion decreases rapidly, the proportion of solids usually increases, especially the fat. At the same time, the secretion reacts decidedly alkaline to litmus paper and usually has a salty taste; sometimes it has an animallike odor and taste. Cows in this stage of lactation are called "strippers." In exceptional cases the milk does not show any noticeable change in chemical composition during the entire period of lactation, while in rare cases the per cent. of solids may decrease at the end of lactation. At different stages of the same milking the milk also shows a regular and constant variation in composition, the first milk drawn containing a lower per cent. of fat than the last or "end" milk. Incomplete milking may lower the per cent. of fat, because the end milk is much richer in fat than the first milk.

Transitory and irregular variations in composition may be observed in the milk of the same cow from day to day, or even in the milk drawn at different milkings on the same day. The fat content may show a difference of as much as one per cent. These variations are attributed to change in the character of the feed, or in the time of feeding and watering, change of milkers, the weather, change of stable, and unusual occurrences (storms, strangers, etc.). The quantity of milk secreted is also affected by the same causes. While the feed has no pronounced permanent effect on the composition of the milk, a change from dry to green feed may cause a temporary increase in the fat of from 0.5 to 1 per cent., while distillery slops 
or other very watery feed may cause a temporary decrease of from 0.25 to 0.5 per cent.

The time of milking will influence the composition of milk. When the intervals between the milkings are equal and the feed, amount of water, etc., are the same, there is no difference between the composition of the morning and evening milk; but in practice the periods are usually unequal, the shorter interval preceding the morning milking in the summer and the evening milking in winter. At the milking following the shorter interval the quantity of milk obtained is less and the fat per cent. is greater than at the other milking. Hence it follows that in summer the morning's milk is richer in fat but of lesser quantity than the evening's milk, while in winter the reverse is true. The age of the cow has no appreciable effect on the composition of milk. Voluntary exercise in the open air increases the fat per cent. as well as the quantity of milk yielded; forced exercise decreases the water in the milk and consequently decreases the volume of the milk flow, but the per cent. of fat is increased, while violent exercise reduces both the volume and the per cent. of solids. The effects of oestrum are not uniform; the fat may be increased or decreased, the albumin may be increased to such an extent that the milk will curdle when boiled, or there may be no change in the composition. In one test of milk from a cow with nymphomania the proteids were increased to 5.72 per cent. Weaning, or removing the calf, when it causes the cow to become restless and fretful, is attended with a decrease in the fat per cent. The variations in quantity and composition caused by disease will be considered in the chapter on the "Influence of Disease on Milk."

Market Milk varies less in composition than indi- 
vidual milk, because the different variations in the milk of individual cows balance one another more or less. Under certain conditions, milk from different herds, i.e., herd milk, may show a greater variation in composition than the mixed milk of several herds. For example, milk from a Jersey or Guernsey herd will usually show a higher fat content than milk from a Holstein or Ayrshire herd. The presence of a large proportion of "fresh" cows in a herd at one time may cause the mixed milk of the herd to be low in solids, especially fat, while a large proportion of "strippers" may have the opposite effect. The per cent. of fat in market milk may range from 3 to 5 per cent., and the per cent. of solids not fat from 8.5 to 10.5 per cent. The average composition, as reported by Flieschmann, is: fat, 3.4 per cent.; lactose, 4.6 per cent.; casein, 3 per cent.; albumin, 0.5 per cent.; globulin, a trace; salts, 0.75 per cent.; water, 87.75 per cent.

Over 5000 samples of milk examined at the New York State Experiment Station at Geneva, N. Y., were found to contain an average of 3.9 per cent. of fat, 5.1 per cent. of lactose, 2.5 per cent. of casein, 0.7 per cent. of albumin, $\mathbf{0 . 7}$ per cent. of salts, and $\mathbf{8 7 . 1}$ per cent. of water.

Although it is unusual, normal market milk may fall below the usual limit for solids, especially fat, particularly milk from a single herd, under some of the conditions mentioned above. For this reason, difficulty has at times been experienced in legally proving that milk has been skimmed or diluted with skimmed milk or water, and this has led to the adoption of legal standards for milk and other dairy products by different states, the United States government, and some municipalities. 


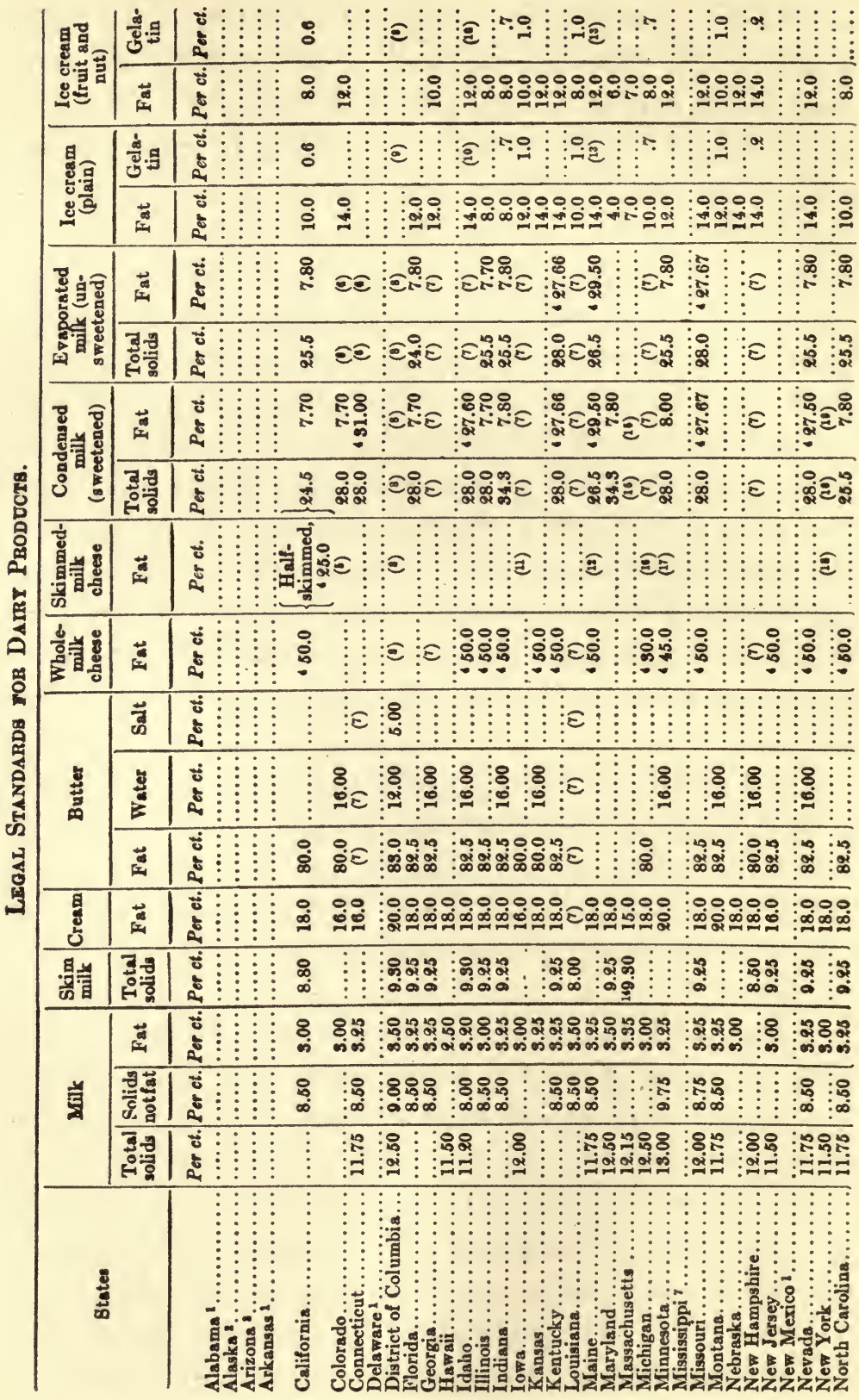




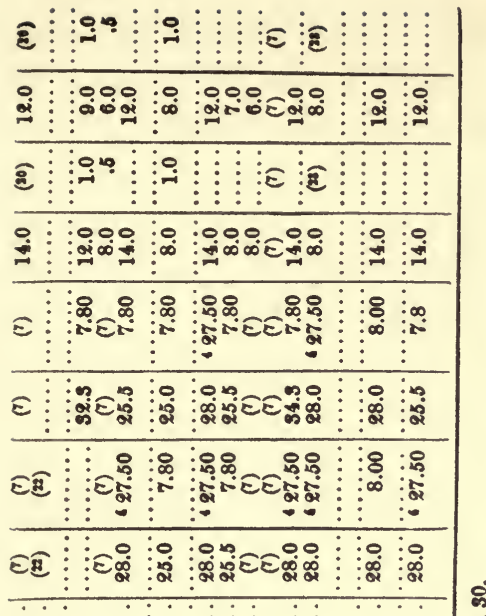

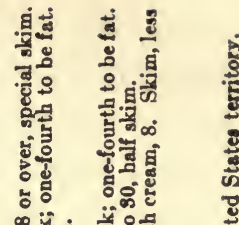

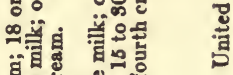

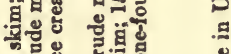

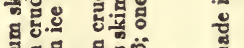

苟.․․․

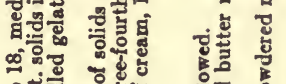

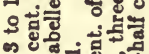

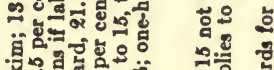

我

कि

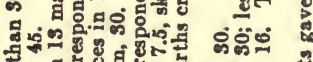

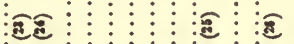

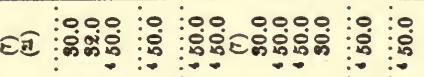

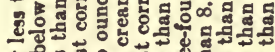

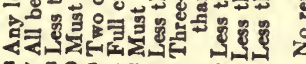

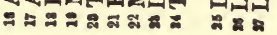

E $\vdots \vdots \vdots \vdots \vdots$

E

E

웅

๑ :

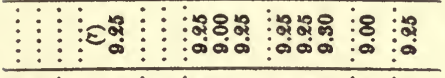

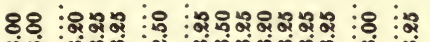

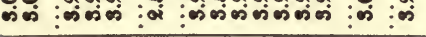

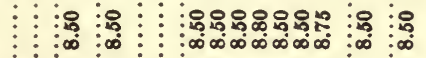

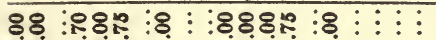

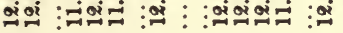
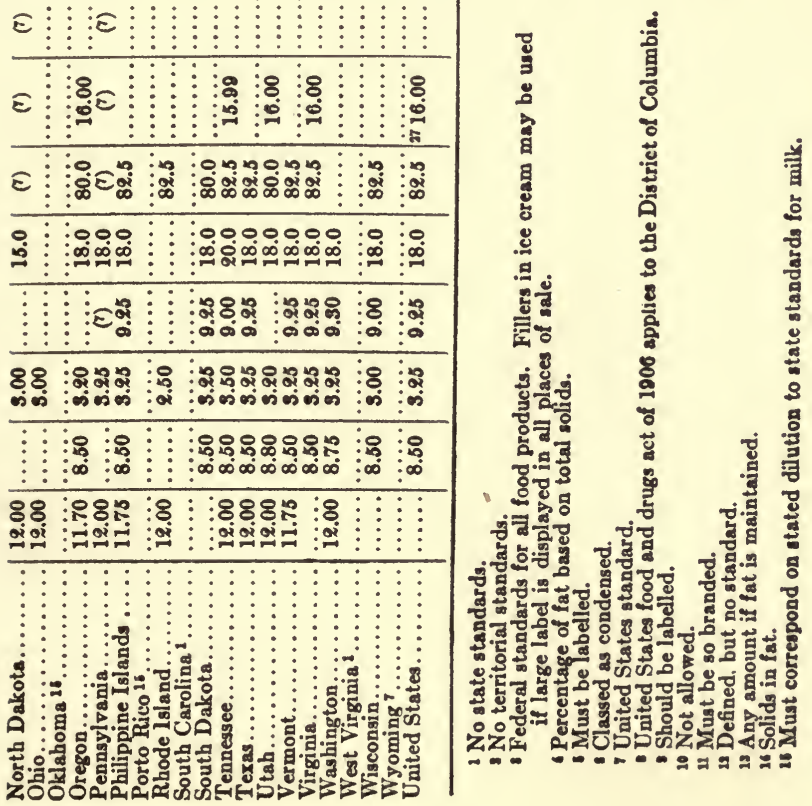
The standard of the United States Department of Agriculture calls for 3.25 per cent. of fat and 8.5 per cent. solids not fat for milk; 9.25 per cent. solids for skim milk, and 18 per cent. fat for cream. The standards for milk and other dairy products adopted by the various states and territories, as reported by the United States Bureau of Animal Industry, will be found on pages 24 and 25.

Reaction.-The reaction of milk is amphoteric to litmus-i.e., it turns blue litmus red (acid monobasic phosphates) and changes red litmus to blue (alkaline dibasic phosphates). To phenolphthalein solution it is acid. When phenolphthalein solution is added to milk, no color reaction occurs, because the color of phenolphthalein solution is not changed by acids. But if, after the addition of phenolphthalein solution, sodium hydroxide solution is added to the milk in excess of the amount necessary to neutralize the acidity the fluid assumes a pink color, which is permanent. This reaction is made use of in determining the degree of acidity of milk and cream.

To neutralize the acidity in 100 c.c. of normal, fresh market milk, 18 to 19 c.c. of a one-tenth normal solution of sodium hydroxide are required. This represents an acidity of 0.16 to 0.17 per cent. The acidity of milk when it is drawn from the udder is less than 0.1 per cent. This original or native acidity is due to the casein and acid phosphates. The fermentation of the milk sugar by bacteria increases the acidity. Lactic or other acids formed in this manner are present whenever the acidity is over $\mathbf{0 . 1}$ per cent. Market milk with an acidity of $\mathbf{0 . 1}$ to $\mathbf{0 . 2}$ per cent. is considered fresh and good. In some 
cities the legal limit is $\mathbf{0 . 2}$ per cent. A sour taste is not present until the acidity exceeds 0.3 per cent.

The acidity of colostrum is about three times as great as that of milk. As the colostrum changes to milk, the acidity gradually decreases until it reaches the point normal for milk. Toward the end of lactation the acidity is further decreased, and in "strippers" is very low, or the reaction may even be alkaline.

The reaction of the milk of individual cows is usually below normal in acidity, or may even be alkaline, in ordinary inflammations of the udder, tuberculosis of the udder, and probably also when the udder is eliminating abnormal substances, as in cowpox; but this is by no means always the case. In streptococcic mastitis the milk may be more acid than normal. The reaction alone of the milk of individual cows cannot therefore be relied upon to discover diseased conditions. It is hardly necessary to mention that nothing can be learned on this point from determining the reaction of market milk.

High acidity in market milk is usually the result of excessive fermentation of the lactose, and is an indication that the milk is stale, or was produced under unclean conditions, or was not properly cooled and cared for. The addition of boric acid or formaldehyde also increases the acidity. Salicylic acid has less effect on the reaction because it is usually not added in very great quantity. The acidity may be reduced by the addition of alkalies (bicarbonate of soda, chalk, potash), but the addition of these substances to milk is illegal. Addition of water and heating (loss of $\mathrm{CO}_{2}$ ) also reduce the acidity.

(For methods of determining acidity, see pages 254 to 257 .) 


\section{PHYSICAL PROPERTIES}

The physical properties of milk which are of greatest importance in milk hygiene are the color, odor and taste, specific gravity, and refraction. Other physical properties which have been extensively studied are the viscosity, surface tension, freezing point, and electrical conductivity.

Color.-Milk is a white, opaque fluid, sometimes with a yellowish or bluish tinge. The white color is due to the calcium caseinate, while the opacity is due in part to the same substance and in part to the fat. Not only the quantity of fat, but also the size of the fat globules, affects the opacity, the opacity being less when the globules are large than when they are small. Since opacity does not depend entirely on the quantity of fat, tests for fat based upon transparency, such as the lactoscope test (p. 239), are not accurate. The yellowish tinge of milk is due to a pigment in the fat (carotin) ; it is more pronounced in milk from cows of certain breeds, as the Guernseys. A bluish tinge indicates that the milk has a low fat per cent., and is sometimes associated with skimming and watering, but it must be remembered that any milk in a thin layer has a bluish tinge.

Odor and Taste.-Normal milk has a slight odor, resembling the exhalations from the cow's skin, and a slightly sweetish taste. During the colostral period and near the end of lactation, individual cow's milk may have a salty, bitter, or a rancid, animal-like taste. A large proportion of "strippers" in a herd may give the mixed milk a similar taste. The milk of the individual cow may also be salty or bitter in advanced pregnancy, after abortion, in mastitis, and when digestion is disturbed. Milk with a certain degree of acidity will acquire a bitter, 
astringent taste in rusted vessels in consequence of the formation of iron lactate. A "fishy" taste may also be present when the milk vessels are rusty or when they have not been rinsed free of soap powder.

Certain aromatic feeds impart a characteristic odor and taste to the milk. Among these are ensilage, rape, cabbage, and beets, turnips, rutabagas, carrots, and their tops. This is not ordinarily due to the ingestion with the feed of substances responsible for the taste and odor and their elimination with the milk through the udder, but to the absorption by the milk of the odor of the feed from the air of the stable. This is demonstrated by the fact that when these feeds are fed in ordinary quantity and after milking, and not immediately before or during milking, the odor and taste of the milk are not affected. If these feeds are given in large quantity, it is probable that some of the aromatic substances may be excreted through the udder. In the case of garlic, however, the volatile oil to which the odor of that substance is due is eliminated through the udder in the milk. Odors are readily absorbed by milk, especially when it is warm. Milk drawn and allowed to stand in an unclean or poorly ventilated stable will acquire a stable-like odor and taste. It has been demonstrated experimentally that if milk at a temperature of 14 to $22^{\circ} \mathrm{C}$. ( 57 to $72^{\circ} \mathrm{F}$.) is exposed to the odor of ensilage or horse manure for a half hour to an hour and a half it will acquire an odor and taste resembling these substances (Russell).

Abnormal odors and tastes result also from the growth of bacteria in milk. The activity of the peptonizing bacteria may produce first a bitter taste, due to the production of peptone, and later a foul and unpleasant odor and taste, the result of decomposition processes. 
Bacilli of the coli-aerogenous group may produce an unclean, even nauseating, taste with a stable or manurelike odor, while the lactic acid bacteria give to milk a sour odor and taste. Specific organisms have been identified which produce bitter, soapy, oily, and burnt tastes and a stable-like odor and taste. Other bacteria produce a rancid odor and taste, and some produce an unclean odor and taste. While some of the peptonizing bacteria (udder cocci) are normal inhabitants of the udder, the other bacteria usually enter the milk after it is drawn from the cow. Sometimes, however, bacteria which are the cause of abnormal odors and tastes become established in the udder. Odors and tastes of bacterial origin are often not apparent until a certain period after the milk has been taken from the udder and usually become more pronounced as the milk increases in age. Milk acquires a cooked taste when heated above 68 to $71^{\circ} \mathrm{C}$. (155 to $160^{\circ} \mathrm{F}$.) Heating in open vessels has a more pronounced effect on the taste than heating in closed vessels or bottles.

The senses of smell and taste tire very quickly and cannot be depended upon to judge many samples of milk. Odors and tastes are more apparent when the milk is warm.

Specific Gravity.-As would naturally be expected from the statements made in regard to the variation in the composition of milk, the specific gravity or density of different samples of milk varies considerable. The range of variation is greater for individual milk than for market milk. The specific gravity of the milk of individual cows will range from 1.027 to 1.040 , while that of market milk will fluctuate between 1.028 and 1.034 , with an average of 1.032 , at the standard tempera- 
ture of $15^{\circ} \mathrm{C} . \quad\left(60^{\circ} \mathrm{F}\right.$.). At higher temperatures the specific gravity or density is decreased, and at lower temperatures it is increased.

The specific gravity depends not only upon the total quantity of solids contained in the milk, but also upon the relative proportion in which the individual solids are present, because the individual solids are of different specific gravity. Fat shows the greatest difference, being much lighter than the other solids; it is even lighter than water. The solids not fat are all heavier than water, the specific gravity of the salts being 4.12 , lactose 1.666, and proteids 1.346 (Richmond). Therefore the removal of fat, i.e., skimming, increases the specific gravity, and the addition of skim milk has the same effect, while the addition of water reduces the specific gravity. But the specific gravity has such a wide normal variation that it is possible to remove a small amount of fat from milk with a normally low specific gravity without causing the specific gravity to rise above the normal range, and, conversely, a certain amount of water may be added to milk with a normally high specific gravity without lowering the specific gravity below the normal limit. However, in the first case the per cent. of fat will be decreased, and in the second there will be a decrease in both the per cent. of fat and of solids not fat. When the specific gravity of milk is raised above the normal by skimming it may be brought within the normal range by the addition of water, but the per cent. of fat and of solids not fat will be decreased. Therefore, in examining market milk to detect skimming or the addition of skimmed milk or water, the per cent. of fat and of solids not fat must always be considered in connection with the specific gravity. (For method of determining the specific 
gravity, see page 228.) Determination of the specific gravity of the milk solids and of the per cent. of fat in the milk solids will assist in detecting milk which has been skimmed or skimmed and watered. (See page $\mathbf{2 4 6}$ for methods.) The milk solids of normal market milk have a specific gravity of 1.31 to 1.36 , and the per cent. of fat in the milk solids is 20 to 34. When milk is skimmed or skimmed and watered, the specific gravity of the milk solids is increased, while the per cent. of fat in the solids is decreased.

The influence of disease on the specific gravity of individual milk is not constant, but the specific gravity is usually lowered. However, the specific gravity of individual cow's milk cannot be made use of to discover diseased conditions, because milk from different cows shows such great variations under normal conditions. The specific gravity of milk is lower when it is drawn from the udder than it is several hours later.

Refraction.-Rays of light passing through one medium into another of different optical density, as through air into milk, are broken or refracted at the point of contact of the two media. The degree of refraction, or the refractive power compared with that of air, is called the refractive index. Since the calcium caseinate and fat contained in milk prevent the light rays from passing through it, these substances must be removed before the refractive index can be determined. The refractive index of milk, so-called, is really the refractive index of the milk serum or whey, i.e., the milk minus the calcium caseinate and fat.

The refractive power of the milk serum depends upon the quantity of lactose or of lactose and salts present. Adding water to milk reduces the proportion of these 
substances, and therefore reduces the refractive index. Hence the refractive index may be used to detect watered milk. (See method on page 249.) The refractive index of normal market milk ranges from 1.3429 to 1.3445. On the scale of the Zeiss dipping refractometer, the reading for normal milk ranges from 37.3 to 41.5.

$V$ iscosity is manifested by the adherence of milk to the sides of a glass vessel. It increases as the temperature of the milk is lowered, and vice versa. It is decreased by skimming and by the addition of water. During the colostral period and near the end of lactation it is greater than at other times during the lactation period; it is also increased in disease or injuries of the genital organs, especially the udder.

Boiling momentarily, or heating for a longer time at lower temperatures, decreases the viscosity of milk, causing it to appear thinner than normal raw milk. Cream heated at $60^{\circ} \mathrm{C}$. $\left(140^{\circ} \mathrm{F}\right.$.) for twenty minutes appears thinner and less viscous than raw cream with the same fat per cent. and will not "whip" readily. Viscogen, a mixture of cane sugar and lime, has been added to heated cream to overcome this change. This preparation has also been used to increase the viscosity of raw cream of low fat per cent., and also to increase the consistency of skimmed or watered milk. The addition of viscogen to cream or milk is illegal unless the product is sold as visco-cream or visco-milk. The specific gravity of watered or skimmed milk is increased by the addition of viscogen, and the per cent. of solids not fat, especially the salts, is also increased. The acidity is reduced.

Starch is also added to cream to increase the body or consistency.

Freezing Point.-The freezing point of milk is 
-0.54 to $-0.57^{\circ} \mathrm{C}$. $\left(31.02\right.$ to $30.9^{\circ} \mathrm{F}$.). It varies with the amount of the dissolved substances contained in the milk, especially the salts. When water is added to milk the freezing point rises, while in disease it is sometimes lowered and sometimes raised. The determination of the freezing point has as yet proven of no practical value in routine milk examination. Surface tension and electrical conductivity are likewise of no practical importance.

MICROSCOPICAL APPEARANCE OF MILK AND MILK SEDIMENT

When examined under the microscope, milk is found to contain numerous fat globules with a few cells, cell fragments, and free nuclei scattered among them. If a small quantity of milk is placed in a sediment tube and centrifugalized, only a part of the cells and cell remnants are thrown down to the bottom of the tube with the heavier constituents of the milk; many adhere to the fat globules and are carried to the top, while the others remain in the intermediate fluid. According to Prescott and Breed, only about one-fourth is contained in the sediment, one-half being in the cream and the remainder in the milk. Heating the milk to $60^{\circ} \mathrm{C}$. $\left(140^{\circ} \mathrm{F}\right.$.) or above before centrifugalizing will increase the cellular content of the sediment. If some of the sediment is spread out in a thin layer on a glass slide, dried in the air, fixed by heating, and stained, the cellular bodies can be more readily studied.

Cellular Content.- It will then be observed that the cells are of two principal kinds: leucocytes and epithelial cells. The leucocytes are of the polymorphonuclear and lymphocyte varieties, while the epithelial cells are of the pavement, cuboidal and cylindrical types. Fre- 
quently the epithelial cells are folded on themselves, when they appear as rounded, oval, or irregular shapes, and sometimes they are arranged in groups like the petals of a flower. Degenerated and disintegrated cells, free nuclei, bacteria, and vegetable cells and fibres may also be present.

Number of Cells.-The number of cells in different samples of milk will vary very much. Milk from individual cows in normal condition may contain from 50,000 to $1,000,000$ and over per c.c. (Savage). Milk from the same cow may show considerable differences when examined at intervals of a week or a month, and variations may also be found in the milk from different quarters of the udder of the same cow. The number of cells may differ at different stages of the same milking, being much greater in the end milk than in the first milk.

The cellular content is very high for a few days after calving. Near the end of lactation the cells again increase in number, and they are also present in excess after incomplete or delayed milking. In mastitis there is usually a pronounced increase in the number of cells, particularly the leucocytes. In some cases the number is as high as $200,000,000$ to $300,000,000$ per c.c. (Savage), but in others it is as low as 500,000 per c.c. The cell content of milk from an udder affected with mastitis exhibits two other features which are important, viz: the cells are clumped or grouped together, and 75 to 80 per cent. are polymorphonuclear leucocytes. Red-blood cells may also be present in the milk when the udder is very much congested, as may occur at the beginning of lactation and in acute inflammation, and also following traumatic injuries.

The differences in the cell content of the individual 
milk of normal cows are likely to balance one another when the milk of several cows is mixed together; consequently different samples of market milk show less variation in the number of leucocytes than individual milk. On the other hand, when the milk from one cow affected with mastitis is mixed with the milk of other cows in the herd which are in normal condition, the cell content of the mixed milk is not likely to be very much increased unless the herd is a very small one or the milk from the diseased cow contains an enormous number of cells.

Several methods have been devised for detecting an excessive number of cells in milk (see pages 281 to 284). When used to examine the milk of individual cows, these methods are of great assistance in discovering cases of mastitis before clinical symptoms or visible milk changes appear, but when applied to samples of mixed market milk they cannot be depended upon entirely for the purpose of detecting mastitis in the herds supplying the milk.

\section{BIOLOGICAL PROPERTIES OF MILK}

Ferments or Enzymes.-Milk contains a number of ferments or enzymes. Some of them resemble the digestive ferments in their action. This class includes a proteolytic ferment called galactase, and diastase, an amylolytic ferment. These ferments are believed to assist in the digestion of milk. A tripsin-like ferment and fat-splitting ferments or lipases have been reported, but their existence is questioned. There are also oxidizing ferments: the oxydases and peroxydase, and reducing ferments: catalase and reductase. The diastase, 
peroxydase, catalase, and reductase reactions have been made use of in milk control work.

Original and Bacterial Ferments.-In milk hygiene it is important to distinguish between original and bacterial ferments. An original ferment is one which is secreted by the cells of the udder, or which is contained in cells like the leucocytes and becomes free in the milk when these cells disintegrate. A bacterial ferment is secreted by the bacteria which gain access to milk after it is formed in the udder. A bacterial ferment increases in quantity after milk is drawn from the udder as a result of the growth of bacteria, and if it is destroyed by heat it will again appear unless the bacteria are all killed and the milk is not reinfected. On the other hand, an original ferment cannot increase in quantity after the milk leaves the udder, and if it is destroyed by heat it does not reappear in the milk. Diastase and peroxydase are original ferments, catalase is both an original and a bacterial ferment, and reductase is a bacterial ferment.

Diastase.-One hundred c.c. of normal milk will digest 0.015 to 0.02 gramme of starch in thirty minutes. This action is due to an amylolytic ferment contained in the milk, which has been called diastase. This ferment operates best at a temperature of $45^{\circ} \mathrm{C} .\left(113^{\circ} \mathrm{F}\right.$.) and is destroyed by a temperature of 65 to $68^{\circ} \mathrm{C}$. (149 to $154^{\circ} \mathrm{F}$.) for thirty minutes. It is present in the milk when it is formed in the udder, and is therefore an original ferment. It is not produced by bacteria. Colostrum is richer in diastase than ordinary milk, and the ferment is also present in greater quantity near the end of lactation. The end milk contains more diastase than the first milk drawn from the udder. (See diastase test on page 297.) 
Peroxydase.-If paraphenyldiamin or tincture of guaiac is added to milk with a little hydrogen peroxide, the milk at once assumes a blue color. This change occurs because the ferment contained in the milk called "peroxydase" splits off oxygen from the hydrogen peroxide and this free oxygen oxidizes the paraphenyldiamin or the guaiac to a colored compound. If the milk is heated to $80^{\circ} \mathrm{C}$. $\left(176^{\circ} \mathrm{F}\right)$, the reaction does not occur because the ferment is destroyed. The reaction occurs best at 40 to $50^{\circ} \mathrm{C}$. (104 to $122^{\circ} \mathrm{F}$.). Peroxydase is present in milk when it is formed in the udder and it is not secreted by bacteria. It is therefore an original ferment. (See tests for heated milk on page 298.)

Catalase.-This ferment, which is also known as superoxidase, possesses the specific property of splitting up hydrogen peroxide into water and oxygen. The reaction which occurs is as follows: $2 \mathrm{H}_{2} \mathrm{O}_{2}=\mathbf{2} \mathrm{H}_{2} \mathrm{O}+\mathrm{O}_{2}$. Catalase is both an original and a bacterial ferment. It is secreted with the milk and is contained in leucocytes and in blood. It is also secreted by many of the bacteria found in milk, but the various species differ in their capacity to produce the ferment. The putrefactive organisms appear to produce it in the greatest quantity. The ability of the lactic acid bacteria to produce catalase is in dispute.

The amount of catalase in milk as it comes from the udder varies at different stages of lactation. The catalase content is high during the colostral period and this condition usually continues for three weeks, although in exceptional cases it falls to the amount normal for milk by the fourth or fifth day after parturition. Near the end of lactation, when the milk has fallen to about a quart per day or less, the catalase again increases. Some 
observers report that no increase occurs duing oestum, but others state that when the cow is nervous and excitable the catalase is sometimes increased. Pronounced changes in the feed may affect the quantity of catalase. The first milk drawn at a milking contains less catalase than the end milk.

When milk is separated, the greater portion of the catalase passes over into the cream. Skim milk, therefore, has a very low catalase content. After milk has reached a certain degree of acidity (about 0.36 per cent.), the acid begins to exert an inhibitory influence on the activity of the catalase. Up to this point the catalytic activity is increased because the amount of catalase is increased by bacterial growth. In milk which has undergone "sour curdling," the catalase is paralyzed by the acid and is inactive. The catalytic activity may be restored to such milk by neutralizing it with lime water.

When milk is exposed to a low temperature in winter or to prolonged refrigeration, the catalase is partially or completely destroyed. Catalase operates best at a temperature of $37^{\circ} \mathrm{C} .\left(98.6^{\circ} \mathrm{F}\right.$.). The lethal temperature is around $68^{\circ} \mathrm{C}$. $\left(154^{\circ} \mathrm{F}\right.$.), but varies within wide limits according to the source of the catalase. Heated milk may be reactivated, since catalase is a bacterial as well as an original ferment. (See catalase test on pages $\mathbf{2 8 7}$ to 294 .)

Reductase.-If a small quantity of methylene blue solution is added to milk, the mixture will be colored blue, but the blue color will disappear after a time because the methylene blue is reduced and converted into its leuco-base. This change is brought about by a ferment in the milk called reductase. If formalin is added to the methylene blue solution, forming what is known as Schar- 
dinger's reagent, and a little of this solution is added to milk, the mixture will also be colored blue, but the color will disappear more rapidly. At first the difference in the time of reduction was attributed to the difference in the composition of the solution, but further research demonstrated the presence in milk of two different reducing agents. The ferment which reduces the methylene blue solution is called "M-reductase," while the one which reduces the formalin-methylene blue solution has been named "FM-reductase."

M-Reductase.-This ferment is not secreted in the udder with the milk. It is generally regarded as of bacterial origin, although the opinion has been expressed (Burri and Kürsteiner) that the cellular elements of milk, like all living protoplasm, have a reduction power and that the high reduction power of colostrum during the first day after parturition and of mastitis milk is due to the rich cellular content of these secretions. It has been well established, however, that the capacity of milk to reduce methylene blue increases with the number of bacteria.

The different species of bacteria vary in their reduction power. Reduction power appears to depend first upon the species, then upon the number of bacteria, and, finally, upon the media in which the organisms are growing. The anaerobic organisms usually have a greater reduction power than the aerobes, while the facultative anaerobes act more powerfully in the absence of oxygen than when it is present. The colon bacilli belong to the facultative anaerobes of high reduction power. On the other hand, the reduction power of the lactic acid bacteria is weak. Different samples of fresh milk containing about the same number of bacteria may differ greatly in 
reduction power because of the difference in the species of bacteria present. But, according to Barthel and $\mathbf{O}$. Jensen, when milk is stored under suitable conditions, the relative proportion of the different species of bacteria present is almost always changed in favor of the lactic acid organisms, so that in the case of market milk there is usually correspondence between the reduction time and the number of bacteria.

The reduction power of a microörganism is not constant, but depends upon the vitality of the organism; it will therefore decrease with the age of the organism and also when nutritive conditions are unfavorable. Hence, the reduction activity of milk rich in bacteria is relatively less than milk containing fewer bacteria. These factors render the reductase test less exact than the plate method for estimating the number of bacteria in market milk, but not for judging the "keeping qualities" of the milk, since the more vitally active the contained bacteria the more rapidly will the milk undergo bacterial decomposition.

The reduction power of cream is greater than that of skim milk. The reduction power is greatest just before curdling. In curdling, the ferment is precipitated with the curd. The ferment operates best at a temperature of 40 to $55^{\circ}$ C. $\left(104\right.$ to $131^{\circ}$ F.) and is destroyed by a temperature of 70 to $80^{\circ} \mathrm{C}$. (158 to $176^{\circ}$ F.).

FM-Reductase.-The knowledge concerning this ferment is not sufficiently definite at this time to be of any value in the practice of milk hygiene. FM-reductase is present in colostrum on the first day after parturition and is then absent from the udder secretion for two to three weeks, when it again appears in the milk. Schern 
therefore proposed the FM-reductase test as a means of determining whether or not a cow is "fresh." FMreductase is absent, or present only in very small quantity, in the first milk drawn at a milking, but it is always present in the end milk. After stasis of milk, it is absent. The reaction cannot be used for the detection of mastitis, because while reduction occurs rapidly in some cases, in others it occurs more slowly than in normal milk or may not occur at all.

Antibodies or Immune Bodies.-Antibodies are substances which are produced in the animal body to protect it from the action of bacteria or their toxins. The term includes antitoxins, agglutinins, precipitins, opsonins, lysins (amboceptors), complement, etc. Complement is always present in the blood and the other kinds of antibodies are also contained in the normal serum in a non-specific form, but these antibodies do not appear in the blood in a specific form until after the body is invaded by pathogenic organisms or their toxins.

It has been demonstrated that antitoxins, agglutinins, and opsonins pass over from the blood into the milk when the udder is in a normal condition. Bacterio-lysins are eliminated in the milk when the udder is affected with mastitis and during the colostral stage, but it is doubtful if they pass over from the blood into the milk under normal conditions at other times. Complement is present in colostrum and also in milk when the udder is affected with mastitis. It may be present in normal milk for as long as twenty-six days after parturition, but after that time it is absent, according to some observers. The complement demonstration test has not come into general use for the detection of mastitis principally because cer- 
tain investigators have reported that complement is always present in milk from apparently normal cows.

The quantity of antibodies in the milk compared with the quantity circulating in the blood is not definitely known. The question has been more extensively studied in connection with antitoxins than with the other antibodies, and it was found that the milk contains only onethirtieth to one-fifteenth of the quantity of antitoxin circulating in the blood. Agglutinins may be present in the milk in the same quantity as in the blood, or in greater or less amount. The immunizing value of the milk has not been completely determined. It has been demonstrated that antibodies in milk ingested by sucklings are absorbed through the intestines into the blood when the suckling and the animal from which the milk is obtained are of the same species. There is no direct evidence, however, that the antibodies are absorbed into the blood of the young animal when the milk is from a different species, as when a child ingests cow's milk, although many observations have been made which indicate that antibodies are absorbed under such circumstances, if only to a limited extent. It would therefore appear that antibodies in cow's milk are of more value to the calf than to a child ingesting such milk. The absorption of antibodies from the intestines is greatest during the first few days after birth and decreases with age. In older animals, the antibodies are split up by digestion like other proteids.

Germicidal Action of Milk.-Milk from cows in normal condition always contains antibodies which destroy many of the bacteria commonly present in milk. The intensity and duration of this germicidal action varies with the temperature. If the milk is kept at $37^{\circ} \mathrm{C} .\left(98.6^{\circ} \mathrm{F}\right.$.), 
there will be a decided decrease in the number of bacteria for the first six hours after the milk is drawn from the cow; at 26 to $29^{\circ} \mathrm{C}$. (79 to $84^{\circ} \mathrm{F}$.) the decrease is less rapid, but continues for eight to ten hours, and at $15^{\circ} \mathrm{C}$. $\left(60^{\circ} \mathrm{F}\right.$. $)$ it is still further reduced in rate but continues for about twenty-four hours (Rosenau and McCoy). The effect of the same milk on different species of bacteria is different, and the effect of different milks on the same species of bacteria also varies, showing that the antibodies are specific for certain species of bacteria. The germicidal power of milk is not capable of destroying all bacteria which may gain access to milk during milking and the subsequent handling; hence precautions against bacterial contamination together with proper cooling are none the less necessary. It is also incapable of always preventing the development of pathogenic bacteria. These organisms may enter the teat canal and milk cistern and even invade the gland alveoli. Heating milk for thirty minutes to $56^{\circ} \mathrm{C}$. $\left(133^{\circ} \mathrm{F}\right.$.) considerably weakens the germicidal property, and it is entirely destroyed by a temperature of $70^{\circ} \mathrm{C}$. $\left(158^{\circ} \mathrm{F}\right.$.), or above, for thirty minutes. Bacteria, therefore, grow more rapidly in heated milk than in fresh raw milk. The germicidal power of colostrum and of milk from cows affected with mastitis is greater than that of normal milk.

Toxins.- It has been demonstrated that tetanus toxin may be eliminated in the milk of a cow affected with tetanus, and in sufficient quantity to kill mice fed with the milk (Miessner). There is, therefore, reason to believe that other bacterial toxins are also eliminated in the milk, although there is no direct proof. However, the quantity of toxin circulating in the blood is very small, even in severely infected animals, and only a 
minute quantity could be eliminated in the milk. When it is considered in addition that the milk secretion ceases in severely affected animals, the danger from toxins eliminated in the milk is very slight. Toxins may be produced by bacteria growing in milk after it is drawn from the udder. There is evidence to show that toxins are very readily absorbed through the gastro-intestinal mucous membrane of young animals. Toxins in milk from a different species are absorbed with much less facility than when the milk is from the same species. Diphtheria and tetanus toxins have been given to adult animals by the mouth in large quantities without any harmful effect, the toxins apparently being split up in the process of digestion like other proteids. These, however, are soluble toxins (exogenous) which are more susceptible to chemicals and ferments than endotoxins. What may happen when the digestive processes are deranged, or when wounds are present in the mucous membrane, is not known. Milk from animals affected with rabies contains the virus of the disease, but such milk does not produce rabies when ingested if the mucous membrane of the digestive tract is intact and the gastric secretion is normal.

Aggressins and other substances which inhibit the protective reaction of the body against the action of bacteria and their toxins have also been demonstrated in milk.

\section{CLASSES OR GRADES OF MARKET MILK}

Until quite recently no effort was made to establish uniform grades or classes of milk. In some instances, the terms sanitary milk, hygienic milk; aërated milk, baby's milk, nursery milk, etc., have been applied by distributers to some of the milk sold by them, but these 
terms are very indefinite and have been frequently used indiscriminately. Since 1893, milk produced under the supervision of a medical milk commission has been sold under the name of certified milk, but the term has also been applied to milk which was not produced under these conditions. The desirability of defining the special names used for milk, and the advantage to both the producer and consumer of grading or classifying market milk according to its hygienic quality, has long been recognized, but no definite steps were taken in the matter until 1907 when Melvin ${ }^{1}$ proposed that market milk be graded in three classes, as follows:

Class 1. Certified Milk.-This may be briefly defined as milk produced in accordance with the requirements of the American Association of Medical Milk Commissions (see Appendix).

Class 2. Inspected Milk. - This term should be limited to clean raw milk from healthy cows, as determined by the tuberculin test and physical examination by a qualified veterinarian. The cows are to be fed, watered, housed, and milked under good conditions, but not necessarily equal to the conditions provided for Class 1. All persons who come in contact with the milk must exercise scrupulous cleanliness, and must not harbor the germs of typhoid fever, tuberculosis, diphtheria, and other infections liable to be conveyed by the milk. This milk is to be delivered in sterilized containers, and is to be kept at a temperature not exceeding $50^{\circ} \mathrm{F}$. until it reaches the consumer. It shall contain not more than 100,000 bacteria per cubic centimetre.

Class 3. Pasteurized Milk.-Milk from the dairies not able to comply with the requirements specified for Classes 1 and 2 is to be pasteurized before being sold, and must be sold under the designation "pasteurized milk." Milk for pasteurization shall be kept at all times at a temperature not exceeding $60^{\circ} \mathrm{F}$. while in transit from the dairy farm to the pasteurization plant,

1 24th Annual Report, U. S. Bureau of Animal Industry, pp. 179 to 182 . 
and milk after pasteurization should be placed in sterilized containers and delivered to the consumer at a temperature not exceeding $50^{\circ} \mathrm{F}$. All milk of an unknown origin should be placed in Class 3 and subjected to clarification and pasteurization. No cow in any way unfit for the production of milk for use by man, as determined upon physical examination by an authorized veterinarian, and no cow suffering from a communicable disease should be permitted to remain on any dairy farm on which milk of Class 3 is produced, except that cows which upon physical examination do not show physical signs of tuberculosis may be included in dairy herds supplying milk of this class. This milk is to be clarified and pasteurized at central pasteurization plants, which shall be under the personal supervision of an officer or officers of the health department. These pasteurizing plants may be provided either by private enterprise or by the municipality, and should be located within the city.

A further attempt at classification was made in 1911 by a commission on milk standards appointed by the New York Milk Committee. This commission recommended that milk be graded in four classes, viz.: Class $\mathbf{A}$, certified milk or its equivalent; Class B, inspected milk; Class C, pasteurized milk, and Class D, milk not suitable for drinking purposes. A year later, however, the commission presented a second report ${ }^{1}$ in which the following classification was recommended:

\section{GRADE A}

Rare Milk.-Milk of this class shall come from cows free from disease as determined by tuberculin tests and physical examinations by a qualified veterinarian, and shall be produced and handled by employees free from disease as determined by

${ }^{1}$ Reprint No. 141 from the Public Health Reports, Aug. 22, 1913. 
medical inspection of a qualified physician, under sanitary conditions such that the bacterial count shall not exceed 100,000 per cubic centimetre at the time of delivery to the consumer. It is recommended that dairies from which this supply is obtained shall score at least 80 on the United States Bureau of Animal Industry score card.

Pasteurized Milk.-Milk of this class shall come from cows free from disease as determined by physical examinations by a qualified veterinarian and shall be produced and handled under sanitary conditions such that the bacterial count at no time exceeds 200,000 per cubic centimetre. All milk of this class shall be pasteurized under official supervision, and the bacterial count shall not exceed 10,000 per cubic centimetre at the time of delivery to the consumer. It is recommended that dairies from which this supply is obtained shall score at least 65 on the United States Bureau of Animal Industry score card.

The above represents only the minimum standards under which milk may be classified in Grade A. The commission recognizes, however, that there are grades of milk which are produced under unusually good conditions, in especially sanitary dairies, many of which are operated under the supervision of medical associations. Such milks clearly stand at the head of this grade.

\section{GRADE B}

Milk of this class shall come from cows free from disease as determined by physical examinations, of which one each year shall be by a qualified veterinarian, and shall be produced and handled under sanitary conditions such that the bacterial count at no time exceeds $1,000,000$ per cubic centimetre. All milk of this class shall be pasteurized under official supervision, and the bacterial count shall not exceed 50,000 per cubic centimetre when delivered to the consumer.

It is recommended that dairies producing Grade B milk should be scored and that the health departments or the controlling departments, whatever they may be, strive to bring these scores up as rapidly as possible. 
GRADE C

Milk of this class shall come from cows free from disease as determined by physical examinations and shall include all milk that is preduced under conditions such that the bacterial count is in excess of $1,000,000$ per cubic centimetre.

All milk of this class shall be pasteurized, or heated to a higher temperature, and shall contain less than 50,000 bacteria per cubic centimetre when delivered to the consumer.

Whenever any large city or community finds it necessary, on account of the length of haul or other peculiar conditions, to allow the sale of Grade $\mathbf{C}$ milk, its sale shall be surrounded by safeguards such as to insure the restriction of its use to cooking and manufacturing purposes.

In 1917 the commission published a third report ${ }^{1}$ in which the above-mentioned grades were again recommended with the same specifications for each grade except that the bacterial limit for Grade A, raw milk, was reduced from 100,000 to 10,000 bacteria per c.c. This is an extremely low bacterial limit for market milk to be used for general purposes and it is very doubtful if it can be adopted by any community without considerably reducing the supply of raw milk and increasing its cost to the consumer. Certified milk meets the demand for a milk of low bacterial content for special purposes, such as infant feeding, etc.

${ }^{1}$ Public Health Reports, Vol. 32, No. 7, Feb. 16, 1917. 


\section{CHAPTER IV \\ BACTERIA OF MILK}

UnLess drawn under special conditions, which are not obtainable in dairy practice, milk always contains bacteria. Some of them come from the udder; others are derived from the cow's skin, the dust of the fodder and litter, the milk vessels and utensils, the person and clothing of the milker, etc., and enter the milk during the process of milking and in the subsequent handling of the milk. They are, under normal conditions, non-pathogenic organisms, and, since they are always present in milk, are called the common milk bacteria. Under certain conditions, which are discussed in another chapter, milk contains also pathogenic bacteria.

\section{COMMON MILK BACTERIA}

Some of the non-pathogenic bacteria do not bring about any perceptible change in milk. Many of them, however, produce marked alterations, and it is because of their presence that milk is so extremely perishable or unstable. In growing in milk, these organisms split up certain constituents, notably the lactose and casein, into various products, some of which are capable of exerting an injurious effect upon persons drinking the milk, particularly children and invalid adults. Certain of these changes, including the more harmful kinds, may be considerably advanced before they are indicated by any alteration in the appearance, odor, or taste of the milk. Therefore, while the common milk bacteria are in themselves harmless, and while their growth in milk to a limited 
extent is not attended with any appreciable injurious effects, their presence in large numbers is not desirable because it may be accompanied by harmful results.

There are numerous species of these organisms. For facility of study as well as for practical purposes, it is convenient to group them according to the changes which they bring about in milk. Although some of the species which ferment lactose produce both acids and gases, and although a part of those which act principally upon the lactose also operate upon the casein in a lesser degree and vice versa, nevertheless by grouping the different species according to their dominant effect a very clear conception is obtained of the important changes produced in milk by the organisms of each group. Following this plan, the numerous species of common milk bacteria may be classified in the following groups:

1. Acid-forming Bacteria.-These organisms split up the lactose in milk and form acids. The milk first acquires a sour odor and taste and later curdles. This is the most quickly apparent change which occurs in milk. The acids combine with the calcium of the calcium caseinate, and the casein, being thus set free, is precipitated in the form of a smooth, white jelly-like curd, which may contain a few gas bubbles or furrows made by ascending bubbles. In the beginning, the curd is dry and is equal in size to the original volume of the milk, but later on it contracts and expresses a fluid or serum which holds in solution certain of the milk constituents.

The time required for milk to sour and curdle depends upon the number and kind of acid-forming bacteria it contains and the temperature at which it is kept. On the average, about 0.45 per cent. acidity is necessary to bring about curdling. The acid-forming bacteria con- 
tinue to grow and to ferment lactose until the acidity reaches 0.8 per cent., but the growth of other bacteria stops when the acidity exceeds 0.2 per cent. The acidforming bacteria, therefore, perform the very important service of inhibiting the growth of the more harmful bacteria. If their development is interfered with, the milk will undergo putrefaction instead of souring.

Sour milk is not harmful to healthy adults; on the contrary, in certain forms (curds and whey, buttermilk, kefir, etc.) it is a regular article of diet, and milk containing certain acid-forming bacteria is beneficial in some diseased conditions. But, nevertheless, milk in which the fermentation is not sufficiently advanced to cause coagulation or even to produce an appreciable sour taste may cause vomiting and indigestion in small children and in persons affected with catarrh of the stomach.

The usual cause of the spontaneous curdling of milk is the Bacterium lactis acidi (Fig. 5), also called Streptococcus lacticus, which occurs as a coccus or as a short oval or pointed bacterium, arranged in pairs, frequently in short and sometimes in long chains, and forms on solid media very small, white, circular or lenticular colonies, many of them being situated below the surface. In addition to the difference in form, variations occur in the ability to ferment lactose and in other biological characters. These are regarded by some bacteriologists as changes due to environment, while others consider them a sufficient basis for recognizing the existence of different varieties or species. In general, however, organisms of the Streptococcus lacticus type ferment lactose more rapidly than the other species of acid-forming bacteria, forming principally lactic acid, with little or no gas. The milk has a clean, sour taste, while the fluid expressed from 
the curd is clear. Being commonly concerned in the souring of milk and producing principally lactic acid, the organisms of this type are known as the true lactic acid bacteria. The Streptococcus lacticus must not be confused with the mastitis streptococci (Fig. 6), which also ferment lactose and have other corresponding characteristics. The latter organisms grow in long, intertwined chains, the individual members of which are rectangular or oval in form, with the long axis at right

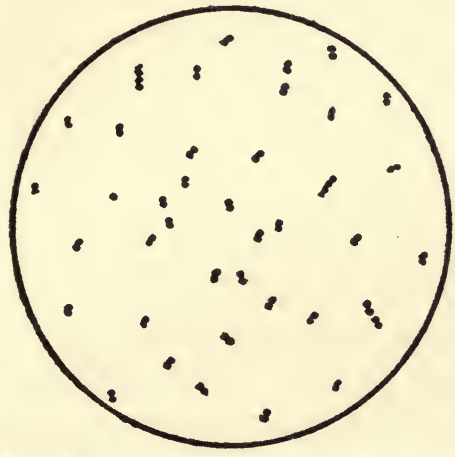

Fra. 5.-Preparation showing Streptococcus lacticus or Bacterium lactis acidi.

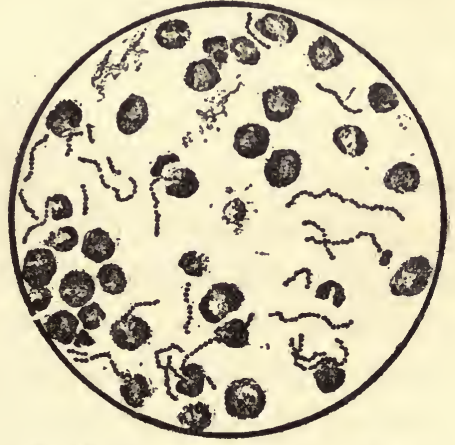

Fra. 6.-Preparation from sediment obtained by centrifugalizing milk from a cow affected with catarrhal mastitis, showing streptococci and leucocytes.

angles to the length of the chain. On agar, they form extremely minute, punctiform, brownish colonies.

The Bacterium acidi lactici (Hueppe), also called the Bacillus lactis aerogenes, is frequently concerned in the spontaneous souring of milk, usually in association with the Streptococcus lacticus. This is a short, plump, nonmotile bacterium which is closely related to the coli-aerogenes group of bacteria and may be regarded as the most active acid-forming member of that group. It grows upon the surface of solid media, forming thin, partially translucent, leaf-shaped colonies, or round semi-globular 
colonies. It ferments lactose more slowly and requires a higher temperature than the Streptococcus lacticus. Acetic acid is the principal product of the lactose fermentation, although lactic and succinic acids and gas are also formed. Gas bubbles are rather numerous in the curd and the fluid expressed from the latter is not always clear. The sour taste of the milk is frequently unpleasant. The Bacterium acidi lactici is regarded by some bacteriologists as a distinct species with strains showing differences resulting from environment and by others as the type of a number of species or varieties. The mastitis organisms, Bacillus Guillebeau ( $a$ and $b$ ), and some of the bacteria which produce slimy or viscid milk are closely related forms.

Several varieties of long, thin, rod-shaped organisms, of which the Bacterium bulgaricus is a type, also form acid from lactose, but they operate so slowly at the usual temperatures that they are not a factor in the ordinary souring of milk. They are chiefly of interest because of their use in the preparation of the oriental milks (mazun, kefir, yoghurt). The organisms of the Bacterium bulgaricus group are usually present in ensilage and those found in milk are no doubt derived directly or indirectly from this source.

The temperature at which the milk is kept has an important influence upon the character of the lactose fermentation. In milk kept at 15 to $20^{\circ} \mathrm{C}$. ( 59 to $68^{\circ}$ F.), the organisms of the Streptococcus lacticus type will grow much more rapidly than those of the Bacterium acidi lactici type. The $\boldsymbol{S}$ treptococcus lacticus grows quite well at $15^{\circ} \mathrm{C} .\left(59^{\circ} \mathrm{F}\right.$.) and continues to grow at $10^{\circ}$ C. $\left(50^{\circ} \mathrm{F}\right.$.), while the Bacterium acidi lactici grows better at higher temperatures and practically stops grow- 


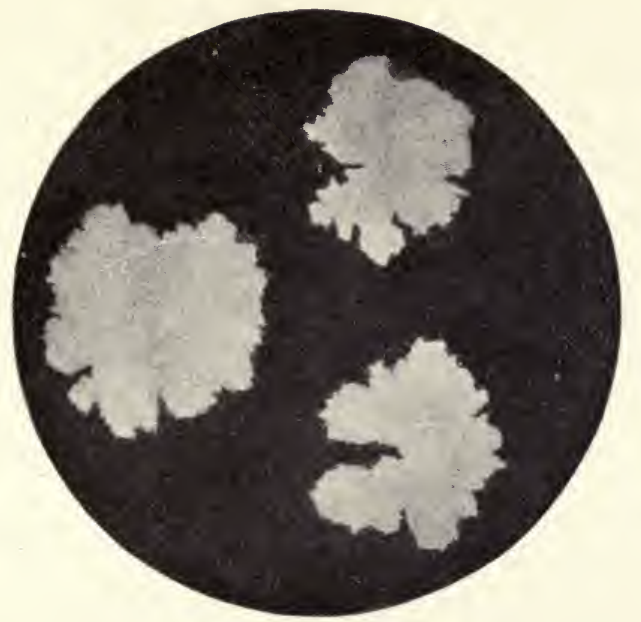

FIG. 7.-Colonies of coli aërogenes bacteria (Weigmann).

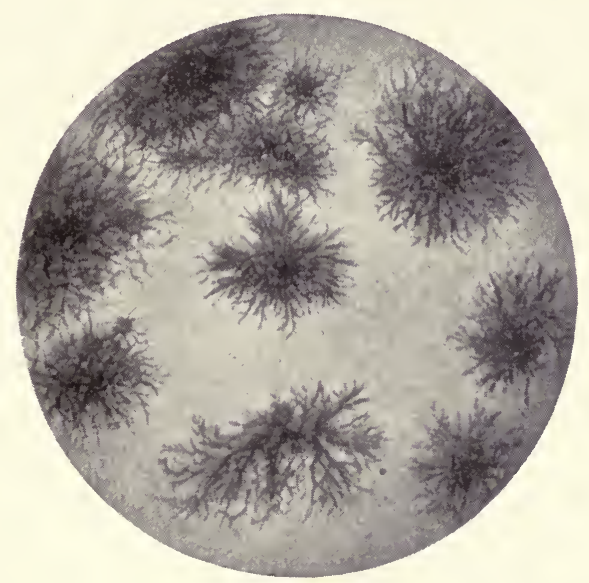

Frg. 8.-Colonies of Proteus vulgaris, natural size (Weigmann). 

ing at $15^{\circ} \mathrm{C}$. $\left(59^{\circ} \mathrm{F}\right.$. $)$. Keeping milk at a temperature of $15^{\circ} \mathrm{C} .\left(59^{\circ} \mathrm{F}\right.$.) or below, therefore, inhibits the least desirable type of lactose fermentation. The Bacillus bulgaricus requires a temperature of at least $25^{\circ} \mathrm{C}$. $\left(77^{\circ} \mathrm{F}.\right)$.

The acid-forming bacteria are widely distributed, but according to Esten ${ }^{1}$ the chief primary source of those of the Streptococcus lacticus type found in milk is the cow's mouth. The organisms are present in the manger and on everything within reach of the cow's mouth, also in the fæces. The acid-formers of the Bacterium acidi lactici type are derived from sugar-containing grain and roots like corn, beets, and carrots, especially when they are cut into small pieces, packed and fermented (ensilage) ; they are also contained in the fæces of cows (Weigmann). Milk vessels and utensils, and other things and places with which milk comes in contact become seeded with acid-forming bacteria when not properly cleaned and sterilized, and are usually the principal sources of contamination when these organisms are present in milk in excessive numbers.

2. Gas-forming Bacteria.-Included in this group are the bacteria which ferment the lactose in milk and form gases in addition to acids. They also decompose the proteids to some extent, especially the casein (Fig. 7). Most of them belong to the large coli-aerogenes group of organisms. The milk is curdled in the form of a smooth, white, jelly-like curd, which is more or less permeated with gas bubbles and is associated with some fluid. The aerogenes organisms form a greater quantity of acids and gases than the coli and they also form more

1 "Bacterium Acidi Lactici and Its Sources," Storr's Agr. Expt. Sta. Bull. No. 59. 
lactic acid than the coli, but the latter are more active in proteid decomposition. Carbon dioxide, hydrogen, carburetted hydrogen, and nitrogen are the gases produced, while the acids formed are lactic, acetic, and succinic. In the early stages of this change, the milk has a sweetishsour refreshing taste and an odor that is not unpleasant, especially when the aerogenes bacteria are operating, but later the taste is unclean, while the odor is stable-like, and finally the taste becomes nauseating and salty and the odor is like that of decomposing manure and urine. Milk undergoing this form of fermentation and decomposition may prove harmful to persons drinking it, especially infants and adults with weak digestion.

The principal representatives of this group of bacteria are the Bacillus coli and the Bacillus aerogenes, also called Bacillus lactis aerogenes and Bacterium acidi lactici (Hueppe). The Bacillus coli is a short, thick, oval organism, which is motile, and which forms on solid media colonies which are usually flat, leaf-shaped and partially translucent, sometimes moist and globular. Some varieties render the milk alkaline and do not curdle it nor produce any other visible change; others peptonize the casein. Several varieties of coli are pathogenic, e.g., the bacilli of calf cholera, the Bacillus enteritidis (Gärtner) and the Bacillus phlegmasia überis, which is one of the causes of parenchymatous mastitis according to Kitt. The Bacillus lactis aerogenes or Bacterium acidi lactici (Hueppe), described previously in connection with the acid-forming bacteria, may be regarded as a type of the aerogenes bacteria, of which there are a number of varieties.

The optimum temperature of the coli-aerogenes bacteria is $37^{\circ} \mathrm{C}$. $\left(98.6^{\circ} \mathrm{F}\right.$.), but they grow quite well at 
lower temperatures down to $20^{\circ} \mathrm{C}$. $\left(68^{\circ} \mathrm{F}\right.$.). They do not grow as well as the Streptococcus lacticus between 15 and $20^{\circ} \mathrm{C}$. (59 and $68^{\circ} \mathrm{F}$.), and at lower temperatures the difference is still greater.

These organisms are normal inhabitants of the intestines of the cow and consequently are hardly ever entirely absent from milk. They are present in water polluted by drainage from barnyards, manure heaps and cesspools, and also on field crops, especially roots grown on manured ground. Their presence in milk in any considerable number indicates that it has been contaminated with manure or with polluted water.

Milk also contains anaerobic bacteria which ferment lactose and its salts, forming gas in large quantity and producing strong-smelling acids like butyric, valerianic and propionic. These organisms are present ordinarily in small number and their development is usually prevented by the acid-forming bacteria. When they grow in milk in large numbers, a curd containing many gas bubbles is formed. The milk has the odor of the acid produced and frequently an odor of putrefaction also. Because of the latter condition, these organisms are regarded as putrefactive bacteria. The best known are those which produce butyric acid and are consequently called butyric acid bacteria. They are very large sporeforming bacilli which live in cultivated soil in symbiosis with the peptonizing bacteria. They are usually present in the spore-forming stage on the products of the field. Morphologically, they are distinguished from the other spore-forming milk bacteria by a change in form during spore formation, becoming shuttle-shape, drum-stickshape, etc.

Ayers and Johnson found gas-forming bacteria in 
milk which were not members of the coli-aerogenes group but which were apparently spore-formers, having survived a temperature of $93.3^{\circ} \mathrm{C}$. $\left(200^{\circ} \mathrm{F}\right.$.) for thirty minutes. ${ }^{1}$

3. Peptonizing or Casease Bacteria.-The bacteria of this group are also known as liquefiers and are the cause of decay and putrefaction in general. They secrete two enzymes or ferments which attack the proteids of milk, especially the casein. One is a rennet-like ferment which acts upon the calcium caseinate in the same manner as rennet, splitting it up into calcium paracaseinate and a substance called whey-proteid. The calcium paracaseinate being insoluble, it is precipitated and forms a curd. The whey-proteid remains in solution in the whey, hence the name. The other enzyme is casease, a proteolytic ferment resembling trypsin, which digests the proteids in the curd and whey, splitting them up into soluble compounds like albumoses and peptones (peptonization) and then again into simpler compounds like amino-acids and ammonium bases (decomposition). The two ferments are produced in varying proportions by different species of bacteria. When the rennet-like ferment predominates a firm white curd is formed and is slowly digested. There is more or less fluid (whey) present. As digestion proceeds, the curd gradually disappears and is replaced by a turbid fluid. The surface of the curd in contact with the fluid has a rough or fuzzy appearance. When the proteolytic ferment (casease) is present in greatest quantity, the curd is soft, flocculent and "mushy," or coagulation does not occur at all, while peptonization takes place rapidly. In the earlier stages

${ }^{1}$ B. A. I. Bulletin No. 161, pp. 47 and 48. 
of this type of decomposition, the milk acquires a bitter taste (peptones) and later the taste and odor are foul and unpleasant. Some of the decomposition products are capable of exerting an injurious effect upon persons drinking the milk. Nausea and vomiting may occur, even in adults, when the taste is only bitter and before it has become decidedly foul. The reaction of the milk is usually alkaline, but some of the peptonizers are acidformers and curdle milk by souring it.

Included in this group are certain of the cocci which appear to be constantly present in the lower parts of the cow's udder and are consequently called udder cocci. These organisms are to be found regularly in milk when it comes from the udder, especially in the fore milk. They are present in greater proportion in milk produced under good conditions than in ordinary milk. There are many varieties or species of these organisms which differ principally in their fermentative properties and in the color of their colonies. In milk hygiene, it is desirable to divide them into peptonizers and non-peptonizers. Part of the peptonizers first curdle milk and then digest the curd; others bring about digestion without previous curdling. Some of the organisms which curdle the milk do so by means of a rennet-like ferment; the others by means of acid resulting from fermentation of the lactose (acid peptonizers). The non-peptonizers are practically inert, producing no apparent change in milk. On agar plates, the udder cocci form small, irregularly round colonies which are usually white. The colonies of Staphylococcus pyogenes albus vary from white to cream color, while those of Staphylococcus pyogenes aureus are orangeyellow. The latter two organisms are peptonizers and also form lactic acid. The ordinary udder cocci and 
Staphylococcus pyogenes albus and aureus are similar in so many respects that all are regarded by some bacteriologists as different varieties of the same species. The optimum temperature for the udder cocci is 35 to $37^{\circ}$ C. $\left(95\right.$ to $98.6^{\circ} \mathrm{F}$.), but they grow well at much lower temperatures, development continuing down to freezing. The peptonizing action is exerted at these low temperatures.

Many of the peptonizers are spore-forming bacteria. The most common representatives of this division are the hay bacillus (Bacillus subtilis) and the potato bacillus (Bacillus mesentericus vulgatus). They belong to a large group of organisms which are very numerous in cultivated soil and are consequently found on all products of the soil, especially hay, straw, roots, etc. They are large rod-shaped bacteria with rounded ends. The spores form in the middle or end of the organism without changing its shape. On agar plates these bacteria form dry, thin, superficial skin-like colonies, with irregular borders. The colonies have a tendency to extend over the surface of the media and are consequently called "spreaders." These organisms are very numerous in the dust of hay and other dry fodder, also in straw, and they may get into the milk in large numbers if the fodder or litter is brought into the stable and distributed a short time before milking, or if dust from hay or other dry fodder is permitted to sift down into the stable through cracks in the ceiling. When a cow lies upon bedding or upon loose soil, these bacteria enter the folds and creases of the skin and become attached to the hair, and when the cow is milked those upon the udder, flanks and surrounding parts are dislodged and may fall into the milk pail. These organisms are especially numerous on the hair 
and skin of cows at pasture. The manure does not contain very many and few are carried into milk on this substance (Weigmann). The hay and potato bacilli grow best at 23 to $37^{\circ} \mathrm{C}$. (73 to $99.6^{\circ} \mathrm{F}$.), but will develop at any temperature between 10 and $45^{\circ} \mathrm{C}$. (50 to $\left.113^{\circ} \mathrm{F}.\right)$. The spores are very resistant to heat and will survive several hours boiling.

Other peptonizers include the bacteria of the proteus group of putrefactive organisms, which are often present in milk, although more frequently found in water (Fig. 8). They are long, thin bacilli which grow in colonies of various forms. The most common representative of these organisms is the Bacillus proteus vulgaris, which grows in colonies with branches or ray-like projections. They get into the milk principally through the water used to wash the milk vessels and utensils. The Bacillus proteus vulgaris grows best at about $25^{\circ} \mathrm{C} .\left(77^{\circ} \mathrm{F}\right.$.)

4. Alkali-forming Bacteria.-Some of the bacteria commonly found in milk render the milk alkaline without producing any change for a time in its appearance, taste, or odor. When the alkalinity has attained a certain degree, the fat is saponified and the neutral calcium caseinate compound becomes basic, in consequence of which the milk is changed to a yellow, translucent, wheylike fluid (Jensen). Within the ordinary life of milk, however, the bacteria of this group are practically without effect. Usually they get into the milk in the same manner as hay bacilli (page 60), their source being the soil, but occasionally they are derived from the fæces (Rogers).

5. Inert Bacteria.-A large number of the common milk bacteria produce no change in the appearance, odor, taste, or reaction of milk and are consequently said to 
be inert. Many bacteria belong to this group, which includes some of the udder cocci. Many of the most important pathogenic organisms are also inert in so far as their effect on milk is concerned, notably the tubercle bacillus, the bacillus of typhoid fever, paracoli or paratyphus bacilli, and the diphtheria bacillus. The presence of these harmful organisms is not indicated by any apparent change in the milk.

VARIATIONS IN NUMBER AND KIND OF BACTERIA

Different samples of market milk may show the greatest differences in the number and kind of bacteria present. One sample may contain much fewer than $\mathbf{1 0 0 0}$ bacteria per c.c. and another may contain four or five million and even more. In one sample, the bacteria may be largely of the inert forms and in another the bacteria of the gas-forming group may predominate. Market milk containing not more than 100,000 bacteria per c.c. is considered of good quality. The limit for certified milk is 10,000 bacteria per c.c.

The kind or species of the bacteria must be considered as well as the number. Generally, the smaller the number of bacteria present the better the milk, but there are exceptions to this rule. A few pathogenic organisms would be more harmful than a much larger number of the common milk bacteria. Between the different groups of the latter there are also important differences. Milk containing a rather large number of bacteria the greater proportion of which belong to the inert or lactic acid groups is less objectionable than milk containing a smaller number of bacteria with the greater proportion belonging to the gas-forming or peptonizing groups. On the other hand, while milk containing a large percentage 
of peptonizing bacteria is not objectionable when the total number of bacteria is small, it is always objectionable when the bacterial count is high.

The number of bacteria present in market milk depends upon (1) the original contamination, (2) the temperature at which the milk has been kept, and (3) the age of the milk, i.e., the time which has elapsed since the milk was drawn from the cow.

1. By original contamination is meant the bacteria which get into the milk during milking and the subsequent handling of the milk. The extent of this depends upon the cleanliness and health of the cows, stable practices, method of milking, cleanliness of the milk vessels and utensils, etc.

2. The temperature at which milk is kept affects not only the total number of bacteria but also influences the relative rate of increase of the different kinds or species. As a rule, the higher the temperature the more rapidly the bacteria multiply. For example, Conn found that when fresh milk contained 6525 bacteria per c.c., after 25 hours at $10^{\circ} \mathrm{C} .\left(50^{\circ} \mathrm{F}\right.$.) it contained 6425 bacteria per c.c., while after 25 hours at $21^{\circ} \mathrm{C} .\left(70^{\circ} \mathrm{F}\right.$. $)$ it contained $6,275,000$ bacteria per c.c.

When milk is promptly cooled to $10^{\circ} \mathrm{C}$. $\left(50^{\circ} \mathrm{F}\right.$. $)$ and held at that temperature, little or no increase of bacteria will occur for twenty-four to thirty-six hours, and even at $15^{\circ} \mathrm{C} .\left(59^{\circ} \mathrm{F}\right.$.) the increase will not be very great. At temperatures above $20^{\circ} \mathrm{C} .\left(68^{\circ} \mathrm{F}\right.$. $)$, however, the bacteria increase very rapidly.

As stated above, the temperature affects not only the number of bacteria but also the relative development of the different species. In other words, it determines the type of fermentation or decomposition which the milk 
will undergo with age. Most species of bacteria thrive best at about body temperature ( 37 to $38^{\circ} \mathrm{C}$., 98.6 to $100.4^{\circ} \mathrm{F}$.), but at lower temperatures some multiply more rapidly than others. At temperatures below $15^{\circ} \mathrm{C}$. $\left(59^{\circ} \mathrm{F}\right.$. $)$, and especially below $10^{\circ} \mathrm{C}$. $\left(50^{\circ} \mathrm{F}\right.$. $)$, the organisms of the peptonizing group develop more rapidly than any of the other common milk bacteria. At 15 to $20^{\circ} \mathrm{C}$. $\left(59\right.$ to $68^{\circ} \mathrm{F}$.), the true lactic acid bacteria increase faster than any of the others. At temperatures above $20^{\circ} \mathrm{C}$. $\left(68^{\circ} \mathrm{F}\right.$.), the acid-forming bacteria may continue to multiply more rapidly than the others, but the gas-formers are more likely to increase most rapidly. The higher temperatures are also favorable to the development of pathogenic organisms.

3. The age of milk has considerable influence on the number of bacteria. The longer the period which has elapsed since the milk was drawn from the cow the more time afforded for the multiplication of the bacteria included in the original contamination.

(The method of determining the number of bacteria is described on pages 260 to 272 .)

Proportion of Different Groups of Bacteria.-The kind or species of bacteria included in the original contamination, and the relative proportion in which the different groups are represented, will vary with the conditions under which the milk is produced. In milk produced under good conditions and examined shortly after it was drawn from the cows, Conn found that the greater portion of the bacteria are udder cocci, including both peptonizers and the inert variety. Usually 1 or 2 per cent., sometimes more, are lactic acid bacteria. A few gas-producing bacteria and hay and potato bacilli are likely to be present, but they should never be numerous. 
The kind of bacteria which will predominate in milk of this kind when it reaches the consumer will depend upon the temperature at which it is kept (see above). The fermentation test offers a rapid and convenient method of determining the kind of bacteria which predominates in a sample of milk (see page 278 ).

A large percentage of the bacteria present in market milk belongs to the inert group. This is shown by the following table compiled from examinations reported by Ayers and Johnson ${ }^{1}$ :

\begin{tabular}{crrrrrr}
$\begin{array}{c}\text { No. samples } \\
\text { examined. }\end{array}$ & $\begin{array}{c}\text { Average } \\
\text { number bac- } \\
\text { teria per c.c. }\end{array}$ & $\begin{array}{c}\text { Percent. } \\
\text { peptonizing. }\end{array}$ & $\begin{array}{c}\text { Percent. } \\
\text { Alkali- } \\
\text { forming. }\end{array}$ & $\begin{array}{c}\text { Percent. } \\
\text { inert. }\end{array}$ & $\begin{array}{c}\text { Percent. } \\
\text { Acid, coag- } \\
\text { ulating. }\end{array}$ Acid, noagulating. \\
12 & $32,950,000$ & 17.31 & 6.47 & 29.31 & 36.17 & 10.71 \\
17 & $3,451,000$ & 14.10 & 19.66 & 43.51 & 12.98 & 9.74 \\
& 24,700 & 12.81 & 3.33 & 43.13 & 33.85 & 6.85 \\
\hline
\end{tabular}

${ }^{1}$ B. A. I. Bull. 161, pp.20-2\%. 


\section{CHAPTER V}

\section{MILK DEFECTS}

IN addition to the changes in milk caused by the common milk bacteria and those occurring in the course of diseases of the cow, there are certain alterations in consistency, odor, taste, and color which are known as milk defects. Some of these defects make the milk revolting, even nauseating, while a few render it harmful. They may be divided into two groups $(a)$ those which are present when the milk is drawn from the udder and (b) those which appear shortly afterward.

(a) Milk Defects which are Present in Milk when it Comes from the Udder.-The most important of these are named below, together with the causes, the latter being given because they indicate the measures to be taken for the correction or removal of the defects.

1. Corw-like or Salty, Corw-like Taste.-The milk has a strong cow-like taste or a salty, cow-like taste, is of a gray color and may have the appearance of soapy water. This may be due to several causes. Milk from cows in the last stages of lactation has a mild, cow-like taste which is attributed to the relaxation of the gland tissue and filtration of blood serum between the epithelial cells of the alveoli. The cow-like taste also occurs when the cow has been incompletely milked at the previous milking, and it is claimed that the first few streams of every milking have a similar taste. In these cases it is thought that the abnormal taste is due to bacteria which enter the teat canal. Certain staphylococci and streptococci and some 
bacteria of the coli-aerogenes group give milk a cow-like, salty taste (Weigmann).

2. "Fishy" Milk.-Milk from cows near the end of lactation may have a " fishy" taste. This defect is believed to result also from feeding fish meal and from grazing cows on marshes subject to overflow with salt water; but cows have been fed on large quantities of fish meal without affecting the taste of the milk or butter. In one instance, the milk of one cow in a herd had such a pronounced "fishy" taste that it tainted the milk from the entire herd, although this cow was fed and stabled in exactly the same manner as the others. The cause in this case could not be determined. Milk may acquire a "fishy" taste from milk vessels which are rusted and also from those which have not been rinsed clean of the soap powder used in washing them.

3. Rancid Milk.-A rancid odor and taste in milk as it comes from the udder may be due to the same conditions which give milk a cow-like taste. A rancid odor and taste may appear a short time after the milk is drawn from the udder as a result of the growth of butyric acid bacteria (page 57). On several occasions an unidentified biscuit-shaped organism, growing in pairs, with the flat sides toward each other, has been found to be the cause of a rancid odor and taste.

4. Slow-creaming Milk.-The milk is thicker and more viscous than usual; the cream separates slowly and in less quantity than normal, sours slowly and does not "butter" readily. This defect has been observed in the milk from cows near the end of lactation and in milk from cows fed on beets, carrots, and turnips. Certain species of bacteria greatly increase the viscosity of milk, pro- 
ducing what is known as viscid, "ropy," or "stringy" milk (page 69).

5. Premature curdling may occur in connection with disturbances of digestion, udder diseases, advanced pregnancy, overexertion and feeding sour brewers' grains and distillery slop; it may also result from the development of excessive numbers of the acid-forming and peptonizing udder cocci as a consequence of incomplete milking. In the latter case, sodium bicarbonate or salicylic acid internally is recommended.

6. "Gritty" or "Sandy" Milk.-Small granular particles, concrements of calcium and magnesium phosphate, occur in milk when defects exist in the epithelium of the alveoli of the udder which permit the passage of the salts of the blood; also when salts are present in the blood in excessive quantity as a result of the feeding of substances containing a high percentage of mineral matter (Weigmann). These granules may be increased in size by the adhesion of mucus, epithelial cells, salts, etc., and form milk stones or udder stones (calculi), which may make milking difficult or painful. The calculi are of various shapes and sizes and may be as large as a bean.

"Bloody" milk, the "flaky" milk occurring in mastitis and the other changes associated with disease of the udder and other pathological conditions are considered in the chapter on the "Influence of Disease Upon Milk." For other defects, see also the remarks under odor and taste (page 28).

(b) Milk Defects which Appear after the Milk is Drawn from the Udder.-The greater part of these defects are caused by certain species of bacteria, yeasts and fungi which grow well at low temperatures. Springhouses, cooling-rooms and other dark, damp places fur- 
nish an environment favorable to their development. Measures for the correction of these defects must be based upon the source of the organisms concerned.

1. Bitter Milk.-Several species of bacteria, yeasts and fungi have been isolated at different times from bitter milk. In some instances the organisms responsible for the bitter taste were found in the udder. Milk may acquire a bitter taste from the action of the organisms belonging to the peptonizing and gas-forming groups of the common milk bacteria. This is especially true of heated milk, in which the spores of the soil bacteria (hay and potato bacilli ) survive. The occurrence of a bitter taste in milk is often associated with the feeding of certain substances, notably mouldy or decomposed fodder, beet and turnip leaves, and raw potatoes; also vetch, wild mustard and other cruciferous plants, leek, dog-fennel, tansy, etc. The use of mouldy or decomposed straw for bedding is accompanied by the same effect. It is believed that the bitter taste is caused by organisms which are present on these substances and which enter the milk after it is drawn from the udder, and it is recommended, therefore, that these feeds be given after milking, excepting, of course, those which are mouldy or decomposed. Another theory is that the taste is due to a bitter substance which is ingested with the food and eliminated through the udder. If milk is stored in rusted vessels until a certain degree of acidity develops, it acquires a bitter, astringent taste, due to formation of iron lactate or acetate. Milk may also have a bitter taste just before parturition and near the end of lactation.

2. Viscid, "Ropy," or "Stringy," Milk.-The milk is thick and viscid and when it is poured from one vessel to another strings are formed; it may also be drawn out 
into long strings with a rod or stick. The bacteria which cause this defect are frequently introduced into the milk by the water used to wash the milk vessels and utensils. Milk-houses, storage tanks, etc., may be infected by the same means. Water from streams and shallow wells receiving surface drainage, also from springs receiving surface or subsurface drainage, is especially likely to contain the organisms. They are also to be found on vegetation growing in low, damp places and on straw stored in a damp condition. In Sweden " stringy" milk is prepared artificially and is a popular article of food (tätmjölk), while, in Holland, Edam cheese is made from "stringy" milk produced by a certain organism.

3. "Soapy" Taste.-Milk may acquire a "soapy" taste from the action of bacteria which attack the proteids and fat of milk. Several species of these organisms have been found on straw and fodder.

4. Failure to Sour and "Butter."-Milk may not sour and cream may not sour and "butter" at all or only very slowly. This defect may be due to a deficiency in acid-forming bacteria or to an excess of peptonizers. In the latter case, the milk or cream usually has a bitter taste; occasionally a " soapy " taste. Alkali-forming bacteria, butyric acid bacteria, some of the organisms of the coli-aerogenes group and certain yeasts and fungi may also delay or prevent souring and "buttering." In some cases the cream foams when churned, in consequence of the formation of gas. This defect is especially liable to occur when cows are pastured on low, wet land; also when the leaves of roots (beets, etc.), are fed, and in cold, wet weather. Cream from the milk of cows near the end of lactation will not "butter" sometimes because of the alkalinity of the secretion. 
5. Stable-like, turnip-like, and beet-like tastes, and a burnt or malt-like taste and odor are each caused by certain species of bacteria.

6. Blue Mill.-The Bacillus cyanogenus, also called the Bacterium syncyaneum, produces a grayish color on the surface of milk and, when the milk is sour, blue spots, which may become confluent. There are several other species of bacteria which produce a blue color in milk.

7. Red Milk.-Red spots or a diff use red color on the surface are produced by the Bacillus prodigiosus, also by Sarcina rosacea and several other species of organisms. The Bacterium lactis erythrogenis curdles milk, then dissolves the curd and colors the fluid diffusely red.

8. Yellow- or orange-colored spots are produced usually by the Bacillus synxanthus; also by the Sarcina lutea, Sarcina flava and the Bacterium fulvum.

9. A yellowish-green discoloration is produced by the Bacillus pyocyaneus.

10. Greenish-yellow spots and diffuse discoloration may occur in sour milk as a result of the growth of the Bacillus fluorescens.

11. Violet-colored spots are produced by the Bacillus violaceus, Bacterium janthinum, Bacillus lividus and Bacterium amethystinus.

In some cases, although very rarely, these pigmentforming bacteria are present in the udder. Usually, they enter the milk after it is drawn from the udder. They can generally be excluded by sterilizing the milk vessels and cleaning and disinfecting the places where the milk is stored; sunning it also if possible. Sometimes it will also be necessary to clean and disinfect the stable and to see that the cows are thoroughly cleaned before milking. 


\section{CHAPTER VI}

\section{INFLUENCE OF DISEASE UPO,N MILK}

MAN is susceptible to several of the specific infectious diseases of cattle viz: tuberculosis, aphthous fever or foot and mouth disease, cowpox, anthrax, rabies, and actinomycosis. Furthermore, mastitis, calf cholera, acute croupous and hemorrhagic enteritis (paracoli infection), septic metritis, and many suppurative conditions in cattle are caused by bacteria which are pathogenic for man. In certain non-bacterial affections, such as gastro-intestinal catarrh, the milk sometimes becomes unpalatable and, when ingested, may cause irritation of the gastro-intestinal tract, especially in children.

The study of the conditions under which disease-producing organisms enter the milk and the effect of disease upon the milk secretion is one of the important divisions of milk hygiene. Bacteria or virus may be carried by the blood to the udder and be eliminated with the milk, or they may be excreted through one of the other normal open channels or discharged from wounds and enter the milk after it is drawn from the udder. The first method is called direct infection and the latter secondary infection. There is no doubt that bacteria circulating in the blood may pass over into the milk when the tissue separating the udder alveoli and tubules from the capillaries is broken down by disease. Some investigators are of the opinion that this may also occur when the udder tissue is intact, but this view is disputed by others. When bacteria invade the udder through the teat canal, as 
occurs in the non-tuberculous forms of mastitis, they are, of course, always eliminated in the milk.

In considering the influence of disease of the cow on market milk, the effect of dilution must not be overlooked. Milk from a diseased cow may be injurious when ingested by itself, but when it is mixed with the milk from a number of other cows in a normal condition it may be so diluted as to render it harmless. The character of the mixed milk in this respect will depend partly upon the proportion of diseased cows to those in health, partly upon the ability of the organism concerned to grow in milk, and the temperature at which the milk is kept.

The diseased conditions affecting milch cows which are of importance in milk hygiene will now be considered separately.

\section{Diseases of Cattle Transmissible to Man Through Milk}

\section{TUBERCULOSIS}

In milk hygiene there are four points to be considered in connection with tuberculosis: (1) The frequency of tubercle bacilli in market milk, (2) the virulence for man of tubercle bacilli from cattle, (3) the conditions under which milk is infected with tubercle bacilli by tuberculous cows, and (4) how can contamination of market milk with tubercle bacilli be prevented.

1. The Frequency of Tubercle Bacilli in Market Milk.In a number of cities in this country and abroad, samples of market milk have been collected and examined for tubercle bacilli. Anderson ${ }^{1}$ examined 233 samples in Washington in 1906 and found tubercle bacilli in 6.72

${ }^{1}$ U. S. Hygienic Lab. Bull., No. 56, pp. 167-19\%. 
per cent. In Philadelphia, in 1908, Campbell ${ }^{2}$ examined 130 samples of raw milk and found tubercle bacilli in 13.8 per cent.; twelve samples of milk sold as " pasteurized "were also examined by him and one sample, or $\mathbf{8 . 3}$ per cent., contained virulent tubercle bacilli. Hess ${ }^{3}$ found tubercle bacilli in $\mathbf{1 6}$ per cent. of the samples he examined in New York in 1909, and of 144 samples examined by Tonney in Chicago in 191010.5 per cent. were infected with tubercle bacilli. In Germany, from 16.5 to 27.1 per cent. of the samples of market milk examined in various cities contained tubercle bacilli; in England, 10 to 25 per cent.; in Paris, 20 per cent., and in Copenhagen, 4 per cent. ${ }^{4}$ Another evidence of the frequency of tubercle bacilli in milk is the general virulence of separator milk from creameries. This milk has been found to be such a great factor in the dissemination of tuberculosis among calves and hogs that several states, among them Pennsylvania, have passed laws requiring such milk to be pasteurized before it is removed from the creamery to be fed to cattle or swine.

There are no statistics which show definitely the extent to which tuberculosis exists among dairy cattle in the United States. The disease is found in less than 1 per cent. of the cattle slaughtered for meat under Federal inspection, but the greater proportion of these are beef cattle and many of them are of young age, a period when tuberculosis is not as frequently found as in later life. The proportion of dairy cows affected with tuberculosis is not known. The per cent. of infected animals varies

2 26th Annual Report, B. A. I., pp. 175-17\%.

${ }^{3}$ The Incidence of Tubercle Bacilli in New York City Milk, Jour. Am. Med. Assoc., No. 13, Vol. 52.

${ }^{4}$ Rievel, Milchkunde, pp. 99-100. 
greatly in different localities and in different herds in the same section. The proportion of animals reacting to the tuberculin test ranges from none in herds which have been subjected to annual tests for several years to 30 per cent. and over in herds in which no effort has been made to control the disease.

2. Virulence for Man of Tubercle Bacilli from Cattle.-Until 1901 it was very generally accepted that tuberculosis in man and animals was the same disease, although Theobold Smith, in 1896, and, subsequently, others, pointed out important differences in virulence, morphology, and cultural characteristics between bacilli from human and bovine sources. In 1901 Koch announced that tuberculosis of cattle was so rarely transmitted to man that it could practically be disregarded in formulating plans to protect man against the disease. This announcement was based on the failure of Koch and Schütz to infect calves and other animals with tuberculous material from man, and upon post-mortem statistics collected by them of a number of cases of tuberculosis in man which happened to include only a small proportion of individuals showing primary lesions in the digestive tract or attached lymph glands. Koch's announcement made a pronounced impression upon the general public, although his experiments were not original nor were his results undisputed. Theobold Smith, Frothingham, and Dinwiddie in this country, and Pütz, Gaiser, Nocard, McFadyean, Thomasson, Chauveau, Klebbs, Kitt, Bollinger, and Crookshank abroad, had previously attempted to infect cattle with tuberculous material from man and had succeeded in doing so, although they found that these animals were less susceptible to human tuberculous material than to that from bovine sources. Since 
Koch's announcement was made, some thirty-five or forty investigators in different parts of the world have attempted to transmit human tuberculosis to cattle and all have succeeded but one.

As to the other point upon which Koch based his views, the frequency of primary tuberculosis of the digestive tract or attached lymph glands, we learn from the investigations of others that, while this form of tuberculosis is rare in adults, the proportion of cases found in children by different investigators is extremely variable, ranging from $1 / 2$ to 37.8 per cent.; consequently the statistics collected by any one or two men cannot be accepted as representing the percentage of cases in which the lesions are primary in the digestive tract or attached lymph glands. Evidence has also been produced by the experiments of Mohler, Ravenel, Calmette, and others that tubercle bacilli may be introduced through the digestive tract and primary lesions established in the lungs or thoracic lymph glands without producing any lesions in the intestines or mesenteric lymph glands.

Koch's views were not accepted by many of those who had made a special study of tuberculosis, and his announcement instigated a vast amount of research work. Commissions were appointed by the British and German governments to investigate the relation of bovine to human tuberculosis, and other official bodies, and many individuals also took up the study of the subject. Koch contended that it could be assumed that the infecting material had been ingested with the food only when primary lesions were found in the digestive tract or its attached lymph glands, and that only those cases in which tubercle bacilli of the bovine type were demonstrated in the lesions could be regarded as having been infected by 
the products (meat and milk) of tuberculous animals. The investigations were therefore largely directed along these lines. The present views of those who have studied the subject are fairly represented by the conclusions reached by the British commission and published in 1911 after a careful and thorough inquiry extending over ten years. These conclusions are as follows:

"There can be no doubt that a considerable proportion of the tuberculosis affecting children is of bovine origin, more particularly that which affects primarily the abdominal organs and the cervical glands. And, further, there can be no doubt that primary abdominal tuberculosis as well as tuberculosis of the cervical glands is commonly due to ingestion of tuberculous infective material." One hundred and eight cases of human tuberculosis other than lupus were examined by the Commission and bacilli of the bovine type were found in twentyfour, or 22 per cent. The latter included sixteen cases of primary abdominal tuberculosis, three of tuberculosis of the cervical lymph glands, two of pulmonary tuberculosis, two of tuberculosis of the bronchial lymph glands and one of joint tuberculosis. Bacilli of the bovine type were found in nearly half of the fatal cases of primary abdominal tuberculosis.

The German commission made a study of fifty-six different cultures obtained from cases of tuberculosis in man and found six, or more than 10 per cent., to be of the bovine type.

Park and Krumwiede ${ }^{5}$ determined the type of bacilli present in 487 cases of tuberculosis in man and collected from the literature the records of $\mathbf{1 0 3 3}$ cases in which the

${ }^{5}$ Journal Med. Research, pp. 109-114, vol. $2 \%$. 
type of the organism was determined by others, a total of 1511 cases. There were 955 cases in individuals over 16 years of age, 177 in children between 5 and 16 years, and 368 in children under 5 . Tubercle bacilli of the bovine type were found in $\mathbf{3 5}$ per cent. of the cases in children between the ages of 5 and 16, and in 26 per cent. of the cases in children under 5. In addition to these, there were eleven cases in which both types of bacilli were found.

It is usually difficult to discover the source of infection in cases of tuberculosis in man because the disease does not become apparent for a long time after exposure to infection has occurred. Nevertheless, there are a number of cases recorded of tuberculosis in children and adults using milk from tuberculous cows for which no other source of infection could be found. ${ }^{6}$ Regarding the evidence in these cases as generally incomplete, Koch, in 1902, suggested that a search be made for cows in which tuberculosis of the udder could be positively diagnosed and, when such cases were found, that it be ascertained how long the disease had existed, who consumed the milk or its products, whether the milk was used raw or cooked, and if the persons who used the milk or its products were infected with tuberculosis. Between 1905 and 1909 Weber and Ungerman ${ }^{7}$ found in Germany 69 cases of udder tuberculosis concerning which the information desired could be obtained. Three hundred and sixty persons, including 151 children, used milk from these cows. Two boys were affected with tuberculosis of the cervical lymph glands in which bacilli of the bovine type were

${ }^{6}$ Rievel, Milchkunde, pp. 107-108.

${ }^{7}$ Cited by Ostertag, Zeitschr. für Fleisch u. Milchhygiene, pp. 26 and 27 , No. 2, vol. xxiii; p. 123, No. 6, vol. xxiv. 
demonstrated. Six other children and one adult were found with swelling of the cervical lymph glands, four children and one adult showed symptoms indicative of abdominal tuberculosis and one child suffered from scrofula, but in these cases no material could be obtained for bacteriological examination. Forty-one other persons showed various symptoms of disease, but tubercle bacilli could be demonstrated in only 4 , and these bacilli were of the human type. The other 304 individuals who had used milk from the tuberculous udders, or products made from such milk, showed no symptoms of disturbed health in 1910. Subsequently, one of these, a girl, developed a peritonitis for which the infected milk was probably responsible. While in some instances the milk was heated, mixed with milk from apparently healthy cows, or only a small quantity was used in tea or coffee, nevertheless the results of this investigation would indicate that a considerable amount of infectious material and favorable accessory conditions are required to infect man with bovine tuberculosis. But, as Weber himself has pointed out, it must be remembered that it is not known positively that the individuals manifesting symptoms suspicious of cervical lymph gland and abdominal tuberculosis were not actually infected, nor how many of the apparently healthy persons concerned were affected with latent tuberculosis which may later, under some debilitating influence, become active and progress to a fatal termination.

Furthermore, Weber's observations are not confirmed by others who have studied the frequency of the transmission of bovine infection to man by milk. A comparison of the occurrence of tuberculosis in breast-fed children 
with the frequency of the disease in children receiving cow's milk was made by Sobotta. Of 80 exclusively breast-fed children, 17.5 per cent. were infected with tuberculosis; of 57 children receiving cow's milk in addition to mother's milk, 35.1 per cent. were infected, and of 30 fed exclusively on cow's milk 41 per cent. became tuberculous. ${ }^{8}$ Mitchell ${ }^{9}$ examined 72 cases of cervical gland tuberculosis in the Children's Hospital in Edinburgh and found tubercle bacilli of the bovine type in 65 , or 90 per cent. These children came from districts in which the cattle are extensively infected with tuberculosis and most of them had been nourished on cow's milk. Of 70 cases of tuberculosis of the bones and joints in children examined by Fraser $^{9}$ in Edinburgh, 41, or 60 per cent., were due to bacilli of the bovine type and in the greater number of cases the history indicated that the infection was introduced by cow's milk. In 261 cases of bone and joint disease examined by Eastwood and Griffith, ${ }^{10}$ bacilli of the bovine type were found in 55, or 21.1 per cent. Of these latter, 29 per cent. were from patients under 10 years of age and 9.4 from patients over that age. Seventeen cases of genito-urinary diseases were examined. Bacilli of the bovine type were found in three cases of kidney disease in persons 25, 19 and 20 years old, respectively. Twelve and one-half per cent. of the fatal cases of tuberculosis in children under 5 years old studied by Park and Krumweide ${ }^{11}$ were

${ }^{8}$ Cited by Rievel, Milchkunde, p. 110.

${ }^{9}$ Cited by Ostertag, Zeitschr. für Fleisch u. Milchhygiene, p. 69 , No. 3, vol. 24 ; p. 118, No. 5. vol. 24.

${ }_{10}$ Journal of Hygiene, pp. 257-309, 310-314, No. 2, vol. 15.

11 Jour. Med. Research, pp. 109-114, vol. $2 \%$. 
due to bovine infection. They had nine cases in a foundling asylum in children under 6 years who were nourished exclusively on cow's milk and found bovine infection in five, or over 50 per cent. Of the fatal cases in the Babies' Hospital in New York City 61/2 per cent. were due to bovine infection.

These observations cannot be ignored in considering the results of Weber and Ungermann's investigation, especially since they all indicate that bovine tuberculosis is a considerable source of infection for children and are also in accord with the results of other studies of the disease.

3. Conditions under which Milk is Infected with Tubercle Bacilli by Tuberculous Cows.-The milk of individual cows affected with tuberculosis in various forms has been tested for the presence of tubercle bacilli by injecting it into guinea pigs and by feeding it to these animals. Numerous experiments of this kind have been conducted, and upon the basis of these experiments tuberculous cows may be divided into three classes as regards the infectiousness in their milk, viz: (a) Cows affected with tuberculosis of the udder; $(b)$ cows with apparently normal udders but showing clinical symptoms in other organs or parts, and $(c)$ cows which do not show any clinical symptoms but which have reacted to the tuberculin test.

(a) Cores Affected with Tuberculosis of the Udder. -When the udder is tuberculous, tubercle bacilli are eliminated in the milk. In advanced or extensive cases of this form of the disease, the milk is very infectious; it contains from 50,000 to 100,000 and even $1,000,000$ tubercle bacilli per c.c. (Ostermann), and remains virulent when injected into guinea pigs after it has been 
diluted one billion times (Ostertag). ${ }^{12}$ In the initial stages, when the tuberculous areas in the udder are small and isolated, the tubercle bacilli are less numerous, numbering about 1000 per c.c. While such milk must be diluted about 1000 times to render it non-virulent when injected into guinea pigs, it may be repeatedly fed to them undiluted without producing tuberculosis.

As to the frequency of tuberculosis of the udder, in the post-mortem examination of 1200 cattle reacting to the tuberculin test, nearly all of which were dairy cows, Pearson found the udder tuberculous in 104, or 5.75 per cent. Ostertag estimates that the disease is present in the udder of 0.1 to 0.3 per cent. of all cows. In considering the frequency of tuberculosis of the udder, the large number of bacilli present in the milk in advanced cases must be remembered. The milk of one cow affected with advanced or extensive tuberculosis of the udder can infect thousands of quarts of milk from other cows, if mixed with it, and may even render the entire supply of a small town infectious.

(b) Cores with Apparently Normal Udders but Showing Clinical Symptoms in Other Organs or Parts.Milk from cows in this condition frequently contains tubercle bacilli. It appears very probable that the udder is actually diseased when tubercle bacilli are eliminated in the milk of such cows. The udder may be tuberculous and yet be apparently normal. The disease is always extensive when clinical symptoms are present, and usually it is generalized - tubercle bacilli have repeatedly invaded the blood stream and have had abundant oppor-

${ }^{12}$ Zeitschr für Fleisch u. Milchhy., pp. 26 and 27, No. 2, vol. xxiii. 
tunity to locate in the udder and to produce small, fresh tubercles, too small to be discovered by palpation of the udder. Such lesions may even escape observation on post-mortem examination because of their similarity in appearance to the actively secreting udder tissue. Rick found the udder tuberculous in $\mathbf{1 7 . 6}$ per cent. of the cases of generalized tuberculosis examined by him. Joest and Kracht ${ }^{13}$ found the supramammary lymph glands tuberculous, when tested by inoculation, in 50 per cent. of the cases examined by them of generalized tuberculosis in which the udder did not show any clinical symptoms or macroscopic lesions on post-mortem examination; some of the lymph glands were slightly enlarged but otherwise they were of normal appearance. In one-half of these cases the udder tissue was also infected. It would therefore appear that the udder is much more frequently tuberculous in cases of generalized tuberculosis than is generally suspected.

Contradictory views exist as to the possibility of tubercle bacilli passing through the sound udder. Ostertag and Prettner injected tubercle bacilli intravenously into cows with sound udders and found the milk nonvirulent when inoculated into guinea pigs.

Milk may be infected secondarily with tubercle bacilli when open tuberculosis is present in the lungs, intestines, or uterus. Cows affected with open tuberculosis of the lungs swallow the greater part of the infected material coughed up, and it passes out with the fæces; the tubercle bacilli are not destroyed by the digestive secretions and remain virulent. Schroeder ${ }^{14}$ and the British tubercu-

13 Joest and Kracht, Zeitschr. für Infectionskrank., etc., pp. 315-316, vol. 12, No. 4, 1912.

${ }^{14}$ Schroeder, p. 120, 25th Annual Report B. A. I. 
losis commission found the fæces infectious from tuberculous cows which did not show any clinical symptoms, but these results have not been confirmed by others. Titze, Thieringer and $\mathrm{Jahn}^{15}$ demonstrated tubercle bacilli in the fæces of cows affected with open pulmonary tuberculosis, but not in the fæces of reacting cows which did not show clinical symptoms. Traum ${ }^{16}$ inoculated guinea pigs with fecal material from 36 cows, "practically all tuberculin reactors," and none of the guinea pigs was infected with tuberculosis, although two of the cows exhibited physical symptoms of disease of the lungs. These results correspond with those obtained when samples of mixed milk from herds known to be infected with tuberculosis have been examined for tubercle bacilli. For example, O. Müller examined samples of milk from 1598 herds in East Prussia and tubercle bacilli were demonstrated in the samples from only $\mathbf{9 7}$ herds, aIthough non-clinical reactors were present in the other herds. In the 97 herds from which the samples containing tubercle bacilli were obtained, cows were found which exhibited clinical symptoms of udder tuberculosis or other forms of the disease. Similar results could be cited. Reichel ${ }^{17}$ found the fæces infectious from cows which were not tuberculous but which were stabled with cows affected with open tuberculosis. It therefore appears probable that the sputum coughed out by cows with open tuberculosis, or the fine spray expelled from the mouth in coughing, may contaminate the feed of other

15 Arbeit. K. Gesundheitsamt, pp. 1-34, No. 1, 1913.

16 Annual Report University of California Expt. Station, 1915, p. 40.

17 Verbal communication. 
cows and that these cows may eliminate virulent tubercle bacilli in the fæces even when they are not infected with tuberculosis. The presence of the bacilli in the fæces of tuberculous cows without open lesions in the lungs or intestines and without disease of the liver may be explained on the same basis. Titze and Jahn found that in tuberculosis of the liver virulent tubercle bacilli may be excreted in the bile and eliminated with the fæces, thus confirming the earlier findings of Joest and Emshoff. The udder and posterior parts of the cows affected with open tuberculosis become soiled with the infected fæces or vaginal discharges, and particles of this material drop off into the milk during milking, thus infecting the milk secondarily. The demonstration of tubercle bacilli in the milk of individual cows does not therefore necessarily indicate that the bacilli were excreted through the udder. Milk from cows with open tuberculosis usually contains about 1000 tubercle bacilli per c.c. While it does not always produce tuberculosis when fed to guinea pigs, or even when injected into them, it is often infectious and must therefore be regarded as dangerous.

(c) Cores which do not Show any Clinical Symptoms but rohich have Reacted to the Tuberculin Test (Non-clinical Reactors).-The experiments with individual milk from cows which had reacted to the tuberculin test, but which did not show any clinical symptoms of the disease, have given contradictory results. Ostertag, Brauer, Ascher, Müller, Stenström, Bassett, and others have found the milk from non-clinical reactors to be free from tubercle bacilli, while Rabinowitch and Kempner, Schroeder, Ravenel, Mohler, Martel, Guérin, DeJong, Moussu, and Fay have found tubercle bacilli present in milk from such cows. Ostertag tested the milk of 49 
non-clinical reactors and not a single sample produced tuberculosis when injected into guinea pigs. Later, in conjunction with Brauer, ${ }^{18}$ he made a thorough test of the milk from 10 non-clinical reactors, inoculating guinea pigs, and feeding guinea pigs, calves and pigs. Not one of the experimental animals developed tuberculosis. Some of the guinea pigs in the feeding experiment received 66 grammes of milk daily for 5 months, or 33 times their body weight; 10 calves received 7 to 12 litres each day for 8 to 11 months and 20 pigs were given 1 to 6 litres daily for 4 months. O. Müller made inoculation tests on guinea pigs with the milk from 9 non-clinical reactors, and Ascher with the milk from 7, and tubercle bacilli were not demonstrated in a single case. Ostertag contends that in those cases in which tubercle bacilli were demonstrated in the milk from non-clinical reactors, the milk was infected secondarily, and in support of this view he points out that in some of the cases in which tubercle bacilli were demonstrated in the milk no lesions of tuberculosis could be found on postmortem, while in other cases lesions of open tuberculosis were present. At any rate, the evidence in its entirety indicates that the milk of non-clinical reactors is much less likely to contain tubercle than the milk of cows with tuberculous udders or which show clinical symptoms of the disease in other organs.

Influence of Dilution.-While these experimental results indicate very accurately the conditions under which tuberculous cows contaminate milk, it must not be forgotten that they relate to the milk of individual cows tested separately, while in practice the milk of tuber-

${ }^{18}$ Zeitschr. für Fleisch u. Milchhy., p. 80, No. 4, vol. xxiv. 
culous cows is diluted more or less with the milk of noninfected cows. The extent of the dilution will depend upon the method of handling the milk. Ordinary market milk, however, is frequently the mixed milk of several herds, but at any rate it is the mixed milk of a number of cows in the same herd. It has been demonstrated that the milk of cows affected with advanced or extensive tuberculosis of the udder may render the entire supply infectious when mixed with milk from other cows which are not tuberculous; but this is not true of milk from cows which do not show clinical symptoms of the disease. Müller and Hessler examined by inoculation samples of mixed milk from $\mathbf{2 9 4 9}$ herds, each sample representing the milk from 30 to 200 cows. Tubercle bacilli were present in the samples from 156 herds. All of these herds except five were found to contain cows affected with udder tuberculosis or other forms of open tuberculosis. In the five herds in which tuberculosis was not established clinically, Hessler is of the opinion that the tubercle bacilli were eliminated in the fæces by cows with incipient cases of open lung tuberculosis which had not yet become perceptible. The other 2793 herds, in the milk samples from which tubercle bacilli were not demonstrated, certainly contained a considerable number of cows which would have reacted to the tuberculin test, judging from the extent to which tuberculosis was known to exist in the district in which they were located.

Delépine examined the milk from 1385 farms and found tubercle bacilli in the samples from 294 farms. The cattle on 276 of these farms were examined and on 190 farms one or more cows were found affected with tuberculosis of the udder, a bacteriological examination of the individual milk being necessary in some cases to 
discover the condition. After these cows were removed, the milk from these farms ceased to infect guinea pigs. No clinical cases of udder tuberculosis were found in the other $\mathbf{8 6}$ herds examined, but on these farms cows had been sold between the time the milk samples were collected and the herd was examined, or the farmer had been buying milk from other sources when the samples were collected.

Friis inoculated guinea pigs with samples of mixed milk from 28 dairy farms in and about Copenhagen and demonstrated tubercle bacilli in the samples from four farms. On one of these farms two cows with tuberculosis of the udder were found and one cow with udder tuberculosis was found on another, while on the other two farms cows were found showing physical symptoms of tuberculosis in other organs. There is no doubt that the other twenty-four farms contained cows which would have reacted to the tuberculin test.

The milk from 12 non-clinical reactors was tested for tubercle bacilli by Klein and Campbell by injection into guinea pigs. These cows were in a stable with 12 other non-clinical reactors which were not included in the experiment because they were approaching the end of the lactation period. The stable was light, well-ventilated, of suitable size and clean. The cows were cleaned with a curry-comb and brush and the udders wiped with a damp cloth before each milking. All the cows in the stable were examined by inspection, palpation and auscultation when the experiment began and no symptoms indicating tuberculosis were found. They were all in a good, thrifty condition and none had a chronic cough. (All suspicious animals had been previously removed.) The 12 cows used in the experiment were arranged in groups of three 
each according to the stage of lactation and once each week the milk from each group was put into a separate can, the cows being groomed and milked in the usual manner by the regular attendants. A sample of milk was taken from each can for examination. Two guinea pigs were inoculated from each sample-one with the cream and one with the sediment. This was repeated each week for six weeks. Then the cows in the stable were again examined in the same way and, no symptoms indicating tuberculosis being found, samples of milk were collected and examined as before once a week for another period of six weeks. Altogether, 96 guinea pigs were inoculated. Thirty died of intercurrent disease and the other 66 were chloroformed two months after inoculation. A post-mortem examination was made of every animal, but in no instance were any lesions of tuberculosis found. One of the cows in the experiment had reacted to tuberculin over 8 years before, one 7 years, two 6 years, two 4 years, two 3 years, two 2 years, one 1 year and one 4 months before.

These observations show that non-clinical reactors play a minor rôle in the infection of market milk with tubercle bacilli, even when the virulence of the milk is tested by the delicate inoculation test. That there is a vast difference between the number of tubercle bacilli necessary to produce infection by the mouth and by inoculation has been demonstrated by a number of investigators. Ostertag and others have shown that two and a half million times more material is required to infect an animal by feeding than by inoculation. Schroeder and Cotton found that milk which would produce tuberculosis in guinea pigs when 5 c.c. was injected into the peritoneal cavity could be fed $\mathbf{3 0}$ days without producing 
the disease. Findel, Reichenbach and Alexander ${ }^{19}$ found that at least $400,000,000$ tubercle bacilli are necessary to produce infection when only a single dose is fed to guinea pigs and that 800,000 tubercle bacilli given fifty times by the mouth are not certain to produce infection. Ostermann ${ }^{20}$ reports that milk containing 1000 bacilli per c.c. may be repeatedly ingested without effect. Flügge and his co-workers also found that while a very few tubercle bacilli are sufficient to produce a severe tuberculosis when injected into a guinea pig, 200 are necessary when the bacilli are inhaled and 140,000,000 when they are ingested.

4. How can Contamination of Market Milk with Tubercle Bacilli be Prevented? - The information at hand shows that cows with tuberculosis of the udder are by far the greatest factors in infecting market milk with tubercle bacilli and that next in order are those with apparently healthy udders but showing clinical symptoms of the disease in other organs. Compared with these two classes, cows which present no evidence of tuberculosis except a reaction to the tuberculin test are a rather insignificant source of contamination.

The contamination of milk with tubercle bacilli can be most thoroughly and most certainly prevented by removing from the herds concerned in a milk supply the cows belonging to all three classes. This could only be accomplished by making a tuberculin test and physical examination and repeating them at certain intervals. A

${ }^{19}$ Cited by Ostertag, Zeitschr. für Fleisch u. Milchhy., p. 27, No. 2, vol. xxiii.

${ }^{20}$ Cited by Klimmer, Osterreich. Wochenschr. für tierheilk. ?. Tierzucht, No. 45, 1912. 
physical examination in addition to a tuberculin test is necessary because the tuberculin test alone will not detect all cases of tuberculosis. Ostertag, for instance, tested with tuberculin nine cows affected with udder tuberculosis and two failed to react. The adoption of such a plan, however, immediately upon the introduction of dairy inspection in districts in which tuberculosis is common will meet with many practical difficulties. Few dairymen in such districts are able to bear the expense of disposing of non-clinical reactors as well as clinical cases and of replacing them with healthy cows, even with state assistance; and the state would not have sufficient funds to render the assistance provided by present laws if such a plan was generally adopted. Difficulty would also be experienced in replacing the reacting cattle with animals free from tuberculosis, and this would increase with the number of herds included in the inspection. The opposition of the dairymen concerned would be very generally incurred and there would not exist that friendly coöperation between the inspector and dairyman which is necessary to insure the most satisfactory results. A careful and thorough physical examination repeated at intervals is next in the order of effectiveness. By this method those cows can be discovered which are the most concerned in the contamination of milk with tubercle bacilli. Such an examination should include a careful inspection and palpation of the udder and supramammary lymph glands; inspection of the milk in each quarter; palpation of the other superficial lymph glands; examination of the general condition of the animal; inspection for nasal discharge; examination for cough; examination of the respiration; auscultation of the lungs; examination of the digestive tract, especially for chronic 
tympanites and diarrhœa, and inspection for vaginal discharge. In some cases it will also be necessary to take the temperature and pulse and to examine the lungs and pleura by percussion as well as auscultation, and in suspicious cases, when a definite decision cannot be made, it may be necessary to apply the tuberculin test to the animal under examination or to collect sputum from the trachea or œsophagus, secretions from the vagina, scrapings from the rectum, and milk, and submit them to a microscopic examination and inoculation test (see p. 275). In tuberculin-testing such animals, a large dose of tuberculin must be used, from two and one-half to five times the ordinary dose. When the microscopic examination of material from an animal of this kind gives a negative result it cannot be accepted as final, but guinea pigs must be inoculated. If death does not occur earlier, the guinea pigs must be held for two months after inoculation before they can be killed for post-mortem examination. Most owners would prefer to dispose of an ordinary cow on suspicion rather than feed it for this length of time and keep it isolated and not be permitted to use the milk without heating it. It is usually more satisfactory to apply the tuberculin test in such cases. Clinical cases of tuberculosis are usually unthrifty and are generally not good milkers and the owner can usually be convinced that such animals are unprofitable. Another reason for disposing of such cows, which will appeal to the owner, is that they are sources of infection for the other cattle in the herd. As a rule, the removal of animals of this kind, advice and assistance in securing healthy cows to replace them, and proper attention to the other features of dairy inspection will gain the confidence of the owner rather than his opposition, and after a system of inspec- 
tion of this character has been in operation for several years the tuberculin test may be added with very little objection. Fewer reactions will then be obtained and the reacting animals can be more readily replaced with non-tuberculous animals.

When milk is produced especially for children's use, however, the greater susceptibility of children to tubercle bacilli of bovine origin must be taken into account, and the most thorough methods for protecting milk from contamination with tubercle bacilli should be applied. Children's milk should therefore be obtained only from herds which are tuberculin-tested at least once a year and which are subjected to a physical examination at least once each month.

The efficiency of the clinical examination of dairy cows in preventing the contamination of a milk supply with tubercle bacilli as compared with the bacteriological examination of the milk for the presence of the bacilli is fairly presented in the following statement from the report of the British Commission on tuberculosis: "The presence of tubercle bacilli in cow's milk can be discovered, though with some difficulty, if proper means be adopted," but "it is much easier to demonstrate with certainty by clinical examination that a cow is affected with tuberculosis and will in consequence perhaps produce tuberculous milk." Furthermore, milk from a cow eliminating tubercle bacilli is not constantly infected. On certain days, the organisms may be absent entirely or present in only small numbers. A single examination may therefore give misleading results.

The destruction of tubercle bacilli in milk by heat is considered in the chapter on pasteurization (page 203). 
Diagnosis of Tuberculosis of the Udder.-For a time after the disease has been established in the udder, the tubercles are not large enough to be discovered by palpation and the milk retains its normal appearance, but during this initial stage of the disease symptoms are usually present in other organs which enable one to discover the presence of the disease by physical examination. In 119 cows affected with tuberculosis of the udder, Lungwitz ${ }^{21}$ found tuberculosis in other organs in every one. The observations of Rick and of Joest and Kracht, already quoted, show that the disease is usually generalized when the udder becomes infected.

Tuberculosis of the udder runs a slow, insidious course. The perceptible changes in the udder which indicate its presence are firm nodules, which are neither hot nor painful, or a rather diffuse painless induration without local increase of temperature, in one or more quarters. Later, abscesses may form and rupture (mixed infection); atrophy may also occur. The posterior quarters are most commonly affected. The supramammary lymph glands may be enlarged, while the udder is of normal appearance, but in these cases the udder is usually also infected. In rare cases, the disease runs an acute course, the udder showing the symptoms of acute inflammation.

In contrast with what occurs in other forms of udder disease, the milk remains of normal appearance for eight to ten weeks, although it may be highly virulent. Finally, it becomes thin and transparent like water, assumes a yellowish color and contains small clots or flakes. When it is permitted to stand, a pus-like sediment is deposited with a yellow, transparent fluid resembling serum above it. The acidity is reduced one-half (Raudnitz), or the reaction is even sometimes alkaline (Ostertag). In advanced cases, the secretion of milk ceases and only a purulent fluid in moderate amount can be obtained from the affected quarter.

Diagnosis of Open Tuberculosis.-(a) Pulmonary Tuberculosis.-The most characteristic symptom is a chronic cough, at

21 Leblanc, Diseases of Mammary Gland (Nunn's translation). 
first vigorous, later weak. The respiration is of ten unchanged, but in advanced cases it is usually rapid and labored. Sometimes there is a purulent nasal discharge. Percussion does not usually give much information; on auscultation increased vesicular murmur, râles, and indefinite sounds may be detected. These symptoms are usually accompanied by anæmia, unthriftiness, emaciation, dull and sunken eyes, variable or poor appetite, diarrhœa, repeated bloating after meals, or distention of the jugular vein. In advanced cases the pulse is accelerated and soft.

(b) Intestinal Tuberculosis.-The symptoms of intestinal tuberculosis are not characteristic. Repeated attacks of colic and constipation alternating with diarrhœa are the most suspicious. The intestinal discharges may be quite fluid and frequently contain mucus and pus, sometimes blood. The digestive disturbances which are nearly always present in advanced tuberculosis are usually due to the involvement of the intestines, but on the other hand, they may be entirely absent when the intestines are tuberculous.

(c) Tuberculosis of the Uterus.-A turbid, mucous or mucopurulent discharge, yellowish or rather ichorous and of foul odor, is a constant symptom of tuberculosis of the uterus. Fragments of caseous material or streaks of blood are sometimes present. The cow is sterile and frequently in heat. On rectal examination the sacral lymph-glands may be found enlarged or the horns of the uterus hard and nodular.

When the mucous membrane of the vagina or vulva is tuberculous, ulcers or nodules are present, together with a similar discharge.

Enlargement of the superficial lymph glands is an important symptom.

While these symptoms in themselves are not sufficient to justify a positive diagnosis of tuberculosis, nevertheless when they are presented by an animal in a herd in which tuberculosis is known to exist, and when other possible causes for them can be excluded, an error will not often be made if the animal is regarded as tuberculous. In doubtful cases the tuberculin test can be applied or a microscopic examination or an inoculation test made. 
APHTHOUS FEVER OR FOOT AND MOUTH DISEASE

In the milder forms of foot and mouth disease the milk secretion may not be affected, but in the more severe cases the milk flow is reduced one-half and the milk is considerably changed in composition and appearance. The alterations are similar to those observed in inflammation of the udder. The albumin, globulin and salts are increased in quantity, while the sugar, casein, and usually the fat are decreased, although sometimes the fat is increased. The milk becomes thin, and after it stands for a while a layer of slimy, dirty cream forms at the top of the fluid and considerable sediment is deposited at the bottom of the vessel. When examined microscopically, the sediment is found to be rich in cells-epithelial cells, leucocytes, and red-blood cells. The milk coagulates when boiled, reacts positively to the alcohol test and contains a large amount of catalase.

Nocard has shown that the milk of affected cows does not contain the virus of foot and mouth disease when it is drawn from the udder in a manner which prevents external contamination. But when vesicles or ulcers are present on the teats or udder it is not possible to draw milk in the ordinary way without it becoming contaminated with the virus. Merely a trace of the serum from the vesicles is sufficient to render 50 to 100 quarts of milk infectious. Practical experience indicates that the milk of affected cows is frequently infectious. Furthermore, the extraordinary facility with which the virus is disseminated makes it extremely probable that all of the milk of a herd in which the disease exists may be infected secondarily.

The disease may be transmitted to man through milk, 
and also to cattle and swine. It may also be transmitted by butter and cheese. Man may be mildly or severely affected; in some instances, the disease has terminated fatally. The symptoms are fever, weakness, conjunctivitis, nausea, vomiting, and diarrhœa, with formation of vesicles on the mucous membrane of the lips, mouth or nose, and on the ears, fingers or other places on the body; sometimes the skin is red and the joints painful.

The sale of milk from herds in which foot and mouth disease exists should not be permitted, unless it is heated sufficiently to destroy the virus and is not changed in appearance. The virus is not very resistant. A temperature of $50^{\circ} \mathrm{C} .\left(122^{\circ} \mathrm{F}\right.$.) for 15 minutes; $70^{\circ} \mathrm{C}$. $\left(168^{\circ} \mathrm{F}\right.$.) for 10 minutes; or $85^{\circ}$ C. $\left(185^{\circ} \mathrm{F}\right.$.) momentarily will destroy it (Ernst).

\section{COWPOX}

Cowpox is closely related to variola or smallpox of man. Before vaccination was introduced, when smallpox frequently became epidemic, it is very probable that cowpox often originated from this source. Vaccinia of man is also transmissible to cattle and many instances are on record in which cows have been infected by vaccinated persons. Infection takes place during milking as a rule, the contagion being rubbed into the skin of the teat by the hands of the milker. The disease is therefore most commonly seen in cows in milk. It usually begins with a rise of temperature, but this may pass unnoticed unless it is accompanied by dullness and loss of appetite, as is sometimes the case. The teats and neighboring parts of the udder become swollen, hot, and painful. In two or three days, papules appear, which may be as large as a pea and which are surrounded by a red area. On the 
udder they are round; on the teats oblong, with the greatest diameter parallel with the length of the teat. In a day or two they change into vesicles of a bluish-white or yellowish-white color. The vesicles ripen into pustules in eight or ten days and a depression or umbilication appears in the top, after which they rupture and leave an ulcer, or dry and heal under a scab. They may be ruptured during milking before they are ripe.

The milk may become thin, bluish, and of lighter specific gravity than normal; it may be nauseating and may coagulate very readily. The acidity may be below normal. These changes, however, do not always occur. When the disease is complicated with parenchymatous mastitis, as sometimes happens, then the milk undergoes the pronounced changes which occur in the latter condition (see page 109).

Cowpox is transmitted from cow to cow by the milker and by infected bedding, fodder, and stalls. The disease is also transmissible from the cow to man through milk. There is no proof that the virus is excreted through the udder, but as the pox are located on the teats and the adjacent parts of the udder it is practically impossible to draw the milk without the virus contained in the vesicles and pustules getting into it. Stern saw cowpox transmitted to a large number of children by milk from a dairy in which the disease was enzoötic. The children were affected with an eruption on the face which healed under a scab. Not many such observations have been recorded, however. The reason for this is that the general custom of vaccinating against smallpox has rendered most persons immune to the disease. The transmission of the disease to the milkers by direct infection of wounds on the hands or fingers has been more frequently ob- 
served; in some cases the face has been affected in this way.

Milk from cows affected with cowpox should not be used for food. When the disease is enzoötic, the healthy and diseased cows should be separated and separate milkers provided for each class. This is especially important when the milk is to be used by children. The virus of cowpox is destroyed by a temperature of $48^{\circ} \mathrm{C}$. $\left(119^{\circ}\right.$ F.). Milk from infected animals which has not undergone any physical change and milk which has been exposed to infection may be rendered safe by heating to this temperature.

False Coropox.-Cowpox should not be confused with a condition more commonly affecting the udder which is known as false cowpox. In this condition, small nodular swellings which may be as large as a pea appear on the teats and neighboring parts of the udder, rupture in a few days, and then heal under a scab. The teats are not hot, swollen or tender and there is no red area around the nodules, as in true cowpox; fever is also absent. The condition is supposed to be caused by the ordinary pyogenic cocci, which are rubbed into the skin during milking or enter through wounds. Cows with teats covered with a fine skin seem to be most susceptible. The condition may be transmitted from cow to cow by the hands of the milker, but is not transmissible to man. The milk is not affected except in so far as it may be contaminated with purulent matter from the ruptured nodules. There is only a small quantity of this material and the contamination from this source therefore can only be very slight.

Furunculosis of the $\boldsymbol{U} d d e r$ is sometimes called cowpox by dairymen. This condition usually occurs sporadically, 
but it is occasionally enzoötic, especially when musty or mouldy straw is used for bedding. It is most frequently seen in fresh cows, after they have been put on full feed, and it is probably for this reason that the furuncles are spoken of as feed boils. Firm, painful, nodular swellings, varying in size from a pea to a walnut, appear in the subcutaneous tissue of the udder. In seven or eight days a dark area of puriform softening develops in the centre of each individual swelling, which subsequently ruptures at this point and discharges its contents of pus mixed with shreds of tissue. This dark patch, or the scab of dried blood which subsequently forms at the point of rupture, has given the process the popular name of black scab in some sections. The milk secretion is not affected, but the milk may be contaminated secondarily with the purulent discharge.

\section{ANTHRAX}

The question of using the milk from a cow affected with anthrax does not often arise in practice because, as a rule, the milk secretion ceases suddenly with the onset of the fever, while in those cases in which it continues it is reduced to a small quantity and is very much changed in appearance. It is more yellowish than normal, slimy, sometimes bloody, with a bitter taste, and after standing undisturbed for a few hours separates into a layer of cream and of serum. Anthrax bacilli are excreted through the udder only in the advanced stages of the disease, after they have invaded the blood stream and when the udder is affected. But the chances of milk becoming infected secondarily are very great. The bloody discharges and the manure from infected animals contain the anthrax 
bacilli and their spores, and the spores may also be present in the dust of the stable and in the dust of straw and hay from infected fields. The organisms may gain access not only to the milk of the affected cow, but also to the milk of other cows in the stable. Anthrax bacilli and spores entering milk in this way may multiply rapidly, as milk is an excellent culture medium for this organism. While the bacilli are digested by the gastric juice, the spores are not affected and in disturbances of digestion the bacilli may also escape destruction. . Ernst mentions a typhoid fever patient who developed intestinal anthrax after drinking milk from a cow with a malignant pustule on the udder.

All milk from a herd in which anthrax is present must therefore be regarded as dangerous to man until proper precautions are taken to prevent the secondary infection of the milk from the cows which are not diseased. Diseased and dead animals should be at once removed from the stable, which should be thoroughly cleaned and disinfected. McFadyean recommends that the temperature of every exposed cow be taken each day before milking for seven to ten days, and that all those showing a rise of temperature be treated as suspicious cases and taken out of the stable, the milk not being used.

\section{RABIES}

Cattle are usually infected with rabies by being bitten by a rabid dog. Frequently several animals in a herd are infected at the same time. While the virus of rabies is to be found in its purest and most concentrated form in the central nervous system, it is also present in the milk of affected animals as well as in the secretions 
of the salivary and lachrymal glands and pancreas. Numerous feeding experiments with milk and other substances from rabid animals show that the virus is not absorbed, and that the disease is not produced, when the mucous membrane of the digestive tract is intact and the digestive functions are acting normally. In the upper part of the digestive tract, stratified squamous epithelium acts as a barrier to the entrance of the virus into the blood stream and when it reaches the stomach it is digested by the gastric juice. But when wounds are present in the mucous membrane of the lips, mouth or throat, or when the secretion of gastric juice is disturbed, the ingestion of milk containing the virus of rabies may produce the disease. Milk from cows affected with rabies must therefore be regarded as dangerous. Whether the milk of infected cows contains the virus before symptoms of the disease appear, as is the case with the saliva of dogs, is not known. Until this question is determined it will be advisable not to use the milk of a cow which has been bitten by a rabid dog until it is determined that infection did not occur.

\section{ACTINOMYCOSIS}

Actinomycosis usually affects the maxillæ, tongue or other parts about the head, but it sometimes occurs in the udder, also in the lungs and other internal organs. When present in the udder it is usually of primary origin, i.e., the infection enters through the teat canal. Actinomycosis of the udder is generally indicated by the presence of one or several firm nodules of the size of a bean up to a hen's egg in one or more quarters of the organ. These nodules consist of a thick wall of connective tissue surrounding a purulent centre in which the actinomyces may be seen in the form of sulphur-yellow 
granules. They may rupture internally or externally and discharge pus containing the fungi. The milk cistern may be filled with the nodules. Sometimes the disease appears in the udder in a miliary form; the affected quarters are enlarged, hard and somewhat nodular, and on section numerous very small nodules of granulation tissue with softened purulent centres are found disseminated through the gland tissue. Similar nodules may be found on the mucous membrane of the larger canals and cistern. Numerous actinomyces are found in the softened centre of the nodules. As a rule, actinomycosis of the udder has not been recognized until after the slaughter of the affected animal, consequently nothing definite is known regarding the appearance of the milk in this condition. Up to this time, actinomyces have not been demonstrated in milk, but they are no doubt excreted with the milk when the actinomycotic nodules rupture into an alveolus or duct of the udder. The milk may be infected secondarily when an actinomycotic nodule in the udder ruptures externally or when an actinomycotic tumor in the maxilla or adjacent parts opens. In such cases the discharge contains not only actinomyces but also bacteria, particularly the pyogenic organisms, and these, too, may gain access to the milk.

There is no record of the transmission of actinomycosis to man through milk. This may be due in part to the slow development of the disease, as in the case of tuberculosis. Infection with actinomyces may occur in man, as it does in cattle, through the food, especially when wounds exist in the mouth or other anterior parts of the digestive tract. Since there is a possibility of the transmission of this disease by milk, it is advisable to exclude from dairies all cows with actinomycosis of the 
udder or with open, discharging actinomycotic tumors. Milk from cows in the latter condition is further objectionable because it may contain pus and pyogenic organisms, and, in advanced cases, for the additional reason that the general condition is affected, the animal becoming emaciated, weak and dull.

\section{MILK SICKNESS OR TREMBLES}

Cattle and horses when pastured on certain lands in circumscribed areas in the United States develop a disease known as milk sickness or trembles. Its etiology has been the subject of much speculation and investigation. In $1907 \mathrm{~J}$ ordan and Harris isolated in pure culture from the blood and organs of animals dead of the disease a spore-forming bacillus with which they succeeded in reproducing the disease in experimental animals. They have given this organism the name of Bacillus lactimorbi. The principal symptoms of the disease are violent trembling and great restlessness, followed by paralysis. The animal may fall and die suddenly, but usually it lies several days in a paralyzed condition. The disease is transmitted to man through the milk, butter, and meat from affected animals. The symptoms in man are severe vomiting, difficult breathing, subnormal temperature, paralysis, and death.

\section{Diseases of Cattle which may Render Milk Harmful to Man.}

\section{INFLAMMATION OF THE UDDER-MASTITIS}

Cows are very frequently affected with mastitis, a disease of great economic as well as hygienic importance. There are three forms of the disease: (1) Catarrhal mastitis, which may be either mucous or purulent, and which 
runs a subacute or chronic course; (2) parenchymatous mastitis, which is purulent and acute, and which is sometimes accompanied by abscess formation and gangrene, and (3) interstitial mastitis, which may be a simple inflammation or a phlegmonous condition. The three forms differ in the type of the inflammation (acute or chronic), the part of the udder tissue affected, the effect upon the milk secretion, and in the character of the bacteria concerned. One form may be associated with another. The disease is commonly called "garget" by dairymen and farmers.

1. Catarrhal Mastitis.-From a hygienic standpoint, catarrhal mastitis is of greatest importance because it occurs more frequently than the other forms and also because the milk may contain the causative bacteria before clinical symptoms or marked changes in the milk are apparent and for a time after they have disappeared. This latter circumstance has been the inspiration of numerous efforts to discover a method of examining milk by which this disease could be detected in its incipiency.

Catarrhal mastitis is a mucous or purulent catarrh of the mucous membrane of the teat canal, milk cistern, and large milk ducts. It is frequently accompanied or followed by a productive inflammation of the submucous and interstitial connective tissue, in which case it often terminates in atrophy of the gland tissue and loss of function. It is usually caused by streptococci of varying degrees of virulence; sometimes, but not often, mucous catarrh occurs without the intervention of bacteria from the effects of cold or overfeeding. The symptoms are never pronounced. The history of the cow is of great assistance in detecting incipient cases, although it is sometimes difficult to obtain. A statement that the cow 
"milks hard," i.e., that there is difficulty in expressing the milk through the teat canal, or that the milk is not "let down " or is " drawn up," or that the cow has recently developed a tendency to kick during milking, should excite suspicion of the presence of the disease. The first condition is due to obstruction of the teat canal by swelling of the mucous membrane or by dried secretion; the others occur because milking is painful. Among the first noticeable symptoms of the disease are changes in the milk stream expressed from the teat. This may be split, deflected from the proper direction, or it may not be cut off promptly and may therefore smear the end of the teat-all indications of catarrh of the mucous membrane of the teat canal. In such cases small yellow crusts may be found covering the opening of the teat canal, but crusts of dried milk may also be present at this point when the sphincter of the teat canal does not close properly. When pressure is exerted upon the lower end of the teat, a drop of pus or mucus may be squeezed out of the teat canal or the thickened mucous membrane may project through the opening. Later, the mucous membrane of the cistern may become thickened, in which case a cord about as thick as a lead pencil is felt running through the middle of the teat when the teat is rolled between the thumb and fingers. Flat, disc-shaped thickenings about the size of a quarter dollar and nodular indurations may be present in the upper limits of the cistern when the mucous membrane of the lower end of the large milk ducts is thickened. Growths upon the wall of the cistern or teat canal ("spider in the teat") may also be discovered by palpation. The induration usually extends slowly into the interstitial tissue, generally from the teat 
upward, producing a hard firm area ("cake," "caked udder," "cold garget"), which may eventually involve the entire quarter. The newly formed connective tissue subsequently contracts and causes atrophy of the gland tissue and loss of function.

In the early stages of the disease, and also throughout mild cases of mucous catarrh, the milk does not show any marked change at the time it is drawn from the udder: Very often it contains small flakes, some of which may be as small as a pin-head; they may be present only in the first milk drawn, but sometimes they do not appear until the middle or at the end of the milking. After the milk stands for a time, or is centrifugalized, a grayishyellow sediment is deposited and a dirty-gray, clumpy or granular cream layer is formed. In severe cases of mucous catarrh, the secretion becomes slimy and viscid. In purulent catarrh, the secretion of milk decreases while the pus cells and fibrin increase and the fluid obtained from the affected quarter gradually changes to a thick, yellowish, purulent exudate or to a yellowish serum containing clumps of pus and fibrin. Frequently, the exudation ceases entirely and the milk secretion does not return until the next lactation or not at all. The chemical composition of the milk is only slightly changed at the beginning of the disease, the lactose being decreased and the mineral salts, especially the sodium chloride, increased, while the other constituents are present in the usual amount. L'ater, there is a greater decrease in the lactose, the casein is also below normal, and the fat is usually decreased, while the albumin, globulin, and mineral salts are increased. Fibrin is also present. The reaction of the milk is usually, but not always, alkaline. The taste is salty or bitter. Cells are present in large 
numbers in the sediment and cream, especially the polymorphonuclear leucocytes in purulent catarrh. The catalase content is increased. Coagulation occurs when the alcohol or the boiling test (see pages 284, 285) is applied.

On account of the difficulty of detecting catarrhal mastitis in its early stages, the determination of the leucocytic content of samples of market milk has sometimes been relied on to discover the presence of the disease. It has been demonstrated that cases of catarrhal mastitis may be detected by this method but we have no means of knowing how many of such cases escape discovery; there is reason to believe that many are overlooked. The examination of samples of milk from individual cows by means of the catalase test is the most efficient method of detecting the disease (see page 287). When numerous very small, punctiform, brownish colonies appear in the plates prepared for determining the number of bacteria in milk and these are found upon microscopic examination to consist of streptococci in long chains, an examination of the herd will usually discover the presence of one or more cases of catarrhal mastitis.

A special form of purulent catarrhal mastitis which leads to multiple abscess formation is caused by the Bacillus pyogenes. The secretion has a foul odor. The disease occurs most commonly in " dry " cows, but is usually not discovered until they become "fresh."

2. Parenchymatous Mastitis.-The detection of this form of mastitis offers no difficulties to the dairy inspector. It is attended with an immediate and pronounced swelling of the affected portion of the udder and the milk at once presents marked changes. As the name indicates, it is an inflammation of the alveoli and small tubules of 
the udder and is usually caused by the Bacillus phlegmasia überis or other varieties of colon bacilli, sometimes by organisms of the paracolon or paratyphus group, the enteriditis bacillus or by staphylococci. Septicæmia may develop in the course of the disease. Severe cases may terminate in gangrenous mastitis. In the beginning of the disease, and throughout mild cases, a turbid fluid resembling whey in appearance and containing flakes of casein, is obtained from the affected quarter. Later, in cases of medium degree, the fluid resembles serum and contains clots of fibrin. In the more severe cases, the secretion is discolored with blood. In gangrenous mastitis, a small amount of bloody-serous, dark, foul-smelling fluid, which contains gas bubbles, may be obtained from the affected quarter. The chemical changes which occur in the milk in parenchymatous mastitis are similar to those which take place in catarrhal mastitis. There is a decrease in the lactose, which is sometimes entirely absent; the fat is usually decreased, although sometimes it is increased; the casein is decreased, while the albumin, globulin, and salts, especially sodium chloride, are increased. The taste is salty or bitter. There is an increase in the content of catalase and coagulation takes place when the alcohol or boiling test is applied.

3. Interstitial Mastitis. - The simple, traumatic form of interstitial mastitis, in which the inflammatory process is limited in extent and rather mild, has no important effect upon the milk secretion, but when the disease is due to the entrance of bacteria through fissures or wounds, as is most frequently the case, a phlegmonous inflammation occurs in the subcutaneous or interstitial connective tissue which is accompanied by a rise of the body temperature, sometimes to $107^{\circ}$ F., and other symp- 
toms of constitutional disturbance. There is then more or less extensive and painful swelling of the affected quarter which begins at the teats and extends upward. The milk secretion is somewhat reduced in quantity in the beginning of the disease, but is otherwise unchanged. Later, the secretion from the affected quarter is diminished; the fat is decreased and the milk has a pale, watery appearance. The inflammation may extend into the gland tissue, in which case the milk will undergo the same changes as in parenchymatous mastitis.

Harmful Properties of Mastitis Milk.-In mastitis the secretion from the udder nearly always contains bacteria which may be harmful to man. In the catarrhal form streptococci are usually present, sometimes staphylococci or the Bacillus pyogenes. In the parenchymatous form bacteria of the colon group are usually present, sometimes bacilli of the paratyphus or paracolon group, the enteriditis bacillus, or staphylococci. In catarrhal mastitis the bacteria may be present when the milk is of normal appearance and before clinical symptoms appear and also after the clinical symptoms have subsided and the milk has again become normal in appearance. Bacteria not only occur in the secretion from the affected quarter but they may also be present in the milk from the other quarters. The skin of the teats and udder is contaminated by the secretion from the diseased quarter and some of this infected material can easily fall into the milk pail during the drawing of milk from the other quarters. Secondary infection of the milk is also likely to occur when the secretion from the diseased quarter is milked onto the floor, as is frequently done. The mastitis bacteria find an excellent culture media in milk and rapidly multiply when the milk is kept at room temperature. 
Considering the frequency of the catarrhal and parenchymatous forms of mastitis in dairy cows, cases of illness in man resulting from the ingestion of milk from cows affected with this disease have not been reported as often as would be expected. There are several reasons for this. The milk from a diseased cow may be diluted with milk from cows in normal condition to such an extent as to render the mixed milk harmless. Furthermore, some of the mastitis bacteria have a relatively low virulence for man. Finally, it rarely happens that the physician is able to establish the connection between the disease in his patient and the cow affected with mastitis, even when milk from the latter is the cause of the disease. Nevertheless, there are on record numerous cases of illness in man caused by the ingestion of milk from cows affected with mastitis, the symptoms in these cases being nausea, vomiting, and diarrhœa, sometimes associated with fever, faintness, languor, and cramps in the legs. In two instances the milk which was the cause of the disease had been boiled. It is not known whether the illness in these cases was due to a heat-resisting toxin or to bacteria which survived the heat because of the protection furnished by the membrane which forms on the surface of milk when it is heated.

Numerous epidemics of septic sore throat have been reported in which the infection was transmitted by milk. In some of these epidemics, cows affected with streptococcic mastitis were found to be the source of the infection, but in the other outbreaks the circumstances seemed to point to the infection of the milk by dairy workers suffering from the disease. To account for the persistence of streptococci for several days in the milk supplies involved in the second group of epidemics, the theory has been 
advanced by Theobald Smith that the offending organisms were introduced into the udder of some of the cows by infected milkers, multiplied there without producing any changes in the organ or in the milk, and were eliminated in the milk in large numbers at each milking. In two of the epidemics in the United States (Chicago 1911, Baltimore 1912), the milk which spread the disease had been subjected to a pasteurizing process. Rosenau observed that when the Streptococcus pyogenes is grown in raw milk it is modified to correspond with the streptococcus of epidemic sore throat.

Milk from cows affected with catarrhal and parenchymatous mastitis is also objectionable because the pus which it contains often gives it an unpleasant taste and frequently causes it to putrefy and to curdle quickly. The pus itself may be harmful to children, even if no bacteria are present. The greatest harm, however, is done by the bacteria. In the phlegmonous form of interstitial mastitis the presence of fever and other constitutional disturbances renders the milk unsuitable for food; there is also the possibility that the parenchyma of the udder may at any time become affected and the causative bacteria would then be eliminated in the milk.

Therefore, when a cow is affected with mastitis, the milk should not be used for food and, if possible, the cow should be removed from the milk stable until the udder returns to the normal condition. Cows affected with infectious streptococcic, septic, or gangrenous mastitis should always be isolated. When infectious streptococcic mastitis is present in a herd it may be necessary to prohibit the use of any of the milk for food unless it is boiled or pasteurized, but even then such milk should not be used for children. 


\section{BLOOD IN MILK}

A mixture of blood with the milk may occur as a result of traumatisms of the udder, such as kicking, hooking or treading, which cause hemorrhages or blood infiltrations into the udder tissue. The pulling or dragging to which a greatly distended udder is subjected when the cow walks may cause a tearing of the udder tissue which will permit the mixing of blood with the milk. When large blood vessels have been injured the milk is colored diffusely red. But when small vessels are torn or ruptured, which is more often the case, only small streaks of blood are observed which disappear when the milk is shaken and do not discolor it. When such milk is centrifugalized, the sediment shows a red color which, on microscopic examination, is found to be due to the presence of red-blood cells. Blood is observed in the colostrum or milk during the first week following parturition in those cases in which the udder is intensely hyperæmic, resulting in a diapedesis of red-blood cells.

\section{CEDEMA OF THE UDDER}

Sometimes, especially in heifers with the first calf, the udder becomes very much swollen and odematous shortly before parturition. The swelling is not hot, nor is it painful unless the skin is intensely stretched; it disappears a few days after parturition. Usually, no essential changes are observed in the milk. It is probable that some of the serous transudate is mixed with the milk, but nothing definite is known on this point. Sometimes the milk contains blood. Generally, the odema has disappeared by the time the colostral stage is passed. 


\section{INDIGESTION}

When the digestive functions of the dairy cow are disturbed, as in gastro-intestinal catarrh, there is not only a decrease in the quantity of milk secreted, but quite frequently the milk has a bitter or salty taste and coagulates prematurely (six to eight hours after milking). It contains less fat than normal milk and sometimes appears thinner and of a yellow color. Milk from cows in this condition may possess irritant properties and when ingested unmixed with the milk of other cows may produce diarrhœa, especially in children.

The milk may undergo similar changes in other internal diseases which do not directly involve the udder.

Spoiled Feed.-The milk of cows fed on mouldy, fermented, or putrefied feed has produced diarrhœa in persons ingesting it. This effect has been attributed to the elimination in the milk of abnormal substances contained in such feeds, but it is possible that the organisms causing the changes in the feed may have gained access to the milk during milking and caused changes in the milk itself which brought on the diarrhœa.

SEPTIC OR HEMORRHAGIC ENTERITIS

This disease consists of a severe or bloody diarrhoea associated with a high temperature and other constitutional disturbarices. It may occur sporadically or enzoötically, especially among young cattle. According to Jensen, it is caused by bacteria of the paracolon group which circulate in the blood and which are also present in large numbers in the fecal discharges. Secondary infection of the milk during milking is almost certain to occur since the udder, thighs, and flanks of the diseased animal will be soiled by the fecal matter. The bacteria, 
having entered the blood stream, may also be excreted in the milk when hemorrhages have occurred in the udder tissue. Two instances are reported in which milk from cows affected with this disease has produced disease in man. One individual was affected with diarrhœa, weakness, and headache, while the other exhibited symptoms resembling typhoid fever. Cows affected with a severe or bloody diarrhœa or with a diarrhœa associated with fever should be removed from the milk stable, since they are likely to infect not only their own milk but also the milk of other cows with pathogenic bacteria. The stable should be cleaned and disinfected.

\section{SEPTIC METRITIS}

In acute septic metritis, the milk secretion usually ceases with the sudden onset of the fever and the animal generally dies in a few days, so that the question of using the milk does not often have to be considered. In the less acute cases, a large amount of chocolate-colored fluid, which is frequently putrid, is excreted from the uterus and soils the tail, inner surface of the thighs, and udder, as well as the bedding, stall, and suroundings. This fluid may contain staphylococci, streptococci, bacilli of the colon and paratyphus groups, and putrefactive bacteria. These organisms may enter the milk during milking. The milk of such animals usually gives a positive reaction to the alcohol test, indicating that some of the products of the disease are absorbed from the uterus and eliminated through the udder. The foul odor of the uterine discharges and the odor of antiseptics which may be used in the treatment of such cows will be absorbed by the milk. While no cases of disease in man from the use of milk from cows affected with septic metritis have 
been reported, there is no doubt that the milk is injurious to health because numerous cases of meat poisoning are on record from the use of meat from cows slaughtered while suffering from this condition. Cows affected with septic metritis should therefore be removed from the milk stable and the milk should not be used for food.

\section{RETAINED PLACENTA}

Following retention of the placenta, there is a discharge from the uterus which frequently contains particles of the fetal membranes and cotyledons which are undergoing putrefaction, also pus, pyogenic organisms, and putrefactive bacteria. The tail, thighs, and udder become soiled with the discharges and the milk may be contaminated during milking. In cases where the milk has been centrifugalized and the sediment examined microscopically, large numbers of staphylococci and diplococci have been found. The milk will also give a positive reaction to the alcohol test, indicating that the secretion is not normal. Milk from cows with a purulent or putrid vaginal discharge should not be used for food purposes. Such cows should not be placed in the milk stable until the condition disappears, as there is a possibility of the discharge contaminating the milk of the other cows.

\section{INFECTIOUS ABORTION}

The milk of cows which have aborted contains the Bacillus abortus Bang very frequently, in some cases for months after the abortion. Immediately before and for several weeks after abortion, the bacillus is also eliminated through the vagina and may infect the milk secondarily. When the placenta is retained, the vaginal discharge also contains pyogenic and putrefactive organ- 
isms. At the time of abortion the udder secretion frequently assumes the characteristics of colostrum.

When injected into guinea pigs or fed to them, milk containing the abortion bacillus produces proliferative changes similar to those caused by the tubercle bacillus. The organism is also pathogenic for animals of several other species. This widespread pathogenicity and its frequent occurrence in milk suggested the desirability of investigations to determine if the organism was concerned in the sclerotic changes occurring in the organs and tissues of man and the domestic animals. Mohler and Traum inoculated guinea pigs with material from twenty-eight tonsils and adenoids from milk-consuming children. The material from two of the tonsils produced lesions in three guinea pigs, but the Bacillus abortus was recovered only from the lesions in one of these animals. Whether the organism was actually responsible for the change in the tonsil or whether it merely happened to be lodged on the surface could not be determined. Schroeder also made a number of similar tests, all with negative results. Mohler tested the blood serum of twenty-five persons with the complement fixation and agglutination tests and obtained negative results in all cases, while Larsen and Sedgwick, in applying the complement fixation test to the blood serum from 425 children, obtained 73 positive reactions (17 per cent.). Ramsey tested the blood of $\mathbf{1 1 6}$ children in the same manner, but the reaction was positive in only seven cases. Nicholl and Pratt obtained positive reactions with the agglutination test on the blood serum of several children. No definite statement can be made as to whether the anti- 
bodies responsible for these positive reactions were present because the individuals from which the blood samples were obtained had actually passed through some form of disease due to the abortion bacillus or whether they were the results of a passive immunity due to the ingestion of milk containing the bacillus or its antibodies. But it has been demonstrated in a number of experiments that after the ingestion of an organism in large numbers the specific antibodies may be present in the blood without the organism producing disease, and there is some reason to believe that antibodies contained in the milk may be absorbed by the blood from the intestinal canal of children (see page 43). However, there is no definite information that abortion bacilli in milk have any injurious effect upon the health of individuals ingesting such milk.

\section{OTHER DISEASES}

Any disease of the dairy cow attended with a considerable disturbance of the general condition usually causes a decrease or a complete cessation of the milk secretion. Although the milk is generally of normal appearance when secretion continues in such cases, it frequently contains an increased amount of mineral salts, has a salty taste and coagulates prematurely. While it is not known that milk of this kind is harmful to man, the change in its composition is sufficient to justify its condemnation as a food.

When suppurating wounds or ulcerative or phlegmonous inflammations are present in any part of the body, there is danger of the milk being infected with the pyogenic organisms. 
EXCRETION OF MEDICINES THROUGH THE UDDER

A number of medicines used in the treatment of diseased conditions in cattle are eliminated in part through the udder, namely: iodine, mercury, lead, copper, antimony, arsenic, salicylic acid, antipyrin, boric acid, aloes, rhubarb, senna, croton oil, euphorbium, morphine, strychnine, atropine and veratrin. Although, under ordinary conditions, these substances are eliminated in the milk in small quantity, there is a possibility that milk from cows being treated with these drugs may be injurious to children and weak adults. When elimination through the normal channels is retarded by disease, they may be eliminated through the udder in larger quantity, and substances which are not usually excreted through the udder may also pass out with the milk. For this reason milk should not be used for food from a cow which is being treated with medicines that are poisonous. Aloes, rhubarb and senna affect the taste and color of milk.

\section{Diseases of Man Transmissible Through Milk}

Milk may act as a carrier of the bacteria or virus of certain specific diseases of man. From time to time, epidemics in which the infectious agent has been disseminated by milk have been reported, particularly outbreaks of typhoid fever, septic sore throat, diphtheria, and scarlet fever. These milk-borne epidemics have certain characteristics by which they may be recognized, viz: 1 . The epidemic is explosive in character, a large number of cases occurring at about the same time, followed later by a rapid decrease in the number of new cases. 2. The disease is limited to those families receiving their milk supply from a certain distributer; occurs in families using the greatest amount of milk and affects those individuals 
using the most milk, generally women and children. 3. The period of incubation is relatively short. 4. The disease is of mild type. 5. The mortality is lower than usual.

As a rule, the conclusion that the disease is disseminated by milk must be based upon these characteristics and upon information obtained regarding the manner in which the milk may have been infected, rather than upon the demonstration of the infectious agent in the milk. The cause of scarlet fever is not known and consequently its presence cannot be detected by any known method of examining milk. The bacillus of typhoid fever has been demonstrated in milk several times, thus affording positive proof that this organism is transmitted by milk, but the examination has been unsuccessful in a much larger number of cases. The diphtheria bacillus has been recovered from milk in even fewer instances. There are several reasons why efforts to isolate these organisms from milk which is the cause of an epidemic may be unsuccessful. 1. Only a small quantity of the milk, a drop or two, is subjected to examination, and this may be free from the organisms even when the latter are relatively numerous in the whole volume of milk concerned. 2. The period during which the milk is infected may be terminated before it is suspected and examined. 3. The organisms may be overgrown by the other kinds of bacteria which are present in milk in greater number. In practice, the presence of these infectious agents in milk is not suspected until several cases of disease have appeared. Even if they could be detected in milk with more certainty, it would be a mistake to defer action after an epidemic has started until the milk can be examined, because this would allow more time for the dissemination of the infection. 


\section{TYPHOID FEVER}

Typhoid fever is more frequently spread by milk than any of the other infectious diseases of man except tuberculosis. As a carrier of typhoid infection, milk is second only to water, although the cases caused by infected water greatly outnumber those resulting from infected milk. Milk may be infected with the Bacillus typhosus in several ways. The organisms may be introduced into milk when infected water is used to wash the milk vessels and utensils. Infected water may contaminate the milk when there is a leak in the milk cooler or when a can of milk is submerged in such water to cool. Water in open or thin-walled springs, surface wells, and in streams receiving surface drainage may be readily infected by excretions from typhoid fever patients, convalescents, and chronic bacilli carriers. Milk bottles from houses where the disease exists may be a source of infection; one or two infected bottles may contaminate the water in which they are washed or rinsed, and this water will infect other bottles washed in it. A few bacilli introduced into a vessel or bottle by infected water will multiply rapidly when milk is placed in it, for the Bacillus typhosus grows abundantly in milk. Milk may be infected directly when the cows are milked or the milk or milk vessels are handled by persons affected with the disease, by convalescents, by chronic bacilli carriers, and by those attending typhoid fever patients. The greatest danger of direct infection is from those cases in which the disease is of such a mild type that it is not recognized, the so-called walking typhoid, and from chronic bacilli carriers, i.e., individuals who continue to excrete typhoid bacilli in the fæces and urine after they have recovered from the disease. It is estimated that 2 to 4 per cent. of typhoid fever patients 
become chronic bacilli carriers. The bacilli may also be carried by flies and be blown about in dust.

The typhoid bacillus multiplies rapidly in milk and the number may be greatly increased in a short time. The milk is not changed in appearance. The organism grows in slightly sour milk; it is checked or destroyed by a high degree of acidity, but it survives the degree of acidity existing in cream ripe for churning. It may live in milk several days and may be present in fresh butter and new cheese. Bruck found virulent bacilli in butter after twenty-seven days. Typhoid bacilli in milk are destroyed when exposed to a temperature of $60^{\circ} \mathrm{C}$. $\left(140^{\circ} \mathrm{F}\right.$.) for two minutes (Rosenau).

When an outbreak of typhoid fever occurs which has the characteristics of a milk-borne epidemic, the suspected milk supply should be stopped, or pasteurized under supervision, and an investigation made with the object of discovering and abolishing the source of the infection of the milk. Immediate medical attention to cases of illness affecting the dairyman, his employees, or members of their households, proper supervision of cases of typhoid fever by health authorities, the sterilization of milk bottles before refilling, and a pure water supply will greatly reduce the liability of the occurrence of such epidemics. There is no method known which is entirely satisfactory in preventing the direct infection of milk by walking typhoid cases or by chronic bacilli carriers. Recently, some local health authorities have required that blood samples be taken from dairy employees and submitted to the Widal test as a safeguard against chronic bacilli carriers; a few high-class dairies have been following this plan for some time. Several states have laws requiring dairymen to report to the local health author- 
ities all cases of typhoid fever and other infectious discases occurring in their own families and among their employees or in the families of the latter.

\section{PARATYPHOID FEVER}

Paratyphoid fever is also transmitted by milk, but less frequently than typhoid fever. The milk may be infected directly with the paratyphus bacilli by contact with persons affected with the disease or indirectly by polluted water being used to wash the milk vessels, utensils, and bottles. Water may be contaminated by fecal matter from infected persons.

\section{DIPHTHERIA}

A number of milk-borne epidemics of diphtheria are on record, although this disease has been less frequently disseminated by milk than typhoid fever. The diphtheria bacilli are present in the oral cavity and on the nasal mucous membrane of persons affected with the disease and may persist in these locations for months after the patient has apparently recovered. Persons who have attended diphtheria patients may also carry the bacilli. Infected persons may infect the milk directly or indirectly. In the beginning of some cases of diphtheria, the throat is apparently normal or only slightly affected. These cases and cases of chronic nasal diphtheria are most difficult to diagnose from clinical symptoms. Because of the occurrence of cases of this type and the continuance of the bacilli in some individuals after the subsidence of clinical symptoms, it is not possible to guard entirely against the occasional infection of milk by the diphtheria bacillus. But the danger will be greatly reduced if prompt attention is given to all cases of sore 
throat occurring among dairy workers or in their families; if persons who have attended diphtheria patients or individuals recovering from the disease are not permitted to handle milk or milk vessels until cultures from the throat prove to be free from the bacilli, and if returned bottles are sterilized before refilling. Frequently the bacilli are not very virulent.

The diphtheria bacillus has been demonstrated in milk only a few times, principally because the organism is present in infected milk in small numbers and usually for only a short period. There is no doubt, however, of its transmission by milk. The milk is not changed in appearance by the growth of the organism. The bacillus is not affected by the degree of acidity present in cream ripe for churning, and it may therefore be present in butter and also in other dairy products, although we have no reports of the latter carrying infection. A comparatively low degree of heat is sufficient to destroy the organism. It is usually killed by a temperature of $55^{\circ} \mathrm{C}$. $\left(131^{\circ} \mathrm{F}.\right)$, but occasionally some individuals survive until the temperature reaches $60^{\circ} \mathrm{C} .\left(140^{\circ} \mathrm{F}\right.$.).

When an outbreak of diphtheria occurs with the characteristics of a milk-borne epidemic, the same procedure should be followed as described under typhoid fever.

\section{SEPTIC SORE THROAT}

Epidemics of septic sore throat originating from infected milk have been reported from England for a number of years and, in recent years, several outbreaks of the disease, affecting thousands of persons, have occurred in this country. In some instances the infection of the milk was traced to cows affected with streptococcic 
mastitis, but in other cases there seemed to be reason to suspect that the milk had been infected by persons affected with septic sore throat (see page 111).

\section{SCARLET FEVER}

Scarlet fever has been disseminated by milk more rarely than some of the other infectious diseases of man. The epidemics reported occurred principally in the United States and England. The infectious agent of this disease has not been discovered and it is not definitely known how it gains access to milk, but it is presumed that the milk is infected directly or indirectly by persons affected with the disease. The same action should be taken against a milk-borne epidemic of this disease as is indicated under typhoid fever.

\section{TUBERCULOSIS}

Tubercle bacilli of the human type have been demonstrated in milk (Hess, Rabinowitsch), and there would seem to be abundant opportunity for milk to be infected by a consumptive working in a dairy. Tuberculous individuals should therefore not be permitted to handle milk. 


\section{CHAPTER VII}

\section{DAIRY FARM INSPECTION}

THE hygienic qualities of milk depend very largely upon the conditions existing at the source of supply. A knowledge of these conditions can be obtained only by an inspection of the dairy farm. Collecting a sample of milk in the city or town and examining it in the laboratory will disclose certain conditions, and it will usually be correct to infer that the same conditions exist in the entire volume of milk from which the sample was taken. Some of these conditions may be dangerous to the health of the milk consumer, but the milk will have been consumed before they have been discovered. Determining the number of bacteria per c.c. in a sample of milk will furnish a good basis for judging the care observed in producing and handling the milk, especially in regard to cleanliness and cooling, but it will not discover the presence of the bacilli of typhoid fever, tuberculosis, or diphtheria, nor other important pathogenic organisms. Even if it were practicable to subject each sample of milk to the comprehensive examination necessary to discover these organisms, the milk from which the sample was taken would be consumed long before the examination could be completed. It is more rational to guard the milk against contamination at the source than to attempt to discover contaminated milk after it reaches the city and then exclude it from the supply.

While it may not be possible to discover the actual contamination of the milk in all cases by inspecting the dairy farm, the conditions which permit or favor con- 
tamination can, with few exceptions, be discovered by a careful inspection. A proper laboratory examination of the milk in connection with the inspection will generally detect those conditions which may escape discovery at the inspection. The information obtained by inspection will serve as a basis for judging the quality of milk which may be produced, not only on the day of inspection but also thereafter. Moreover, inspection brings a representative of the health authorities into personal contact with the dairyman, a condition which should make for a better understanding and more sympathy on both sides.

It is sometimes asserted that the bacterial testing of milk is more efficient in improving or controlling a milk supply than dairy inspection. This statement, however, will not bear critical examination. The ordinary bacterial test merely approximates the number of clumps of bacteria present in a very small portion of milk. It does not determine the number of bacteria present, the kind, nor their source. It does not tell whether a high count is due to conditions existing at the dairy farm, during transportation, or at the distributing plant. It does not discover the presence of pathogenic organisms, excepting, perhaps, streptococci, and it does not indicate the source of these latter organisms. On the other hand, inspection of a dairy farm will disclose the physical condition of the cows, the sanitary condition of the premises, the character of the equipment, the methods in use, and the physical condition and proficiency of the dairyman and his employees. Dairy inspection alone will certainly furnish more useful information for judging the hygienic properties of milk than bacterial testing alone. As an adjunct to dairy inspection, however, bacterial testing and other laboratory methods of examining milk are of great ser- 
vice. Unless bacterial testing is to be used only to find faults and no assistance is to be offered in correcting them, it must be combined with dairy inspection.

Inspection of a dairy farm should include an examination of the following:

I. Stable:
1. Exterior.
2. Interior.

II. Cows:

1. Cleanliness.

2. Stage of lactation.

3. Symptoms of disease.

III. Stable practices:

1. Cleaning the stable.

2. Cleaning the cows.

3. Milking.

4. Feeding.

5. Bedding.

IV. Milk House:
1. Location.
2. Construction.
3. Apparatus.
4. Water supply.

A certain system or routine should be followed in making the inspection so that nothing will be overlooked. It is usually convenient to begin with the stable and then to follow the course of the milk from here to the storage cans or bottles, although the point of beginning will have to be varied to suit the circumstances. The best time to make an inspection is while the cows are being milked, but, unfortunately, all dairies cannot be visited at this particular time. The inspector should provide himself 
with a suit of thin, washable material to protect his clothing, and should also wear a close-fitting cap to protect his hair while ausculting the lungs. Material of blue or a darker color is more desirable than white, because in stables where white suits are not worn by the milkers some of the cows are likely to kick at a stranger wearing white clothing. The inspection should be carried out as follows:

\section{STABLE}

1. Exterior.-On approaching the stable, the inspector should take note of:

(a) The location of the building with regard to surface drainage. It is desirable to have the floor of the stable about eight inches above the surrounding ground and to have the adjoining ground slope away from the stable.

(b) The type of stable and its general construction -whether a bank barn with the stable in the basement and storage space above for feed, or a one-story stable entirely above the ground; also, whether the building is constructed of stone, wood, or cement. Information on these points may be of value later in the inspection in considering the arrangements for lighting and ventilation.

(c) Exposure.-The direction in which the windows and doors face is of importance, as it has considerable influence on the temperature and lighting of the interior. When there can be windows and doors on only one side of the stable it is best to have them facing the south. This exposure will permit the morning sun to shine into the stable and will keep out the hot afternoon sun in summer and the cold winds in winter. When the cows stand in a double row the most desirable arrangement 
is to have the windows on the east and west sides with the two rows of cows extending north and south. The windows on the west side can be provided with wood shutters to keep out the sun on hot summer afternoons. When the shutters are up the flies will also be less troublesome on that side of the stable.

(d) Surroundings.-The location of the manure dump and the direction of the surface drainage from the same should be observed, particularly with relation to the location of the source of the water supply. The accessibility of the manure pile to cows turned out for exercise or being driven into or out of the stable should also be considered. When cows are permitted to wander about in a lot of manure they become very much soiled, especially their legs and udders, and also carry a good deal of dirt into the stable.

The proximity of other buildings, especially if used as horse stables, chicken houses, pigpens, etc., should be noted. Buildings used for these purposes, as well as manure piles, are breeding places for flies and are therefore objectionable when too close to a dairy stable or milk house.

Attention should be given to the condition of the barnyard or exercise yard. Note its size and whether or not it is well drained. The condition of the barnyard has a considerable effect upon the cleanliness of the cows and stable. If it is muddy or dirty, some of this material will become attached to the cows and will be carried into the stable, increasing the labor of cleaning the cows and the stable.

2. Interior of the Stable.--In examining the cow stable, the fact should be kept in mind that it is not only a shelter for animals but is also a place where human food is pro- 
duced. Cows in milk should not be kept in the same stable with horses or other animals; they should have a separate stable for their exclusive use. There should be a special stable for parturition and for cows which are not in health.

(a) Odor of the Air.-On entering the stable the odor of the air should be noted, since any slight abnormality will be more perceptible at this time than later, when the inspector has become accustomed to the atmosphere. The odor of the air is a good test of the efficiency of the ventilation and also of the degree of cleanliness of the stable, especially in cold weather when the doors and windows are closed and the cows are kept in the stable almost continuously. Abnormal odors in stable air usually originate from two sources: exhalations from the cows and decomposing manure and urine. Condensation of moisture on the walls, ceiling, or windows or the presence of frost is another indication of defective ventilation. A moist atmosphere assists in the spread of tuberculosis in a stable. The droplets of infected saliva expelled by tuberculous cattle in the act of coughing float more readily in the stable air when it is saturated with moisture than when it is drier. In most instances cattle are infected with tuberculosis by the inhalation of infected air or by the ingestion of infected food or water. Insufficient ventilation has the effect of concentrating any infection in the air of a stable, while ventilation dilutes it.

Recent experiments have shown that the harmfulness of insufficient ventilation is not due to a deficiency of oxygen, an excess of carbon dioxide, or the presence of organic poisons in expired air, but to the warmth and moisture of the air in unventilated places and to its lack of movement. A warm, moist atmosphere has a depress- 
ing effect upon the animal organism. It decreases the working capacity of the muscles and lowers the vasomotor tone. It also causes a congestion of the nasal mucous membrane, rendering the animal more susceptible to respiratory infection. There is also reason to believe that metabolism is depressed. A moderately cool and moderately dry air in motion is the most healthful atmosphere for animal life.

Ventilation.-The best system of ventilation for dairy stables is the one devised by the late Prof. F. H. King. Like other systems, it has inlets for the admission of fresh air and outlets

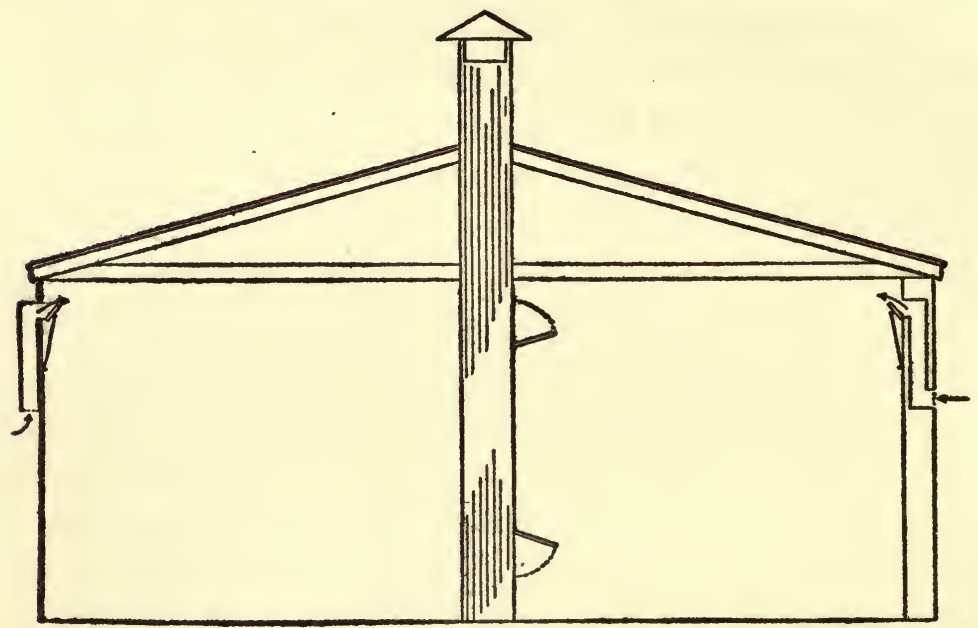

FIG. 9.-Showing on the left how an inlet can be placed in a wall already constructed; on the right, how an inlet can be put in a wall being built; and in the centre, an outlet shaft with two openings-one just under the ceiling and one a foot above the floor.

for the removal of impure air, but it has two features which are peculiar to it. The inlet flues are bent at a right angle, and the outside opening is lower than the inner one, the purpose being to prevent the escape of air from the stable through the inlets. The outlet flues are built from the floor up and have an opening near the floor as well as one near the ceiling, thus providing a means of drawing air not only from the upper 
part of the stable, but also from the lower. Inlets are placed in all of the outer walls of the stable if possible, with the inside opening just under the ceiling and the outside opening five feet lower (Fig. 9).

The number and size of inlets necessary will vary with weather conditions, and it is therefore desirable to have as many as possible and then use as many as may be needed. Weather conditions exert considerable influence on the air in stables ventilated by any system which depends for its operation on natural forces. When the atmosphere is still or moist, the ventilation is often inefficient in stables which under other conditions are well ventilated.

A cow requires 59 cubic feet of air per minute and it is estimated that air will pass through a flue at the rate of 290 to 300 feet per minute. The minimum number and size of inlets and of outlets required may therefore be calculated according to the following formula: ${ }^{1}$

$\frac{\text { No. cows in stable } \times 59}{300} \times 144 \mathrm{sq}$. in. $=$ Total cross-sectional area in square inches 300 of inlets and of outlets.

By dividing the total cross-sectional area by the number of inlets and of outlets, the cross-sectional area of each inlet and outlet is ascertained. The number of inlets and of outlets will depend upon the size of the stable. Inlets should not be over 12 feet apart; closer if possible. Several outlet flues of moderate size in different parts of the stable are preferable to one or two large outlets.

Each inlet should be provided with a sliding door or other contrivance by which it can be conveniently opened or closed. The outlet flues should extend from the floor to 6 feet above the highest point of the roof and should be capped with a hood 1 foot above the top. If they cannot be placed where they will not act as obstructions, they may be hinged at the ceiling so that they can be drawn up out of the way temporarily (Fig. 10). Each outlet flue should have two openings into the stable, one just under the ceiling and the other a foot above the floor, both openings being provided with doors which can be readily opened

${ }^{1}$ Wisconsin Exp. Sta., Bull. No. 266. 


\section{PRINCIPLES AND PRACTICE OF MILK HYGIENE}

or closed. The outlet flues must be air-tight and protected against cold in exposed places. The best material for the construction of these flues is galvanized iron (No. 28), $2 \times 4$ inch lumber being used in the corners and joints. Where the shaft is exposed, the iron should be covered with $7 / 8$-inch boards. Outlets may also be constructed of a double layer of tongued and grooved boards with a layer of heavy building paper between. If tin or galvanized iron pipes are used, they should be surrounded by a square wood frame and the interstices filled

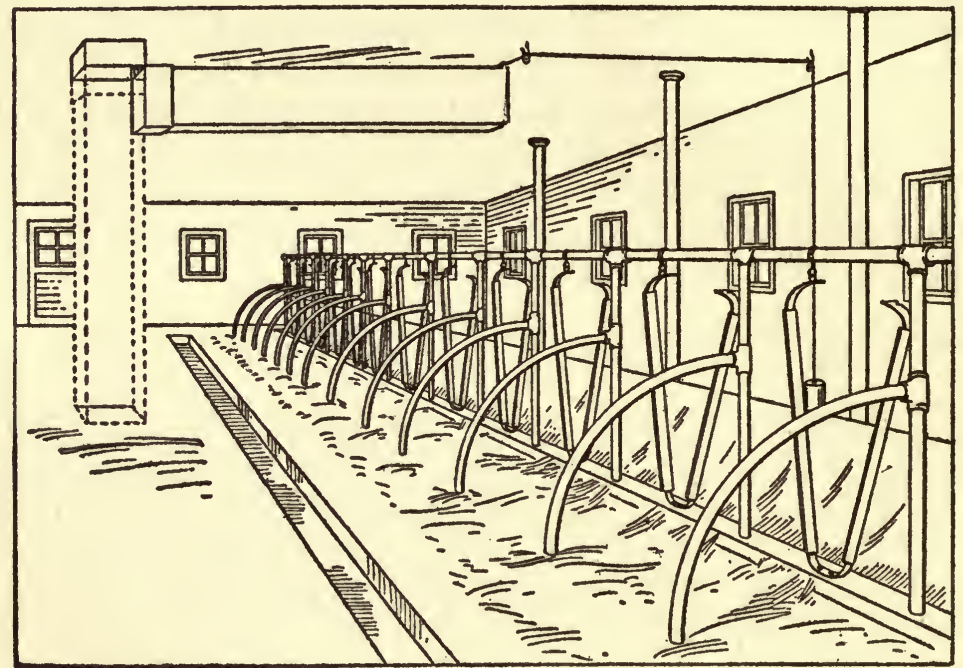

FIG. 10.-An outlet flue hinged at the ceiling so that it can be drawn up out of the way.

in with sawdust. Protection against cold is necessary because the air in the outlet flue must be kept warm, otherwise it will cease to ascend. The ceiling and walls of the stable should be air-tight and should be constructed with a view to preventing the radiation of heat as much as possible.

The circulation of air through the stable results from the operation of two factors, called by Professor King aeromotive forces, namely: heat generated by the cattle, and wind. The wind drives air through the inlets on the windward side of the stable and thus increases the air pressure within the stable, as a result of which air is forced out of the stable through the outlets. 
If the wind is very strong, air may also be forced out through the inlets on the leeward side, but ordinarily the right-angled bend in the inlets and the position of the outer opening at a lower level than the inner prevents or retards the escape of air through these inlets. In addition, wind passing over the top of an outlet shaft produces a suction action within the flue, and this draws air out of the stable. The force of this suction action increases with the height of the outlet shaft, because air movement or wind increases in velocity with the distance about the ground.

The heat given off by the animals in the stable through the skin and in the respired air warms the stable air around them, expanding it and decreasing its density or weight, which causes it to rise toward the ceiling. Fresh air entering through the inlets, being colder and heavier than the air in the stable, gravitates toward the floor. Through the operation of these two currents the stable air and fresh air are mixed, the fresh air is warmed while the stable air is cooled and the moisture it contains is diluted. However, when the respired air is cooled below $81^{\circ} \mathrm{F}$., it becomes heavier than fresh air of the same temperature because of the carbon dioxide which it contains and consequently settles toward the floor. For this reason, it is desirable to have the outlet flues arranged to draw air from the lower as well as the upper part of the stable. The expansion of the air in the stable by the animal heat increases the pressure within the stable and this has the effect of forcing air through the outlets; the construction of the inlets prevents air from being forced out through them. To obtain satisfactory results, the air in the stable should be about $20^{\circ} \mathrm{F}$. warmer than the air outside. The effect of temperature differences on the draft in outlet flues increases with the length of the flue. The resistance encountered by air in passing through inlets and outlets modifies to some extent the effects of wind and heat. It is therefore desirable to have the outlet flues as straight as possible.

Cloth Method of Ventilation.-Stables may be ventilated by covering windows with muslin or cheese cloth. Glass windows should be alternated with the cloth-covered windows in order to permit sufficient light to enter the stable. Three square feet 
of glass and 2 square feet of cloth for each 1000 pounds of animal weight is a good proportion. When the air is still, a stable ventilated by means of muslin-covered windows will not be more than 1 to $3^{\circ} \mathbf{F}$. colder than stables in which the King system is used, and there will be 7 to 10 per cent. less humidity in the stable air; but when high winds prevail, the animal heat will be rapidly dissipated and the stable will be colder. If the cloth becomes wet and freezes, ventilation will cease.

(b) Cubic Air Space.-This is determined by measuring the length and width of the stable, multiplying the length by the width, and then multiplying the result thus obtained by the height of the ceiling. After the total cubic feet of air space has been ascertained in this manner, the stanchions or ties should be counted and the total cubic feet of air space divided by the number of stanchions. The result will be the cubic feet of air space per animal. The number of stanchions or ties should be used for this purpose instead of the number of animals present because this method will give the minimum cubic feet of air space per animal under all conditions.

The size of a stable in proportion to the number of animals in it bears an important relation to ventilation. The less air space per animal the more frequently the air in the stable must be changed. The heat given off by animals is only sufficient to warm a certain quantity of air, and if this limit is exceeded the stable will be cold in winter. A stable with insufficient cubic air spaces will also be hot and uncomfortable in summer.

It is desirable to have 1 cubic foot of air space for each pound of animal weight, but this amount cannot always be provided because of the cost of building materials and for other reasons. With suitable arrangements for ventilation, 500 to 600 cubic feet of air space per cow 
will answer quite well. A cow requires 59 cubic feet of air per minute, or $\mathbf{3 5 4 0}$ cubic feet per hour. To provide this amount for a cow occupying a space of 500 to 600 cubic feet, it would be necessary to entirely change the air in the space occupied by the cow six to seven times per hour. It is estimated that the heat given off by a cow in 24 hours is equal to 76,133 British thermal units, which is sufficient to heat 79,603 cubic feet of dry air from $0^{\circ}$ to $50^{\circ} \mathrm{F}$. This quantity of air would provide 3316 cubic feet of air per hour, only 224 cubic feet less than the quantity required by the cow. ${ }^{1}$ It would appear, therefore, that the required amount of fresh air could be admitted to a stable with 500 to 600 cubic feet of air space per cow without lowering the temperature too much, especially since the temperature only rarely falls to $0^{\circ} \mathrm{F}$. in the dairy sections in the northern part of the United States. The most comfortable temperature for the dairy cow is from $60^{\circ}$ to $65^{\circ} \mathrm{F}$., but if the temperature is kept lower by ventilation, say down to $50^{\circ} \mathrm{F}$., the cow will not suffer in health and the milk flow will not be reduced, provided exposure to the low temperature begins in the autumn and is continuous. Milk cows have been kept through the winter in sheds open to the south with quite satisfactory results.

The distribution of the cubic air space is important. If the ceiling is too high, the stable is likely to be cold at the level occupied by the cows, although the upper part may be warm enough. The height of the ceiling should be regulated by the size of the stable. Eight feet is a sufficient height for small stables. In a stable for 12 cows

1 These figures are taken from Prof. F. H. King's book on "Ventilation." 
the ceiling should not be over 10 feet high; for $\mathbf{3 0}$ cows, not over 12 to 15 feet; more than 30 cows, not over 16 feet (Rievel). The length and width of the stable should be such as will provide sufficient floor space to accommodate the cows comfortably and to make it convenient to milk and care for them. When the cows stand facing the centre of the stable, the alley or passageway in back of them should be of sufficient width to permit the passage of a man carrying a pail of milk without the pail touching or coming too near the cows. To meet this requirement it is necessary for the passageway to be at least 3 feet wide, the milk pail being carried on the side of the milker farthest from the cow, but a width of 5 or 6 feet is much better. A narrow passageway back of the cows makes it difficult to keep the wall clean. The passageway between two rows of cows standing tail to tail should be at least 8 feet wide; it can hardly be wide enough to prevent milk carried in a pail between the cows from being contaminated by the dust dislodged by the switching of the tails. There is also danger of contamination from splashing urine and manure.

To provide 500 to 600 cubic feet of air space per cow the floor space, with a 9-foot ceiling, may be distributed as follows:

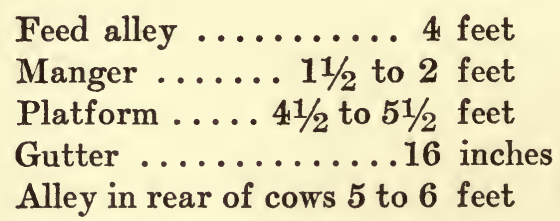

The total of these dimensions would be $\mathbf{1 8}$ feet. Allowing $3^{1 / 2}$ feet for the width of the stall, there would be 63 square feet of floor space for each cow, which, with a 
ceiling 9 feet high, would provide 567 cubic feet of air space per cow. With the cows standing in two rows, the stable would be $\mathbf{3 6}$ feet wide, which is not too wide for it to be well lighted if windows are placed on both sides. It will therefore be seen that the necessary area of floor space to make the cows comfortable and the stable work convenient will also provide a fair amount of cubic air space.

(c) Interior Construction.-The material used in the construction of the ceiling, walls, floor, platform, feed trough, drop or gutter, and stall fittings, their state of repair and their condition in regard to cleanliness should be noted. While defects and deficiencies in stable construction may be overcome to a considerable extent by careful and painstaking methods, at the same time a properly constructed and conveniently arranged stable saves labor and therefore encourages the practice of good methods; it also adds to the comfort of the cows and consequently increases their productiveness.

The ceiling should be tight and smooth, plastered, painted, oiled, or whitewashed, and free from cobwebs. There is no objection to storing hay or fodder above the cow stable if the ceiling is tight. It is better not to have any openings in the ceiling through which hay, fodder or straw may be thrown down into the stable; but if there must be such openings, they should be in front of the cows and not in the rear.

The walls should be smooth and clean. It is desirable to have the inner surface of the walls back of the cows finished smooth with cement for at least 4 feet above the floor and covered with an impervious paint from which dirt can be readily removed by washing. Where paint or cement cannot be used, the application of whitewash will 
improve the conditions. Any woodwork can be treated in the same manner. Whitewashing removes dirt and cobwebs, improves the light, and exerts a disinfectant action.

The platform, or the floor of the stall, should be about 8 inches above the bottom of the drop or gutter and should be smooth, free from cracks or depressions and impervious. All things considered, cement is probably the best material of which to construct platforms. Cement platforms are objected to on the ground that they are slippery, cold, and hard. If given a rough finish with a wood trowel or by drawing a stiff broom over the surface before the cement is dry, they will not be slippery. A layer of coal tar or pitch about $1 \frac{1 / 2}{2}$ inches below the surface will reduce the conduction of heat from the body of the cow and will therefore make the platform warmer, while the hardness can be overcome to a certain extent by the use of plenty of bedding. Recently, a mixture of two parts of sawdust and one part of cement has been recommended in place of the usual cement mixture, the claim being made that it is warmer and is not as slippery. A covering of inch boards is sometimes laid down over the cement to reduce the hardness and coldness. Cement floors have several advantages: they are readily cleaned, wear well, and do not absorb urine or liquid manure nor permit these substances to leak through and saturate the earth beneath. Next to cement, the most desirable floor is one of matched planks, with the joints filled with tar. Wood is less of a heat conductor than cement and is not as hard, but it absorbs urine and liquid manure and is liable to crack and form crevices in which manure and other material may lodge and decompose; it is also less durable than cement. Cork bricks 
laid on concrete are also used for platforms and floors. It is claimed for them that they combine the good properties of cement and wood and at the same time do not have any of the undesirable properties of those substances. An earth floor is most objectionable. Unless plenty of good absorbent litter is used it is very likely to be wet and dirty; it finally becomes saturated with urine and liquid manure, which decompose and liberate foul-smelling gases.

The rear 18 inches of the platform should slope slightly toward the gutter, just sufficient to cause liquids to flow in that direction. Too much slope is likely to cause the cow to slip; it also causes the cow to stand down in the gutter and favors prolapse of the vagina and similar troubles. It is desirable to have a depression in the front of the platform $3 / 4$ inch deep and extending back about 18 inches from the anterior border. This will prevent cows from falling on their knees when attempting to rise or when reaching for feed, and will also have a tendency to keep the litter from being pushed toward the rear of the stall (Fig. 11).

The length of the platform is important; if too long, the fæces are dropped where the cow can lie upon them; if too short, the cow is uncomfortable and stands down in the gutter. The proper length is $41 / 2$ to $5^{1 / 2}$ feet, differing with the size of the cow. Frequently, where a number of cows stand in a row, the platforms are made $41 / 2$ feet long at one end with a gradual increase to $5 \frac{1}{2}$ feet at the other end of the row, thus supplying platforms of different lengths on which the cows can be placed according to size. The platform for each cow should be $3 \frac{1}{2}$ to 4 feet wide, depending upon the size of the cow. The width is quite as important as the length, because 


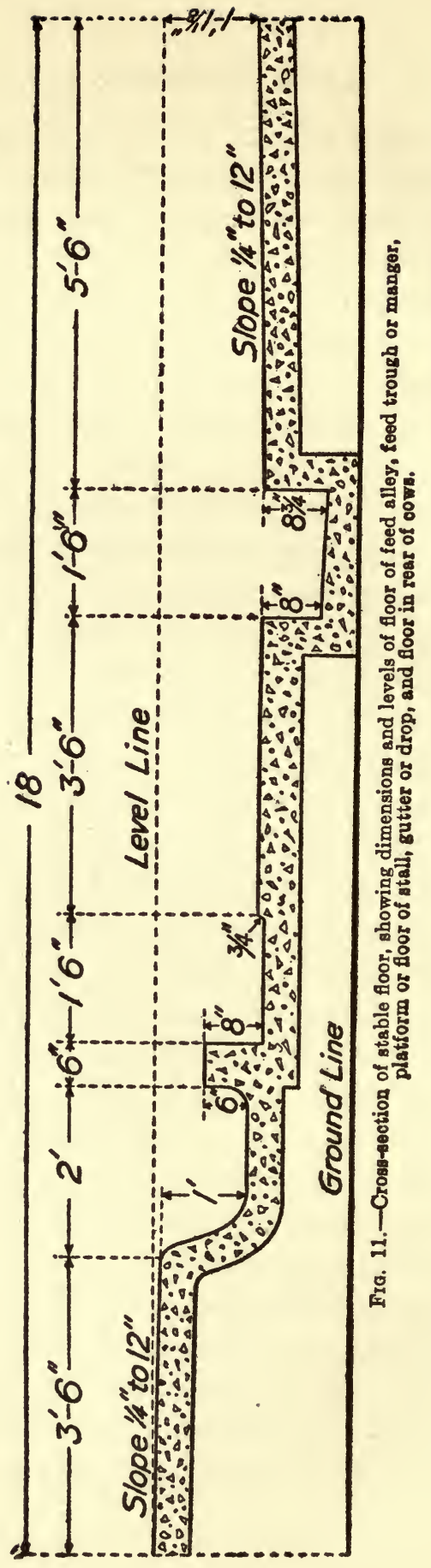


if the stall is too wide and the cow stands diagonally the result will be the same as if the platform was too long. The stall should be constructed with the view of preventing the dropping of manure where the cow can lie down upon it, in so far as this is possible, and thus save labor in keeping the cow clean. Other points to be considered are the comfort of the cow, convenience of cleaning the stall, milking, and feeding, and the cost.

The feed trough or manger may be built of wood or cement. Cement is better because it is easier to keep clean. A continuous cement trough, extending in front of a row of cows without any divisions, can also be used for water. In addition, the continuous trough is more conveniently cleaned, but on the other hand it favors the spread of infectious diseases, especially tuberculosis. Feed placed before a tuberculous cow may be contaminated by infected saliva and material ejected in coughing, after which it can be readily obtained by cows in adjoining stalls; the tuberculous cow may also contaminate the feed of the cows standing on either side, and also of cows standing opposite, and when water is run into the trough infection may be carried from one end of it to the other. On the other hand, separate feed troughs or mangers, although decreasing the danger of infection, increase the labor of cleaning; they also make it necessary to have individual drinking cups or to drive the cows to water outside of the stable. When a herd is regularly tested with tuberculin and the reactors promptly removed, and when the trough is swept and washed daily, the danger of infection from the common feeding trough is greatly reduced. The bottom of the feed trough should be 2 inches higher than the level of the platform. When cows have to reach too far for their 
feed, the front feet frequently slip backward and the cows are thrown on their knees, causing bruises which often lead to the development of knee tumors. The feed trough should be 18 inches wide and at least 6 inches deep, with the front high enough to prevent feed from being pushed out of it.

The gutter or drop should be constructed of cement. Wood or earth gutters cannot be kept clean and free from odor. The gutter should be $\mathbf{1 6}$ to 18 inches wide, with an average depth of 8 inches below the level of the platform. It should be deeper at one end than at the other, to give the bottom sufficient slope for drainage, or the entire floor may be sloped and the depth of the gutter remain the same. Sometimes the floor back of the platforms is laid on a level with the bottom of the gutter or $\mathbf{2}$ or 3 inches above it, thus removing the back wall of the gutter entirely or making it 4 or 5 inches lower than the front wall. This has the advantage of permitting the sun to shine into the gutter when there are windows in the rear of the cows, but it also increases the likelihood of manure being splashed upon the wall; when the back wall of the gutter is lacking entirely there is a tendency for the hind feet of cows to slip backward when they are stepping up onto the platform. Plenty of litter should be kept in the gutter to absorb the urine and thus prevent it from being splashed by droppings or by the cow's tail when the animal is lying down and switching at flies. The floor of the gutter sometimes has a $3 / 4$ inch slope from the front to the rear with the object of raising the toe and increasing the tension upon the posterior tendons when cows stand down in the gutter, the intention being to make the position uncomfortable, but this construction does not always have the desired effect. 
Ties or Stanchions.-From a sanitary standpoint, stanchions or jacks are better than chains because they are more likely to hold the cow in the proper place in the stall to cause the manure to be dropped into the gutter, thus assisting indirectly in keeping the cows clean. The swinging chain-stanchion is also quite comfortable. The best material for stanchions and their supports is metal piping.

Stall divisions help to keep the cow in place and thus assist in keeping the platform and the cow clean; they also prevent the cow from treading on the udder or teats of a neighboring cow. Solid, board partitions, extending from the floor upward, are objectionable because they increase the difficulty of keeping the stable clean and interfere with the circulation of air; they may also be in the way of the milker. Wood fittings with flat surfaces and cracks are not as easily kept clean as round, smooth surfaces, and the cracks make disinfection more difficult. Stall divisions consisting of a single piece of metal pipe, extending in a curve from the front post of the stall to the rear of the platform, with a radius of 3 feet, are not open to these objections.

Arrangement of the Stalls.-When stalls in a stable are placed in two rows, they are arranged with the cows in one row facing those in the other, with the feed alley in the centre between the mangers, and a passageway in the rear between the manure gutter and the side wall; or, the stalls are arranged with the cows in each row facing outward toward the side walls, with a feed alley in front of each row between the manger and the wall and a passageway extending through the middle of the stable between the two rows of cows. Both plans have advantages and disadvantages. When the cows stand facing a 
central feed alley, feeding is facilitated and, if there are windows in the side walls, the posterior part of the cow is in the lightest part of the stable, which is a convenience in cleaning the cow and in milking; but the spread of infection is favored because material coughed out by one cow may be deposited in the feed trough of the cow standing opposite in the other row. With the cows facing outward toward the side walls, the cleansing of the stable and the removal of the manure is facilitated and there is less exposure to infection by coughing, but the cleaning of the cow and the milking must be done in the darkest part of the stable and the milk must also be carried between the two rows of cows and is thus exposed to external contamination, especially in the fly season when the cows frequently switch their tails.

Maternity and hospital stalls should be provided in another part of the building or in another building. If there are not special stalls for these purposes, cows with vaginal discharge from retained placenta and with other pathological excretions will be stabled in the milking line and may infect the milk indirectly.

(d) Light.-The cow stable should receive sufficient daylight to make it possible to read ordinary newspaper print in the middle of it. This much light is necessary for the cleaning and the milking of the cows to receive proper attention. Nearly all of the work which must be done in a cow stable can be done better and easier in the light than in the dark. The admission of sunlight into a stable is beneficial in several respects. It lights the stable and exposes dirt, thus assisting in keeping the stable and cows clean; it facilitates careful milking; assists in drying out the stable; supplies some warmth to the stable in winter, and has a disinfectant action. The germicidal 
effect of sunlight is not fully appreciated. Experiments with artificial cultures of various bacteria have shown that direct sunlight is very destructive to germ life, while the action of diffused light, although less powerful, is also quite effective. Tubercle bacilli are killed by direct sunlight in a few hours, while even diffused daylight destroys them in a few days (Koch). Direct sunlight kills anthrax spores in five hours and the bacilli in thirty hours, spores being more susceptible to sunlight than bacilli (Arloing, Roux). Direct sunlight destroys or decreases the virulence of colon bacilli, the bacilli of fowl cholera and swine erysipelas, and the virus of hog cholera, while diffuse daylight also exerts a similar but less powerful action (Neumark).

The inspector should note the location and size of the windows and determine the total square feet of window surface. He should also observe whether the

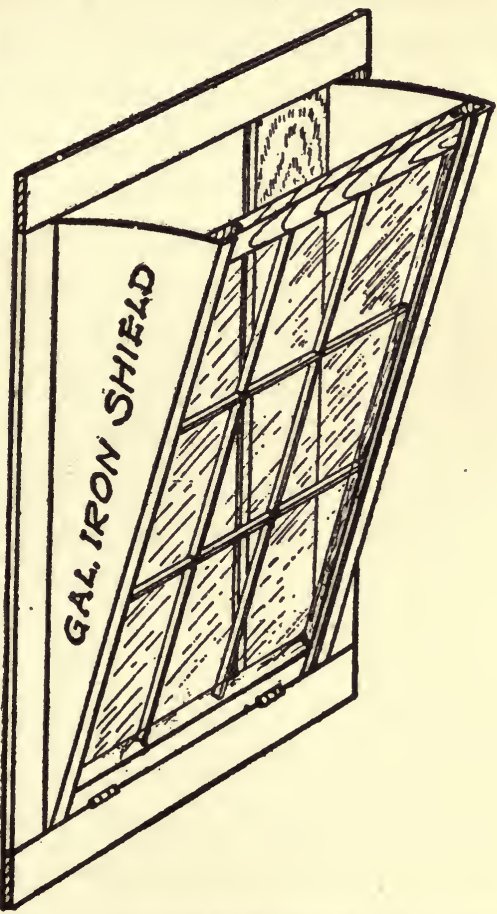

Fig. 12.-Window arranged to act as a fresh air inlet (Wis. Exp. Sta. Bull. No. 266). glass is clean and if other buildings obstruct the entrance of light. Three to four square feet of window surface for each cow will usually admit sufficient light, provided the windows are properly placed and equally distributed. In cold climates, an excess of window surface may increase the radiation of heat to such an 
extent as to interfere with ventilation; this can be avoided by constructing double windows, with an air space between. Where cows stand in a double row, a row of windows along each side of the barn is very desirable. The windows may be hinged at the bottom and arranged to open and close by turning a continuous rod; or they may be unattached, as many prefer, and merely rest in a groove in the window sill, being held in place by a peg near the top. If the windows are to be used as inlets for ventilation, the openings formed at either side when the sash is inclined inward at the top should be closed by boards or galvanized iron strips extending inward from the window frame on each side. The galvanized iron shields prevent the wind from entering at the sides and blowing directly upon the cattle (see Fig. 12).

The arrangements for artificial lighting should be noted. These are rather important, for much of the work in the stable in winter is done before and after daylight.

\section{COWS}

The examination of the cow is one of the most important parts of dairy inspection. If the cows are not in the stable at the time of the inspector's visit and if it is not convenient to bring them in, this part of the inspection should be made at a more opportune time, but the inspection of the dairy should not be regarded as completed until the cows are examined. No attempt should be made to examine the cows while they are running free in the pasture or exercise lot, unless each one can be readily caught and handled.

1. Examination for Cleanliness.-Observe the condition of the cows with regard to cleanliness, especially the con- 
dition of the flanks and udder. The condition of the cows in this respect is usually an indication of the care they receive and of the efforts made to keep the milk clean. It is not necessary for the inspector to be present when the work is done in order to determine if the cows are regularly cleaned. When cows are regularly groomed, the posterior quarters are comparatively free from dried manure and the hair coat is smooth and somewhat glossy. The hair is also shorter and thinner than on cows which are not regularly brushed. Clipping the hair short on the udder, flanks, buttocks, and tail, and cutting three or four inches off the switch if it touches the floor, is of great assistance in keeping the cows clean, and evidence of clipping is an indication that the cows are regularly groomed. Exfoliations from the skin and particles of dirt are likely to collect in the hollows about the root of the tail and their presence in any great quantity points to carelessness or neglect in cleaning. Fresh manure on the buttocks (point of ischium) is not necessarily an indication that the cow was not properly cleaned. These parts are readily soiled if, during defecation, the tail is pressed down on the fæces and is subsequently moved from side to side.

2. Stage of Lactation.-Examination and inquiry should be made regarding the stage of lactation. The daily milk record, if available, will be of great assistance in discovering cows near the end of lactation. When the milk flow has decreased to a quart ( 2 pounds) a day or less, the milk is likely to have a salty taste or a strong, cow-like odor and taste, and in many cases the cream will not " butter." Such cows should be " dried off." The secretion of fresh cows should be examined for the characteristics of colostrum. 
3. Examination for Symptoms of Disease.-This examination consists of two parts: (a) General examination and $(b)$ special examination.

(a) GENERAL EXAMINATION

The general examination is made first, with the cow in the stall. Taking a position in the rear and slightly to one side, the inspector proceeds with the examination in the following order:

1. Attitude.-Note the general appearance, the carriage of the head, position of the ears (erect or hanging), standing position, behavior (quiet or restless).

Dullness or depression from fever, also weakness and pain may be discovered in this way. Very sick animals and those with a high fever usually hold the head low, with the ears drooping. In severe vaginitis and metritis, and sometimes in constipation and colic, cows stand with the back arched, head lowered, tail elevated, and legs spread apart. Sometimes cows affected with vaginitis stand a long time in the attitude of urination. An arched back and erect hair, in association with shivering and a cold skin are symptoms of fever, although they are not constant. In dyspnoa and sore throat the head is extended. Pain causes restlessness; soreness of the extremities is indicated by resting the affected limb, or, when more than one limb is affected, by continually shifting the body weight from one leg to another. Cows often lie down during the day, especially after eating, and do not rise on the approach of man; therefore, a recumbent position is of less significance with these animals than in the case of the horse. A disposition to lie down continually may be due to erticular rheumatism or to osteomalacia. Inability to rise is caused by paralysis (spinal fractures), milk fever, and ante and postpartum paralysis. Sometimes refusal to rise is due to stubbornness.

2. Skin and Hair.-Observe the condition of the skin and hair and look for swellings, enlargements and irregularities of form. 
Rough, bristling, lustreless hair and a dry, stiff skin (hidebound) indicates unthriftiness or lack of condition, which may be due to disease or improper care. In stables in which the cows are regularly groomed, fresh cows, especially heifers with the first calf, may appear rough and thin in comparison with the other cows for a week or two after they are placed in the milk stable. This condition is due to the effects of parturition and to not being regularly groomed previously; it must not be confused with unthriftiness. When associated with a good appetite, unthriftiness and progressive emaciation are indications of chronic disease, frequently of tuberculosis. Emaciation, however, may be due to old age. Mere thinness must not be mistaken for unthriftiness or emaciation; heavy milking cows are often thin. The condition of the skin and hair is a better indication of the actual physical condition than the degree of fleshiness or leanness.

Swellings may occur in or beneath the skin (local inflammations, œdemas, abscesses, enlarged lymph glands, actinomycosis, etc.) and suppurating wounds may involve the skin and subcutaneous structures. Distension of the left side of the abdomen occurs in impaction and tympanites of the rumen.

3. Vulva, Anus, and Tail.-These should be examined for evidences of pathological discharges. Diseases of the uterus, vagina, and digestive tract may be discovered in this way. There are certain normal discharges from the vulva which must not be mistaken for pathological discharges. A small amount of glassy mucous, frequently blood-stained, is discharged during œstrum; a bloody or grayish albuminous discharge is sometimes seen after breeding, while near the end of pregnancy there is usually observed a glassy mucous discharge which is often of a red color.

A foul, chocolate-colored or reddish fluid containing fragments of tissue is discharged from the vulva following retention of the placenta. In metritis and vaginitis the discharge is either 
colorless or yellow, red or chocolate color, thin at first and gradually becoming thicker. In chronic metritis the discharge is white, sticky, and odorless, or muco-purulent, purulent, or chocolate-colored and foul-smelling. A slight purulent discharge occurs in tuberculosis of the uterus. When the discharge is slight it may be observed only when the cow lies down or its presence may be indicated only by a soiled condition of the tail. The vulva is swollen in metritis and in puerperal septicæmia. In tuberculosis of the uterus the vulva is flabby and the broad ligaments are relaxed and sunken. Relaxation of the broad ligaments also occurs in ovarian disease and frequently in aged cows.

If defecation does not occur during the examination the character of the bowel discharges may be determined by examining the manure in the gutter or drop and by observing the condition of the tail and buttocks. Soft bowel discharges, if general, may indicate a sudden change in feed, overfeeding, or the feeding of spoiled feed, as well as disease. Dry, hard fæces, often of a darker color than normal, are seen in constipation and in severe febrile disease; soft or semi-fluid fæces in intestinal catarrh, advanced tuberculosis of the mesenteric lymph glands, pseudo-tuberculosis or Johne's disease and enteritis ; red, chocolate-colored or black fæces in hemorrhagic enteritis and dysentery. Blood is present in streaks or clots in hemorrhage of the rectum and bloody discharges occur in anthrax. Coarse particles of food in the fæces indicate disturbance of rumination in consequence of impaction, torpidity, or paralysis of the rumen.

4. Respiration. - The rate, rhythm, intensity, and character of the respiratory movements can be determined by observing the movement of the flanks.

Rapid breathing is often seen in advanced pulmonary tuberculosis, but it is not a constant symptom. The rate of respiration is increased in other diseases of the respiratory tract, in fever and in painful conditions. An increase in the respiratory rate occurs also immediately after eating, after exercise, and in hot weather. Increase in the intensity or depth of the respira- 
tory movements is a symptom of disease, except when it occurs after exercise. A decrease in the intensity or depth (shallow respiration) is observed in pleurisy and in painful conditions of the chest wall.

5. Udder.-Examine the udder by inspection. This can be done best when the udder is full. Compare the form and size of the different quarters. Look for swelling (mastitis), atrophy, furuncles (feed boils), alterations of cowpox, etc.

6. Appetite.-Look into the manger and see if the feed has been eaten and note if the animal is ruminating.

7. Muzzle and Nostrils.-Touch the muzzle and determine the degree of temperature and moisture. Examine the nostrils for pathological discharges.

The muzzle is dry and sometimes roughened in fever and diarrhoea. It is alternately hot and cold in fever, and cold and dry in low conditions endangering life. Vesicles occur on the muzzle in foot and mouth disease.

A discharge from the nostrils occurs in exudative diseases of the respiratory tract, but in tuberculosis the discharge is frequently not present because the exudate is usually coughed up and swallowed. A nasal discharge may escape notice in cattle because it is generally licked off with the tongue. It is most likely to be seen after coughing. A slight mucous discharge is normal.

8. Submaxillary and Peripharyngeal Regions.-Attempt to palpate the submaxillary, parotid, retropharyngeal and atlantal lymph glands; they cannot be felt unless enlarged.

The submaxillary lymph-gland is situated within the posterior angle of the lower jaw, between the sternocephalicus (sternomaxillaris) muscle and the submaxillary salivary gland. 
The subparotid lymph-gland is about $21 / 2$ inches long, flat and tongue-like in form and is located just under the anterior border of the parotid salivary gland and about 3 inches below the base of the ear. In feeling for this gland press the finger inward and backward in the groove between the posterior border of the lower jaw and the parotid salivary gland.

The retropharyngeal lymph-gland, also called the pharyngeal and superior pharyngeal, is about 2 inches long and is situated on the posterior wall of the pharynx. It can be palpated, when enlarged, by pressing the extended fingers inward from each side toward the median line and as far forward as possible between the muscles of the neck and the larynx.

The atlantal or posterior retropharyngeal lymph-gland is situated under the wing of the atlas, partly covered by the upper end of the submaxillary salivary gland. By pressing the fingers inward and upward under the wing of the atlas this gland is forced against the under surface of the wing of the atlas.

When any of these glands in cattle are enlarged and firm and not hot or painful, tuberculosis is usually present. Enlargement of the retropharyngeal glands may interfere with swallowing and respiration.

Actinomycotic tumors may be observed in the submaxillary and peripharyngeal regions as well as in the maxillæ and tongue.

9. Cough.-Test each cow for cough by exerting pressure with the fingers on the larynx or first three rings of the trachea, or close both nostrils for about a minute; also grasp the skin over the withers with the fingers of both hands and draw it upward. Take note of any coughing which occurs spontaneously and identify the cow each time.

A frequent, chronic cough is one of the most prominent symptoms of pulmonary tuberculosis. If a cow can be made to cough by pinching the larynx or the adjoining rings of the trachea, or by closing the nostrils, it is an indication of disease of the respiratory tract. Cough can usually be induced in this 
way in advanced tuberculosis of the lungs; if the cough is low, weak, and moist, it is especially suspicious. Old cows are not infrequently affected with pulmonary emphysema, and a short, dry cough may be readily induced in such animals; but even a cough of this character is suspicious of tuberculosis. A cow in health may cough as a result of inhaling dust, cold air, or irritating gases, but the cough is not frequent or chronic. Cough in cattle is softer, hollow (toneless), and more prolonged than in the horse.

If drawing the skin up over the withers produces cough, it is an indication of an irritated condition of the lungs or pleura.

10. Lungs. - The lungs should be examined by auscultation. In doubtful cases, closing the nostrils for a short time or exercise will render the sounds more audible.

Exaggeration of the vesicular murmur (when not due to exercise) and the presence of the bronchial sound, râles, or vague sounds are evidences of disease of the bronchi or lungs. Friction sounds occur in pleuritis (fibrinous). In tuberculosis, especially after exercise, the vesicular murmur may be exaggerated and rough, and râles and vague sounds may be heard. The disease may exist, however, when no abnormal sounds can be detected. In old cows sibilant râles may be heard because of the presence of pulmonary emphysema.

11. Prescapular and Precrural Lymph-glands.The precrural glands can be palpated whether normal or enlarged, but the prescapular glands cannot be felt unless they are enlarged.

The prescapular lymph-gland, also called the superficial cervical, is situated beneath a layer of muscular tissue at the anterior border of the shoulder, a little above the shoulder joint.

The precrural lymph-gland is situated in the flank, just under the skin, at the anterior border of the tensor fasciæ 
latæ muscle. Normally, it is about 1 inch in width and 4 to 6 inches long.

When these glands are enlarged, firm and not hot or painful, they are usually tuberculous. The lymph-glands are also enlarged in leukæmia and pseudoleukæmia, but in these diseases all of the superficial lymph-glands on both sides of the body are similarly affected.

12. Complete the Examination of the Udder and Examine the Supramammary Lymph-glands.-Inspect the skin of the udder and teats for furuncles, ulcers, symptoms of cowpox, etc. Inspect the opening of the teat canal for scabs.

Palpate the udder. This is done most satisfactorily when the udder is empty. Beginning with the inferior extremity of the teat and passing upward, palpate successively the teat canal, the milk cistern, the gland tissue and the supramammary lymph-glands. Note the temperature of the parts and look for symptoms of acute inflammation, induration, and nodules. By rolling the teat between the fingers, thickening of the mucous membrane of the cistern and nodular formations in the walls of the cistern and teat canal can be detected. In palpating the udder, pass one hand up between the two halves of the organ, place the other hand on the external surface and then, beginning at the posterior or anterior extremity, slowly work the udder tissue between the fingers, searching for indurations, retention cysts, etc.

Draw milk from each quarter into the palm of the hand and examine it for color, consistency, flakes, clots, etc. In doubtful cases collect a sample for further examination. Press the end of the teat to see if any mucus or pus can be squeezed out of the teat canal. Observe if there is any difficulty in expressing the milk from 
the teat and if the stream is split or deflected from the normal direction.

Palpate the supramammary lymph-glands. Standing in the rear of the cow, press the hand forward along the upper and posterior margin of the udder, with the thumb on one side of the median line and the fingers on the other, and grasp the glands by bringing the fingers and thumb together. Ordinarily, these glands are about 2 inches in diameter, but in heavy milkers they may be larger.

Pronounced swelling, excessive heat, and pain in one or more quarters of the udder, with marked changes in the milk, are symptoms of parenchymatous mastitis.

Firm nodules which are neither hot nor painful, or a rather diffuse induration which is painless and without heat, in one or both posterior quarters, with enlargement of the supramammary lymph-glands, are symptoms of tuberculosis of the udder. There is no apparent alteration of the milk during the first stages of the disease. Indurated areas of greater or less extent result also from parenchymatous and catarrhal mastitis, but they are not accompanied by enlargement of the lymph-glands, except in the acute stage.

Enlargement of the supramammary lymph-glands is associated with tuberculosis of the udder and also occurs during acute mastitis. These glands may be enlarged as a result of tuberculous infection when no symptoms of the disease are apparent in the udder.

Difficulty in expressing milk from the teat and deflection or division of the milk stream are early symptoms of catarrhal mastitis. If pus or mucus can be squeezed out of the teat canal, catarrhal mastitis is present. A scab may be found over the opening of the teat canal when this disease exists, although clots or flakes of dried milk are sometimes present when the udder is normal except for some defect in the sphincter apparatus of the teat. The milk may appear unaltered or show only slight changes when these symptoms are present. 
A thick cord-like induration, about the thickness of a lead pencil, extending vertically through the middle of the teat, is a symptom of catarrhal mastitis; also nodular indurations in the walls of the teat canal and milk cistern. Only slight alterations may be present in the milk, or none at all.

Atrophy is usually a symptom of an existing or previously existing catarrhal mastitis. Milk from the affected quarter may contain the organism responsible for the condition even when it shows no perceptible changes.

(For the changes in milk occurring during udder disease see pages 105-110.)

Firm, nodular swellings, not hot or painful, situated in the superficial parts of the udder tissue, which are not movable and which can be reduced by strong pressure, are retention cysts, formed by the blocking of the milk ducts.

\section{(b) SPECIAL EXAMINATION}

The character of the special examination will depend upon the information obtained during the general examination.

If fever is suspected the temperature should be taken with a thermometer and an examination made for the other symptoms of fever (chill; irregularity of the surface temperature, especially of the extremities; acceleraation of the pulse and respiration, loss of appetite, depression, albuminuria). In cattle the increase in temperature as shown by the thermometer does not always correspond to the degree of fever indicated by the other symptoms.

When thoracic disease is suspected the chest wall should be percussed. Areas of hepatization and solidification may thus be discovered. The area of the lungs of cattle which can be percussed is limited, however, and unfortunately tubercular solidifications usually occur below this area. Percussion may reveal painful conditions of the lungs and pleura and may also produce cough. 
If tuberculosis of the uterus is suspected, the subsacral, sublumbar and internal inguinal lymph-glands should be palpated per rectum. These glands are enlarged, firm, and often nodular when the uterus is tuberculous. The mesenteric lymph-glands can also be examined in the same manner.

Further information regarding internal conditions can be obtained by examining the sclerotic conjunctiva and the mucous membrane of the cheeks. These membranes are pale in tuberculosis and in other chronic debilitating conditions which lead to anæmia and hydræmia; bluish-red (cyanotic) in febrile, respiratory, and cardiac diseases and in conditions which interfere with the entrance of air into the lungs; brick-red to dark red, with the blood-vessels injected, in hyperæmia and inflammation of the brain and in conditions which interfere with the return of venous blood from the head to the heart (pulmonary emphysema, organic heart disease and cardiac weakness); ecchymotic in anthrax, severe anæmia and pernicious anæmia, and yellow in icterus.

When symptoms suspicious of tuberculosis are present and no definite conclusion can be reached, the cow should be tested with tuberculin.

When catarrhal mastitis is suspected and a definite diagnosis cannot be made, the milk should be examined by the catalase, leucocyte, or alcohol tests and microscopically, for streptococci.

\section{STABLE PRACTICES}

Attention should be given to the manner in which the stable is cleaned, when and how the cows are cleaned, the methods of milking and of caring for the milk, the time of feeding, character of the feed, and when the litter is put down and the material used. 
1. Method of Cleaning the Stable.-If manure is allowed to collect in the stable the cows will become soiled and odors of decomposing manure and urine will permeate the stable air and may be absorbed by the milk. The manure should be removed twice daily if possible, being taken out before each milking. It is necessary to complete this work at least an hour before the cows are milked in order to allow time for the air to become free from dust and odor before milking is begun. When the cows must be milked very early in the morning it is not always practicable to get the manure out of the stable an hour before milking time, and in such cases it is better to remove it after the cows are milked and fed. Milk of good quality can be produced under these conditions. If the manure is not hauled immediately to the fields, it should be stored as far away from the stable as possible. The stable and its immediate surroundings should be kept as free as possible from manure and other decaying organic matter because flies breed in such material. Houseflies may travel considerable distances from where they breed, flights of one-quarter to nearly a mile having been observed, but, as they seem to be attracted by odors, keeping the stable clean will in a measure serve as a protection when flies are permitted to breed in the neighborhood.

After the manure has been taken out, the litter on the rear end of the platform, which is usually soiled, should be swept into the gutter and given an opportunity to absorb any liquid which may be present. When the cows have been cleaned, the rear end of the platforms and the floor back of the gutter should be sprinkled with water and swept clean. In some stables the platforms and floors are again sprinkled after sweeping. This is 
done to keep the atmosphere as free from dust as possible. In other stables land plaster is spread in a thin layer on the floor and in the gutter to act as an absorbent. This is especially desirable when the floor is of wood or earth. The use of land plaster also seems to have the effect of reducing the number of flies. Although the inspector cannot be present during all of these operations, he can make a fairly accurate estimate of how thoroughly the work is done by observing the condition of the stable at the time of his visit. Dirt which has been permitted to remain for some time can be easily distinguished from fresh dirt. The wall in the rear of the cows and the corners formed where the walls, posts, and stall divisions join the floor should be especially examined. The presence of cobwebs on the walls, ceiling, or other places is an evidence of infrequent sweeping.

Flies.-The presence of flies in large numbers in and about a cow stable is objectionable for several reasons. The flies worry the cows and reduce the milk production, while the movements of the cows in their efforts to protect themselves from the insects interfere with milking and are also likely to dislodge dirt from the body of the cow; some of this dirt may fall into the milk pail. The common house-fly (Musca domestica) is especially objectionable. It feeds upon all kinds of organic matter, including human excrement, and becomes contaminated with numerous bacteria. A single fly may carry over a million germs on the surface of its body. When it feeds upon milk or crawls or falls into milk vessels, many of these bacteria are transferred to the milk. Typhoid bacilli may be carried from infected fecal matter to milk in this way. The small, black cowfly or horn-fly (Hematobia serrata, Lyperosia irritans L.) and the stable-fly or biting-fly (Stomoxys calcitrans) disturb the cow more than the house-fly, because they are biting or bloodsucking insects; but they do not as a rule invade the milk vessels or the milk. 
Various methods are used to reduce the number of flies in cow stables and in milk-houses. The cows are sprayed or brushed with mixtures of drugs or chemicals known as fly repellents. Sometimes sheets of fly-paper are placed about the buildings. Milk-houses are very often screened and more rarely stables are also screened. Fly repellents are only temporary in their action and they are often objectionable on account of their odor. Fly-paper is unsightly and inefficient. Fly-traps are more useful. Screening milk-houses gives good results and is desirable in all cases, but screening stables is not satisfactory. Since the doors must be opened frequently and sometimes for long periods to remove manure, to take in the feed, and to drive the cows in and out, there is abundant opportunity for flies to enter. The cow-fly or horn-fly is carried in on the cows. All of these methods are fundamentally defective because none of them prevents the breeding of flies. The most rational method of attacking the fly problem is to remove or abolish, in so far as is possible, the conditions which favor the development of the insects. To do this intelligently it is necessary to consider their habits and life history.

Three varieties of flies are commonly found in cow stables: the common house-fly, the cow-fly or horn-fly, and the stablefly or biting-fly. The house-fly and cow-fly are usually the most numerous, but in some sections of the country, especially in the grain belt, the stable-fly is present in large numbers. The different varieties can usually be distinguished by the part of the cow which they occupy and by their sitting position. The small, black cow-fly is generally located upon the back and sides of the cow, and in rainy weather on the under parts of the body, sitting with the head downward. The stable-fly usually occupies the lower parts of the legs and nearly always sits with the head upward, while the house-fly may be found on any part of the cow and may sit in any position, but never with the head pressed into the hair as though feeding. The stable-fly is about the same size as the house-fly but has a more plump appearance and has longitudinal lines on the thorax and several dark spots on the abdomen. The horn-fly is smaller and black.

The house-fly seems to prefer to deposit its eggs in horse 
manure, but when this is not available the eggs are deposited in other organic material. The heat generated by the decomposition processes which occur in such material hatches the larvæ or maggots from the eggs in one day. The larvæ develop into pupæ in 4 to 5 days and flies emerge 3 to 4 days later. The time from the egg to the fly is 8 to 10 days.

It is recommended that manure be removed to the fields at intervals of seven days or less to prevent the development of the flies, but this plan will be effective only when the manure is stored in a receptacle which has a tight bottom, because the larvæ or maggots frequently burrow into the earth to pupate. The larvæ also bury themselves in the same manner in an earth stable floor. This propensity of the larvæ to migrate has been made use of to trap them by Hutchinson, who constructed a trap consisting of a raised platform with a shallow cement tank beneath it. The platform is made of wood strips $11 / 4$ inches thick and 1 inch wide, laid 1 inch apart. The manure is piled compactly on the platform, each day's addition being moistened with water. When the larvæ are hatched they migrate downward and fall through the spaces in the platform into the water in the tank below, where they are drowned.

Numerous experiments have been made to discover a substance which when mixed with horse manure would destroy the larvæ of the house-fly without affecting the fertilizing value of the manure. Naturally, the chemical fertilizers were tested, but it was found that acid phosphate and ground phosphate rock will not kill the larvæ, while kainit ( $\mathrm{KCl}$ and $\mathrm{MgSO}_{4}$ ) possesses only slight larvæcidal action. In several experiments, Cook and Hutchinson found that calcium cyanamid $\left(\mathrm{CaCN}_{2}\right)$, a substance frequently incorporated in commercial fertilizers to furnish nitrogen, apparently destroyed about 98 per cent. of the larvæ when applied to manure at the rate of $1 / 2$ pound to the bushel with an equal quantity of acid phosphate. The cost of this treatment is 1.8 cents per bushel of manure, but the fertilizing value of the manure is considerably increased, so that the actual cost is much less. A portion of the acid phosphate may be replaced with kainit without affecting the larvæcidal effect and the mixture will then contain all the essential elements of plant food. Unfortunately, calcium cyanamid can be purchased only in car- 
load lots at the present time, but if a demand is created it will no doubt be available in smaller quantities. In the commercial fertilizers it is usually converted into urea, ammonia, etc. Of the various substances tested, the most satisfactory results were obtained with powdered hellebore and borax. One-half pound of powdered hellebore is mixed with 10 gallons of water and allowed to stand 24 hours. This quantity is sufficient to treat 10 cubic feet ( 8 bushels) of manure, being applied with a sprinkler. The borax is applied with a flour-sifter, especially around the edges of the manure heap, and water is then sprinkled over it; about 1 ounce of borax and $21 / 2$ to 3 quarts of water are used to each cubic foot of manure. Floors, crevices, and refuse may be treated in the same manner with either hellebore or borax. Borax is perhaps a little more effective as a larvæcide than hellebore, but the latter is not at all injurious to the manure nor to crops while borax in excessive quantity interferes with plant growth. Manure treated with borax as above may be applied in any quantity up to 15 tons per acre without injuring the crops, except in the case of leguminous plants. When boraxtreated manure is used to grow leguminous plants, it should be mixed with untreated manure. The effect of the repeated application of borax-treated manure has not been determined. The cost of treating manure with powdered hellebore is a little over $1 / 2$ cent per bushel, while the expense of the borax treatment is a little less than $1 / 2$ cent per bushel.

The corv-fly or horn-fly lays its eggs in fresh cow manure. The larvæ are hatched in 24 hours and develop into pupæ in 5 days. The pupæ burrow into the ground and flies emerge in 8 days, the time from the egg to the fly being 14 days.

These flies feed upon the blood of the cow and are therefore not likely to get into the milk or milk vessels. In biting through the skin of the cow to obtain food, they cause the animal considerable discomfort. When driven off the body of the cow, they fly only a short distance away and then immediately return, so that, while feeding, they are a continual torment.

Fly repellents are used to protect the cow from the attacks of these insects. A mixture of one part of oil of tar and nine parts of cotton-seed oil or crude Beaumont oil, applied daily 
with a spray pump or syringe, is an effective and safe repellent. The following mixture, it is claimed, will act effectively for one week: Soap, 1 pound; water, 4 gallons; crude petroleum, 1 gallon, and powdered naphthalene, 4 ounces. The soap is shaved into thin slices and dissolved in the water by heating; the naphthalene is dissolved in the crude oil. The two solutions are mixed by stirring vigorously or churning for 15 minutes. The mixture is stirred thoroughly each time before using and is applied to the cows with a brush once or twice weekly. While fly repellents afford the cow temporary relief from the biting flies, they are of no value in the control or eradication of the flies. Hellebore and borax have not been tested on the larvæ of the cow-fly, but it is very probable that they would be as destructive to these larvæ as to those of the house-fly.

When cows are kept in the stable, with occasional liberty in an exercise yard, the breeding of cow-flies can be prevented by removing the manure from the stable and yard to the fields daily, or if it is stored in the vicinity of the stable, by removing it to the fields at intervals of not less than 12 days, provided the floor of the stable and the floor of the dung-stead are so constructed that the pupæ cannot burrow into the ground. When cows are pastured it is not practicable to control the breeding of cow-flies. The manure dropped in the pasture furnishes ideal breeding conditions. When the flies emerge they take up a position on the body of the cow, where they feed and rest, and are carried into the stable by the cow.

The stable-fly breeds in horse manure and in decaying grass and straw heaps; also in cow droppings which have become dry and disintegrated, and in ensilage. Eggs deposited in these substances hatch out larvæ in 1 to 3 days. The larvæ develop into pupæ in 11 to 30 days or more, and the flies emerge in 6 to 20 days, the time from the egg to the fly being 18 to 53 days and upwards. The stable-fly feeds on the blood of cows and other domestic animals, and also bites man. Unlike the house-fly, it is not likely to infect milk with bacteria, since it does not feed upon that substance. 
2. Cleaning the Cores.-The body surface of the cow may be soiled with dirt and manure when the animal lies down, dust settles on the skin from the air, and dead epidermal cells and hair are cast off from the skin. This material is very rich in bacteria and, if not removed, some of it will be dislodged during milking and may fall into the milk pail. The manure contains numerous gas-forming and putrefactive bacteria and is therefore especially objectionable. Dry dirt and manure should be loosened with a curry-comb and then brushed out with a stiff brush, which will also remove loose hairs and epidermal cells. If the dirt or manure is not dry it must be washed off with a clean cloth and water. The addition of 1 to 2 per cent. of washing soda (a Mason jar lid full to a 12 quart bucket) is of great assistance. White hair is likely to show a stain after the dirt has been washed off and this must not be mistaken for dirt. No dust can be rubbed out of an area that is only stained. In cleaning the cows special attention should be given to the udder, flanks, external surface of the thighs and the switch. In some dairies the switch is washed at short intervals. Keeping the hair clipped short on these parts and on the buttocks will facilitate the work of cleaning. It is advisable to have the switch clear the ground by about 4 inches, but there is some objection to cutting the switch of pure-bred cows.

After the udder has been brushed dry it should be wiped with a damp cloth. The cloth and water should be clean at the start and the water should be changed as soon as it becomes soiled. Ordinarily, a bucket of clean water is required for every eight cows. In high-class dairies a small damp towel is used for each cow; each towel is used only once and is then washed and sterilized. 
The brushing should be finished a half hour before milking, to allow time for the dust to settle from the air of the stable, but the udder should be wiped just before milking is begun. If the udder is brushed immediately before milking the number of bacteria in the milk will be about doubled. The practice indulged in by some milkers of attempting to clean the udder by wiping it with the hand after sitting down to milk is not a good one, as it dislodges a lot of loose hair, epithelial cells and particles of dirt which may fall into the milk pail. The purpose in wiping the udder with a damp cloth is to moisten any loose dirt, hair, etc., that may remain after brushing and thus prevent these particles from falling into the milk.

The number of bacteria dislodged from apparently clean udders by the process of milking is reduced about two-thirds by dampening the surface of the udder. Too much water should not be used, as any excess will run off the end of the teat and may drop into the milk pail, while, in winter, the exposure of a wet udder to cold air is very likely to cause congestion and cracking of the skin, especially at the base of the teats and on the teats, and may also cause catarrhal mastitis. Washing the udder, unless it is afterward rubbed dry, is not as effective in keeping dirt and bacteria out of milk as is wiping it with a damp cloth after dry brushing. The best results are obtained by wiping the udder with a cloth dampened with a 2 per cent. solution of washing soda after it has been cleaned by brushing, and then anointing it with a small quantity of vaseline. As much vaseline as can be taken up on the end of the finger is rubbed over the palms of the hands, which are then passed lightly over the udder. This method takes less time than washing 
the udder, while the skin covering the teats remains soft and pliable and there is an entire absence of cracks and sores, even in winter.

It is sometimes stated that dampening or washing the udder irritates the skin, causing it to swell and crack, and that it decreases the milk flow, but this is not entirely correct. The udder will suffer no injury whatever unless too much water is used and the organ is exposed to cold air in a wet condition. There may be a decrease in the milk secretion when a cow is subjected to the process for the first time, but the milk flow returns to normal in a few days and very frequently it is increased. The massage which accompanies the brushing and the wiping or washing favors the flow of blood to the udder and usually increases the secretion of milk. Udders which are kept clean are affected with disease less frequently than dirty udders.

As a general rule, cows will produce more milk when kept clean and comfortable than when they are kept otherwise. Therefore cleaning the cows not only assists in keeping dirt and bacteria out of the milk but usually also increases the milk production. After the cows have been cleaned they should be fastened so that they cannot lie down before they are milked.

3. Methods of Milking. - The condition of the milker as regards health and cleanliness should receive the attention of the inspector. No one should be permitted to milk cows or handle milk in any way who is affected with any infectious disease, especially typhoid fever, diphtheria, and scarlet fever, or who has been in contact with persons affected with any of these diseases. Persons affected with tuberculosis, syphilis, severe diarrhœa, suppurating sores on exposed surfaces, or any throat 
disease should also be debarred from employment on a dairy farm.

The milker should have special clothing to wear while milking. Considerable dust and dirt collects on the outer surface of clothing worn while cleaning the cows and stable or in doing farmwork, especially if it is made of material with a soft, rough finish, and a good deal of this dirt may drop off into the milk pail during milking. A clean blouse, overalls, and a cap should therefore be put on before beginning to milk. These should be made of washable material with a smooth, hard, finish like duck, linen, or drilling. White linen or duck is best. One or two suits a week in winter and two or three in summer will be required in order to have a reasonably clean suit at all times. An apron or a pair of overalls with a bib is sometimes used because they are easier to put on and off; but they do not cover the shoulders and arms, the parts from which dirt is most likely to be dislodged in milking.

Before beginning to milk, the milker should wash his hands thoroughly, using soap, water and a nail brush, and dry them carefully with a clean towel. After doing so, he should not touch anything but the teats of the cow, milk pail, and milk stool. The inspector should note what facilities are provided for washing and drying the hands.

When the milking of a cow is finished, the pail should be carried to the weigh room and the milk weighed and emptied, the weight of the milk being recorded on the milk record opposite the name or number of the cow. In passing in the rear of the cows, the milk pail should be carried on the side of the body furthest away from the cows; covered-top pails should be carried with the open- 
ing on the opposite side from the body. This will protect the milk from contamination by cows switching the tail, splashing of manure or urine, and dirt falling from the clothing of the milker. The milker should wash his hands again before milking another cow and should dry them well on a clean towel. Small, individual towels, about $10 \times 10$ inches, which can be used once and then thrown aside for washing, are much more desirable than a large towel used in common by several milkers.

Soiled hands are a prolific source of bacteria in milk. As many as 45,000,000 bacteria have been found on one hand of a farm laborer. Washing and drying the hands will reduce the number of bacteria 75 per cent. or more, and also decrease the danger from chronic typhoid bacilli carriers. Experiments indicate that careful drying is quite as important as thorough washing, fewer organisms remaining after careful drying than when the hands are rinsed in an antiseptic solution after washing and are not carefully dried.

Milking should be done with dry hands. When the hands are wet the moisture assists in loosening the epidermal cells and dirt from the surface of the teat, and this material gradually moves down to the end of the teat and drops off into the milk pail. The practice of wetting the hands with milk when beginning to milk is to be condemned because this milk, after being mixed with the dirt on the teats, drops off into the pail.

Sometimes dairymen claim that it is sufficient to wash the hands before beginning to milk, saying that if the udders are clean the hands will not become soiled. This would be true if the udders were bacteriologically clean and if the milker did not touch anything but the clean teats of the udder. But the milker sometimes touches 
other parts of the cow in pushing or striking the animal to cause it to stand over in the stall and in protecting himself against a switching tail. In addition, the milk bucket is often rested on the floor and the bottom subsequently grasped in emptying it, thus soiling the fingers with material from the floor. The milking stool may be another source of contamination for the hands. It should

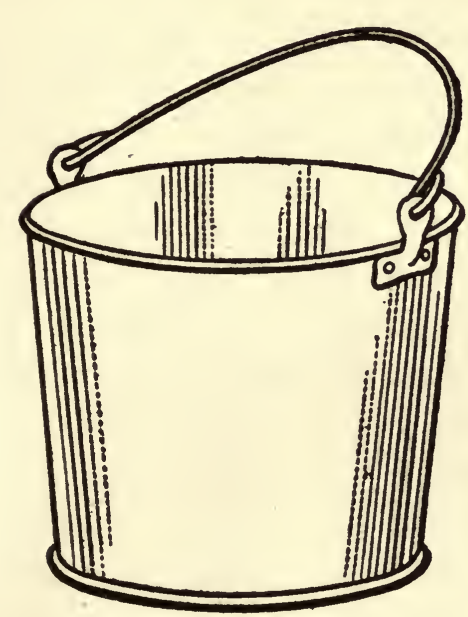

Fra. 13.-Open or uncovered pail.

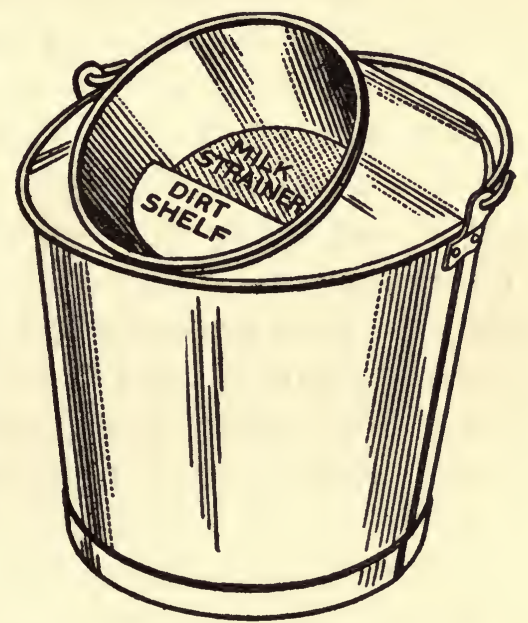

Fra. 14.-Covered-top pail with opening nearly horizontal (with strainer attached).

therefore be kept clean and it is best to use one made of metal.

The milk should be drawn without jerking the teats, as this dislodges dirt and bacteria which are liable to fall into the milk. "Stripping" the teats is also objectionable for the same reason. The first few streams of milk (fore-milk) from each quarter should be drawn into a separate vessel, as this milk washes out the milk cistern and teat canal and contains a greater number of bacteria than the milk subsequently drawn from the udder. The 
fore-milk from a normal udder usually contains from 0 to 500 bacteria per c.c., mostly udder cocci. Sometimes more may be present, but when the number exceeds 5000 per c.c. the udder is infested with mastitis organisms, usually streptococci. The fore-milk should not be milked out upon the floor or litter as this supplies conditions which are favorable to the growth of bacteria.

The type of milk pail has a very pronounced influence on the bacterial content of milk. The larger and more horizontal the opening of the pail the greater the opportunity for contamination. There are two types: The open or uncovered pail and the covered-top pail (Figs. 13, 14, and 15). The top of the open pail is entirely unprotected and is about 12 inches in diameter, while the covered-top pail has an opening only 7 inches in diameter, the remainder of the top being covered. The smaller opening, of course, offers much less opportunity for dirt to fall into the milk. It is more difficult to milk

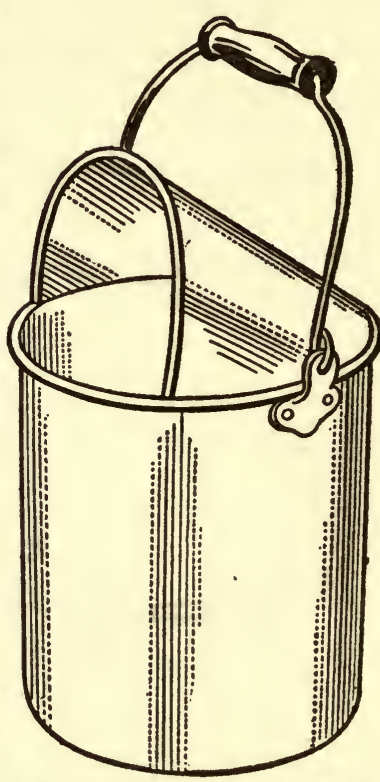

Fra. 15.-Covered-top pail with into the covered-top pail than into the open pail, especially at first, but this is largely overcome by practice. There are two varieties of covered-top pails: One with the opening vertical and protected by a hood and the other with the opening more or less horizontal (Figs. 14 and 15). The pail with the vertical opening is probably somewhat more difficult to milk into than the pail with the horizontal opening, but it affords a much greater 
protection against the contamination of the milk than the pail with the horizontal opening, even when the latter contains a cheese-cloth and wire-gauze strainer. Some varieties of pails in which strainers are used have a spout on the side so that they can be emptied without removing the strainer. There is one type of pail which has no opening in the top, but a spout extending from the side

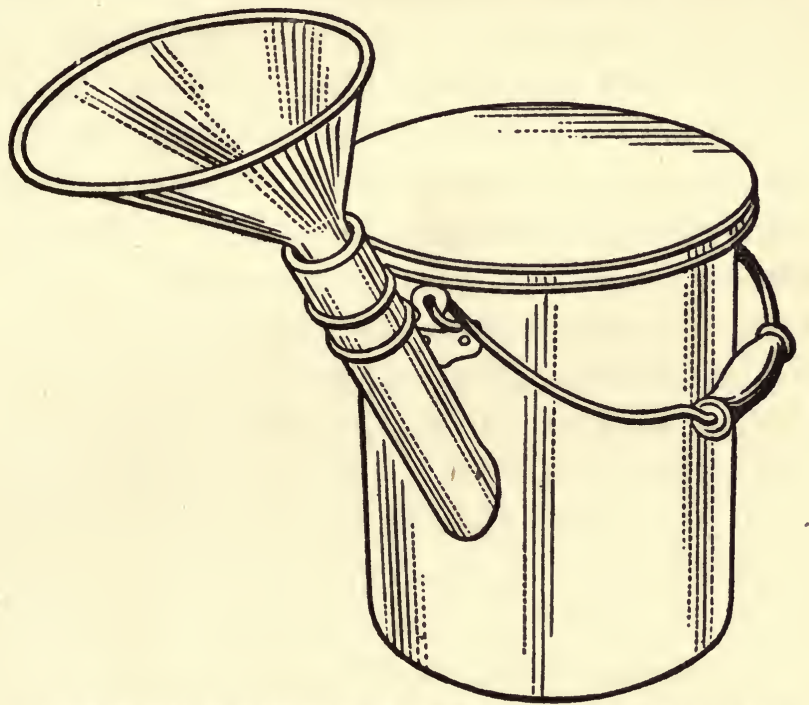

FrG. 16.-Another variety of covered-top pail. The milker sits on the pail and milks into the funnel, which is covered with a cheese-cloth strainer.

has a funnel in the end to receive the milk. The milker sits on the pail and milks into the funnel. When the pail is to be emptied the funnel is removed and the milk is poured out of the spout. Pails with several parts are not as easily kept clean as the other kind. Every additional piece of apparatus not only increases the work of cleaning but also provides another possible medium for the conveyance of bacteria to milk.

Strainers of cheese cloth and wire gauze cannot be 
depended upon to protect milk from contamination. They do not keep out bacteria, but hold back only the larger particles of dirt. Some of these particles are subsequently dissolved by milk and carried through the strainer, while bacteria are washed off of the insoluble particles remaining on the strainer. It is also difficult to clean strainers of this kind thoroughly. Particles of dirt become entangled in the meshes of the wire gauze, especially at the periphery where it is soldered to the tin, and it is difficult to remove them, while the cheese cloth requires much care in cleaning. It should be rinsed in cold water, washed in hot water containing two per cent. of soda, again rinsed in cold water and then wrapped in a clean cloth and sterilized in a steam chest. If a steam chest is not available, it should be put into a thick paper sack and placed in a stove oven and kept there until the sack begins to scorch. A strainer composed of a thin layer of absorbent cotton is much more effective and it can be thrown away after being used and thus save the labor of cleaning. Some of the bacteria are apparently enmeshed in the cotton and kept out of the milk. The use of a cotton strainer has reduced the bacterial content of the milk nearly one-third in some tests. Coarse cotton-flannel and turkish toweling are also used for strainers, but they are no more effective than cheese cloth.

Bacteria cannot be kept out of milk by strainers nor can they be removed by these contrivances after they have entered the milk. The coarse particles of dirt may be strained out, but the most objectionable part of the dirt the bacteria, will remain. Much more satisfactory results will be obtained by cleanliness and care in milking and in the subsequent handling of the milk.

In some receiving stations and distributing plants, 
milk is run through a machine known as a clarifier, in which the milk is centrifugalized and the heavier substances, such as dirt particles, cells, and some of the bacteria, separated from it. The process is known as clarification. When determined by the plate method, the number of bacteria is frequently greater after clarification than before, but this increase is probably due to the breaking up of clumps of organisms by the centrifugalization. Some of the bacteria are removed from the milk since the sludge or residue remaining in the clarifier contains bacteria in considerable numbers. The percentage removed cannot be very great, however, because the milk is exposed to the separating action for only a short time. The sludge or residue is composed very largely of the amorphous substances normally present in milk, the remainder consisting of bacteria, cells, hair, and particles of dirt. If clarified milk is subsequently centrifugalized for three minutes at $\mathbf{3 0 0 0}$ revolutions per minute, sediment will be deposited, showing that all of the sediment is not removed by clarification. All gross suspended dirt, such as hairs, dust particles, etc., are, however, removed by the clarifier, and for this purpose it has many advantages over strainers. But milk containing pathogenic organisms is no cleaner from a hygienic standpoint after clarification than before (Bahlman, Hammer).

4. Feeding.-The cows should not be fed immediately before milking. When hay or other dry fodder is brought into the stable and distributed around among the cows, more or less dust is liberated. This dust contains numbers of bacteria, principally peptonizers, and if milking is done while it is floating about in the stable air some of these organisms will get into the milk. If 
the hay or fodder is thrown down directly into the stable from a loft above, the quantity of dust set free in the stable air is much greater than when it is thrown down into a passageway outside of the stable. Feeding meal or ground grain immediately before milking is also objectionable, and for the same reason. It is not necessary to feed cows before milking to keep them quiet during milking; they soon become accustomed to being fed after milking.

The investigations of Ruehle and Kulp ${ }^{1}$ indicate that under ordinary conditions dust in the stable air is not nearly as much concerned in the bacterial contamination of milk as has been generally believed, but as it is only necessary to perform the several stable operations in a certain order, and does not require additional labor, to protect milk against this source of contamination it is advisable to take this precaution, especially since unusual conditions which will increase the infection from this source are likely to prevail at times.

The feeding of ensilage fills the air of the stable for a time with the odor characteristic of this substance, and if milking is done during this period the odor and taste of the milk is likely to be tainted. This is likewise true of cabbage and rape, and also of beets, turnips, rutabagas and carrots, and their tops (see page 29). Odors in the stable are very quickly absorbed by milk, especially when it is warm.

Sudden changes of feed and overfeeding should be avoided. A sudden change from dry to green feed will produce diarrhœa. Old and highly acid ensilage and sometimes overfeeding will have the same effect. Indi-

${ }^{1}$ Geneva, N. Y., Expt. Sta. Bull. No. 409. 
vidual milk from cows in this condition contains properties which cause digestive and intestinal disturbances in infants; when sufficiently diluted with milk from cows in normal condition, it is not likely to have this effect. The presence of diarrhœa also increases the difficulty of producing clean milk. No grain, meal, or fodder that is musty, mouldy, or otherwise unsound should be fed to milch cows. Diarrhœa has been observed in persons ingesting milk from cows receiving feed of this kind. It has been assumed that the diarrhœa was due to substances formed in the feed being excreted in the milk, but it is possible that in such cases the fungi or bacteria responsible for the change in the feed pass directly from the feed to the milk after it is drawn from the udder and bring about decomposition changes. The use of distillery waste or slop and of wet brewers' grains is prohibited by law in some sections. These substances when fed fresh in moderate quantity have no injurious effect upon the milk, but when they are fed in an advanced stage of fermentation or putrefaction the milk may cause digestive disturbances, especially in babies, and the manure of the cows has a bad odor and is very soft. In addition, when these substances are fed it is difficult to keep the stable clean and free from bad odors, especially the mangers and storage bins or pits. Particles of the feed remain in corners and crevices and decompose, producing a foul odor. On the other hand, dried distillers' grains and dried brewers' grains are entirely wholesome feeds.

It is advisable to water the cows at least twice daily. Whether the water is given before or after feeding is of no consequence, but it is important that a sufficient quantity be given. The greater the milk production, the more water required. 
5. Bedding.-Bedding or litter assists in keeping the cow clean and affords some protection against a hard, cold floor; it also assists in keeping floors clean and dry, especially those of wood and earth, by absorbing the liquid manure. Actual test has shown that when beef cattle are well-bedded they lie down more frequently and for longer periods and make a greater gain in weight in proportion to the feed consumed than they do under less comfortable conditions, and it is reasonable to assume that dairy cows are affected in a similar manner.

The materials usually used for bedding are wheat straw, shredded corn fodder, shavings, and sawdust. From a hygienic standpoint, shavings and sawdust are the most satisfactory. They keep the cows cleaner and are less dusty than shredded corn fodder or straw, but they decay more slowly and are not as satisfactory in supplying humus to the soil. Shredded corn fodder and straw are about equally dusty, but the cows can be kept cleaner with the former. Cut straw is less satisfactory than uncut. Shredded corn fodder excells all of the others in absorbing liquids, with shavings next in order, then straw, and finally sawdust. The low absorption power of sawdust is due to the fact that it is usually damp from exposure to rain. Sawdust is the cheapest material for bedding in localities where it is available. Where there is a convenient market for corn fodder and straw, or where the fodder can be used for feed, it will pay to buy shavings for bedding.

All bedding material, except sawdust when it is damp, being more or less dusty, should be put down in the stable after the milking has been completed. This is especially necessary when corn fodder or straw is used, as the dust in these is likely to contain large numbers 
of peptonizing bacteria. Mouldy or musty straw is objectionable because it contains bacteria and fungi which affect the keeping qualities and wholesomeness of the milk.

The time required to perform the various stable practices described in the preceding pages is of importance to the milk producer, and the inspector should therefore be familiar with this side of the subject. The following figures were obtained from the manager of a large and successful dairy farm and represent the average time required by different men to perform each operation, the men being timed without their knowledge: Taking up manure, $1 / 3$ minute for each cow 4 times daily.

Sweeping platforms, stable floor, and feed troughs, and wiping stanchions, $1 \frac{1}{2}$ minutes for each cow twice daily.

Grooming, 21/4 minutes for each cow twice daily.

Washing flanks and tails, $3 / 4$ minute for each cow twice daily.

Washing udders, two waters, $3 / 4$ minute for each cow twice daily.

Drying udders and drawing fore-milk, $3 / 4$ minute for each cow twice daily.

Bedding, $3 / 4$ minute for each cow twice daily.

Feeding, 11/2 minutes each cow twice daily.

Total time per cow, about $8 \frac{1}{2} 2$ minutes twice daily.

\section{MILK HOUSE}

On every farm where milk is produced there should be a special room or compartment to which the milk can be removed immediately after it is drawn from the cow and where it can be subjected to some method of 
cooling. When the milk from the individual cows is emptied into a shipping can in the stable, it is exposed to contamination by any dust or odors which may be present in the stable air, and, furthermore, it is not likely to be promptly cooled. A milk room is therefore a necessity. On dairy farms it has been found to be convenient as well as economical to have this room in the same building with other rooms in which the utensils and vessels can be washed and in which the milk can be stored. A building of this kind is called a milk house or dairy building and sometimes also contains a room in which the milk is bottled. A spring house may, when the conditions are suitable, serve as a substitute for a storage room or refrigerator, but the practice of washing the milk vessels in the kitchen of the dairyman's residence is very objectionable. The milk house should be arranged so that it will not be necessary for the milkers to enter the room in which the cooler is located or to pass through the wash room to empty their milk pails. This will greatly reduce the labor of keeping the several rooms clean. The floor plan of a milk house in which this idea is carried out is shown in Fig. 17. The milkers pass from the stable to the weigh room, where the milk, after being weighed, is emptied into a tank, from which it is carried by a short pipe passing through the wall to the reservoir on top of the milk cooler.

The inspector should observe the location of the milk room or milk house and the materials of which it is constructed; note the provisions for cooling the milk; examine the condition of the apparatus and utensils and the facilities for washing and cleaning them, and investigate the source of the water used for the latter purpose.

1. Location.-The milk house should be isolated from 
driveways, in so far as this is possible, and there should be an open-air space between it and the stable. If the milk room is not entirely separated from the stable, the chief object of having it, namely, to protect the milk from the stable air, will be defeated. If the surrounding grounds are dusty or if much-used dirt roads are close to it, the atmosphere in the building will be dusty. Some

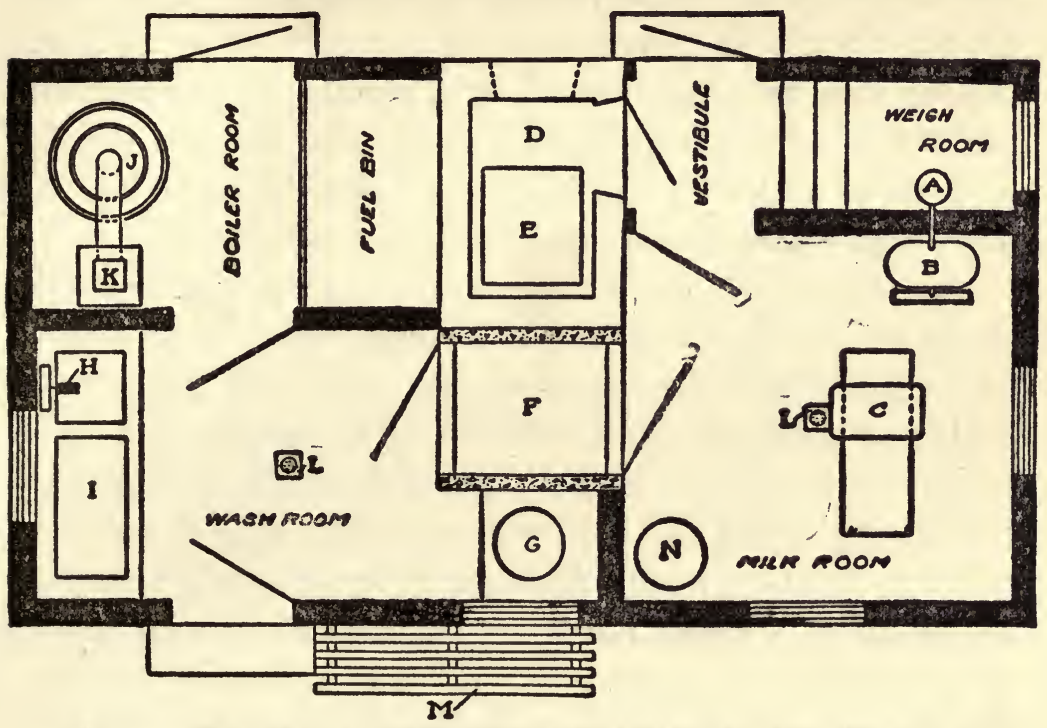

Fra.-17.-Floor plan of a conveniently arranged milk house. A, receiving funnel; $B$, milk cooler; C, bottle filler; D, refigerator; $E$, cooling tank; $F$, sterilizer; $G$, Babcock tester; $H$, bottle washer; $I$, concrete sink; J, boiler; $K$, chimney; $L$, floor drains; $M$, sunning rack; $N$, separator. (Hoard's Dairyman).

system of drainage is necessary to carry off waste water and washings, otherwise the air may become foul from decomposing milk.

2. Construction.-On entering the milk house, the inspector should first note the odor of the air. 'A sour or putrid odor indicates uncleanliness or defective drains. A musty or mouldy odor results from lack of ventilation. The floor, walls, and ceiling should be examined, the material of which they are constructed and their condi- 
tion in regard to cleanliness being noted. Cement is the best material because it can be most readily cleaned, but smooth boards with tight joints, oiled or painted, will do fairly well for the walls and ceiling, although it is desirable to have the walls finished in cement for about four feet above the floor, especially in the room used for washing the milk vessels and utensils. The floor should always be constructed of cement. The lighting should also be observed. There should be a sufficient number of windows to furnish good light, and some good method of artificial lighting is also desirable. All windows and doors should be screened against flies.

3. Apparatus. - The apparatus present in the milk house and its condition should be observed. There ought to be some means of cooling the milk and keeping it cool, and there should be facilities for cleaning the milk vessels and utensils, including a convenient and plentiful supply of hot and cold water. If the milk is bottled, a bottle washer, bottle filler, and bottle capper should be provided. These need not necessarily be expensive. A sterilizer is also desirable. It is a protection against the contamination of the milk through returned bottles and it is also a great aid in keeping the milk vessels and utensils clean. A bottle filler and capper will guard the milk against contamination by the fingers.

A cooler, sometimes called an aërator, is necessary for the rapid cooling of milk. This apparatus is constructed so that the milk flows in a thin layer over a sheet of tinned metal while cold water or brine flows on the other side of the metallic sheet and absorbs heat from the milk. There are four types of milk coolers: $(a)$ conical, $(b)$ corrugated, $(c)$ tubular, and $(d)$ internal or double-tube. 
(a) The conical cooler (Fig. 18) is a cone-shaped tank with a gutter around the base and a movable reservoir at the top. The reservoir has small perforations in the bottom around the periphery. When the cooler is in use, the cavity of the tank is filled with water or ice water. The milk is poured into the reservoir and, passing out through the perforations, flows in a thin layer down over the external surface of the conical tank, collecting in the gutter at the bottom. From the gutter it is permitted to run into the shipping can or bottler.
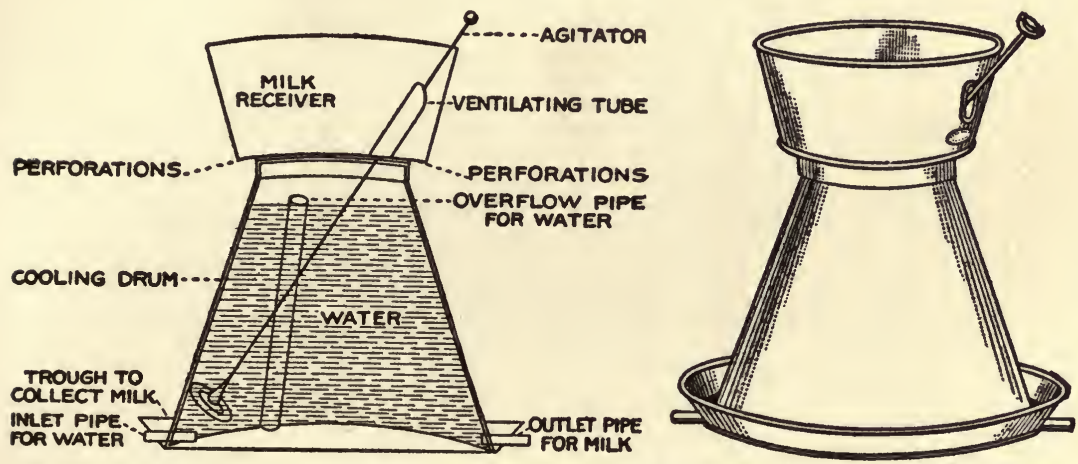

Fra. 18.-Cooler of conical type.

One model of this type of cooler has attachments for pipe or hose to carry cold water into the tank and to remove the water which has been warmed by the heat absorbed from the milk; another which is intended for use on farms without a water pipe system does not have these attachments, and the warm water must be removed and the cold water added with a dipper or similar vessel.

(b) The corrugated type (Fig. 19) of cooler consists of two sheets of corrugated copper, with a small watertight space between them and tinned on the outer surface. The cooling fluid enters through a pipe at the 
lower part of this space and discharges at the top. The milk is poured into a reservoir or tank at the top of the corrugated metallic sheets and, passing out through perforations in the bottom of the reservoir, flows slowly downward in a thin layer over the corrugated surfaces to a trough at the bottom, from which it passes into the

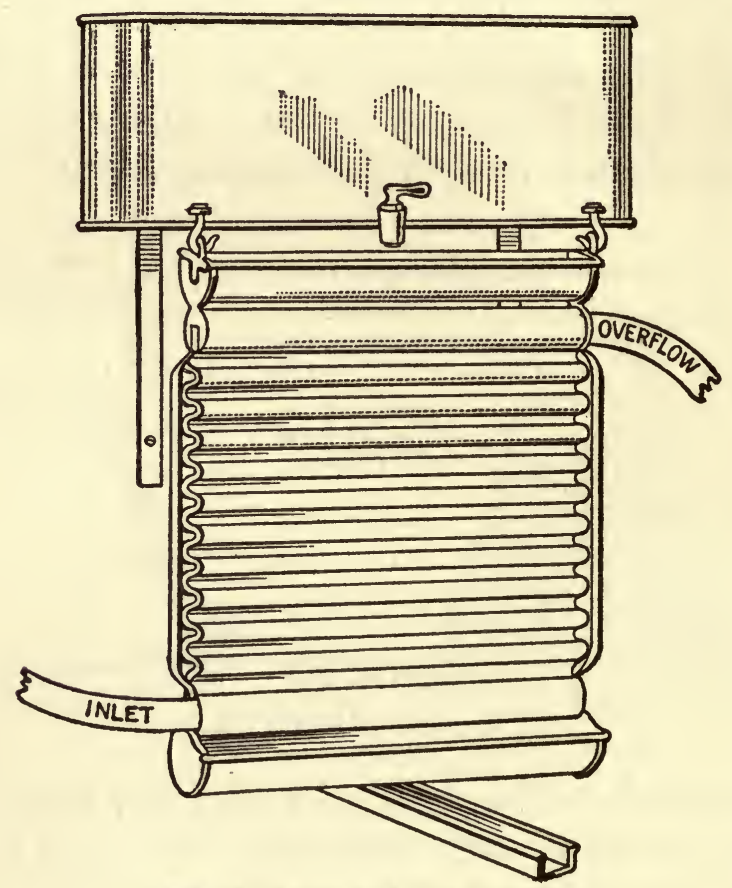

Fra. 19.-Corrugated type of cooler.

collecting can or bottling apparatus. A late model of the corrugated type of cooler is conical in form and is provided with a metal cover to protect the milk from contamination while it is passing over the cooling surface.

(c) The tubular cooler (Fig. 20) consists of a number of pipes arranged horizontally, one under the other 
and close together. They are connected at either end so that fluid can flow from one tube into another. The cooling fluid enters the bottom pipe and flows upward through the various pipes, while the milk flows downward over the outer surface of the pipes from a reservoir

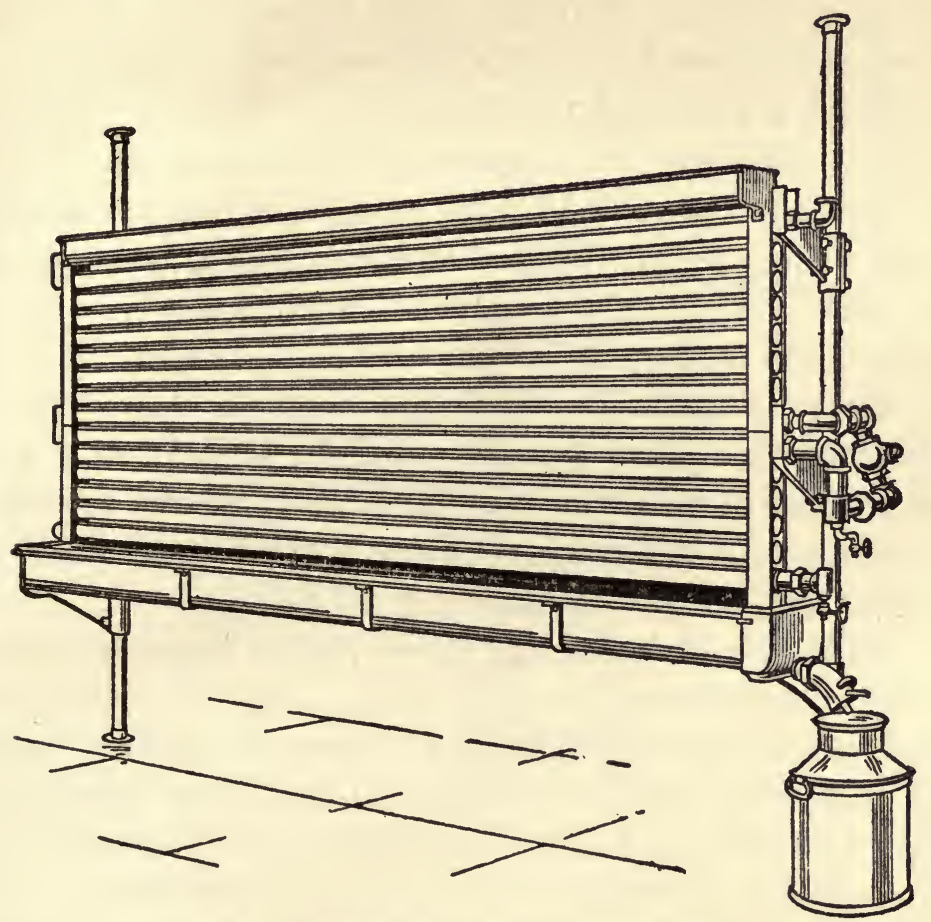

Fro. 20.-Tubular cooler; with continuous surface.

at the top and is received in a collecting tank at the bottom. In some coolers of this type the pipes can be taken out to be cleaned and sterilized. Sometimes these coolers are arranged for ice water to run through the lower pipes and water through the upper pipes, the object being to save ice. The corrugated coolers have an ice-water section which can be attached to the bottom. 
(d) The internal or double-tube cooler (Fig. 21) is a system of double pipes, one within the other. The milk flows through the inner pipes and the cooling fluid through the outer. In this type of cooler the milk is protected from possible contamination from the air. To facilitate cleaning, the connections between the individual pipes are removable (detachable return bends).

With a cooler, the temperature of milk can be lowered to within a few degrees of the cooling fluid in a few minutes, provided the apparatus is not pushed beyond its capacity. If the cooler is not large enough, the milk is likely to be permitted to flow over the cooling surface too rapidly for much of the heat to be absorbed by the cooling fluid. The size of the cooler required will depend on the quantity of milk to be cooled and the number of milkers. The capacity of coolers as stated by manufacturers is usually based on 20 square feet of cooling surface per 1000 pounds of milk.

Milk should be cooled to as low a temperature as possible, and should be kept cool. The lower the temperature, the slower the bacterial growth and the longer the milk will keep in good condition (see page 43). Above $60^{\circ} \mathrm{F}$. the bacteria multiply rapidly, and at $70^{\circ}$ F. or above growth is not only very rapid, but the development of the more objectionable bacteria is favored. When well water or spring water is used for the cooling fluid, the temperature of the milk cannot be reduced much below $60^{\circ} \mathrm{F}$. and often not that low. The temperature of well and spring water in the section around Philadelphia ranges from 52 to $55^{\circ} \mathrm{F}$. in the spring and summer months, but in the late summer and early fall it is usually higher, especially in sandy regions, rising to 69 and $70^{\circ} \mathrm{F}$. in some sections. With ice water, the 


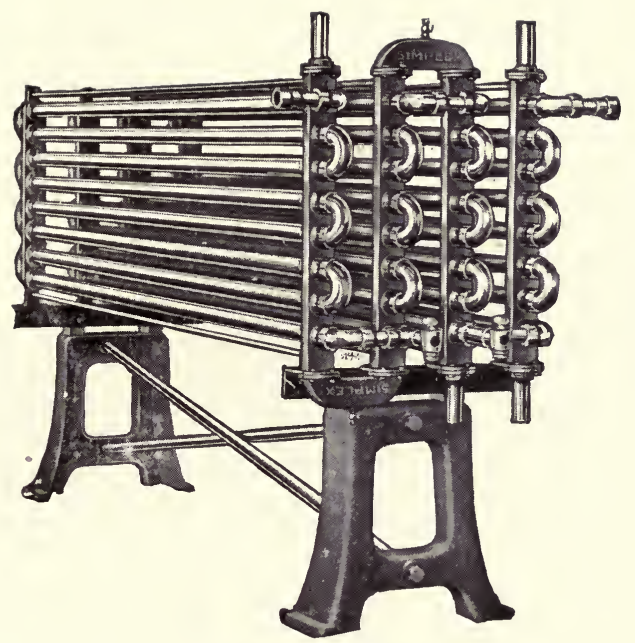

FIG. 21.-Internal or double-tube cooler. 

milk can be cooled down to $40^{\circ} \mathrm{F}$., while with ammonia or brine it can be brought still lower, even to freezing. ${ }^{1}$

The cooler must be thoroughly cleaned each time it is used, stored in a clean place, and protected from dust while in operation, or the milk will take up large numbers of bacteria during the process of cooling. When the cooler is not properly used and cared for, it has been found that better results can be obtained by pouring the milk directly into a shipping can and placing the can in cold water, although the temperature is lowered very slowly under these conditions, three to four hours being required for the temperature to fall to $60^{\circ} \mathrm{F}$. In some cases it has been found more satisfactory to have the milk taken in cans to the shipping station and to cool it there. When this plan is followed the milk must reach the shipping station during the period the germi-

${ }^{1}$ In the northern part of the United States, about $11 / 2$ tons of ice will be required each year to cool the milk obtained from each cow, while in the southern states about 2 tons will be necessary, allowing for the waste by melting. A ton of packed ice will occupy 40 to 50 cubic feet of space; 12 inches should be allowed on the sides and bottom for sawdust or other packing material and 3 to 4 feet on top for packing and ventilation. With these figures, the dimensions of an ice house of any capacity desired can be determined. A foot of packing material should be placed under the ice even when the ice house has an earth floor, earth being a fairly good conductor of heat, especially when wet. Water from the melted ice will usually drain off through the soil unless the latter is of clay, in which case it will be necessary to excavate 1 or 2 feet, put in a tile drain, and fill in with gravel or cinders. The pipe supplying water to the milk cooler may be run under the floor of the ice house with advantage. (A number of good plans for building ice houses will be found in the U. S. Department of Agriculture Farmers' Bulletin No. 623.) 
cidal power is active (see page 43). As a general rule, however, it is best to run the milk over a cooler immediately after it is drawn from the cow. When the milk is emptied from the milk pail directly into the tank of the cooler and passes from the cooler into a bottling machine, it is important to milk the cows in such order that milk of low fat per cent. and milk of higher fat per cent. will be mixed in passing through the bottling machine. After being cooled, the milk should be stored in a cool place, such as a refrigerator, ice-water tank, or spring house, until sent to the railroad station. The inspector should note the facilities provided for this purpose. Milk can be kept cooler in a tank of ice water than in a compartment in which the air is cooled by ice, unless the latter is well insulated. The temperature of air in an ice-cooled refrigerator is usually not much below $50^{\circ} \mathrm{F}$., whereas the temperature of water in which ice is floating is generally as low as $40^{\circ} \mathrm{F}$., and often lower.

While being hauled to the station, the milk should be protected from the heat in summer. This is usually done by covering the cans with a woolen blanket. A wet blanket is more effective than a dry one. Jackets of hair enclosed in canvas are sometimes used to cover the cans. Ice in small pieces should be placed in the boxes in which bottled milk is shipped.

The surface of the milk cooler and the inner surface of all milk vessels should be examined for cleanliness, rusted areas, and open seams. Uncleanliness is indicated by an odor of sour or putrid milk and by the presence of particles of coagulated milk. These particles may be very small, sometimes no larger than a pin's head. All surfaces with which milk comes in contact 
should be covered with tin. Rusted areas are rough and are not easily cleaned, and they sometimes give the milk a "fishy" taste. Milk stored in rusted vessels will acquire a bitter, astringent taste if it becomes very acid, in consequence of the formation of iron lactate by the combination of the lactic acid with the iron. The most common location of rust is in the seams and joints, especially in the joint between the bottom and sides. All seams should be filled flush and smooth with solder. Seamless vessels are best. The use of galvanized iron buckets for milk pails should not be permitted.

Inquiry should be made in regard to the method of cleaning the utensils and vessels, including bottles, and the facilities provided for this purpose should be noted. The utensils and vessels should be first rinsed with cold or lukewarm water. If hot water is used first, it will coagulate the albuminous substances in the milk and cause them to stick to the inner surface of the vessels, to the surface of the milk cooler, etc. After rinsing, they should be washed in hot water containing washing soda or soap powder and then rinsed again in hot water. The brushes used in cleaning should be boiled for ten minutes each time after they are used; they should be of good quality so that the bristles will not come out. The last rinsing ought to be thorough, to insure the removal of all the washing powder, otherwise the milk may have a "fishy" taste.

Unclean milk vessels and utensils are one of the most prolific sources of bacteria in milk. Particles of milk form an excellent culture media for bacterial growth, while the water used to wash the apparatus, the milk itself, and the air furnish the organisms necessary to start the growth. The greater proportion of the organ- 
isms are lactic acid and putrefactive bacteria. Even when the vessels and utensils are thoroughly cleansed in the manner described, they still contain bacteria. To reduce contamination of milk from this source to the minimum, sterilization is necessary in addition to thorough washing. The effects of sterilization are illustrated by the investigations of Prucha, Harding, and Weeter, who found that the same milk which contained 515,203 bacteria per c.c. when the vessels and utensils were washed but not sterilized contained only 3875 per c.c. when the apparatus was sterilized after washing. Bergey observed that when the apparatus was sterilized by steam, the character of the organisms present in the milk after it had come in contact with the milk pail, strainer, cooler, etc., did not differ from those found in samples taken directly from the udder. Milk bottles should be sterilized before refilling for the additional reason that it is a protection against the infection of the milk supply by bottles which may be returned from houses where infectious disease exists.

Exposure to live steam is the most certain method of destroying bacteria in milk vessels and utensils. To obtain complete sterilization, it is necessary to expose the vessels and apparatus to steam under 5 pounds pressure for 20 minutes. This is possible with the cast-iron sterilizers which can be tightly closed. Bottles will stand this amount of pressure. The galvanized-iron steam chests frequently used in dairies are not sufficiently tight to hold the steam under pressure; in these, $\mathbf{9 9 . 2}$ per cent. of the bacteria are destroyed, the spore formers surviving. Rinsing or scalding the vessels and utensils with boiling water after washing does not destroy many bacteria, and while exposure to the sun has a germicidal 
effect it also usually exposes the apparatus to contamination with germ-laden dust.

When facilities for sterilization by steam are not available, the milk vessels and utensils may be sterilized by submerging them for 20 minutes in a 0.1 per cent. solution of hypochlorous acid after they have been cleansed in the usual way. Hypochlorous acid is even more effective as a germicide than the hypochlorites, although the latter are $\mathbf{1 5 0}$ to 200 times as powerful as carbolic acid. A 0.1 per cent. solution will kill typhoid bacilli in $2 \frac{1}{2}$ minutes. The solution may be conveniently prepared as follows: Mix together equal parts by weight of finely ground commercial bleaching powder (chloride of lime) and powdered boric acid; keep in a well-stoppered bottle and protect from light. Dissolve 6 drams of the powder in a quart of water by shaking thoroughly, let stand for 24 hours and pour off the clear fluid; then add 4 quarts of water. This makes a solution containing 0.1 per cent. of hypochlorous acid. When milk bottles are submerged in this solution for 20 minutes, drained for 10 to 20 minutes, and then filled with milk and capped, no odor or taste of chlorine can be detected in the milk. Milk can be strained through cheese cloth moistened with the solution without any effect upon the odor or taste. Tin vessels are not corroded. The powder from which the solution is prepared may be kept for some time under proper conditions, but the solution rapidly loses strength and becomes ineffective in three weeks. Calcium hypochlorite has been in use for a long time as a disinfectant for water supplies and a solution containing 1 ounce to 125 gallons of water is recommended for the sterilization of milk vessels and utensils, but it is much more expensive 
than the hypochlorous acid solution. Winslow reports that a 1 to 1000 solution of chloride of lime may be used in the same manner and with the same results as the hypochlorous acid and the calcium hypochlorite solutions.

When milking machines are in use, careful inquiry should be made regarding the method of cleaning them. The apparatus should be taken apart each time after it is used and thoroughly cleansed and sterilized. On account of the labor involved, this is sometimes done only once a day, but this is not sufficient. Particular attention must be given to cleaning the metallic and rubber tubing and teat cups. After being rinsed with cold water and then with hot water, these parts should be disinfected. The metallic tubes may be sterilized by steam, together with the other metallic parts of the apparatus. The $\mathbf{0 . 1}$ per cent. solution of hypochlorous acid and the $\mathbf{1}$ to $\mathbf{1 0 0 0}$ solution of chloride of lime are very satisfactory disinfectants for the rubber tubing and teat cups and for the metallic parts as well. The rubber parts should be kept submerged in one of these solutions when not in use. A solution of $1 / 4$ pound of chloride of lime and 10 pounds of sodium chloride in 10 gallons of water is also recommended. If air is allowed to remain in any part of the tubing, bacteria may multiply. The apparatus must be properly cared for or the milk will contain a larger number of bacteria than when it is drawn by hand. A milking machine is not in itself a protection against dirt or bacteria in milk. The hair on the udder around the teats must be kept short and this part of the udder must also be cleaned before each milking to obtain good results, while the teat cups must 
not be permitted to fall on the floor or into the bedding when they become detached from the teats.

4. Water Supply.-It is not only important that the water used on a dairy farm for washing the milk utensils and vessels shall be free from fecal contamination, but also that the surroundings of the source of supply are such that there is no probability of contamination. While the first point can be decided by a bacteriological examination of a sample of the water, the second can only be determined by an inspection of the water supply and its surroundings. Frequently inspection will furnish all the information required to condemn a polluted water supply, but in many instances a bacteriological examination will be necessary. The examinations reported of farm water supplies indicate that they are frequently contaminated.

On many farms the water supply is obtained from springs or from dug wells. In either case, the source of supply is the underground water. A well is an artificial opening from the surface down to the underground water, while a spring is a place where the underground water has come to the surface. The underground water is contained in the interstices between rocks, gravel, sand, clay, etc., at various depths below the surface of the ground. The level of the underground water, i.e., the water table, conforms in a general way to the level of the ground surface (Fig. 22).

The purity of spring water depends very largely upon the location of the spring. When springs on farms are contaminated, it is usually due to pollution by surface wash or subsurface drainage. A dry closet situated on the slope of a hill above a spring is especially dangerous. The location of manure piles, houses, barns, pig 
pens, or other structures above springs is objectionable. Water from springs exposed to surface drainage should not be used for washing dairy utensils and vessels, but if no other source is available the spring should be protected by impervious walls. Open springs are sometimes polluted by live stock or contaminated by dust, leaves, and other refuse blowing into them. Pollution of springs by subsurface drainage is not very common on farms, but may occur where the layer of earth above the water table is thin or readily permeable. The permeability will depend upon the material present. Fine sand is a good

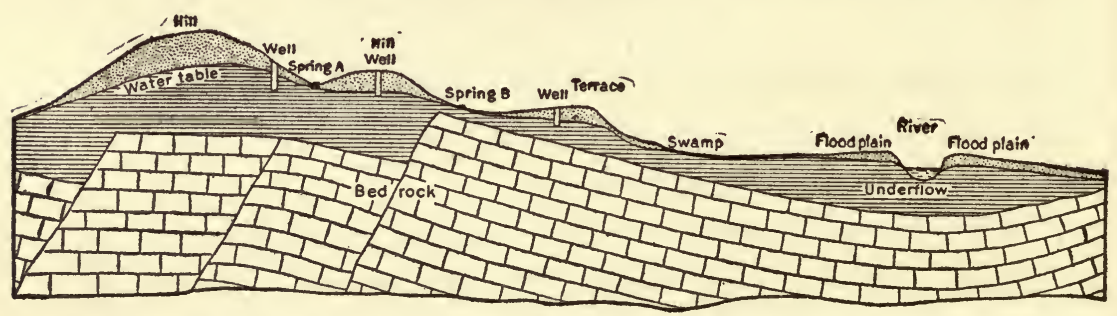

FIG. 22.-Section showing relation of water table to surface irregularities. (From Water Supply Paper 255, U. S. Geological Survey.)

filter, but coarse sand and gravel permit the water to pass through rapidly, carrying some of the contaminating material through with it. Clay and till (largely clay and sand) are good filters. When the layer of earth above the water table is thin or permeable, the water in the spring is likely to be warm. Cesspools, buildings, or anything else which may be a source of pollution should not be placed at a higher level than a spring because of the danger of contamination by subsurface drainage (Fig. 23). When cracks or fissures extend from the surface into the water-bearing strata, as occurs in rock formation, or where tubular channels have been formed, the spring may be contaminated. This may 
occur especially in limestone districts, in which basins or sinks may be found on the surface which are connected with underground water channels. Muddy water or floating material in the spring after severe rains are indications of the existence of these conditions.

The safety of well water depends upon the purity of the water at its source, which is the underground water, and the protection provided against the entrance into the well of contaminated water or polluting material. The purity of the underground water in the case of a well will depend upon the same conditions as control the purity of springs. Contaminated water or polluting

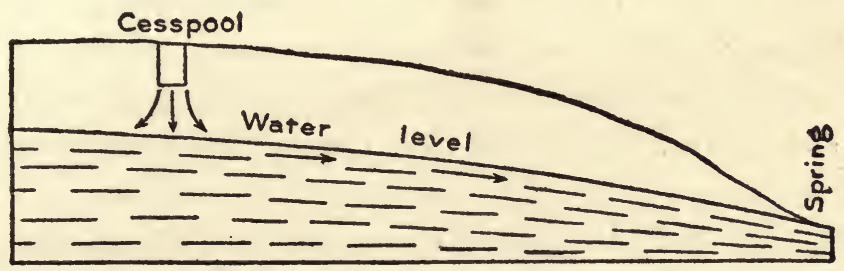

FIG. 23.-How springs may be polluted by subsurface drainage. (From Water Supply Paper 255, U. S. Geological Survey.)

material may enter the well through openings in the curbing or casing and, in open wells, from the surface also.

The open or dug well is the type most commonly found on farms because it is the most cheaply made and the work can be done by ordinary farm labor. With certain precautions, the dug well yields a satisfactory supply of water, but as commonly constructed it is the most dangerous of all sources of water supply. A dug well may be contaminated by material seeping through the ground and curbing, or entering from the top. Stone, brick, or wood curbing usually contains crevices which permit the passage of polluting material. Such 
material may also enter through leaks or holes in the iron casing of drilled wells. Cesspools and privies are the most common sources of seepage. Material thrown out upon the surface of the ground may also be carried down through the soil by rain and seep into the well or reach the underground water. The "safety distance" from such sources of pollution will depend upon the character of the soil and the quantity and concentration of the polluting material, but a rule that may serve as a general guide is the following: A well drains an inverted cone of land whose top surface is four times as wide as the depth of the well. Stone or brick curbs may be made impervious by covering the interior surface with cement. This will prevent contamination by seepage unless the well is shallow, in which case the polluting material may pass down and enter the well under the bottom of the curb.

One of the most common methods of pollution of dug wells is the entrance of material through the top. Dust and surface washings from pump drippings, waste water, and rains are the principal sources of contamination. Small animals, such as toads, mice, rats, moles, and snakes, fall into open wells in seeking water in periods of drought. A water-tight iron or cement cover, tightly joined to the curb, will protect the well from these surface contaminations.

Deep wells, driven or bored, are less likely to be polluted than dug wells or shallow bored wells because the underground water is protected from seepage by a much thicker stratum of earth and the well is protected by an iron casing. If cracks or leaks occur in the casing, polluting material may enter. While deep wells are subject to contamination, they are a much safer source of water supply than shallow wells. 


\section{SCORE CARDS}

It is important to have some system of recording the conditions found on inspection by which the dairy farm can be rated and classified according to a certain standard. Comparisons can then be made, when desired, between different dairy farms and also of the condition of the same farm at different times. In addition, the rating or classification, together with the details of the record, will serve as a basis for an opinion as to the quality of milk which may be expected from each farm. These ratings, or scores, if published, will also serve as a guide to the consumer in purchasing milk.

The most satisfactory system of this kind is what is known as the score-card method. In this method, 100 is taken as a perfect score and various portions of this number are assigned to different parts of the equipment and methods, according to what is considered to be the relative importance of each. Each part of the equipment and the various methods are rated or scored by the inspector according to the degree with which they meet the standard of perfection, and the total of these figures constitutes the score for the dairy farm. Several kinds of score cards are in use. There is one prepared by Dr. W. C. Woodward, health officer of the District of Columbia, the originator of the score-card system. A score card prepared by Prof. Raymond Pearson, known as the Cornell score card, and another published by the U. S. Bureau of Animal Industry are also in rather general use. These three score cards are printed on the following pages: 


\title{
(Front of Card)
}

\section{Health Department of the District of Columbla}

\author{
SCORE CARD FOR DAIRY FARMS
}

Farm of ................... Location.

$\underset{\text { Permit }}{\text { Application }}\}$ Number................ Consignee.

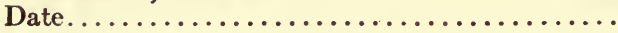

This score card shows conditions only at the time of this inspection. To learn of conditions generally prevailing, reference should be made to a series of consecutive score cards. This may be done at the Health Office.

\section{A. STABLE AND YARD}

1. Stable: Site, well drained, and free from contaminating surroundings.

$\because$....

2. Construction of stable:

Tight, sound floor and proper gutter, tie and manger .......

3. Light: Four sq. ft. or more of glass per cow, and adequate artificial lighting for milking. (Three sq. ft., \&; two sq. ft., 1.)

4. Ventilation: Automatic system (Adjustable windows, 1.) Cubic feet of air space per cow, 1,000 to $600 . \ldots \ldots \ldots \ldots . . . . . . .$. $(500$ to $600,1$.

Stable air..

ธ. Cleanliness:

Floor

Walls...................

Ceiling and ledges...........

Mangers and partitions.......

Windows

Bedding.

6. Water for cattle: Clean and fresh

7. Yard: Free from manure, clean and well drained

(Manure stored less than 50 feet from stable, 0 .)

8. Privy:

(To include accommodations for employ ees.)

Location.

Construction

Cleanliness.

Disposal of Contents

Total carried forward.

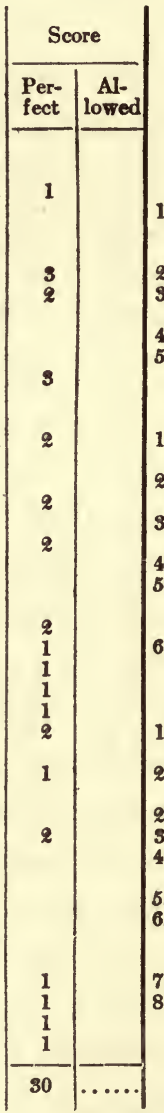

Total brought forward.

B. Mrux Hous

1. Site: Free from contaminating surroundings, with separate wash rooms.................

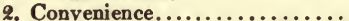

3. Construction of floor, walls, and

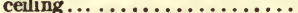

4. Light, ventilation, and screens.

5. Cleanliness of milk room, including freedom from flies.... c. UTENSIIS

1. Small top milking pail. (Removable top, 5.)

2. Facilities for sterilization (Steam, 10; boiling water, $\dot{\delta}$.)

3. Thorough cleansing and sterilizing of utensils.

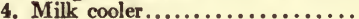

5. Construction: Sound, of good type, and in good repair..................

6. Water for cleaning, clean, convenient, and sufficient.........

D. MILKING AND MILK

1. Udders washed and dried.

(Cleansed with moist cloth, $\dot{z}$.

2. Attendants: Cleanliness and apparent health..............

2a. Med. Insp. Employees.........

5. Clean milking suits............

4. Milk of each cow removed immediately from stable........

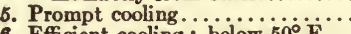

6. Efficient cooling; below $50^{\circ} \mathrm{F} \ldots$ $\left(51^{\circ} \mathrm{F}\right.$. to $55^{\circ} \mathrm{F}$., $2 ; 56^{\circ} \mathrm{F}$. to $60^{\circ}$ F., 1.)

7. Storage; below $50^{\circ} \mathrm{F}$

8. Transportation; (Jacket or wet blanket, $\ddot{z}$ dry blanket or covered wagon, 1.) Total.
Score

\begin{tabular}{|c|c|}
\hline \multicolumn{2}{|c|}{ Score } \\
\hline $\begin{array}{l}\text { Per- } \\
\text { fect }\end{array}$ & $\begin{array}{c}\text { Al- } \\
\text { lowed }\end{array}$ \\
\hline 30 & ..... \\
\hline 1 & \\
\hline & \\
\hline 1 & \\
\hline 3 & \\
\hline 10 & \\
\hline 10 & \\
\hline 10 & \\
\hline 1 & \\
\hline 2 & \\
\hline 6 & \\
\hline $\begin{array}{l}2 \\
3 \\
1\end{array}$ & \\
\hline $\begin{array}{l}2 \\
4 \\
5\end{array}$ & \\
\hline $\begin{array}{l}3 \\
3\end{array}$ & \\
\hline 100 & \\
\hline
\end{tabular}

Remarks

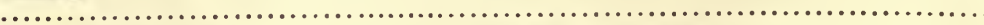

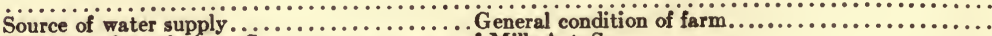

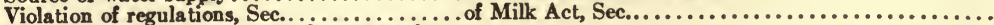
Notices served, to correct, to show cause by 
(Back of Card)

Health Department of the District of Columbia

SCORE FOR CATTLE

\begin{tabular}{|c|c|c|c|c|}
\hline \multicolumn{2}{|c|}{$\begin{array}{c}\begin{array}{c}\text { Number of cattle in } \\
\text { dairy herd }\end{array} \\
\ldots \ldots \ldots \ldots \ldots \ldots \ldots\end{array}$} & $\begin{array}{l}\text { Perfect score. } \\
\text { For each cow } \\
\text { or bull, } 100\end{array}$ & \multicolumn{2}{|c|}{ Total possible score for her } \\
\hline \multicolumn{5}{|c|}{ Deductions on account of cattle diseased, etc. } \\
\hline $\begin{array}{l}\text { Number of } \\
\text { Cattle }\end{array}$ & Nat & lisease, defect, etc. & $\begin{array}{c}\text { Deductions } \\
\text { per cow }\end{array}$ & $\begin{array}{c}\text { Total } \\
\text { Deductions }\end{array}$ \\
\hline & $\begin{array}{l}\text { 1. Tubercu } \\
\text { exami } \\
\text { test... } \\
\text { 2. Absence } \\
\text { one ye } \\
\text { not to } \\
\text { paragr } \\
\text { 3. Inflamm } \\
\text { 4. Diseases } \\
\text { the dis } \\
\text { 5. Unclean } \\
\text { udders } \\
\text { 6. Unclean } \\
\text { than s } \\
\text { agrapl } \\
\text { 7. Undue e } \\
\text { out of }\end{array}$ & 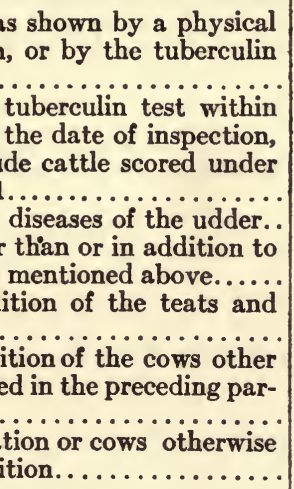 & $\begin{array}{l}100 \\
30 \\
100 \text { or less } \\
100 \text { or less } \\
40 \text { or less } \\
30 \text { or less } \\
10 \text { or less }\end{array}$ & \\
\hline
\end{tabular}

Total deductions for herd

Net score

Net score ( ) divided by the total possible score

for herd ( ) equals Percentage score

Remarks.

Inspector.

The Health Department believes that if a cow is suffering from tuberculosis, her entire value as a dairy cow is gone. If she is suffering from an inflammatory disease of the udder as well as from tuberculosis, she becomes even a greater danger to the herd. And if she is furthermore otherwise diseased, or out of condition, or dirty, she becomes even a more serious menace to public health. For these reasons, the above system of scoring has been arranged so that an individual cow may count against the score of the entire herd more than would have been allotted to her had she been in perfect condition.

All cows stabled with the dairy herd or found in the milking line will be scored as part of the herd. 
(Front of Card)

UNITED STATES DEPARTMENT OF AGRICULTURE, BUREAU OF ANIMAL INDUSTRY DATRY DIVISION

\section{SANItARy Inspection of Dairy Farms}

SCORE CARD

Owner or lessee of farm

P. O. address.

State.

Total number of cows.

Number milking.

Gallons of milk produced daily.

Product is sold by producer in families, hotels, restaurants, stores, to.

dealer.

For milk supply of.

Permit No.

Date of inspection

\section{REMARKs:}


(Back of Card)

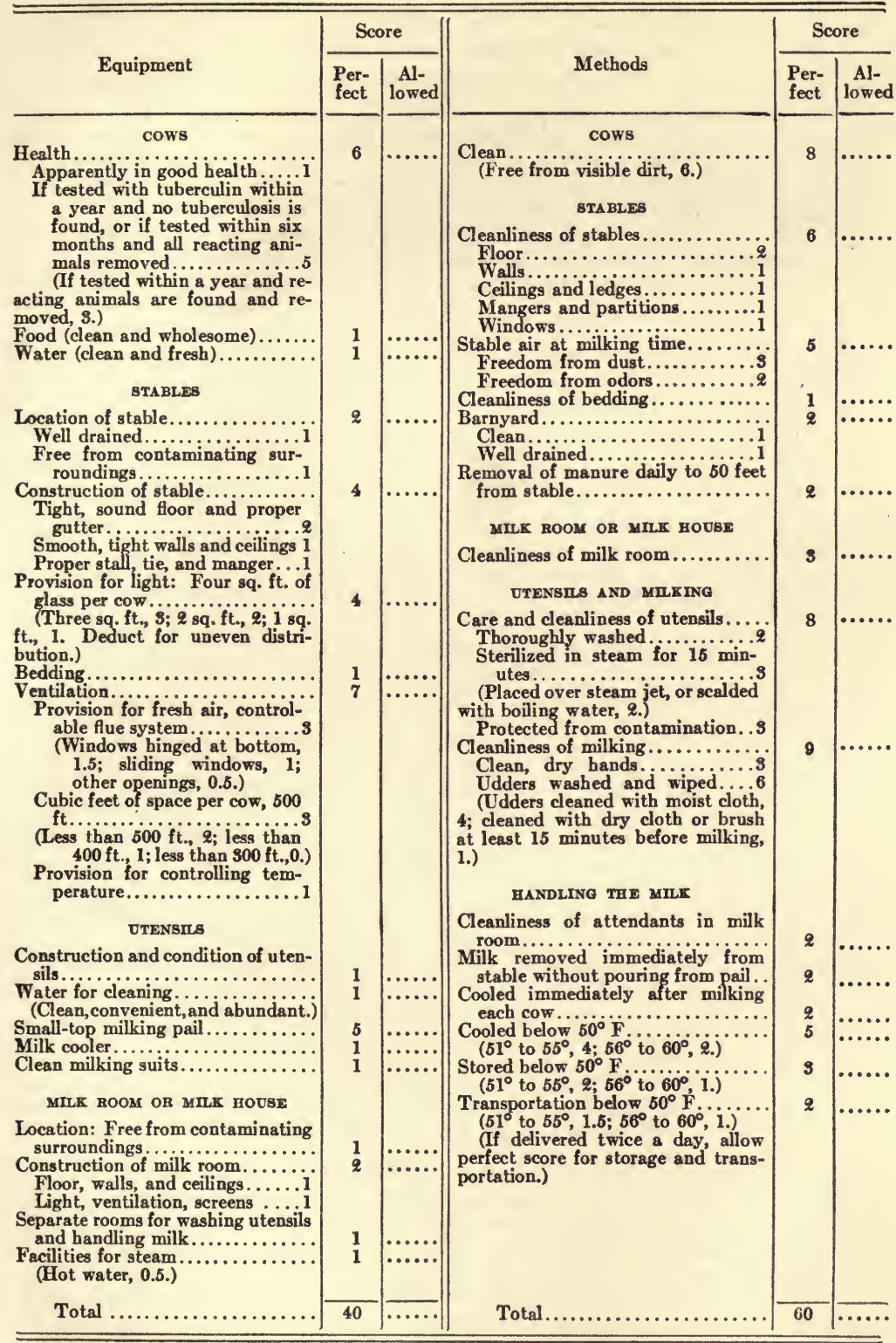

Equipment.

Note 1-If any exceptionally filthy cor may be further limited.

Note 2.- If the water is exposed to dangerous contamination, or there is evidence of the presence of a dangerous disease in animals or attendants, the score shall be 0 . 


\section{Department of Dairy Industry, College of Agriculture, CORNaLL UNTVERSITY}

SCORE CARD FOR PRODUCTION OF SANTTARY MILK

Date.

Dairy of .

\begin{tabular}{|c|c|c|c|}
\hline \multirow{3}{*}{$\begin{array}{l}\text { I. Health of the } \\
\text { herd and its } \\
\text { protection }\end{array}$} & \multirow{3}{*}{ 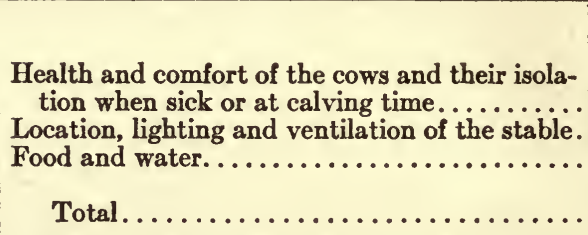 } & $\begin{array}{l}\text { Per- } \\
\text { fect }\end{array}$ & Score \\
\hline & & $\begin{array}{l}45 \\
35 \\
20\end{array}$ & \\
\hline & & 100 & \\
\hline \multirow[t]{2}{*}{$\begin{array}{l}\text { II. Cleanliness of } \\
\text { the cows and } \\
\text { thei r sur- } \\
\text { roundings }\end{array}$} & 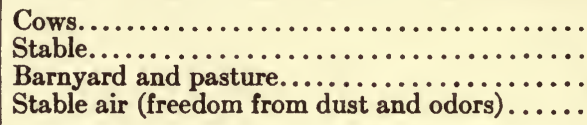 & $\begin{array}{l}30 \\
20 \\
20 \\
30\end{array}$ & \\
\hline & 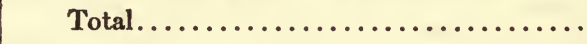 & 100 & \\
\hline \multirow[t]{2}{*}{$\begin{array}{l}\text { III. Construction } \\
\text { and care of } \\
\text { the utensils }\end{array}$} & \multirow{2}{*}{ 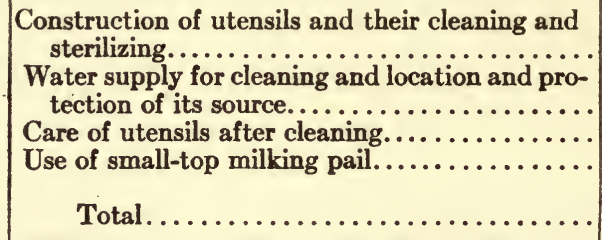 } & $\begin{array}{l}40 \\
25 \\
20 \\
15\end{array}$ & \\
\hline & & 100 & \\
\hline \multirow[t]{2}{*}{$\begin{array}{l}\text { IV. Health of em- } \\
\text { ployees and } \\
\text { manner of } \\
\text { milking }\end{array}$} & \multirow{2}{*}{ 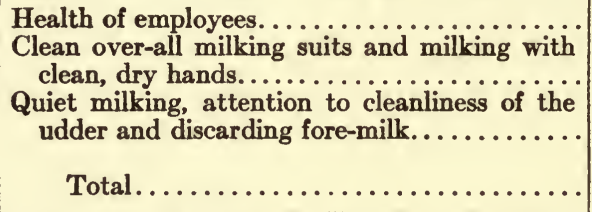 } & $\begin{array}{l}45 \\
30\end{array}$ & \\
\hline & & 100 & \\
\hline \multirow[t]{3}{*}{$\begin{array}{l}\text { V. Handling the } \\
\text { milk }\end{array}$} & \multirow{2}{*}{ 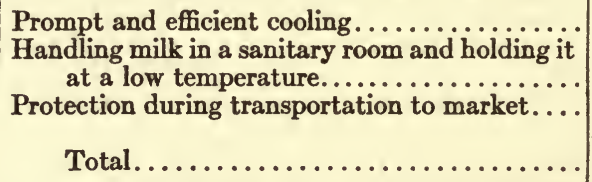 } & $\begin{array}{l}35 \\
30\end{array}$ & \\
\hline & & 100 & \\
\hline & Total of Alu Scores............... & 500 & \\
\hline
\end{tabular}

If the total of all scores is

And each division is

The sanitary conditions are 480 or above............90 or above............. ExcELLENT

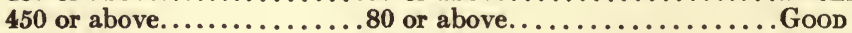

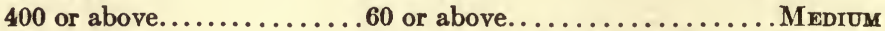
Below $400 \ldots \ldots \ldots \ldots \ldots$. Or any division is below $60 \ldots .$. Poor

The sanitary conditions are. 


\section{CHAPTER VIII}

\section{PASTEURIZATION}

Pasteurization of milk consists in heating the milk at various temperatures below boiling for a variable period of time. The term pasteurized milk is very indefinite in its meaning because the process is not always carried out in the same manner, but since 1913, when the Commission on Milk Standards of the New York Milk Committee published its second report, there has been more uniformity in this country than formerly with regard to temperature and time of exposure, state and local authorities having very generally accepted the standard adopted by the Commission. This standard specifies 140 to $155^{\circ} \mathrm{F}$. ( 60 to $68^{\circ} \mathrm{C}$.) as the minimum temperature at which the milk shall be heated, the minimum period of exposure to be 20 minutes at $140^{\circ} \mathrm{F}$. $\left(60^{\circ}\right.$ C. $)$, with one minute less for each degree of temperature above $140^{\circ} \mathrm{F}$. But, at the same time, in order to allow for the variations in temperature and holdingtime which may occur under commercial conditions, the Commission recommended that the milk be heated to at least $145^{\circ} \mathrm{F} .\left(62.8^{\circ} \mathrm{C}\right.$.) for at least 30 minutes. In Europe, pasteurized milk is usually milk which has been heated for a few moments at $176^{\circ} \mathrm{F} .\left(80^{\circ} \mathrm{C}\right.$. $)$ or above, although within recent years the method of heating the milk at a lower temperature for a longer period has been adopted to some extent.

When the first commercial milk pasteurizer was introduced into this country in 1895 , pasteurization was recommended to milk distributers as a means of pre- 
venting milk from spoiling, and the process was adopted by some dealers for this purpose, being used secretly by many of them. Naturally, this brought the process into disrepute. Sanitarians and public health authorities were also disposed to discourage its use because of the inefficiency of the early apparatus and the lack of exact information regarding the effect of the process upon the milk and the pathogenic organisms which may be contained in it. With the acquirement of further information on the latter phase of the subject and improvement of the apparatus, sanitarians and public health officials came to regard the pasteurization of milk, when properly carried out, as a legitimate and useful process and by 1910 the pendulum had swung so far in the other direction that many of them were advocating the pasteurization of all milk.

\section{PRINCIPLES OF PASTEURIZATION}

To obtain a correct conception of the hygienic value of pasteurization, it is necessary to consider the effect of different degrees of heat and periods of exposure upon the pathogenic organisms which may be present in the milk, upon the common milk bacteria, upon the toxins and decomposition products resulting from bacterial growth, upon the nutritive properties of the milk, and upon the ferments or enzymes. Commercially, the effect upon the taste and the separation of the cream is also of importance.

1. Effect of Heat on Pathogenic Organisms.-The disease-producing bacteria which occur most frequently in milk are streptococci, the bacilli of tuberculosis, typhoid fever and diphtheria, and the pyogenic staphylococci. The infectious agent of scarlet fever, which is 
also sometimes transmitted by milk, has not been identified. Of the organisms mentioned, the tubercle bacillus is the most resistant to heat, with the possible exception of some varieties of streptococci. The streptococci of septic sore throat are destroyed by heating at $140^{\circ} \mathrm{F}$. $\left(60^{\circ} \mathrm{C}\right.$.) for 30 minutes (Davis) or at $145^{\circ} \mathrm{F}$. $\left(62.8^{\circ}\right.$ C.) for 20 minutes (Hamburger), and exposure to a temperature of 125.6 to $143.6^{\circ} \mathrm{F}$. (52 to $62^{\circ} \mathrm{C}$.) for 30 minutes is sufficient to kill Streptococcus pyogenes (Hitchens). There are some varieties of streptococci which are more resistant to heat, but we have no reason to believe that those which occur in milk are pathogenic. It seems very probable that heating milk sufficiently to destroy tubercle bacilli will also kill any pathogenic streptococci which may be present. A temperature of $140^{\circ} \mathrm{F}$. $\left(60^{\circ} \mathrm{C}\right.$.) for 2 minutes will destroy the bacilli of typhoid fever and diphtheria. The question of the amount of heat required to destroy the pathogenic organisms which occur most frequently in milk consequently resolves itself into a question of how much heat is necessary to kill the tubercle bacillus. The evidence on this point must therefore be considered.

Bang found that heating milk momentarily at $185^{\circ}$ F. $\left(85^{\circ}\right.$ C. $)$ destroyed tubercle bacilli in naturally infected milk, and Jensen reports experiments in which tubercle bacilli in milk were killed by a few moments exposure to 158 to $176^{\circ} \mathrm{F}$. ( 70 to $80^{\circ} \mathrm{C}$.). On the other hand, Grimmer and other investigators are of the opinion that, when the exposure is momentary, a temperature of at least $194^{\circ}, \mathrm{F} .\left(90^{\circ} \mathrm{C}\right.$. $)$ is necessary to insure the destruction of the bacilli in all cases.

Concerning the effects of a more prolonged exposure at lower temperatures, experimental results are even 
more divergent. Woodhead reports that while in some experiments a temperature of $140^{\circ} \mathrm{F}$. $\left(60^{\circ} \mathrm{C}\right.$. $)$ killed tubercle bacilli in 25 minutes, in others an exposure of 8 hours was required. Yersin, Bitter, Bonhoff, and other investigators report that although an exposure to $140^{\circ}$ F. $\left(60^{\circ}\right.$ C. $)$ for one hour was nearly always fatal to tubercle bacilli, the effect was uncertain when the time of exposure was much shorter. In Foster and Rullmann's experiments, the bacilli remained alive after 45 minutes at $140^{\circ} \mathrm{F}$. $\left(60^{\circ} \mathrm{C}\right.$.). DeJong asserts that tubercle bacilli will survive heating at 159.8 to $161.6^{\circ} \mathrm{F}$. ( 71 to $72^{\circ}$ C.) for $1 / 2$ hour, while Van der Sluis declares that a temperature of $176^{\circ} \mathrm{F}$. $\left(80^{\circ} \mathrm{C}\right.$.) for 1 hour is necessary to kill tubercle bacilli in naturally infected milk. Hittcher considers 1 hour at 140 to $145.4^{\circ} \mathrm{F}$. $(60$ to $63^{\circ} \mathrm{C}$.), 45 minutes at 147.2 to $149^{\circ} \mathrm{F}$. ( 64 to $65^{\circ} \mathrm{C}$.), or 30 minutes at 150.8 to $158^{\circ} \mathrm{F}$. (66 to $70^{\circ} \mathrm{C}$.) necessary to destroy tubercle bacilli. On the other hand, Hewlett, in England, found that tubercle bacilli did not survive 30 minutes exposure to $140^{\circ} \mathrm{F}$. $\left(60^{\circ} \mathrm{C}\right.$.) and, in this country, Rosenau found 20 minutes at $140^{\circ} \mathrm{F}$., Theobald Smith 15 minutes at $140^{\circ} \mathrm{F}$., and Russell and Hastings 10 minutes at that temperature sufficient to kill the organisms. Hewlett and the American investigators used in their experiments milk artificially infected with tubercle bacilli, while nearly all, if not all, of the other experiments mentioned were made with naturally infected milk.

The conditions were therefore by no means the same. In naturally infected milk, the tubercle bacilli are embedded in masses of mucus, clots of fibrin, or shreds of tissue, and this albuminous covering protects them from the action of the heat. It is true that in those experi- 
ments in which milk from tuberculous udders was used without being diluted with normal milk that the circumstances were not the same as exist under natural conditions; the infection was much more concentrated, and there was not the same opportunity for the albuminous matter surrounding the bacilli to be softened and loosened as occurs when a small quantity of infected milk is mixed with a comparatively large quantity of normal milk several hours before pasteurization. But individual milk was not used in all of the experiments with naturally infected milk; some of them were made with mixed milk which was entirely normal in appearance.

In all of the experiments referred to a small quantity of milk was heated in a laboratory. Under these conditions, the temperature at which the milk is heated and the time of exposure can be accurately controlled. But in commercial pasteurizers fluctuations in temperature and variations in holding-time cannot be entirely avoided and when large quantities of milk are pasteurized under these conditions there is not the same assurance that every particle of milk will be heated at the same temperature for the same length of time as when a small quantity of milk is heated in the laboratory. This is shown by the experiments of Rosenau and Schorer in which they tested the efficiency of pasteurization under commercial conditions. They inoculated milk with cultures of the bacilli of typhoid fever, diphtheria, and tuberculosis and endeavored to heat it at 140 to $145^{\circ} \mathrm{F}$. (60 to $62.8^{\circ} \mathrm{C}$.) for different periods of time. Two tests were made with typhoid bacilli and in one the organisms survived. The same results were obtained with the diphtheria bacillus. In two tests with tubercle bacilli of the bovine type one failed, and in a similar experiment with tubercle bacilli 
of the human type the organisms were not killed in either test. As a result of these experiments, Rosenau and Schorer concluded that in order to allow a margin of safety when milk is pasteurized under commercial conditions it is necessary to expose the milk to a temperature of at least $145^{\circ} \mathrm{F}$. $\left(62.8^{\circ} \mathrm{C}\right.$.) for 30 to 45 minutes.

The only experiment recorded in which naturally infected milk was pasteurized in large quantity under commercial conditions was made by Traum and Hart, who published their results in 1916. The milk came from a large herd of reacting cows and the volume amounted to from 700 to $\mathbf{1 0 0 0}$ quarts daily. Samples were taken at the milk station in the city before and after pasteurization. Twenty-four samples of raw milk were tested on guinea pigs and all except one sample produced tuberculosis in the test animals, and the guinea pigs inoculated with this sample died of septicemia before there was an opportunity for tuberculosis to develop. Eleven samples of milk which had been heated at $140^{\circ} \mathrm{F}$. $\left(60^{\circ}\right.$ C.) for $\mathbf{2 0}$ minutes were tested in the same manner and did not produce tuberculosis in a single instance. Twelve samples of milk which had been heated above $140^{\circ} \mathrm{F}$. $\left(60^{\circ} \mathrm{C}\right.$. $)$ for a longer period than 20 minutes also proved free from tuberculosis infection. While these results appear to indicate that $140^{\circ} \mathrm{F}$. $\left(60^{\circ} \mathrm{C}\right.$. $)$ for 20 minutes will kill tubercle bacilli in naturally infected milk when it is pasteurized under commercial conditions, it would seem desirable, in view of the contradictory data furnished by the other experiments which have been mentioned, to have them confirmed by further tests before drawing final conclusions. There ought to be absolute certainty that a given temperature and period of exposure will kill tubercle bacilli and other pathogenic organ- 
isms in naturally infected milk before they are adopted as a standard for pasteurized milk.

2. Effect of Heat on the Common Milk Bacteria.The effect of pasteurization upon the common milk bacteria is of importance because if, for example, the lactic acid bacteria are destroyed and peptonizing or gas-forming organisms survive the milk may undergo putrefaction instead of souring. Moreover, the putrefactive changes may advance sufficiently to render the milk injurious before the appearance or taste is altered.

The action of different degrees of heat upon the common milk bacteria has been very thoroughly studied by Ayers and Johnson. In their experiments, when milk was heated to $170^{\circ} \mathrm{F}$. $\left(76.7^{\circ} \mathrm{C}\right.$.) or above, the majority of the organisms surviving were peptonizers, but when the temperature was kept below $170^{\circ} \mathrm{F}$. the acid-formers predominated among the surviving organisms. Acid was formed slowly, however, when the temperature had reached $160^{\circ} \mathrm{F}$. $\left(71.1^{\circ} \mathrm{C}\right.$.). The character of the changes which the milk will undergo after pasteurization will depend not only upon the kind of bacteria which predominate after heating, but also upon the temperature at which the milk is kept. If pasteurized milk is not cooled promptly and kept cool it undergoes putrefaction, especially if it has been exposed to high degrees of heat. Milk heated at a low temperature, $145^{\circ} \mathrm{F}$. $\left(62.8^{\circ} \mathrm{C}\right.$.) for 30 minutes, when kept at $50^{\circ} \mathrm{F}$. $\left(10^{\circ} \mathrm{C}\right.$. $)$, will curdle and sour like raw milk, but much more slowly. If milk treated in this manner is stored too long, it may develop a strong, old taste as a result of the growth of the alkali-forming bacteria which survive this amount of heat.

Pasteurization destroys or weakens the germicidal 
power of milk. It was therefore naturally supposed that bacteria would develop more rapidly in pasteurized than in raw milk. Rickards compared the average increase of bacteria occurring in a number of samples of raw and pasteurized milk and found that bacteria multiplied four times faster in commercially pasteurized milk than in raw milk at ice-box temperature. Ayers and Johnson contend, however, that when the growth of bacteria in pasteurized milk is compared with the growth of bacteria in the same grade of raw milk the increase of bacteria is about the same in both kinds of milk. But Savage is of the opinion that organisms which gain access to milk after pasteurization will grow more rapidly than in raw milk if for no other reason than because the bacterial content is much less and the conditions for growth therefore much more favorable. These facts illustrate the importance of promptly cooling pasteurized milk and keeping it cool, and also indicate the necessity of preventing the access of any bacteria, and especially pathogenic organisms, after pasteurization.

3. Toxins and Decomposition Products. - The growth of bacteria in milk is attended by the production of toxins and also by the decomposition of some of the milk constituents. The extent to which these changes occur will depend upon the number of bacteria which gain access to the milk during the drawing of the milk and its subsequent handling, the age of the milk at the time of pasteurization, and the temperature at which it has been kept in the meantime.

While the true or soluble toxins (exogenous, extracellular) are destroyed at comparatively low temperatures, the endotoxins (endogenous, intracellular) are quite resistant to heat. Most of them require a tempera- 
ture of $70^{\circ} \mathrm{C} .\left(158^{\circ} \mathrm{F}\right.$.) for their destruction, and some will even survive boiling. Therefore, there is no certainty that all toxins which may be present in milk will be destroyed even if the milk is boiled. While there is no direct proof that milk containing toxins is injurious to health, at the same time we are also without positive knowledge that such milk is harmless (see page 45 ).

Although there is no definite information regarding the effect of heat upon the cleavage products resulting from the breaking up of the milk constituents by bacteria, we have reason to believe that they are not all destroyed by heat. This is an important point because some of these substances are of a harmful character.

In the light of our present knowledge regarding the effects of pasteurization upon toxins and cleavage products, it would seem advisable to limit the production of these substances as much as possible by protecting the milk from bacterial contamination and by promptly cooling it and keeping it cool until it is pasteurized. There should be a limit to the number of bacteria which may be present in milk which is to be pasteurized, and this limit should be as low as circumstances will permit.

4. Nutritive Properties.-The statement is frequently made that milk may be heated at $145^{\circ}, \mathrm{F} .\left(62.8^{\circ}\right.$ C.) for thirty minutes without affecting its nutritive properties, but this is not confirmed by the experience of Hess, who saw scurvy develop in from two to three months in nearly every one of a group of infants who were being fed on milk pasteurized in that manner; when orange juice or potato water was added to the milk the disease was cured. The observations of Plantenga indicate that this diseased condition is not due entirely to the effect of heat on the milk. He reports that while 
scurvy developed in 23 per cent. of the children fed on milk which was pasteurized 24 hours after it was drawn from the cow by heating it at $158^{\circ} \mathrm{F}$. $\left(70^{\circ} \mathrm{C}\right.$. $)$ for 30 minutes, not a single case of the disease appeared in children receiving milk pasteurized immediately after being drawn from the cow, although it was from the same dairy and was pasteurized in the same manner. While many instances have been reported in which infants have been fed on pasteurized milk without harm, there appears to be no reason to doubt that milk loses some of its antiscorbutic properties in the process of pasteurization and that the age of the milk is also a factor in bringing about the change.

The opinion prevails among medical practitioners that pasteurized or boiled milk is the cause of rickets and malnutrition, as well as scurvy, in children. The development of rickets under such circumstances has been attributed to the conversion of the soluble phosphates of lime and magnesia contained in milk into an insoluble form by the action of the heat. Malnutrition is thought to result from pasteurized or boiled milk being less digestible than raw milk, a condition which is believed to be due to the heat coagulating the proteids and rendering them less susceptible to the action of the digestive fluids. According to Rupp, however, heating milk at $145^{\circ} \mathrm{F}$. $\left(62.8^{\circ}\right.$ C. $)$ for 30 minutes does not affect the soluble phosphates or the albumin. The coagulation of the albumin begins at $150^{\circ} \mathrm{F} .\left(65.6^{\circ} \mathrm{C}\right.$. $)$ and increases with the temperature, but the soluble phosphates are not affected by temperatures up to $155^{\circ} \mathrm{F} .\left(68.3^{\circ} \mathrm{C}\right.$. $)$. Feeding experiments with animals to determine the comparative digestibility of raw and boiled milk have given contradictory results. While in most instances no dif- 
ferences were observed, in some cases calves fed on boiled milk developed a diarrhœa which disappeared when raw milk was substituted.

5. Ferments or Enzymes.-In the opinion of some authorities, the ferments or enzymes contained in milk play a very important rôle in its digestion and assimilation. From this standpoint the effect of heat on these substances is therefore an important consideration in connection with the pasteurization of milk. Most of the ferments in milk can withstand a temperature of from 60 to $65^{\circ} \mathrm{C}$. ( 140 to $149^{\circ} \mathrm{F}$.) for some time, while higher temperatures weaken or destroy them.

6. Taste.-Milk does not acquire a cooked taste unless it is heated to $158^{\circ} \mathrm{F}$. $\left(70^{\circ} \mathrm{C}\right.$.) or above.

7. Cream Line.-If milk is exposed to a temperature of $70^{\circ} \mathrm{C} .\left(158^{\circ} \mathrm{F}\right.$. $)$ or above, the cream will not separate. A temperature of $65^{\circ} \mathrm{C}$. $\left(149^{\circ} \mathrm{F}\right.$.) for $10 \mathrm{~min}$ utes has no effect on the separation of the cream, but as the time of exposure to this temperature is increased beyond this period the separation of the cream is delayed more and more until finally, after 40 minutes exposure, it does not separate at all. A temperature of $145^{\circ} \mathrm{F} .\left(62.8^{\circ} \mathrm{C}\right.$. $)$ for 30 minutes and $60^{\circ} \mathrm{C}$. $\left(140^{\circ} \mathrm{F}\right.$. $)$ for as long as 50 minutes has no effect on the formation of the cream layer. In the commercial pasteurization of milk, the pumping and stirring necessary to force the milk through the heater and to bring it in contact with the heated surfaces may have the effect of breaking up the fat globules and thus interfere with cream separating even when the temperature has not been sufficiently high to alone affect the cream line.

Summarizing the facts which have been definitely established regarding the effects of pasteurization, we 
find that a temperature of $145^{\circ} \mathrm{F}$. $\left(62.8^{\circ} \mathrm{C}\right.$. $)$ for 30 to 45 minutes, under commercial conditions, will destroy the pathogenic bacteria which are most likely to occur in milk, with the possible exception of tubercle bacilli, and it appears probable that this organism will also be destroyed, although it would be desirable to have more definite information on this point. Exposure to heat to this extent, however, cannot be depended upon to destroy all of the toxins and the decomposition products which may be present in milk as a result of bacterial growth, while, at the same time, it destroys the antiscorbutic properties of milk. Moreover, it is not certain that it does not decrease the digestibility of milk.

\section{METHODS OF PASTEURIZATION}

There are three methods of pasteurization:

1. The "flash" or continuous process, in which the milk flows continuously and is exposed to a heated surface for a few seconds.

2. The "holder" process, in which the milk is heated to a certain temperature and is then held at that temperature for a certain period.

3. Pasteurization in the Final Container.-In this method, the raw milk is placed in the bottle in which it is to be delivered, the bottle is capped, and the filled bottle is then exposed to the desired degree of heat.

The "flash" process is less reliable than the "holder" method, as not all of the milk is certain to be heated to the temperature registered by the thermometer; some may be heated in excess of the temperature intended and thus balance any deficiency of temperature in the milk which may not be heated to the desired temperature. Furthermore, a higher degree of heat is required to de- 
stroy pathogenic organisms by the "flash" method than by the "holder" method. Pasteurization in the final container is the best method, because it does not afford any opportunity for the milk to be reinfected. But most of the apparatus constructed to pasteurize milk in bottles is rather costly and it is also more expensive to operate than that of the "flash" or " holder" variety. Furthermore, the bottles must be tightly sealed, and this requires the use of a cap which is more expensive than the ordinary kind. Space must be allowed for the expansion of the milk when it is heated, consequently the bottles cannot be entirely filled. Larger bottles must therefore be provided or the consumer will receive short measure. The vacant space permits the milk to be shaken about, which may disturb the cream. The cream may also "butter" if the milk is subjected to sufficient agitation while warm.

The milk should be cooled immediately after pasteurization. Sudden cooling following exposure to heat has no effect in destroying bacteria, as was formerly supposed, but prompt cooling will retard the development of the bacteria or spores which survive pasteurization. The regulations of the Philadelphia Board of Health require that the milk shall be cooled to $50^{\circ} \mathrm{F}$. $\left(10^{\circ} \mathrm{C}\right.$.) or below immediately after pasteurization, held at that temperature or below while at the pasteurizing plant, and delivered to the consumer within 24 hours. The requirements of the New York Commission on Milk Standards specify that the milk must be cooled immediately to a temperature not exceeding $50^{\circ} \mathrm{F}$. $\left(10^{\circ} \mathrm{C}\right.$.) and held at that temperature until delivered to the consumer.

Types of Pasteurizers.-Various types of pasteuriz- 
ing apparatus are in use. In all of those used in the "flash" and "holder" method, the milk is exposed in some way to surfaces heated by hot water or steam. Hot

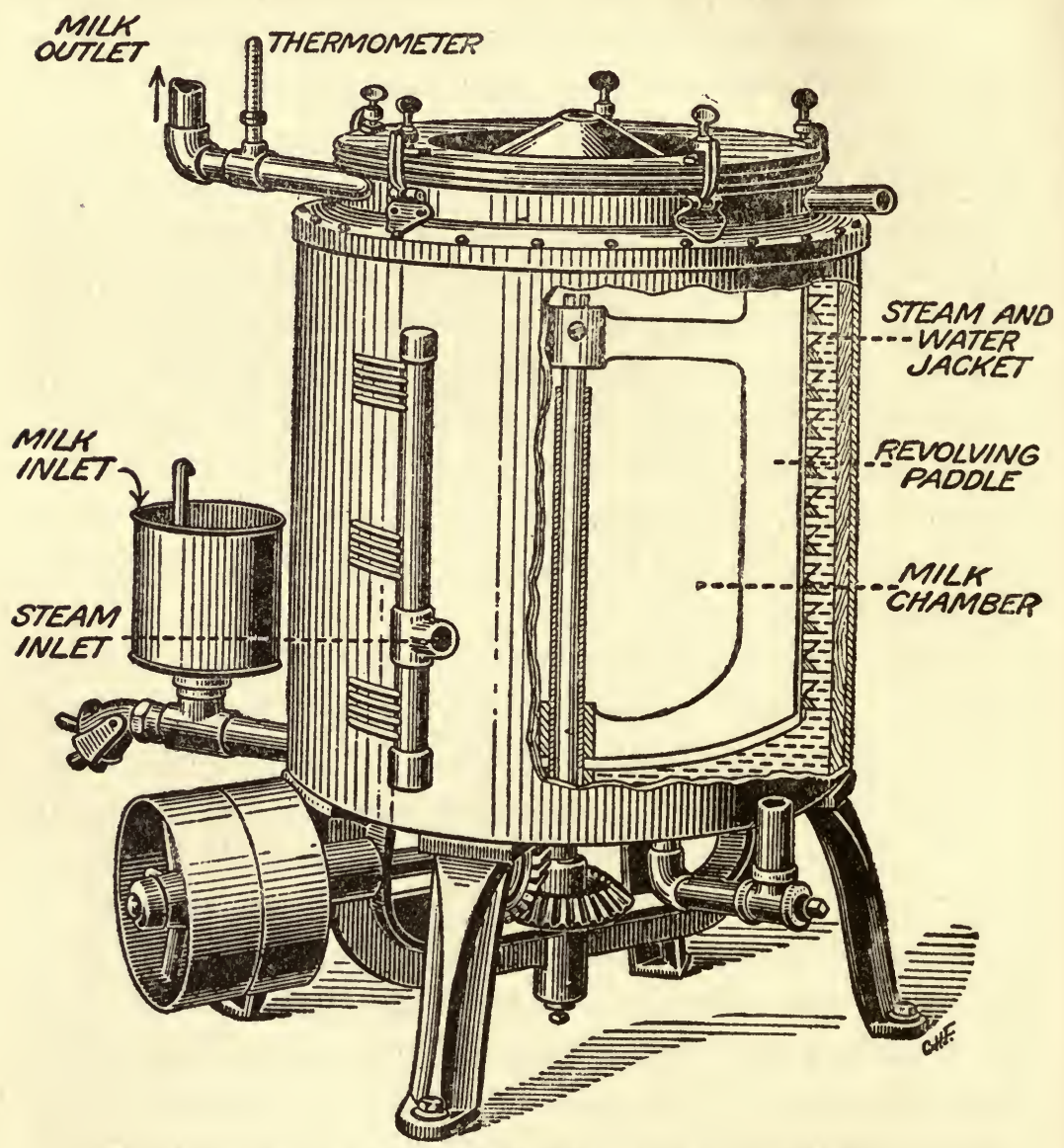

FIG. 24.-A pasteurizer of simple type (B. A. I. Circ. 184).

water is best; it maintains the heating surfaces at a more even temperature and the milk is less likely to be scorched than when steam is used. To meet the necessary requirements, a pasteurizer must heat all of the 
milk to the desired temperature; it must be reliable in operation, and must be convenient to clean. If a film is permitted to form on the top of the milk, which will occur when milk is heated in open vessels, more heat will be required to destroy the bacteria contained in the film than in the other parts of the milk.

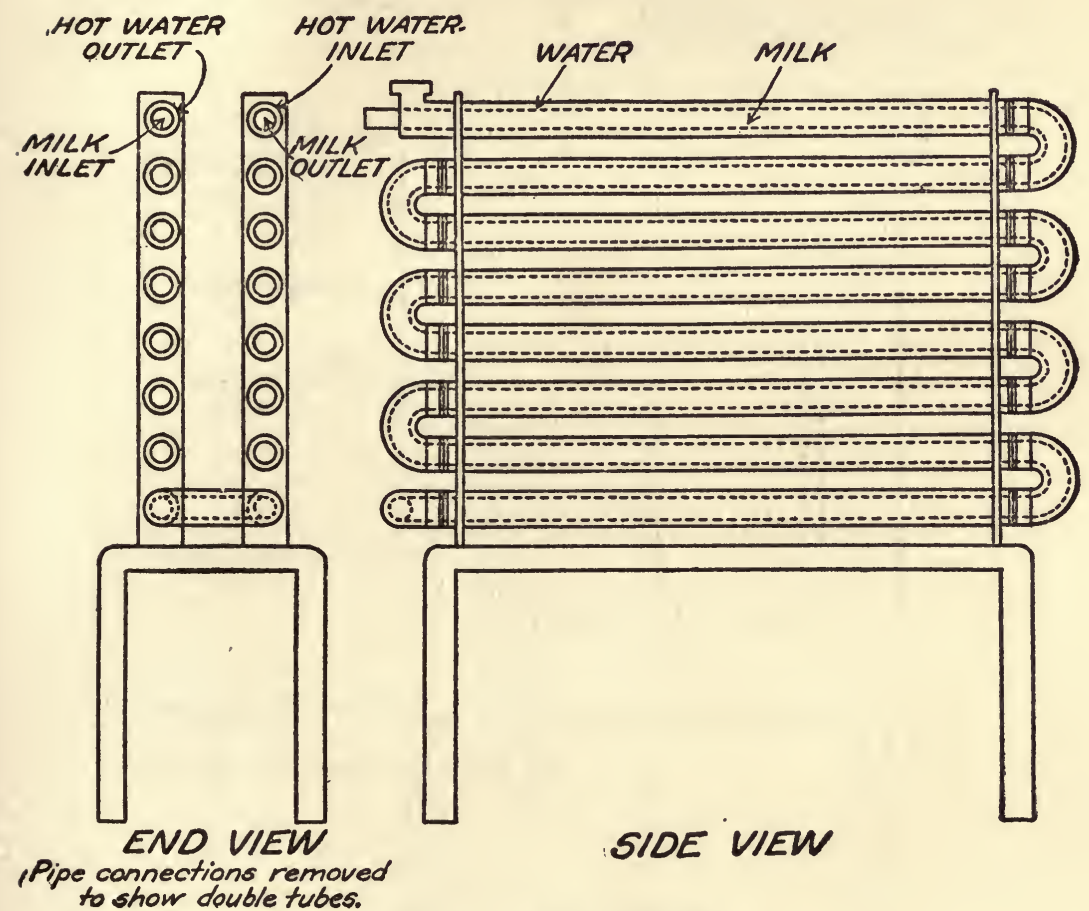

FIG. 25.-(B. A. I. Circ. 184).

A pasteurizer of simple style is shown in Fig. 24. The milk enters through the milk inlet at the bottom and is forced against the heated sides by the revolving paddle. Another type of pasteurizer is shown in Fig. 25. This is a system of double tubes or pipes. The milk flows through the inner tube in one direction and 
the hot water through the outer tube in the opposite direction. The end connections are removable to facilitate cleaning. Fig. 26 shows a "starter can" adapted to pasteurize small quantities of milk. It may also be used as a cooler.

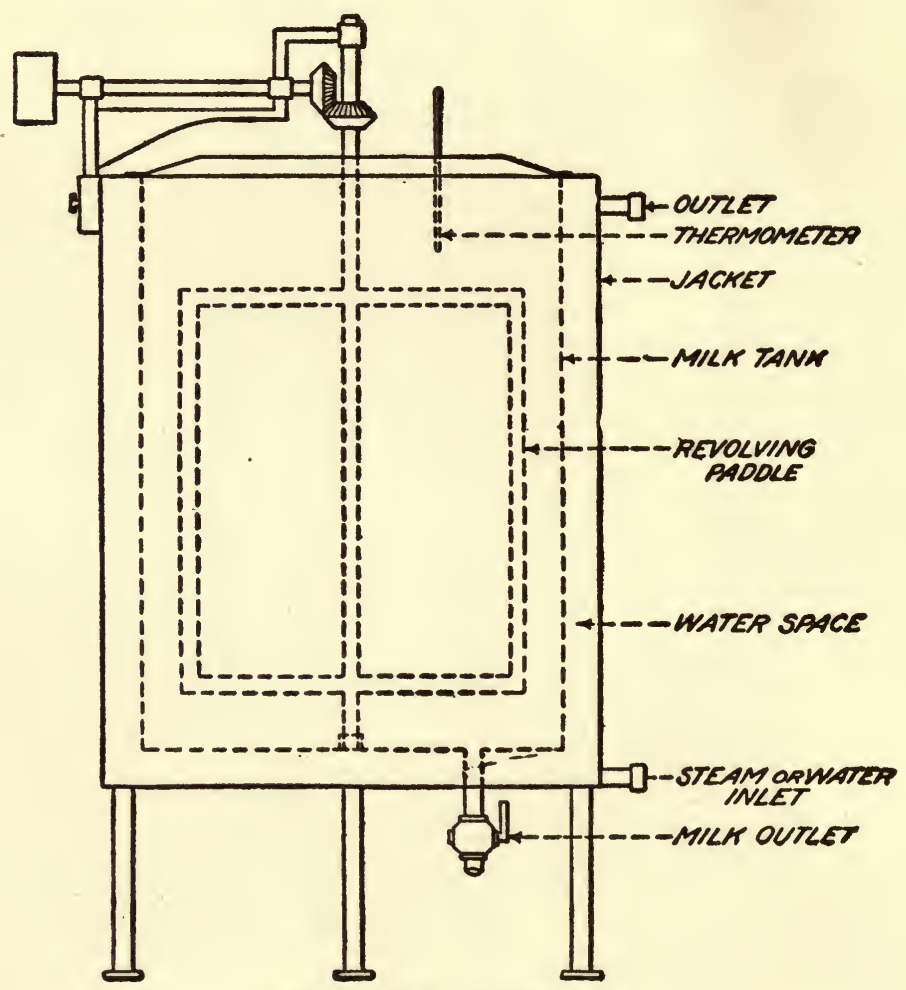

Fig. 26.-(B. A. I. Circ. 184).

In the "flash" method of pasteurization the milk passes from the pasteurizer over a cooler. Sometimes a regenerative cooler is used in which the milk to be pasteurized flows down one side of a corrugated sheet of metal and the milk coming from the pasteurizer flows down the other side, the cold milk thus absorbing some 
of the heat from the hot milk before the latter reaches the cooler. (See Fig. 27.) In the "holder" method, the milk is run from the pasteurizer or heater into the holder or retarder to be held at a certain temperature for a certain period of time. In the holder, the milk stops

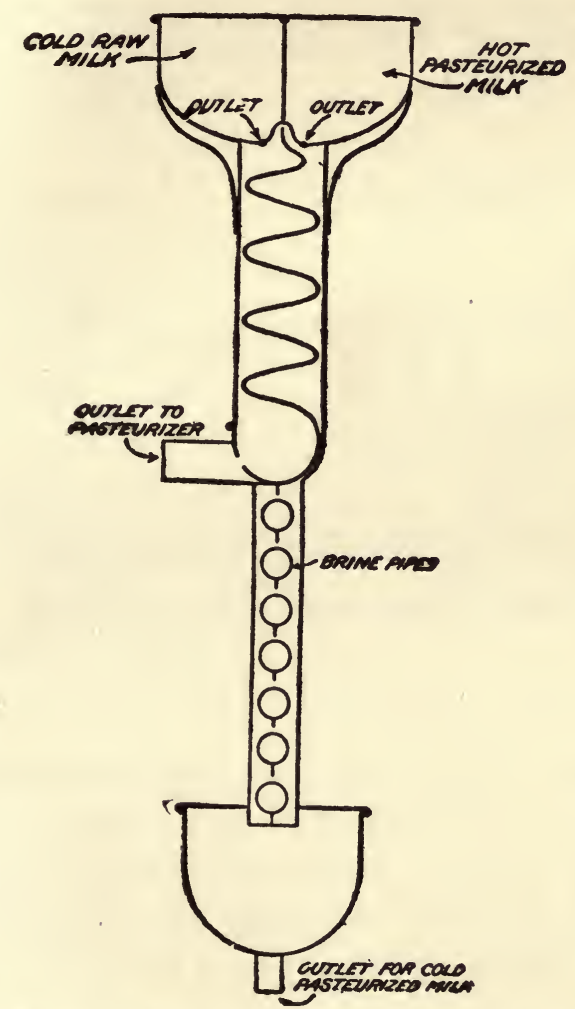

FrG. 27.-Regenerative Cooler. (B. A. I. Circ. 184).

flowing and is actually held for the required time. On the other hand, in the retarder the flow continues, but is slowed or retarded sufficiently to hold the milk for the required period. The retarder is not as reliable as the holder. A simple and cheap holding tank is shown in 
Fig. 28. It was made by dividing a receiving tank of 100 gallons capacity into four compartments of 25 gallons capacity each and providing an outlet valve and a cover for each compartment. Fig. 29 shows a retarder of the tank type. The milk from the pasteurizer enters at $A$ and is carried by the pipe to the bottom of the first compartment. When this is filled, it overflows into the trough $\mathrm{C}$, whence the milk flows through a pipe leading to the bottom of the second compartment. The other compartments are filled successively in the

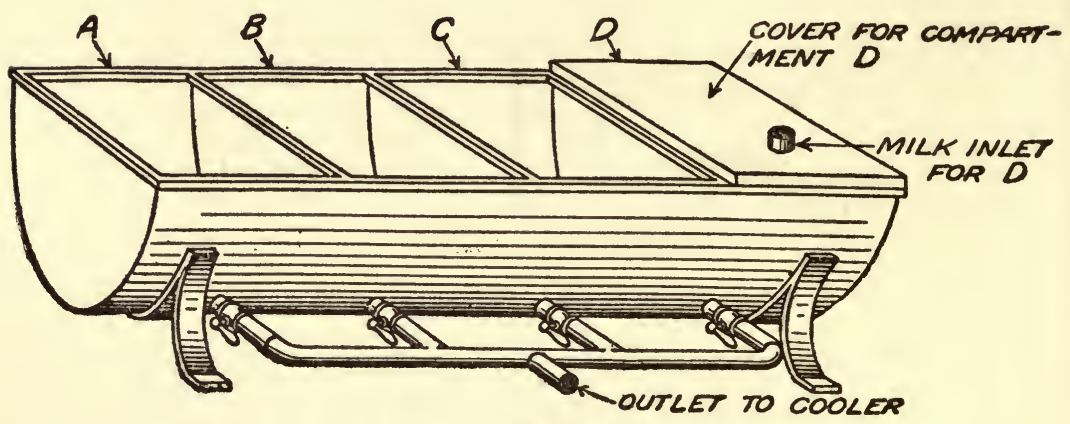

Fra. 28.-A simple holding tank (B. A. I. Circ. 184).

same manner. When the last compartment overflows the milk enters the funnel $\mathbf{B}$ and passes to the cooler. After all the milk has come over from the pasteurizer, the tank is emptied by removing the funnel $\mathrm{B}$ and then taking out the plugs from each compartment successively.

A combined pasteurizer and holder, which may also be used to cool the milk, is shown in outline in Fig. 30 . After the milk has been heated to the temperature desired and held for the required time, it can be cooled by replacing the hot water with cold water and then with ice water or brine. 


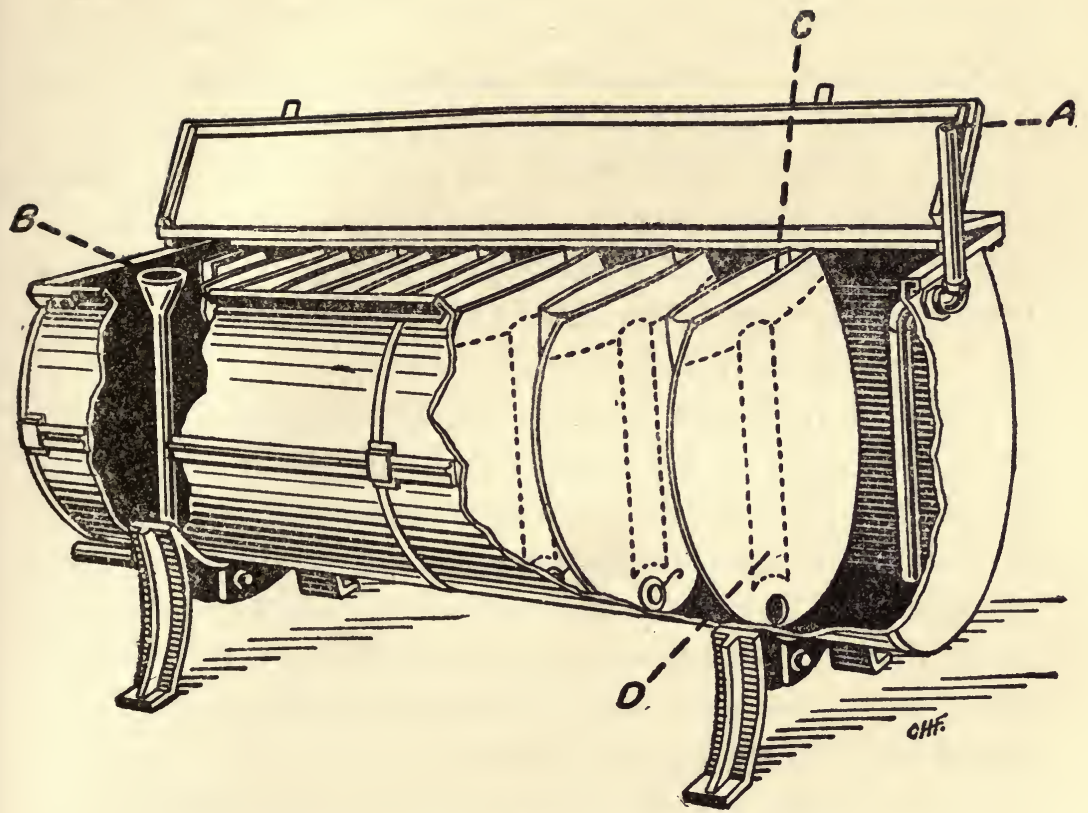

FIG. 29.-Retarder of the tank type (B. A. I. Circ. 184).

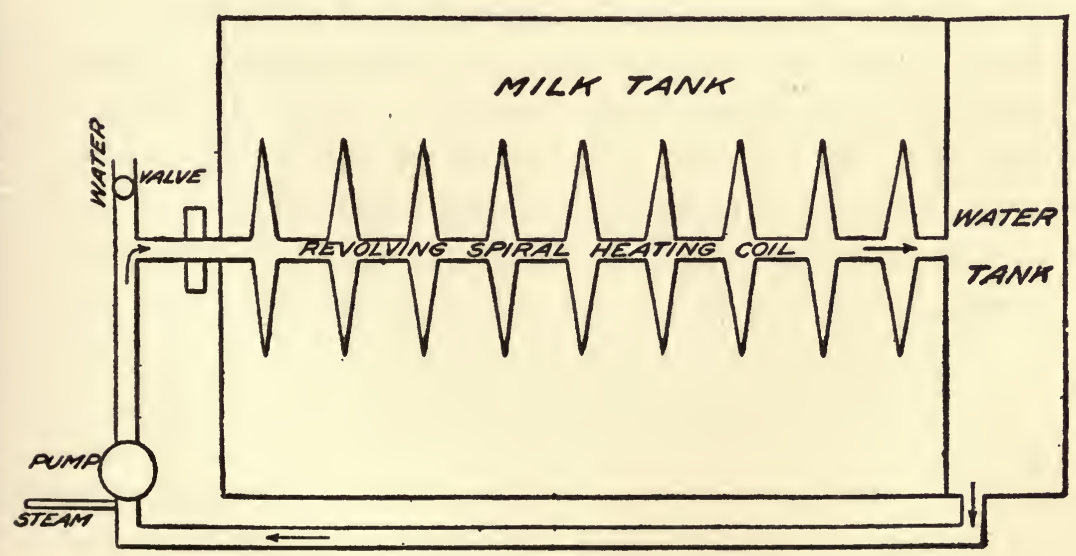

Fra. 30.-A combined pasteurizer and holder (B. A. I. Circ. 184). 
There should be an accurate thermometer in the outflow pipe of the pasteurizer and one in the outflow pipe of the holder. A reliable temperature and time-recording apparatus should be connected with both thermometers and the records should be kept on file for official inspection. These records should show the time of holding as well as the temperature. The efficiency of the pasteurizing apparatus should also be tested frequently by bacteriological tests.

The commercial pasteurization of milk should be permitted only under careful and competent official supervision. The inefficiency of commercial pasteurization without proper supervision has been frequently demonstrated. Two of the worst milk-borne epidemics which have occurred within recent years (Chicago 1911, Baltimore 1912) were due to infected milk which was supposed to have been pasteurized.

Biorization.-This process consists in spraying milk into a chamber in which it is exposed to a temperature of $167^{\circ} \mathrm{F}$. $\left(75^{\circ} \mathrm{C}\right.$.) while under a pressure of 3 to 4 pounds. The apparatus, which is called a biorizator, was invented by Dr. Oscar Lobeck, in Germany, in 1912. The inventor claims that by this process all of the harmful bacteria are destroyed, while the color, odor, taste, albumen, ferments, salts, and cream line are not affected.

It has been proposed to destroy bacteria in milk by subjecting them to the action of ultra-violet rays, electricity, and ozone, but the processes in which these agents are used have all proved less satisfactory than pasteurization. 


\section{CHAPTER IX}

\section{METHODS OF EXAMINING MILK}

Milk may be subjected to various methods of examination for the purpose of detecting adulteration or dilution, the addition of preservatives, or the presence of pathological products, and for the determination of the reaction, the bacterial content, the relative number of leucocytes, the quantity of sediment or dirt, etc.

Collecting Samples.-When milk is permitted to stand undisturbed, the fat rises to the top and the heavier substances settle to the bottom. Some of the cells and bacteria gravitate to the bottom, but many of them are carried up with the fat. The upper part of the milk contains more fat than the lower even before a cream layer is visible. For these reasons, the milk in the container should be thoroughly mixed before a sample is taken for examination. When the milk is cold, considerable shaking or stirring is required to mix the fat equally. In collecting samples of which the specific gravity, the per cent. of fat and total solids or the acidity are to be determined, or which are to be tested for preservatives, alkalies, nitrates and nitrites, etc., the same dipper may be used in taking the different samples without affecting the accuracy of the tests. There appears to be some danger, however, of carrying typhoid fever and diphtheria infection over from one sample to another, although we have no proof of this having actually occurred. The same dipper may be used for stirring and mixing the milk. But when the bacterial content or the ferment reactions are to be determined, each sam- 
ple must be collected in such a manner as to avoid the contamination of one sample by another. The most satisfactory plan is to have a sufficient number of sterile pipettes or aluminum tubes of suitable size and to use a separate pipette or tube for each sample. (See method described on page 261.) The extension of the custom of delivering milk in bottles has greatly simplified the collection of samples for laboratory examination, especially for the bacteriological and ferment tests.

An instrument known as a "milk thief" is frequently used to collect samples of milk from vessels with straight sides, like shipping cans. It consists of a metal tube about 23 inches long with a handle at the upper end. This tube is inserted slowly into the can of milk in a perpendicular position until the lower end of the tube rests on the bottom of the can. The interior of the tube, of course, fills with milk. The opening at the top is closed tightly with the thumb, and the tube is then lifted out of the can, carrying with it the column of milk in the interior. The milk thus withdrawn may be emptied into a vessel by removing the thumb from the top of the tube. By this means, a column of milk extending from the bottom to the top of the fluid is obtained, which includes all of the different strata existing at various levels in the can and which may therefore be regarded as a representative sample. Another type of tube sampler has a cap at the lower end with three openings, which are closed when the cap comes in contact with the bottom of the can. As the tube is pushed down into the can, the milk enters its interior through these openings and is held there when the cap is closed. The tube is then withdrawn and the milk emptied into a vessel.

Preserving Samples.-When the samples are to be 
shipped some distance to a laboratory to be tested for specific gravity, fat per cent., and per cent. of total solids, or to be subjected to any of the chemical tests, an antiseptic may be added to preserve them. Potassium dichromate, $1 / 2$ gram to the liter of milk ( $71 / 2$ grains to the quart) and formalin, 20 drops to the liter, are usually used for this purpose. It is better, however, to sterilize the sample bottle by boiling and to close it with a sterilized stopper. This method must be followed when bacteriological or ferment tests are to be made, as antiseptics cannot be added in such cases, and the samples should be packed in ice.

Stable or Herd Samples. - When a sample of market milk is tested and it appears from the results that the milk has been diluted with water or that it has been skimmed or diluted with skimmed milk, a stable or herd sample may be taken at the dairy farm from which the suspected milk came and tested for comparison. On the day the herd sample is taken, the cows should be fed, watered, and milked as usual and by the regular persons; the two milkings should be thoroughly mixed and the sample taken from the whole. If nitrates or nitrites have been found, samples of the water should also be taken and examined. The importance of the stable or herd test is variously regarded. Some authorities do not consider it of much value, especially for small herds, because of the daily variation in the composition of the milk of the cow, particularly in the per cent. of fat. Others do not believe that accepted averages of the specific gravity and composition of normal milk are a safe basis for judging milk in regard to dilution or skimming, and are of the opinion that a definite conclusion can only be reached 
after a herd sample is tested and the results compared. The establishment of a legal standard for the per cent. of fat and total solids in milk has made it unnecessary in many states to prove that milk has been actually diluted or skimmed. All that is required is to show that the fat and total solids are below the legal standard; consequently the question of taking a stable sample for comparison does not arise.

Individual Samples.-When a sample of milk is taken from an individual cow for the determination of the specific gravity and the per cent. of fat and total solids, the milk should be drawn into a pail in the usual manner and the sample taken from the pail after the milk has been thoroughly mixed. If it is desired to ascertain the average for the day, which is the usual method, an equal quantity of milk is taken from the morning and evening milking, mixed, and then tested. When the ferment tests are to be applied or the number of bacteria is to be determined, the sample must be drawn with a sterile pipette and placed in a sterile bottle, the contents of the pail being first thoroughly mixed. If the milk is to be examined for pathological conditions, a small quantity may be milked from each quarter into a sterile bottle; it is best, however, to have each quarter milked dry and to collect a small quantity of milk at the beginning, in the middle, and at the end of the milking.

Mixing the Milk Sample.-Previous to removing milk from the sample bottle for a test in the laboratory, the milk should be thoroughly mixed. This may be done by inverting the bottle several times if it is tightly stoppered, or by pouring the milk from the bottle into a beaker and back again several times. No cream should 
be permitted to adhere to the stopper or to the sides of the bottle. If the bottle has been standing for several hours and the milk has been thoroughly chilled, it may be necessary to warm the sample in order to avoid this.

Color, Consistency, Odor, and Taste.-As a preliminary examination, the color, consistency, odor, and taste of the milk should be observed. The senses of smell and taste soon tire, however, and it is therefore not possible to properly examine many samples consecutively.

A bluish tinge may indicate a low per cent. of fat, skimming, or watering, but it must be remembered that any milk will have a bluish tinge if in a thin layer. A reddish tinge is sometimes observed in milk from an udder affected with mastitis. Various other changes in color may occur as the result of bacterial action (see page 71).

Thin or watery milk is an indication of dilution with water or of skimming. Flakes or curds are present in milk from an udder affected with mastitis. Other changes in consistency are caused by bacteria (see pages 67 and $69)$.

Abnormal odors may be absorbed from the atmosphere or may be caused by bacteria (see pages 29,30 , 67 and 71 ).

A salty or bitter taste is present in mastitis and indigestion, also near the end of lactation and just before parturition. A bitter, metallic taste may be due to rusted milk vessels. Milk may also have an abnormal taste as a result of the growth of certain bacteria, the absorption of gases, and from other causes (see pages $\mathbf{2 8}$ to $\mathbf{3 0}$ and 66 to 71 ). Heating milk will make an abnormal odor more pronounced. 


\section{DETERMINATION OF SPECIFIC GRAVITY}

The specific gravity of milk is determined by means of Quevenne's lactometer (Fig. 31) or modifications of this apparatus.

After being thoroughly mixed, some of the milk to be tested is poured into a high glass cylinder and the

Fre. 31. - Quevenne's lactometer.

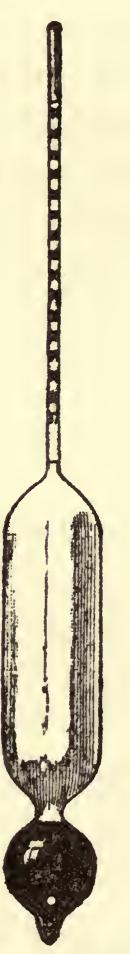

lactometer is slowly and carefully lowered into the fluid until it floats. Care should be taken not to mix air with the milk. This can be avoided by pouring the milk against the side of the vessel. The lactometer must not be permitted to touch the side of the cylinder. When the lactometer has become stationary, the specific gravity is indicated by the figures on the scale in the stem of the lactometer. The reading is taken from the line in the scale which is on a level with the surface of the milk. The stem of the lactometer draws the milk up around it, forming a slight meniscus which obscures the line at the surface of the milk. The reading should not be taken from the top of this meniscus, but at the surface of the milk, the depth of the meniscus being estimated. The figures on the lactometer scale do not express the specific gravity but Quevenne degrees. By dividing Quevenne degrees by 1000 and adding 1, the specific gravity is obtained.

The temperature of the milk should be $15^{\circ} \mathrm{C}$. $\left(60^{\circ}\right.$ F.) when the specific gravity is taken, and the temperature should be taken with an accurate thermometer after 
the milk has been placed in the glass cylinder and the lactometer introduced. The lactometer reading and the temperature should be taken as nearly as possible at the same time. If the temperature of the milk is not exactly $15^{\circ} \mathrm{C} .\left(60^{\circ} \mathrm{F}\right.$. $)$, then the specific gravity at this temperature must be calculated from the lactometer and thermometer reading, because this is the standard temperature. Adding to the specific gravity 0.0002 for each degree Centigrade above 15 or $\mathbf{0 . 0 0 0 1}$ for each degree Fahrenheit above 60, and subtracting the same numbers for each degree below the standard temperature, will give the approximate specific gravity at the standard temperature; but more accurate results will be obtained by using the tables on pages 230 and 231 . If, for example, the lactometer reading is 28 and the temperature is $17^{\circ} \mathrm{C}$., locate 1.028 in the column at the extreme left and follow this line to the right to the column headed $17^{\circ} \mathrm{C}$.; the figures at this point, 28.4, represent the lactometer reading at $15^{\circ} \mathrm{C}$. To obtain exact results, the specific gravity should be taken with the milk at $15^{\circ} \mathrm{C}$., because lactometers are calibrated for this temperature. After the specific gravity is taken the lactometer should be rinsed with water and wiped dry.

The specific gravity of milk may also be determined by means of the Westphal balance (Fig. 32). This instrument consists of a pivoted beam with a float hanging from one end. The milk to be tested is placed in a glass cylinder and the float is let down into the milk. The weights on the beam are then moved until equilibrium is established, and the specific gravity is indicated by the position of the weights.

The specific gravity of normal market milk ranges from 1.028 to 1.034, the average being 1.032. Skimming 


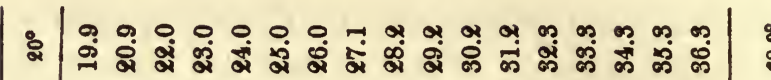

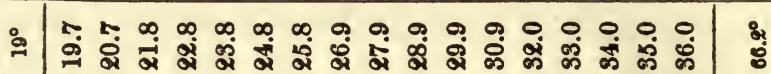
œ| \&| : - $\mid 000000000000000000000$

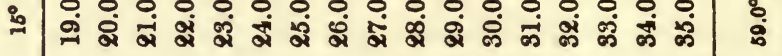

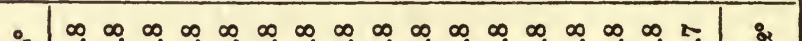

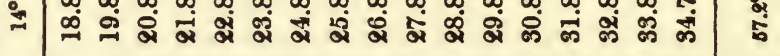

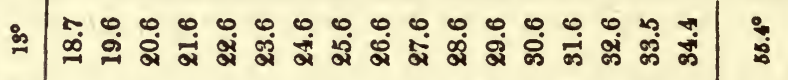

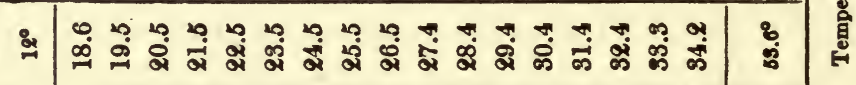
¿ 1- 010

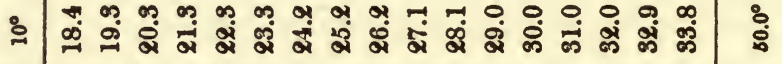

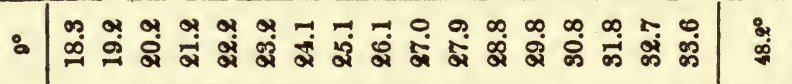

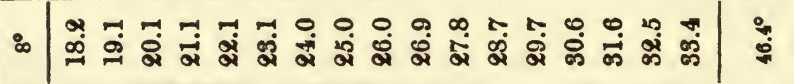

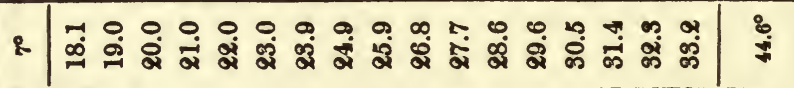

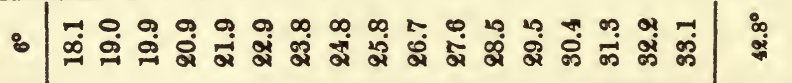




\begin{tabular}{|c|c|c|}
\hline ई & | & \\
\hline$\Xi$ & 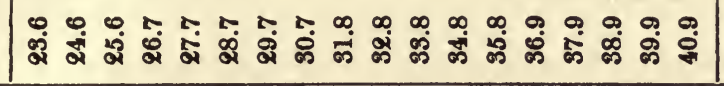 & 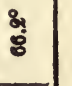 \\
\hline 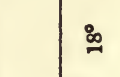 & 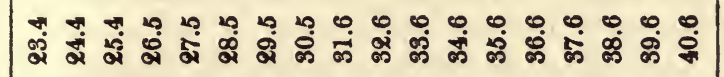 & 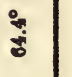 \\
\hline$\stackrel{8}{2}$ & 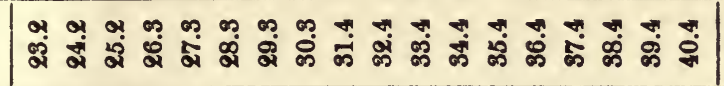 & 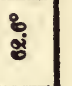 \\
\hline$\because$ & 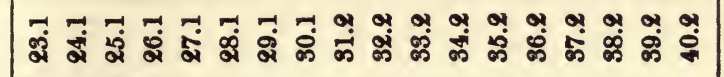 & 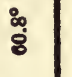 \\
\hline 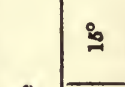 & 官 & 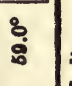 \\
\hline 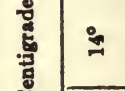 & 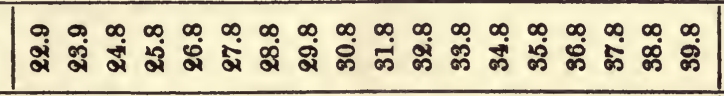 & 8 \\
\hline 党 & 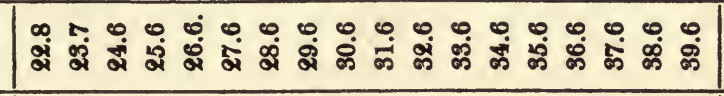 & 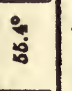 \\
\hline$\approx$ & 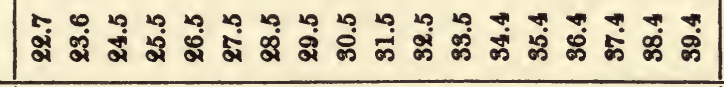 & $\ddot{8}$ \\
\hline 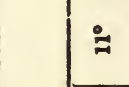 & 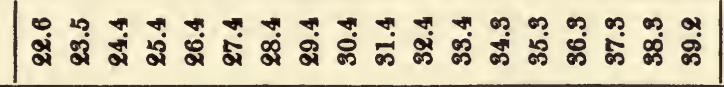 & 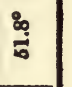 \\
\hline$\vdots$ & 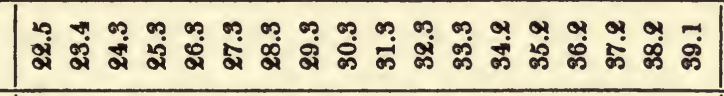 & : \\
\hline$\therefore$ & 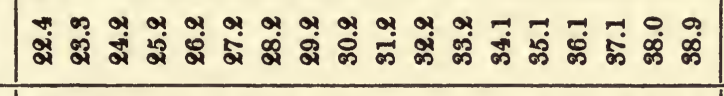 & $\$$ \\
\hline 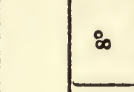 & \% & 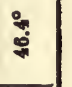 \\
\hline$\&$ & 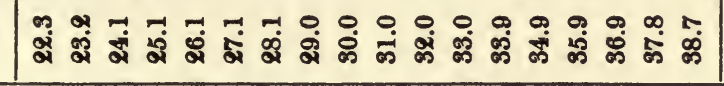 & $\xi$ \\
\hline$\therefore$ & | & $\$$ \\
\hline 营 & 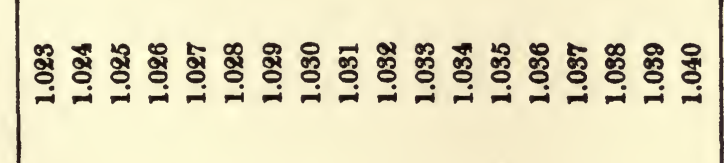 & \\
\hline
\end{tabular}


off the cream or adding skimmed milk increases the specific gravity, while the addition of water decreases it. It is not possible to detect these forms of adulteration from the change in specific gravity alone, on account of the wide range in the specific gravity of normal milk, but when considered in connection with the per cent. of fat and solids not fat the specific gravity is of great assistance. The specific gravity of skimmed milk may be lowered to normal by the addition of a suitable quantity

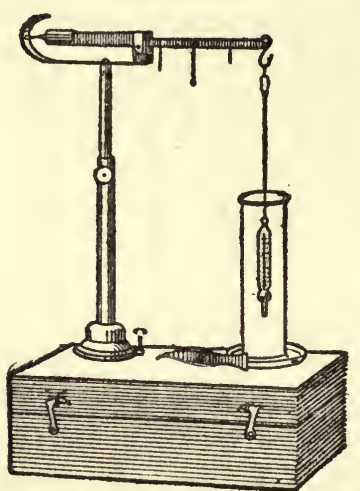

Fra. 32.-Westphal balance. (From Chemical Testing of Milk and Cream, by R. H. Shaw, U. B. Dept. of Agriculture.) of water. When this is suspected, the determination of the specific gravity of the dry matter or solids and the per cent. of fat in the total solids will throw further light on the subject. The test for nitrates and nitrites will assist in discovering the addition of water (see page 247). The refraction number of the milk serum is also of value in this connection (see page 250).

It is necessary to refer to the New York Board of Health lactometer because it is still used to some extent in the East, although it is constructed on the incorrect theory that 1.029 is the lowest specific gravity of pure milk. Its scale is divided into $\mathbf{1 2 0}$ divisions. One hundred corresponds to 29 Quevenne degrees, or a specific gravity of 1.029. Milk testing $\mathbf{9 0}$ on this scale is supposed to be 90 per cent. pure, i.e., 10 per cent. of water is supposed to have been added, which, of course, is not always true. Readings on this scale may be converted into Quevenne degrees by multiplying by 0.29 or the following table may be used: 


\begin{tabular}{|c|c|c|c|c|c|}
\hline $\begin{array}{c}\text { Board of } \\
\text { health degrees }\end{array}$ & $\begin{array}{l}\text { Quevenne } \\
\text { scale }\end{array}$ & $\begin{array}{c}\text { Board of } \\
\text { healtb degrees }\end{array}$ & $\begin{array}{l}\text { Quevenne } \\
\text { scale }\end{array}$ & $\begin{array}{c}\text { Board of } \\
\text { health degrees }\end{array}$ & $\begin{array}{l}\text { Quevenne } \\
\text { scale }\end{array}$ \\
\hline $\begin{array}{l}61 \\
62 \\
63 \\
64 \\
65 \\
66 \\
67 \\
68 \\
69 \\
70 \\
71 \\
72 \\
73 \\
74 \\
75 \\
76 \\
77 \\
78 \\
79 \\
80\end{array}$ & $\begin{array}{l}17-7 \\
18-0 \\
18-3 \\
18-6 \\
18-8 \\
19-1 \\
19-4 \\
19-7 \\
20-0 \\
20-3 \\
20-6 \\
20-9 \\
21-2 \\
21-5 \\
21-7 \\
22-0 \\
22-3 \\
22-6 \\
22-9 \\
23-2\end{array}$ & $\begin{array}{r}81 \\
82 \\
83 \\
84 \\
85 \\
86 \\
87 \\
88 \\
89 \\
90 \\
91 \\
92 \\
93 \\
94 \\
95 \\
96 \\
97 \\
98 \\
99 \\
100\end{array}$ & $\begin{array}{l}23-5 \\
23-8 \\
24-1 \\
24-4 \\
24-6 \\
24-9 \\
25-2 \\
25-5 \\
25-8 \\
26-1 \\
26-4 \\
26-7 \\
27-0 \\
27-3 \\
27-6 \\
27-8 \\
28-1 \\
28-4 \\
28-7 \\
29-0\end{array}$ & $\begin{array}{l}101 \\
102 \\
103 \\
104 \\
105 \\
106 \\
107 \\
108 \\
109 \\
110 \\
111 \\
112 \\
118 \\
114 \\
115 \\
116 \\
117 \\
118 \\
119 \\
120\end{array}$ & $\begin{array}{l}29-3 \\
29-6 \\
29-9 \\
30-2 \\
30-5 \\
30-7 \\
31-0 \\
31-3 \\
31-6 \\
31-9 \\
32-2 \\
32-5 \\
32-8 \\
33-1 \\
33-4 \\
33-6 \\
33-9 \\
34-2 \\
34-5 \\
34-8\end{array}$ \\
\hline
\end{tabular}

DETERMINATION OF THE PER CENT. OF FAT

Babcock Test.-The method devised by Dr. S. M. Babcock is the one most commonly used in the United States for determining the per cent. of fat in milk and other dairy products. The apparatus required consists of a bottle of about 50 c.c. capacity with a long neck containing graduations from which the per cent. of fat can be read off, a pipette holding 17.6 c.c., and a small measuring cylinder graduated to measure 17.5 c.c. A centrifuge is also necessary. The graduations on the neck of the old type of bottle extend from 0 to 10 per cent., with subdivisions of 0.2 per cent., but on the more recent type the scale is divided into tenths and extends from 0 to 8 per cent. Only glassware should be used which has been tested and approved by the United States Bureau of Standards. Commercial sulphuric acid with a specific gravity of 1.82 to 1.83 at $60^{\circ} \mathrm{F}$. is used in 
making the test. The acid dissolves the solids not fat and liberates the fat from its emulsion, generates heat which causes the fat globules to run together, and increases the specific gravity of the serum. The test is made as follows: The temperature of the milk should

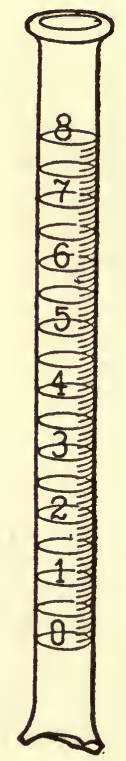

Fra.33.-Moderntype of Babcock milktesting bottle conforming to the requirements of the U. S. Bureau of Standards. (From Chemical Testing of Milk and Cream, by R. H.Shaw, U.S. Dept. of Agriculture.)

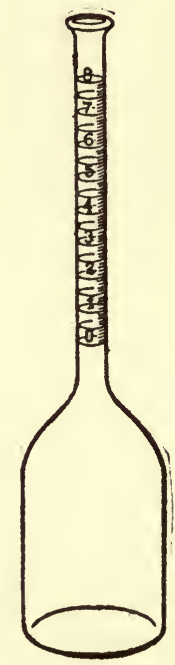

be between $60^{\circ}$ and $70^{\circ} \mathrm{F}$. After the milk has been thoroughly mixed, the tip of the pipette is inserted just beneath the surface and filled to the 17.6 c.c. mark. The pipette is then inserted obliquely into the mouth of the bottle and the milk permitted to run slowly down the inside of the neck. When the milk ceases flowing, the pipette is blown into to force out any residue. To 
obtain accurate results, every particle of milk must be delivered into the bottle. The measuring cylinder is filled to the $\mathbf{1 7 . 5}$ c.c. mark with sulphuric acid; then, with the bottle held by the neck in an oblique position, the acid is poured slowly down the side, the bottle being rotated slowly so that any milk in the neck will be washed down. The acid and milk are then mixed by grasping the bottle by the neck and gently whirling it, first to the right and then to the left, or by holding the bottle by the neck in an inclined position with the edge of the bottom resting on a table and rotating it, first in one direction and then in the other. When mixing is once commenced it must be continued until solution is complete. The solution should finally be of a dark brown color, The bottle is placed in a centrifuge and whirled for five minutes at a speed of 800 to 1200 revolutions per minute. Hot water at a temperature above $120^{\circ} \mathrm{F}$. $\left(49^{\circ} \mathrm{C}\right.$. $)$ is then added until the bottle is filled to the bottom of the

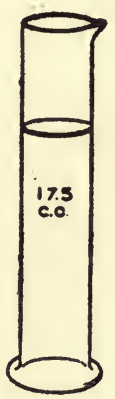

Fia. 35.-Cylinder used in Babcock test for measuring acid. (From Chemical Testing of Milk and Cream, by R. H. Shaw, U.S. Dept. of Agriculture.) neck and the bottle is replaced in the centrifuge and whirled for two minutes. Hot water is again added until the fluid in the bottle is raised to a point near the top of the graduated scale, the water being dropped directly into the fluid, not run down the side, in order to remove any flocculent material which may be entangled in the fat at the top. The bottle is then whirled another minute. After the whirling is completed, the fat should be collected at the top of the fluid in the bottle in a column of clear, yellowish liquid, with a nearly colorless fluid below it. The fat column should have a well-defined 
meniscus at the top and bottom, and the reading should be made from the bottom of the lower meniscus to the top of the upper one. A pair of calipers will be found convenient for measuring the fat column. The temperature of the contents of the bottle should be between $130^{\circ}$ and $140^{\circ} \mathrm{F}$. $\left(54^{\circ}\right.$ to $60^{\circ} \mathrm{C}$.) when the reading is taken. Foam on the top of the fat column is caused by using hard water. Dark colored particles in the fat column may be due to several causes: acid too concentrated, too much acid, milk too warm when acid was added, allowing acid to mix with milk when placing it in the bottle, allowing the bottle to stand too long before mixing the acid and milk, and interrupting the mixing before the solution was complete. White particles in the fat column may result from acid which is too weak, too little acid, acid or milk being too cold, and insuffcient mixing. Immediately after the reading is taken the bottle should be emptied, rinsed out twice with boiling water and placed in a rack to drain. Now and then the bottles should be washed in a solution of soap powder or in a dilute solution of lye.

The Babcock test for fat in cream is made in very much the same manner as for milk, except that a bottle with a longer neck and more extensive graduations is used and the cream is weighed instead of measured. There are two sizes of bottles, one for $\mathbf{9}$ grammes and the other for 18 grammes of cream. The test bottle is placed on the scales and the cream is introduced into the bottle with a pipette. Sufficient sulphuric acid is added to give the mixture the color of coffee; the quantity required will vary with the per cent. of fat in the cream. The bottle is then whirled in the centrifuge and water added exactly as in testing milk. On being finally re- 
moved from the centrifuge, the bottle is placed in water at a temperature of $135^{\circ}$ to $140^{\circ} \mathrm{F}$. $\left(57^{\circ}\right.$ to $60^{\circ} \mathrm{C}$.) and submerged to a point above the fat column for 15 minutes, after which the per cent. of fat is read off from the scale. The reading is taken from the bottom of the lower meniscus to the bottom of the upper one. It is recommended that the upper meniscus be destroyed by dropping a few drops of glymol (liquid petrolatum, white mineral oil) into the test bottle and the reading taken from the bottom of the lower meniscus to the line between the glymol and the fat.

\section{Gerber Test.-(Fig. 36.)} This test is used almost exclusively in Europe and to some extent in this country. The principle is the same as in the Babcock test, except that the fat is not only liberated from its emulsion by sulphuric acid but is also dissolved in amyl alcohol. The apparatus required consists of a special type of bottle

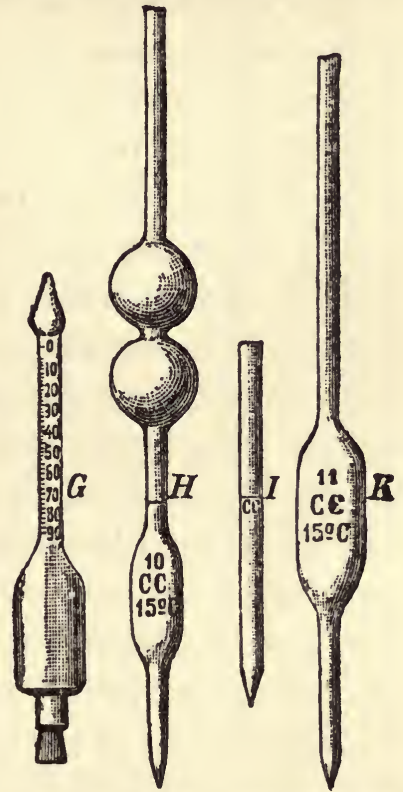

Fra. 36.-Bottle and pipettes used in Gerber test.

(G) known as an acido-butyrometer, which has a long neck containing a scale graduated in tenths, each division representing 0.1 per cent. of fat, and an opening in the bottom which may be closed with a rubber stopper; also three pipettes: 1 of 11 c.c. capacity to measure the milk $(\mathrm{K})$, an acid pipette holding 10 c.c. $(\mathrm{H})$, and a 1 c.c. pipette for the amyl alcohol (I). The chemicals used are commercial sulphuric acid of a specific gravity of 
1.825 at $15^{\circ} \mathrm{C}$. and amyl alcohol. The test is made as follows: The milk and the chemicals should be at a temperature of $15^{\circ}$ C. $; 10$ c.c. of sulphuric acid are measured with the acid pipette and placed in the bottle. The point of the pipette should be passed obliquely through the opening of the bottle until it comes in contact with the side of the bottle, when the acid is allowed to flow slowly out. Care should be taken that no acid is deposited in the spiral grooves on the inner side of the opening. After thoroughly mixing the milk, 11 c.c. are drawn up into the proper pipette and placed in the bottle with the same precautions, the milk being permitted to flow slowly down the side of the bottle so that it will not mix with the acid. Then 1 c.c. of amyl alcohol is placed in the bottle in the same manner with the alcohol pipette. The three fluids should be arranged in three distinct layers. The bottle is closed with the rubber stopper and the fluids are mixed by slowly raising first one end of the bottle and then the other, permitting the fluid to flow in and out of the neck. This is continued until a perfect solution is obtained. The rubber stopper should be forced in sufficiently to raise the fluid to the zero mark on the scale in the neck and it should be held in place with the thumb while the bottle is being shaken. This latter precaution is taken to prevent the stopper from coming out, although this is not likely to occur if it is properly inserted. The bottle should be placed in a water bath at a temperature of $60^{\circ}$ to $65^{\circ} \mathrm{C}$. $\left(140^{\circ}\right.$ to $150^{\circ} \mathrm{F}$.), with the stopper downward and the water covering the entire bottle, until it is centrifugalized. This will not be necessary, however, when only one or two samples are being tested. If a hand centrifuge is used the whirling must be continued 10 minutes, but with a 
power machine making 800 to 1000 revolutions per minute 3 to 4 minutes is sufficient. When the bottles are removed from the centrifuge they should be submerged in an upright position, with the stopper downward, in a water bath at $60^{\circ} \mathrm{C}$. $\left(140^{\circ} \mathrm{F}\right.$.) until the reading is taken, unless the samples are so few that they can all be read in a few seconds. The fat collects in a clear, yellow column at the top of the fluid in the neck. The stopper is turned sufficiently to bring the lower border of the fat column on a level with one of the main divisions of the scale and the per cent. of fat is then read off. The reading is taken from the bottom of the fat column to the lower border of the meniscus at the top. After the reading is taken the bottle should be emptied at once and cleaned as directed for the Babcock bottle.

A special bottle is made for testing cream. The cream placed in the bottle is weighed; otherwise the per cent. of fat in cream is determined in the same manner as that in milk.

Lactoscope Test.-It was proposed some time ago to determine the per cent. of fat in milk by measuring its transpar-

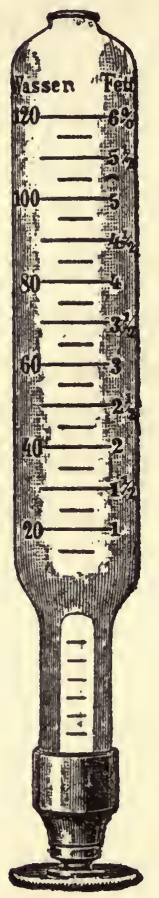

Fig. 37.-Feser's lactoscope. ency. Several forms of apparatus have been devised for this purpose, the simplest being Feser's lactoscope (Fig. 37). This is a glass tube, contracted towards the bottom. A vertical white-glass column, which is encircled by six blaek horizontal lines, projects upward into the contracted part. On the surface of the upper part of the tube there is a graduated scale with a column of figures 
at either side, one column representing the capacity in cubic centimetres and the other standing for per cent. of fat. The test is made as follows: 4 c.c. of the milk to be tested are placed in the glass tube and water is added up to the line marked 40. The two fluids are mixed and the apparatus is then held at arm's length with the back of the examiner to the light. If the black lines on the vertical column can be distinguished, then the figure in the per cent. column opposite the line which is on a level with the top of the fluid is supposed to represent the per cent. of fat. If the black lines are not visible, then water is added until the fluid is on a level with the next line on the scale and the fluid is mixed by shaking; this is repeated until the black lines can be seen, when the per cent. of fat is read off. This test is inaccurate because the degree of opacity of milk is not dependent entirely upon the quantity of fat but is also influenced by the size of the fat globules and by the calcium caseinate (see page 28). An error of 0.5 to 1 per cent. in either direction may occur in the examination of whole milk and the fat per cent. indicated for skim milk is usually too high.

\section{DETERMINATION OF TOTAL SOLIDS}

Gravimetric Method.-The apparatus required includes evaporating dishes, an accurate analytical balance with weights, a pipette, a water bath, a hot-water oven, and a desiccator. Platinum dishes are the most desirable, but porcelain and silica dishes are satisfactory and much cheaper; they should have a diameter of not less than $\mathbf{5}$ centimetres.

The dishes are cleaned and dried, placed in the hot- 
water oven for a half hour, removed to the desiccator until cool and then weighed. After they are placed in the oven they should be handled with tongs or forceps and should not be touched with the fingers. As each dish is weighed the weight is recorded. The milk sample is mixed thoroughly and some of the milk ( 3 to 5 c.c.) is transferred to the dish, which is again weighed, the weight being recorded. The dish is placed on a water bath where it remains until the milk is evaporated to dryness. It is then removed to the desiccator and when cool it is weighed. Following this it is placed in the hot-water oven for $\mathbf{3 0}$ minutes, after which it is again cooled in the desiccator and weighed. If the two weighings agree, or are within 0.2 milligramme of each other, the water has all been driven off. If the weighings do not agree to this extent, the dish must be returned to the hot-water oven for another period, then placed in the desiccator until cool and again weighed, and this must be continued until the weight is constant, or within $\mathbf{0 . 2}$ milligramme of being the same. The last weight minus the weight of the dish represents the weight of the dry matter or total solids in the charge of milk. Multiplying the weight of the dry matter by 100 and dividing by the weight of the charge will give the per cent. of dry matter in milk. The per cent. of ash may be determined by heating the dry matter until the ash is free from carbon, placing the dish in the desiccator until cool, weighing, subtracting the weight of the dish, multiplying the remainder by 100 and dividing by the weight of the charge.

By Calculation.-There are several formulas for calculating the total solids and solids not fat from the specific gravity and per cent. of fat. Of these Babcock's 
formula gives the most accurate results when compared with gravimetric determinations. This formula is as follows:

$$
\begin{aligned}
& \text { Per cent. solids not fat }=\left(\frac{100 \mathrm{~S}-\mathrm{Sf}}{100-1.0753 \mathrm{Sf}}-1\right) \times(100-\mathrm{f}) 2.5 \\
& \quad \mathrm{~S}=\text { specific gravity; } \mathrm{f}=\text { per cent. of fat. }
\end{aligned}
$$

The results obtained with this formula will not differ more than 0.25 to 0.5 per cent. from those obtained by the gravimetric method. A table prepared by Shaw and Eckles, which renders it unnecessary to make the calculation for each sample, will be found on pages 243 to 245. The Babcock formula determines the per cent. of solids not fat, but this table gives the per cent. of total solids; it is a modification of one prepared by Dr. Babcock. In the table the per cent. of total solids in any given sample will be found at the intersection of the column headed by the number representing the lactometer reading (Quevenne degrees) and the line corresponding to the fat per cent., provided the lactometer reading is a whole number. If the lactometer reading is not a whole number then the per cent. of total solids is found for the whole number and to this is added the fraction found opposite the decimal in the table for "proportional parts." Take, for example, a sample of milk with a lactometer reading of 33.5 and a fat per cent. of 3.5. At the point where the column headed 33 and the line marked 3.5 per cent. fat intersect are the figures 12.46. In the table for "proportional parts," opposite the decimal .5 is the fraction .13. This added to 12.46 equals 12.59 , which represents the per cent. of total solids. 
Table for Determining Total Solids in Milk From Any Given Specific Gravity and Percentage of Fat

\begin{tabular}{|c|c|c|c|c|c|c|c|c|c|c|c|}
\hline \multirow{2}{*}{$\begin{array}{l}\text { Per- } \\
\text { cent- } \\
\text { age of } \\
\text { fat }\end{array}$} & \multicolumn{11}{|c|}{ Lactometer reading at $60^{\circ} \mathrm{F}$. (Quevenne degrees) } \\
\hline & 26 & 27 & 28 & 29 & 30 & 81 & 32 & 33 & 34 & 35 & 36 \\
\hline & $\begin{array}{c}\text { Per } \\
\text { cent. } \\
\text { total } \\
\text { solids }\end{array}$ & $\begin{array}{c}\text { Per } \\
\text { cent. } \\
\text { total } \\
\text { solids }\end{array}$ & $\begin{array}{c}\text { Per } \\
\text { cent. } \\
\text { total } \\
\text { solids }\end{array}$ & $\begin{array}{c}\text { Per } \\
\text { cent. } \\
\text { total } \\
\text { solids }\end{array}$ & $\begin{array}{c}\text { Per } \\
\text { cent. } \\
\text { total } \\
\text { solids }\end{array}$ & $\begin{array}{c}\text { Per } \\
\text { cent. } \\
\text { total } \\
\text { solids }\end{array}$ & $\begin{array}{c}\text { Per } \\
\text { cent. } \\
\text { total } \\
\text { solids }\end{array}$ & $\begin{array}{c}\text { Per } \\
\text { cent. } \\
\text { total } \\
\text { solids }\end{array}$ & $\begin{array}{l}\text { Per } \\
\text { cent. } \\
\text { total } \\
\text { solids }\end{array}$ & $\begin{array}{c}\text { Per } \\
\text { cent. } \\
\text { total } \\
\text { solids }\end{array}$ & $\begin{array}{c}\text { Per } \\
\text { cent. } \\
\text { total } \\
\text { solids }\end{array}$ \\
\hline 2.00 & 8.90 & 9.15 & 9.40 & 9.65 & 9.90 & 10.15 & 10.40 & 10.66 & 10.91 & 11.16 & 11.41 \\
\hline 2.05 & 8.96 & 9.21 & 9.46 & 9.71 & 9.96 & 10.21 & 10.46 & 10.72 & 10.97 & 11.22 & 11.47 \\
\hline 2.10 & 9.02 & 9.27 & 9.52 & 9.77 & 10.02 & 10.27 & 10.52 & 10.78 & 11.03 & 11.28 & 11.53 \\
\hline 2.15 & 9.08 & 9.33 & 9.58 & 9.83 & 10.08 & 10.33 & 10.58 & 10.84 & 11.09 & 11.34 & 11.59 \\
\hline 2.20 & 9.14 & 9.39 & 9.64 & 9.89 & 10.14 & 10.39 & 10.64 & 10.90 & 11.15 & 11.40 & 11.65 \\
\hline 2.25 & 9.20 & 9.45 & 9.70 & 9.95 & 10.20 & 10.45 & 10.70 & 10.96 & 11.21 & 11.46 & 11.71 \\
\hline 2.30 & 9.26 & 9.51 & 9.76 & 10.01 & 10.26 & 10.51 & 10.76 & 11.02 & 11.27 & 11.52 & 11.77 \\
\hline 2.35 & 9.32 & 9.57 & 9.82 & 10.07 & 10.32 & 10.57 & 10.82 & 11.08 & 11.33 & 11.58 & 11.83 \\
\hline 2.40 & 9.38 & 9.63 & 9.88 & 10.13 & 10.38 & 10.63 & 10.88 & 11.14 & 11.39 & 11.64 & 11.89 \\
\hline 2.45 & 9.44 & 9.69 & 9.94 & 10.19 & 10.44 & 10.69 & 10.94 & 11.20 & 11.45 & 11.70 & 11.95 \\
\hline 2.50 & 9.50 & 9.75 & 10.00 & 10.25 & 10.50 & 10.75 & 11.00 & 11.26 & 11.51 & 11.76 & 12.01 \\
\hline 2.55 & 9.56 & 9.81 & 10.06 & 10.31 & 10.5 & 10.81 & 11. & 11.32 & 11.57 & & 12. \\
\hline 2.60 & 9.62 & 9.87 & 10.12 & 10.37 & 10.62 & 10.87 & 11.12 & 11.38 & 11.63 & & 12.13 \\
\hline 2.65 & 9.68 & 9.93 & 10.18 & 10.43 & 10.68 & 10.93 & 11.18 & 11.44 & 11.69 & 11.94 & 12.19 \\
\hline 8.70 & 9.74 & 9.99 & 10.24 & 10.49 & 10.74 & 10.99 & 11.24 & 11.50 & 11.75 & 12.00 & 12.25 \\
\hline 2.75 & 9.80 & 10.05 & 10.30 & 10.55 & 10.80 & 11.05 & 11. & 11. & 11.81 & 12.06 & 12.31 \\
\hline 2.80 & 9.86 & 10.11 & 10.36 & 10.61 & 10.86 & 11.11 & 11.3 & 11.6 & 11. & & 12.37 \\
\hline 2.85 & 9.92 & 10.17 & 10.42 & 10.67 & 10.92 & 11.17 & 11.43 & 11.6 & 11.93 & 12. & 12.43 \\
\hline 8.90 & 9.98 & 10.23 & 10.48 & 10.73 & 10.98 & 11.23 & 11.49 & 11.7 & 11.99 & 12.24 & 12.49 \\
\hline 2.95 & 10.04 & 10.29 & 10.54 & 10.79 & 11.04 & 11.30 & 11.55 & 11.80 & 12.05 & 12.30 & 12.55 \\
\hline 3.00 & & & & 10.85 & & 11.36 & 11.61 & 11.8 & & & 12.61 \\
\hline 3.05 & 10.16 & 10.41 & 10.66 & 10.91 & 11.17 & 11.42 & 11.67 & 11.92 & 12.17 & 12.42 & 12.68 \\
\hline 3.10 & 10.22 & 10.47 & 10.72 & 10.97 & 11.23 & 11.48 & 11.73 & 11.98 & 12.23 & 12.48 & 12.74 \\
\hline 3.15 & 10.28 & 10.53 & 10.78 & 11.03 & 11.29 & 11.54 & 11.79 & 12.04 & 12.29 & 12.55 & 12.80 \\
\hline 3.20 & 10.34 & 10.59 & 10.84 & 11.09 & 11.35 & 11.60 & 11.85 & 12.10 & 12.35 & 12.61 & 12.86 \\
\hline 3.25 & 10.40 & 10.65 & 10.90 & 11.16 & 11.41 & 11.66 & 11.9 & 12.16 & 12.42 & 67 & 12.92 \\
\hline 3.30 & 10.46 & 10.71 & 10.96 & 11.22 & 11.47 & 11.72 & 11.97 & 12.22 & 12.48 & 12.73 & 12.98 \\
\hline 3.35 & 10.52 & 10.77 & 11.03 & 11.28 & 11.53 & 11.78 & 12.03 & 12.28 & 12.54 & 18.79 & 13.04 \\
\hline 3.40 & 10.58 & 10.83 & 11.09 & 11.34 & 11.59 & 11.84 & 12.09 & 12.34 & 12.60 & 12.85 & 13.10 \\
\hline 3.45 & 10.64 & 10.89 & 11.15 & 11.40 & 11.65 & 11.90 & 12.15 & 12.40 & 12.66 & 12.91 & 13.16 \\
\hline 3.50 & 10.70 & & 11.21 & 11.46 & 11.71 & 11.96 & 12.21 & 12.46 & 12.72 & 12.97 & 13.22 \\
\hline 3.55 & & & & & & 12.02 & 12.2 & & & & \\
\hline 3.60 & 10.82 & 11.08 & 11.33 & 11.58 & 11.83 & 12.08 & 12.33 & 12.58 & 12.84 & 13.09 & 13.34 \\
\hline 3.65 & 10.88 & 11.14 & 11.39 & 11.64 & 11.89 & 12.14 & 12.39 & 12.64 & 12.90 & 13.15 & 13.40 \\
\hline 3.70 & 10.94 & 11.20 & 11.45 & 11.70 & 11.95 & 12.20 & 12.45 & 12.70 & 12.96 & 13.21 & 13.46 \\
\hline 3.75 & & 11.26 & & 11.76 & 12.01 & 12.26 & 12.51 & 12.76 & & 13.27 & 13.52 \\
\hline 3.80 & .06 & 11.32 & & 11.82 & 12.07 & 12.32 & 12.5 & 12.82 & 13. & 13. & 13.58 \\
\hline 85 & .12 & 11.38 & 11.63 & 11.88 & 12.13 & 12.38 & 12.63 & 12.88 & 13.14 & 13.39 & 13.6 \\
\hline 3.90 & 11.18 & 11.44 & 11.69 & 11.94 & 18.19 & 12.44 & 12.69 & 12.94 & 13.20 & 13.45 & 13.70 \\
\hline 3.95 & 11.24 & 11.50 & 11.75 & 12.00 & 12.25 & 12.50 & 12.75 & 13.00 & 13.26 & 13.51 & 13.77 \\
\hline 4.00 & & & & & & & & & & & \\
\hline 4.05 & 11.36 & 11.62 & 11.87 & 12.12 & 12.3 & 12.62 & 12.8 & 13.12 & & 13.63 & \\
\hline 4.10 & 11.42 & 11.68 & 11.93 & 12.18 & 12.43 & 12.68 & 12.93 & 13.18 & 13. & 13.69 & 13.95 \\
\hline 4.15 & 11.48 & 11.74 & 11.99 & 12.24 & 12.49 & 12.74 & 12.99 & 13.25 & 13.50 & 13.76 & 14.01 \\
\hline 4.20 & 11.54 & 11.80 & 12.05 & 12.30 & 12.55 & 12.80 & 13.05 & 13.31 & 13.56 & 13.82 & 14.07 \\
\hline 4.25 & 11.60 & 11.86 & 12.11 & 12.36 & 12.61 & 12.86 & 13.12 & 13.37 & 13.62 & 13.88 & 14.13 \\
\hline 49 & 11.66 & 11.92 & 12.17 & 12.42 & 12.67 & 12.92 & 13.18 & 13.43 & 13.68 & 13.94 & 14.19 \\
\hline 4.35 & 11.72 & 11.98 & 12.23 & 12.48 & 12.73 & 12.98 & 13.24 & 13.49 & 13.74 & 14.00 & 14.25 \\
\hline 4.40 & 11.78 & 12.04 & 12.29 & 12.54 & 18.79 & 13.04 & 13.30 & 13.55 & 13.80 & 14.06 & 14.31 \\
\hline 4.45 & 11.84 & 12.10 & 12.35 & 12.60 & 12.85 & 13.10 & 13.36 & 13.61 & 13.86 & 14.12 & 14.37 \\
\hline
\end{tabular}


Table for Determining Total Solids in Mrlk From Ant Grven Specific Gravity and Percentage of Fat-Continued

\begin{tabular}{|c|c|c|c|c|c|c|c|c|c|c|c|}
\hline \multirow{2}{*}{$\begin{array}{l}\text { Per } \\
\text { cent- } \\
\text { age of } \\
\text { fat }\end{array}$} & \multicolumn{11}{|c|}{ Lactometer reading at $60^{\circ} \mathrm{F}$. (Quevenne degrees). } \\
\hline & 26 & 27 & 28 & 29 & 30 & 81 & 32 & 33 & 84 & 35 & 36 \\
\hline $\begin{array}{l}4.50 \\
4.55 \\
4.60 \\
4.65 \\
4.70 \\
4.75 \\
4.80 \\
4.85 \\
4.90 \\
4.95\end{array}$ & 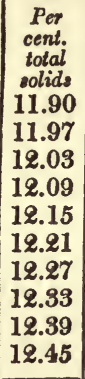 & $\begin{array}{c}\text { Per } \\
\text { cent. } \\
\text { total } \\
\text { solids } \\
12.16 \\
12.22 \\
12.28 \\
12.34 \\
12.40 \\
12.46 \\
12.52 \\
12.58 \\
12.64 \\
12.70\end{array}$ & 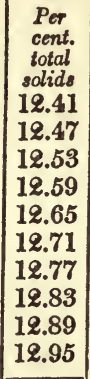 & 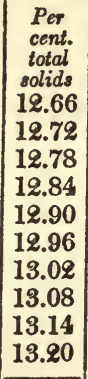 & $\begin{array}{c}\begin{array}{c}\text { Per } \\
\text { cent. } \\
\text { total } \\
\text { solids }\end{array} \\
12.91 \\
12.97 \\
13.03 \\
13.09 \\
13.15 \\
13.21 \\
13.27 \\
13.33 \\
13.39 \\
13.45\end{array}$ & 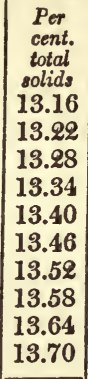 & $\begin{array}{c}\text { Per } \\
\text { cent. } \\
\text { total } \\
\text { eolids } \\
13.42 \\
13.48 \\
13.54 \\
13.60 \\
13.66 \\
13.72 \\
13.78 \\
13.84 \\
13.90 \\
13.96\end{array}$ & $\begin{array}{c}\begin{array}{c}\text { Per } \\
\text { cent. }\end{array} \\
\begin{array}{c}\text { total } \\
\text { solids }\end{array} \\
13.67 \\
13.73 \\
13.79 \\
13.85 \\
13.91 \\
13.97 \\
14.03 \\
14.09 \\
14.15 \\
14.21 \\
\end{array}$ & $\begin{array}{c}\text { Per } \\
\text { cent. } \\
\text { total } \\
\text { solids } \\
13.92 \\
13.98 \\
14.04 \\
14.10 \\
14.16 \\
14.22 \\
14.28 \\
14.34 \\
14.40 \\
14.46\end{array}$ & 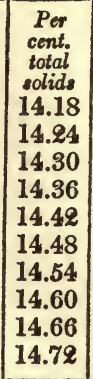 & $\begin{array}{c}\text { Per } \\
\text { cent. } \\
\text { total } \\
\text { solids } \\
14.43 \\
14.49 \\
14.49 \\
14.55 \\
14.61 \\
14.67 \\
14.73 \\
14.79 \\
14.85 \\
14.91 \\
14.97\end{array}$ \\
\hline $\begin{array}{l}5.00 \\
5.05 \\
5.10 \\
5.15 \\
5.20 \\
5.25 \\
5.30 \\
5.35 \\
5.40 \\
5.45\end{array}$ & $\begin{array}{l}12.51 \\
12.57 \\
12.63 \\
12.69 \\
12.75 \\
12.81 \\
12.87 \\
12.93 \\
12.99 \\
13.05\end{array}$ & \begin{tabular}{|l|}
12.76 \\
12.82 \\
12.88 \\
12.94 \\
13.00 \\
13.06 \\
13.12 \\
13.18 \\
13.24 \\
13.30
\end{tabular} & $\begin{array}{l}13.01 \\
13.07 \\
13.13 \\
13.19 \\
13.25 \\
13.31 \\
13.37 \\
13.43 \\
13.49 \\
13.55\end{array}$ & \begin{tabular}{|l|}
13.26 \\
13.32 \\
13.38 \\
13.44 \\
13.50 \\
13.56 \\
13.62 \\
13.68 \\
13.74 \\
13.80
\end{tabular} & \begin{tabular}{|l|}
13.51 \\
13.57 \\
13.63 \\
13.69 \\
13.75 \\
13.81 \\
1387 \\
13.93 \\
14.00 \\
14.06
\end{tabular} & \begin{tabular}{|l|}
13.76 \\
13.83 \\
13.89 \\
13.95 \\
14.01 \\
14.07 \\
14.13 \\
14.19 \\
14.25 \\
14.31 \\
\end{tabular} & \begin{tabular}{|l|}
14.02 \\
14.08 \\
14.14 \\
14.20 \\
14.26 \\
14.32 \\
14.38 \\
14.44 \\
14.50 \\
14.56
\end{tabular} & \begin{tabular}{|l|}
14.27 \\
14.33 \\
14.39 \\
14.45 \\
14.51 \\
14.57 \\
14.63 \\
14.70 \\
14.76 \\
14.82
\end{tabular} & \begin{tabular}{|l|}
14.52 \\
14.58 \\
14.64 \\
14.70 \\
14.76 \\
14.82 \\
14.88 \\
14.95 \\
15.01 \\
15.07
\end{tabular} & $\begin{array}{l}14.78 \\
14.84 \\
14.90 \\
14.96 \\
15.02 \\
15.08 \\
15.14 \\
15.20 \\
15.26 \\
15.32\end{array}$ & $\begin{array}{l}15.03 \\
15.09 \\
15.15 \\
15.21 \\
15.27 \\
15.39 \\
15.39 \\
15.45 \\
15.51 \\
15.57\end{array}$ \\
\hline $\begin{array}{l}5.50 \\
5.55 \\
5.60 \\
5.65 \\
5.70 \\
5.75 \\
5.80 \\
5.85 \\
5.90 \\
5.95\end{array}$ & $\begin{array}{l}13.11 \\
13.17 \\
13.23 \\
13.29 \\
13.35 \\
13.41 \\
13.47 \\
13.53 \\
13.59 \\
13.65\end{array}$ & $\begin{array}{l}13.36 \\
13.48 \\
13.48 \\
13.54 \\
13.60 \\
13.66 \\
13.72 \\
13.78 \\
13.84 \\
13.90\end{array}$ & $\begin{array}{l}13.61 \\
13.67 \\
13.73 \\
13.79 \\
13.85 \\
13.91 \\
13.97 \\
14.04 \\
14.10 \\
14.16\end{array}$ & \begin{tabular}{|l|}
13.86 \\
13.93 \\
13.99 \\
14.05 \\
14.11 \\
14.17 \\
14.23 \\
14.29 \\
14.35 \\
14.41
\end{tabular} & \begin{tabular}{|l|}
14.12 \\
14.18 \\
14.24 \\
14.30 \\
14.36 \\
14.42 \\
14.48 \\
14.54 \\
14.60 \\
14.66
\end{tabular} & \begin{tabular}{|l}
14.37 \\
14.43 \\
14.49 \\
14.55 \\
14.61 \\
14.68 \\
14.74 \\
14.80 \\
14.86 \\
14.92
\end{tabular} & \begin{tabular}{|l|}
14.62 \\
14.69 \\
14.75 \\
14.81 \\
14.87 \\
14.93 \\
14.99 \\
15.05 \\
15.11 \\
15.17
\end{tabular} & $\begin{array}{l}14.88 \\
14.94 \\
15.00 \\
15.06 \\
15.12 \\
15.18 \\
15.24 \\
15.30 \\
15.36 \\
15.42\end{array}$ & $\begin{array}{l}15.13 \\
15.19 \\
15.25 \\
15.31 \\
15.37 \\
15.43 \\
15.49 \\
15.55 \\
15.61 \\
15.67\end{array}$ & $\begin{array}{l}15.38 \\
15.44 \\
15.50 \\
15.56 \\
15.62 \\
15.68 \\
15.74 \\
15.80 \\
15.86 \\
15.92\end{array}$ & $\begin{array}{l}15.63 \\
15.69 \\
15.75 \\
15.81 \\
15.87 \\
15.93 \\
15.99 \\
16.06 \\
16.18 \\
16.18\end{array}$ \\
\hline $\begin{array}{l}6.00 \\
6.05 \\
6.10 \\
6.15 \\
6.20 \\
6.25 \\
6.30 \\
6.35 \\
6.40 \\
6.45\end{array}$ & $\begin{array}{l}13.71 \\
13.77 \\
13.83 \\
13.89 \\
13.95 \\
14.01 \\
14.07 \\
14.13 \\
14.19 \\
14.25\end{array}$ & $\begin{array}{l}13.96 \\
14.02 \\
14.08 \\
14.14 \\
14.20 \\
14.26 \\
14.32 \\
14.38 \\
14.44 \\
14.50\end{array}$ & \begin{tabular}{|l}
14.82 \\
14.28 \\
14.34 \\
14.40 \\
14.46 \\
14.52 \\
14.58 \\
14.64 \\
14.70 \\
14.76
\end{tabular} & \begin{tabular}{|l|}
14.47 \\
14.53 \\
14.59 \\
14.65 \\
14.71 \\
14.77 \\
14.83 \\
14.90 \\
14.96 \\
15.02
\end{tabular} & $\begin{array}{l}14.72 \\
14.78 \\
14.84 \\
14.90 \\
14.96 \\
15.02 \\
15.08 \\
15.14 \\
15.20 \\
15.26\end{array}$ & \begin{tabular}{|l}
14.98 \\
15.04 \\
15.10 \\
15.16 \\
15.22 \\
15.28 \\
15.34 \\
15.40 \\
15.46 \\
15.52
\end{tabular} & \begin{tabular}{|l}
15.23 \\
15.29 \\
15.35 \\
15.41 \\
15.47 \\
15.53 \\
15.59 \\
15.65 \\
15.71 \\
15.77
\end{tabular} & \begin{tabular}{|l}
15.48 \\
15.54 \\
15.60 \\
15.66 \\
15.72 \\
15.78 \\
15.84 \\
15.90 \\
15.96 \\
16.02
\end{tabular} & $\begin{array}{l}15.73 \\
15.79 \\
15.85 \\
15.91 \\
15.97 \\
16.03 \\
16.09 \\
16.15 \\
16.21 \\
16.27\end{array}$ & \begin{tabular}{|l|}
15.98 \\
16.04 \\
16.10 \\
16.16 \\
16.22 \\
16.28 \\
16.34 \\
16.40 \\
16.46 \\
16.52 \\
\end{tabular} & $\begin{array}{l}16.24 \\
16.30 \\
16.35 \\
16.42 \\
16.48 \\
16.54 \\
16.60 \\
16.66 \\
16.72 \\
16.78\end{array}$ \\
\hline $\begin{array}{l}6.50 \\
6.55 \\
6.60 \\
6.65 \\
6.70 \\
6.75 \\
6.80 \\
6.85 \\
6.90 \\
6.95\end{array}$ & $\begin{array}{l}14.31 \\
14.37 \\
14.43 \\
14.49 \\
14.55 \\
14.61 \\
14.67 \\
14.73 \\
14.79 \\
14.85\end{array}$ & \begin{tabular}{|l}
14.56 \\
14.62 \\
14.68 \\
14.74 \\
14.80 \\
14.86 \\
14.92 \\
14.98 \\
15.04 \\
15.10
\end{tabular} & \begin{tabular}{|l|}
14.82 \\
14.88 \\
14.94 \\
15.00 \\
15.06 \\
15.12 \\
15.18 \\
15.24 \\
15.30 \\
15.36 \\
\end{tabular} & \begin{tabular}{|l}
15.08 \\
15.14 \\
15.20 \\
15.26 \\
15.32 \\
15.38 \\
15.44 \\
15.50 \\
15.56 \\
15.62
\end{tabular} & \begin{tabular}{|l|}
15.32 \\
15.38 \\
15.44 \\
15.50 \\
15.56 \\
15.62 \\
15.68 \\
$15 \cdot 74$ \\
15.80 \\
15.86
\end{tabular} & \begin{tabular}{|l}
15.58 \\
15.64 \\
15.70 \\
15.76 \\
15.82 \\
15.88 \\
15.94 \\
16.00 \\
16.06 \\
16.12
\end{tabular} & $\begin{array}{l}15.83 \\
15.89 \\
15.95 \\
16.01 \\
16.07 \\
16.13 \\
16.19 \\
16.25 \\
16.31 \\
16.37\end{array}$ & $\begin{array}{l}16.08 \\
16.14 \\
16.20 \\
16.26 \\
16.32 \\
16.38 \\
16.44 \\
16.50 \\
16.56 \\
16.62\end{array}$ & $\begin{array}{l}16.33 \\
16.39 \\
16.45 \\
16.51 \\
16.57 \\
16.63 \\
16.69 \\
16.75 \\
16.81 \\
16.87\end{array}$ & \begin{tabular}{|l|}
16.58 \\
16.64 \\
16.70 \\
16.76 \\
16.82 \\
16.88 \\
16.94 \\
17.00 \\
17.06 \\
17.12
\end{tabular} & \begin{tabular}{|l}
16.84 \\
16.90 \\
16.96 \\
17.02 \\
17.08 \\
17.14 \\
17.20 \\
17.26 \\
17.32 \\
17.38 \\
\end{tabular} \\
\hline
\end{tabular}


PROPORTIONAL PARTS

\begin{tabular}{c|c||c|c||c|c}
\hline $\begin{array}{c}\text { Lactometer } \\
\text { fraction }\end{array}$ & $\begin{array}{c}\text { Fraction to } \\
\text { be added } \\
\text { to total } \\
\text { solids }\end{array}$ & $\begin{array}{c}\text { Lactometer } \\
\text { fraction }\end{array}$ & $\begin{array}{c}\text { Fraction to } \\
\text { be added } \\
\text { to total } \\
\text { solids }\end{array}$ & $\begin{array}{c}\text { Lactometer } \\
\text { fraction }\end{array}$ & $\begin{array}{c}\text { Fraction to } \\
\text { be added } \\
\text { to total } \\
\text { solids }\end{array}$ \\
\hline 0.1 & 0.03 & 0.4 & 0.10 & 0.7 & 0.18 \\
.2 & .05 & .5 & .13 & .8 & .20 \\
.3 & .08 & .6 & .15 & .9 & .23 \\
\hline
\end{tabular}

A simpler but less accurate formula by Babcock is based on the fact that the per cent. of total solids increases at about the rate of 0.25 for each lactometer (Quevenne) degree and $\mathbf{1 . 2}$ for each per cent. of fat. This formula is as follows.

Per cent. total solids $=1 / 4 \mathrm{~L}+(1.2 \mathrm{f})$

$\mathrm{L}=$ lactometer reading (Quevenne degrees); $\boldsymbol{l}=$ fat per cent.

By Automatic Reckoner.-The per cent. of total solids can also be determined, when the specific gravity and fat per cent. are known, by means of Ackermann's automatic reckoner and Richmond's sliding rule. The former is based upon Fleischmann's formula and the latter upon Richmond's formula. These two formulas do not give quite as accurate results as the Babcock formula on page 242 .

\section{DETERMINATION OF SOLIDS NOT FAT}

When the per cent. of fat and of total solids is known, the per cent. of solids not fat can be determined by simply subtracting the per cent. of fat from the per cent. of total solids. The per cent. of solids not fat can also be closely calculated from the fat per cent. and the specific gravity by means of Babcock's formula (page 242). The per cent. of solids not fat in normal market milk ranges from 8.5 to 10.5 . 
DETERMINATION OF THE SPECIFIC GRAVITY OF THE SOLIDS

The specific gravity of the dry milk solids can be calculated from the per cent. of total solids and the specific gravity of the milk according to the following formula:

$$
m=\frac{s t}{s t-(100 s-100)}
$$

m represents dry milk solids, $s$ specific gravity and $t$ total solids.

The specific gravity of the dry solids of normal whole milk varies from 1.31 to 1.36. Skimming milk increases the specific gravity of the milk solids.

\section{DETERMINATION OF THE PER CENT. OF FAT IN THE TOTAL SOLIDS}

The per cent. of fat in the total solids can be calculated from the per cent. of fat and of total solids in the milk according to the following formula:

$$
\mathrm{p}=\frac{\mathrm{f}}{\mathrm{t}} \times 100
$$

p represents per cent. of fat in total solids, $f$ per cent. of $f$ at in the milk and $t$ per cent. of total solids.

The per cent. of fat in the total solids varies from 20 to 34. It is decreased by skimming.

\section{DETERMINATION OF THE DEGREE OF ADULTERATION}

When it is possible to compare a sample of adulterated milk with a sample of the same milk collected under conditions which exclude the possibility of adulteration, the extent of the adulteration may be determined approximately by the following formulas of Böhmländer:

$$
\begin{aligned}
& M=\frac{R}{r} \times w-W \\
& E=100\left(1-\frac{f R}{F r}\right)
\end{aligned}
$$


In the first formula $W$ is the per cent. of water in the unadulterated sample; $w$ is the per cent. of water in the adulterated sample; $\mathbf{R}$ is the per cent. of solids not fat in the unadulterated sample; $r$ is the per cent. of solids not fat in the adulterated sample; $\mathbf{M}$ represents the quantity of water to 100 grammes of milk.

In the second formula $\mathbf{F}$ is the per cent. of fat in the unadulterated sample; $f$ is the per cent. of fat in the adulterated sample; $\mathbf{R}$ is the per cent. of solids not fat in the unadulterated sample; $r$ is the per cent. of solids not fat in the adulterated sample, and $\mathrm{E}$ represents the per cent. of fat removed by skimming.

\section{TESTS FOR NITRATES AND NITRITES}

Soxhlet's Test.-One-half c.c. of a 20 per cent. calcium chloride solution is mixed with about $\mathbf{3 0}$ c.c. of milk and the mixture is boiled and filtered. A 2 per cent. solution of diphenylamin in chemically pure sulphuric acid is added in sufficient quantity to some of the filtrate to make it milky. Chemically pure sulphuric acid is then poured slowly down the side of the test tube so that it forms a layer at the bottom. If nitrates or nitrites are present a blue zone is formed at the point where the two fluids come in contact. This test will detect one part of nitrates in 100,000; most farm water contains one part in $\mathbf{1 0 , 0 0 0}$ (Jensen).

A modification of this test is described by Rievel as follows: Place a small quantity of milk in a test tube and then pour in slowly, so that the two fluids will not mix, a solution of diphenylamin in chemically pure sulphuric acid $(1: 10)$. If minute traces of nitrites are present a blue ring will form at the point of contact of the two fluids. 
Fritzmann's Method.-Place 2 c.c. of milk in a test tube and slowly run down the side 2 c.c. of pure sulphuric acid to which one drop of a dilute formalin solution has been added. In the presence of nitrites a blueviolet ring will form at the point of contact of the two fluids, but the reaction will not occur in the presence of albumen. According to Riegel a suitable formalin solution may be made by adding one drop of 40 per cent. formalin to 300 c.c. of distilled water and mixing 15 grammes of this solution with one litre of concentrated sulphuric acid. This method gives very accurate results and is easily carried out (Rievel).

Fresh, clean milk does not contain nitrites. According to Jensen, nitrites are not present in the milk even when they have been contained in the food or drinking water of the cow. Marcus and Huyge assert that if nitrate of potassium is administered to the cow in quantities of 5 to 10 grammes the milk sometimes contains nitrates. It would seem likely that nitrates would also be excreted through the udder if the cow obtained access to fertilizer containing nitrates or to sacks which had contained such fertilizer.

The demonstration of nitrates or nitrites in milk is generally regarded as evidence that water has been added to the milk. Most farm waters contain nitrates and nitrites, as do also some city water supplies. But Rievel points out that the presence of nitrates or nitrites in milk cannot be regarded as positive proof that the milk has been watered, because when milk vessels are merely rinsed with water containing nitrates or nitrites the milk may give a positive reaction if the water is quite rich in nitrates or nitrites. Tillmans says that normal milk may 
contain up to 1 to $2 \mathrm{mg}$. per litre from this source. Rievel also states that a positive reaction may occur with milk soiled with manure, but Tillmans has never found dirty milk to give any indication of containing more nitrates or nitrites than milk from vessels that had been washed with water rich in nitrates or nitrites. A negative reaction to the nitrate test is no evidence that the milk has not been watered, as water free from these substances may be used for dilution. According to Utz, milk to be tested for nitrates should be boiled unless the test can be made at once, because the action of the lactic acidforming bacteria may reduce the nitrates or cause them to disappear entirely.

\section{DETECTION OF THE USUAL ADULTERATIONS}

When milk is adulterated, it is usually by partial skimming, dilution with skimmed milk, or dilution with water. The changes caused by these various forms of adulteration are shown in the following table, which is taken from Jensen's Milk Hygiene:

\begin{tabular}{|c|c|c|c|c|c|c|c|}
\hline & $\begin{array}{l}\text { Specific } \\
\text { gravity } \\
\text { of the } \\
\text { milk }\end{array}$ & $\begin{array}{c}\text { Per- } \\
\text { centage } \\
\text { of fat }\end{array}$ & $\begin{array}{l}\text { Percent- } \\
\text { age of } \\
\text { solids } \\
\text { not fat }\end{array}$ & $\begin{array}{c}\text { Specific } \\
\text { gravity } \\
\text { of the } \\
\text { milk } \\
\text { solids }\end{array}$ & $\begin{array}{c}\text { Per- } \\
\text { centage } \\
\text { of fat } \\
\text { in the } \\
\text { total } \\
\text { solids }\end{array}$ & $\begin{array}{c}\text { Per- } \\
\text { centage } \\
\text { of ash }\end{array}$ & $\begin{array}{l}\text { Presence } \\
\text { or absence } \\
\text { of nitrate }\end{array}$ \\
\hline Normal milk. & $\begin{array}{c}1.029 \text { to } \\
1.034 \\
\text { aver. } \\
1.032\end{array}$ & 3 to 5 & $\begin{array}{l}8.5 \text { to } \\
10.5\end{array}$ & $\begin{array}{l}1.30 \text { to } \\
1.34\end{array}$ & $\begin{array}{l}20 \text { to } \\
34\end{array}$ & $\left|\begin{array}{c}0.7 \text { to } \\
0.75\end{array}\right|$ & 0 \\
\hline $\begin{array}{l}\text { Skimmed or diluted } \\
\text { with skimmed milk }\end{array}$ & Higher & Lower & $\begin{array}{l}\text { Very } \\
\text { slightly } \\
\text { higher }\end{array}$ & Higher & Lower & Higher & 0 \\
\hline Water added... & Lower & Lower & Lower & $\begin{array}{l}\text { No } \\
\text { change }\end{array}$ & $\begin{array}{c}\text { No } \\
\text { change }\end{array}$ & Lower & + or 0 \\
\hline $\begin{array}{l}\text { Skimmed and water } \\
\text { added............. }\end{array}$ & $\begin{array}{l}\text { Little } \\
\text { change }\end{array}$ & Lower & Lower & Higher & Lower & Lower & + or 0 \\
\hline
\end{tabular}


Starch, flour, viscogen, etc., may be added to skimmed milk or cream to increase the viscosity (see page 33).

The test for starch is made as follows: Add a few drops of acetic acid to the milk or cream, boil and filter. To the filtrate add a few drops of a dilute iodine solution. If starch is present the filtrate becomes blue.

The presence of viscogen is indicated by a high per cent. of salts.

\section{DETERMINATION OF THE REFRACTION NUMBER}

The most satisfactory milk serum for this test is obtained by Ackermann's calcium chloride method and the refractive index is most conveniently determined by Zeiss' dipping refractometer. The method is as follows:

30 c.c. of the milk to be tested is placed in a test tube of 75 c.c. capacity and mixed with 0.25 c.c. of a 1 to 10 solution of calcium chloride in distilled water (specific gravity 1.1375 and refraction number 26 at $17.5^{\circ}$ C.). The test tube is closed with a perforated rubber stopper, then connected with a 22 c.c. condenser and heated for 15 minutes in a bath of briskly boiling water. ${ }^{1}$ It is then placed in cold water and cooled. During this process the serum separates from the curd and is poured off into a beaker. If the serum is not sufficiently free of coagula to permit of the passage of adequate light, it is an indication that acid fermentation has advanced too far for the milk to be investigated with the refractometer, the loss of lactose suffered in such cases being sufficient to render the result inaccurate. The beaker containing the serum is placed in the water bath

${ }^{1}$ If the milk tube is not connected with a condenser the result of the test will be nearly, if not exactly, the same and the test is much simplified. 
of the refractometer. The temperature of the water bath should be $17.5^{\circ} \mathrm{C}$. After allowing 8 to 10 minutes for the serum in the beaker to reach the same temperature, the prism of the refractometer is inserted in the beaker and the refraction number is read from the scale,

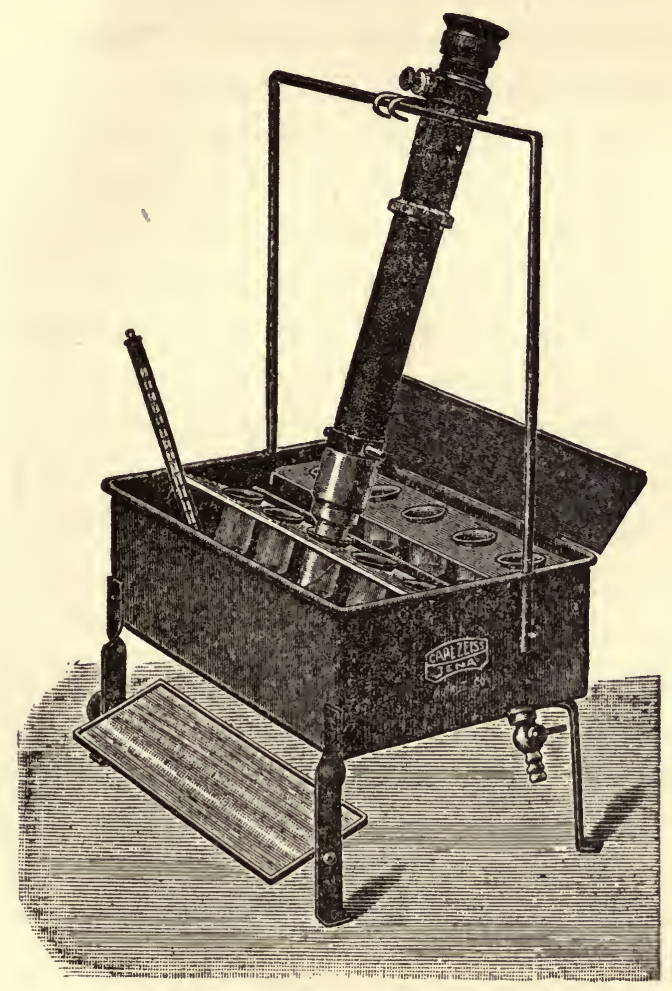

Fra. 38.-Zeiss dipping refractometer.

which is located in the refractometer beneath the ocular. On looking into the ocular it will be observed that a portion of the field is dark and the remainder light. The border line is usually fringed with colors and the compensator must then be rotated by means of the milled 
ring on the barrel of the refractometer until the line of demarcation between the dark and light areas is sharply defined and colorless. When this line falls on one of the divisions of the scale it is merely necessary to note the number, which is then the refraction number. When the line falls between two divisions of the scale the scale is then moved towards the border line by turning the thumb screw of the micrometer below the ocular until the scale division which was nearest to the border line on the dark side is exactly on it. The figure opposite the indicator on the micrometer is then noted and is added to the figure of the scale division as a decimal. For example, if the figure opposite the scale division nearest to the border line on the dark side was $\mathbf{3 8}$ and the micrometer was rotated to 7 in moving the scale division to the border line, then the refraction number is $\mathbf{3 8 . 7}$ The refraction number can be converted into the refractive index by means of a formula furnished with the refractometer, but this is not necessary.

Before beginning the examination of a number of samples of milk, the refractometer should be tested with distilled water, which at $17.5^{\circ} \mathrm{C}$. should give a reading of 15.5. The water bath is made to hold 12 beakers at one time so that when a number of samples are to be examined there will be an opportunity for each one to reach the required temperature without delaying the examinations. When the prism of the refractometer is removed from one sample, or from the distilled water, it should be wiped dry with a soft linen cloth before being introduced into another.

The refraction number of normal market milk is in most cases between 38 and 40.5. In rare cases it may be as low as $\mathbf{3 7 . 3}$ and in one case reported by Mai and 
Rothenfusser it reached 41.5. The addition of a small quantity of water to milk lowers the refraction number, but on account of the wide range in the refraction number of normal market milk it is necessary, in order to detect slight additions of water, to have the herd under suspicion milked under supervision and to take a sample of the milk and compare the refraction number of this sample with the refraction number of the sample of market milk. The daily variation in the refraction number of the milk of a herd will not exceed 0.1 to $\mathbf{0 . 5 5}$. Changes of feed have only a slight influence and incomplete milking has no effect. When the refraction number is as low as $\mathbf{3 6 . 5}$ or below the milk may be unhesitatingly pronounced watered.

The refraction number is not affected by the per cent. of fat. A sample of milk taken from the top of a can and one taken from the bottom of the same can will both have exactly the same refraction number, although there will be a great difference in the fat per cent. This is an important advantage, because when a charge that milk has been watered is based on the specific gravity and fat per cent. the claim is often made that the sample was taken from the bottom of the can or after the top milk had been sold.

The presence of boric acid and borax in the proportion usually used to preserve milk ( 0.1 to 0.2 per cent.) will increase the refraction of the milk serum. Salicylic acid also increases the refraction when present in as small amount as $\mathbf{0 . 0 5}$ per cent. which is the quantity used as a preservative, but formaldehyde causes no increase when present in the amount ordinarily used as a preservative. Sodium bicarbonate does not have any effect when added up to 0.1 per cent. 
In individual milk from diseased cows the refraction number has been found to be decreased in tuberculosis, febrile diseases, foot and mouth disease, and mastitis. In some cases of streptococcic mastitis Obladen found it as low as 24.8. The effect of mixing milk from diseased cows with normal milk has not been determined, but since diseased milk and watered milk are both low in refraction there is a possibility of confusion unless a proper investigation is made.

\section{DETERMINATION OF THE REACTION}

Litmus Test.-A strip of red and a strip of blue litmus paper are dipped in the milk for a few seconds and the color of the wet and dry portions is compared. Normal milk, when drawn from the udder, is amphoteric to litmus, i.e., the blue litmus is changed to red and the red litmus to blue. If the milk is more acid than normal, the blue paper will be colored red but the red paper will not be changed, while if the alkalinity is increased the red paper will be colored blue and the blue paper will not be changed. Individual milk is frequently alkaline to litmus in the last stages of lactation; it also gives an alkaline reaction in most cases of mastitis, but in some cases it is acid. Market milk is usually acid to litmus; it is never alkaline except when an alkali has been added. The litmus test is only of value as a preliminary test for individual milk.

Mann's Acidity Test.-The apparatus required for this test is a 50 c.c. burette with a stopcock, a stand, a beaker or a white cup, a stirring rod, and a 50 c.c. pipette. The reagents required are a solution of phenolphthalein and a one-tenth normal solution of sodium hydroxide. The phenolphthalein solution is prepared by dissolving 
10 grammes of powdered phenolphthalein in 300 c.c. of 90 per cent. alcohol. The one-tenth normal $\left({ }^{\mathrm{n}} / 10\right)$ solution of sodium hydroxide $(\mathrm{NaOH})$ should be prepared and standardized as directed by the U. S. Pharmacopœia. Each cubic centimetre of this solution contains sufficient sodium hydroxide (0.004 gramme) to neutralize 0.009 gramme of lactic acid.

After thoroughly mixing the milk or cream to be tested, 50 c.c. are measured into the beaker or cup with the pipette. The pipette is then filled to the 50 c.c. mark with water, preferably distilled, which is added to the milk or cream. This is done for the purpose of rinsing all milk or cream from the pipette. Five to ten drops of the phenolphthalein solution are then placed in the beaker or cup and the fluid is mixed by stirring with a glass rod. The tenth normal sodium hydroxide solution is run into the beaker or cup drop by drop, stirring frequently, until a pink color appears and remains permanently. The amount of sodium hydroxide solution used is then read off from the burette.

The result of the test may be expressed in degrees or in per cent of acidity. Degrees of acidity correspond to the number of c.c. of tenth-normal sodium hydroxide solution used to the hundred c.c. of milk or cream. The per cent. of acidity may be obtained by the following calculation:

\section{$\frac{\text { No. c.c. }=/ 10 \mathrm{NaOH} \text { used } \times 0.009}{\text { No. c.c. milk or cream used }} \times 100=$ per cent. acidity.}

For example, if 9 c.c. of the one-tenth normal solution are used in testing 50 c.c. of milk or cream, then

$$
\frac{9 \times 0.009}{30} \times 1^{2} 00=9 \times 0.018=0.16 \text { per cent. acidity. }
$$


If the reaction is alkaline, i.e., if the milk or cream becomes permanently pink when the phenolphthalein solution is added, or if the pink color appears and remains before the addition of the quantity of tenth-normal sodium hydroxide solution required for normal milk, then the rosolic acid test for alkalies should be applied (see page 260).

Acidity Test With Babcock Pipette.-The test for acidity may also be made by using a Babcock fat-test pipette to measure the milk or cream. 17.6 c.c. of milk or cream is placed in the cup or beaker, a few drops of the phenolphthalein solution added and the tenth-normal solution of sodium hydroxide run in slowly until the pink color appears and remains permanently. The per cent. of acid may be determined by dividing the number of c.c. of tenth-normal sodium hydroxide solution used by two, and expressing the quotient in tenths, thus:

$$
6 \div 2=3 \text {, or } 0.3 \text { per cent. acid. }
$$

Farrington's Alkaline Tablet Test.-The special feature of this test is the use of tablets of sodium carbonate for making the alkaline solution. Each tablet contains sufficient alkali to neutralize $\mathbf{0 . 0 3 4}$ gramme of acid. Five tablets are placed in a 100 c.c. graduated cylinder and clean, soft water, preferably distilled, is added up to the $\mathbf{9 7}$ c.c. mark. The cylinder is then closed tightly with a stopper and laid on its side for several hours to give the tablets an opportunity to dissolve. Solution is never entirely complete, a slight flocculent residue remaining. After thoroughly mixing by shaking, 17.6 c.c. of the milk or cream to be tested is measured into the beaker or cup with a Babcock fat-test pipette. The pipette is then filled with water to the 17.6 mark 
to rinse it and this is added to the milk or cream. A few drops of phenolphthalein solution are added and the alkali solution in the cylinder, after thorough shaking, is added to the mixture in the cup or beaker until the pink color remains permanent. The number of c.c. used is then read off from the measuring cylinder. Each c.c. represents one-tenth per cent. of acid in the sample tested.

\section{TESTS FOR PRESERVATIVES}

The use of antiseptics to inhibit bacterial growth and thus prevent the souring or decomposition of milk is much less common than formerly, but is still practised to some extent. This is also true of the addition of alkalies to neutralize acidity and delay curdling. Not only may the antiseptics do harm themselves, but they and the alkalies conceal conditions in milk which are undesirable and may prove injurious. For these reasons, the addition of these substances to milk is forbidden by Federal and State laws.

A simple test for preservatives may be made by setting a sample of milk aside and observing if it curdles within the usual time. If it does not, the presence of preservatives or alkalies may be suspected. The preservatives most commonly used and tests for detecting their presence are given below.

Boric Acid and Borax.-Until the introduction of formaldehyde, boric acid and borax were the most popular preservatives; 0.1 to $\mathbf{0 . 2}$ per cent. of these substances will delay the curdling of milk for several days. They may be detected by the following tests:

Villiers' and Fayolle's Test.-About 10 c.c. of the milk is placed in a porcelain crucible, evaporated to dryness and the residue burned to an ash. Sufficient sul- 
phuric acid to make a paste is added to the ash and 3 c.c. of methyl alcohol is mixed with it. The vapor which is then given off is ignited. If boric acid or borax is present, even in very small quantity, the flame will be green.

Turmeric Test.-Add 6 or 7 drops of hydrochloric acid to $\mathbf{1 0}$ c.c. of milk and, after coagulation has occurred, filter. Dip a piece of turmeric paper into the filtrate and allow it to dry. If boric acid is present in the proportion of 0.02 per cent. or borax in the proportion of 0.03 per cent., the paper will be colored cherry-red (Kühl); this color will be changed to bluish-black by ammonia water.

Another method of applying the turmeric test is described by Farrington and Woll as follows: "One hundred cubic centimetres of milk are made alkaline with a soda or potash solution and then evaporated to dryness and incinerated. The ash is dissolved in water, to which a little hydrochloric acid has been added, and the solution filtered. A strip of turmeric paper moistened with the filtrate will be colored reddish-brown when dried at $100^{\circ} \mathrm{C}$. on a watch glass if boric acid is present."

Formaldehyde.-Formaldehyde, the favorite preservative for milk, is used in the form of formaldehyde solution, formalin, formol, etc. A very small quantity $(0.008 \mathrm{per}$ cent. of formaldehyde, $\mathbf{0 . 0 2}$ per cent. of formalin) will prevent curdling for four days. The following tests may be used for detecting the presence of formaldehyde:

Richmond's Test.-Place a small quantity of milk in a test tube, add an equal quantity of water and then pour a little commercial sulphuric acid slowly down the side of the tube so that it will form a layer at the bottom. A bluish or violet ring at the point where the acid and milk come in contact indicates the presence of formaldehyde. If no formaldehyde is present a faint, greenish 
ring is formed. This test will detect 1 part of formaldehyde in 200,000 parts of milk.

Leach's Test.- The reagent used in this test is a solution of hydrochloric acid and ferric chloride consisting of 998 c.c. of hydrochloric acid of a specific gravity of 1.2, and 2 c.c. of a 10 per cent. aqueous solution of ferric chloride. Place about 10 c.c. of milk and an equal quantity of this solution in a white cup or casserole and slowly heat over a flame to boiling, giving the fluid a rotary motion. If formaldehyde is present a blue or violet color appears.

Salicylic Acid.-Salicylic acid is not often used to preserve milk because it is not very soluble in that fluid; 0.04 per cent. will prevent milk from souring for 36 hours. The presence of salicylic acid may be detected by the following test:

Remont's Test.-Place 20 c.c. of milk in a measuring cylinder or large test tube, add 2 to 3 drops of sulphuric acid and 20 c.c. of ether. Mix by shaking and stand aside until the ether separates and forms a layer at the top. The fat of the milk and any salicylic acid present is dissolved by the ether. The ether solution is drawn off with a pipette, placed in a small crucible and evaporated by floating the crucible in hot water. The residue is rubbed up with a small quantity of 40 per cent. alcohol and filtered and a few drops of ferric chloride solution are added to the filtrate. A violet color appears if salicylic acid is present.

Benzoic Acid.-Like salicylic acid, benzoic acid is also not very soluble, and consequently is not used very often to preserve milk. The various tests for this substance are all more or less complicated.

Peter's test, as described by Leffmann, is as follows: "The material is made slightly acid and extracted with 
chloroform, which is then evaporated spontaneously. The vessel containing the residue is placed in melting ice, 2 c.c. of sulphuric acid added, and stirred until the residue is dissolved. Barium dioxide is dusted into the mass, with constant stirring, until the liquid begins to foam, when 3 c.c. of hydrogen dioxide ( 3 per cent.) are added drop by drop. The dish is then removed from the cold bath, the contents diluted with water to convenient bulk, and filtered. The acid filtrate is extracted with chloroform. The benzoic acid will have been converted into salicylic acid by the process and the latter may be detected by dilute solution of ferric chloride or ammonio-ferric sulphate."

Alkalies.-Alkalies delay the curdling of milk by neutralizing the acid formed by bacteria. The substances which have been used for this purpose are the carbonate and bicarbonate of soda, chalk, and potash. When market milk gives an alkaline reaction to litmus or has a low acidity, as determined by Mann's test, it should be tested for alkalies. This test is made as follows:

Ten c.c. of milk are mixed in a test tube with an equal quantity of 95 per cent. alcohol, a few drops of a 1 per cent. solution of rosolic acid are added and mixed with the other fluid by shaking. If an alkali is present the mixture will assume a rose-red color. If no alkali is present a brownish-yellow color will appear.

\section{STANDARD METHODS OF COUNTING BACTERIA 1}

Collection of Samples.-The milk should be mixed thoroughly before the sample is taken and not less than 10 c.c. should be collected for examination. Bottled

${ }^{1}$ From the report of the Laboratory Section of the American Public Health Association, Oct. 24, 1916. 
milk may be mixed by inverting the bottle several times. If the milk is in a vessel which is open and which cannot therefore be inverted, it may be stirred with the pipette which is used to transfer the sample to the sample bottle. The pipette should, of course, be sterile and should not be used to take another sample until it has again been sterilized. A sterile tube with straight sides should be used for taking a sample from a can. An aluminum tube $1 / 4$ inch in diameter and 21 inches long is most convenient. If the tube is held vertically, with the opening at the top unobstructed, and is inserted into the milk slowly until the lower end reaches the bottom of the can, it will contain a column of milk which will be representative of all the milk in the can. If the finger is then placed firmly upon the top of the tube, the column of milk can be withdrawn and transferred to a sterile sample bottle, which should be large enough to hold the entire contents of the tube, all of which must be emptied into the bottle. The tube must be washed and sterilized before being used to collect a sample from another container. If the temperature of the milk is to be taken, a separate sample should be used for this purpose and then discarded. Glass-stoppered bottles or those provided with cork-lined screw caps are the most satisfactory. The bottle containing the sample should be properly labelled and immediately placed in a carrying case containing cracked ice so that the milk will be promptly cooled to near the freezing point. The sample bottles should be transferred to the laboratory as soon as possible and the milk plated at once. If the plates are not prepared within four hours after the collection of the samples the elapsed time should be noted in the report. If the samples are 
placed in iced-water they may be kept for twelve hours without an increase in bacteria.

All apparatus used for collecting, measuring, diluting, and plating the samples must be sterilized by heating at a temperature of at least $175^{\circ} \mathrm{C}$. for one hour.

There are two methods of counting bacteria in milk: The plate method, in which the number of bacteria per c.c. of milk is determined by counting the colonies developing on agar plates to which a measured quantity of milk has been added; and the direct microscopic method, in which a small measured quantity of milk is spread over a definite area on a glass slide, dried, fixed and stained, and the bacteria counted under the microscope. The plate method is the oldest and best understood and is recommended for general purposes. The microscopic method is useful when rapid results are desired, as when samples are examined for the purpose of classifying or grading milk.

\section{PLATE METHOD}

Medium.-The medium used is standard beef extract agar, which should be prepared according to the following directions:

"To 1000 c.c. of water add 5 grammes of peptone and 3 grammes of beef extract. The peptone shall be the best available, and the beef extract shall be Liebig's where this is obtainable. Weigh the containing dish and its contents.

"Dissolve the peptone and beef extract by boiling and replace the water lost through evaporation.

"While still hot filter through filter paper.

"Add 12 grammes of oven-dried agar, or 15 grammes of market agar, and dissolve by boiling, or in an autoclav. 
Restore the weight lost by evaporation. It is imperative that the agar be of the best quality and clean, or it is impossible to obtain a clear medium. (When an autoclav is at hand the following modification is convenient. Add the peptone and beef extract to about 300 c.c. of water, and the agar to 700 c.c. Heat both in an autoclav under 15 lbs. pressure one-quarter hour. Filter the broth while hot through filtered paper, and then mix the broth with the melted agar and filter through absorbent cotton.)

"Determine the acidity of the medium by titrating 5 c.c., diluted with 45 c.c. water, with $1 / 20$ normal $\mathrm{NaOH}$, phenolphthalein being used as an indicator. Any attempt to adjust the acidity is likely to make undesirable changes in the medium. Inasmuch as variations between +.5 and +1 . acid make no appreciable difference in the results, the reaction of the medium is not to be changed if it falls between +.5 and +.1 acid. It will usually be between these limits. If it should be above +1 . acid, add enough normal $\mathrm{NaOH}$ to bring it to +1 ., and if it is below +.5 acid add enough normal $\mathrm{HCl}$ to bring it to +.5 , always adding the smallest amount of the reagent possible to bring the reaction within these limits.

"Cool to $45^{\circ} \mathrm{C}$. and then heat to boiling (15 minutes) and filter through filter paper or absorbent cotton. It is necessary that the filtering be continued till the medium is clear. If the procedure here given is followed and a high grade of agar and other materials is used there will be no difficulty in getting the agar clear. Egg should not be used as a clarifier.

"After filtering, the agar may be either tubed, 10 c.c. in each tube, or placed in flasks containing about 150 c.c. each. The latter method requires less glassware and 
less time, and is found to be equally satisfactory for plating, as explained below.

"Sterilize in an autoclav at $\mathbf{1 5} \mathrm{lbs}$. pressure (never above) for one-half hour after dry steam comes from the autoclav. As an alternative the medium may be sterilized on three successive days in streaming steam, in which it must remain 20 minutes each day after the agar has completely melted.

"If the flasks are to be kept for more than a couple of days, or are to be shipped, before using, cover the mouths of the flasks before sterilizing with paper fastened by a rubber band or by tinfoil to retard evaporation."

Dilutions.- "For miscellaneous milk samples the character of which is not known three dilutions shall be made: 1-100, 1-1000, 1-10,000. Where the character of the milk is known the number of dilutions may be reduced. If the milk is pasteurized, certified, or known to be fresh and of high grade, the 10,000 and $\mathbf{1 0 0 0}$ dilutions may be omitted; if the milk is known to be old and of high bacterial content the $\mathbf{1 0 0}$ dilution may be omitted. In no case shall less than two plates be made of each sample.

"Any convenient method of making dilutions may be used, always using pipettes and sterile water blanks. The water used for dilutions may be placed in dilution bottles (99 c.c. and 9 c.c. are convenient sizes) and sterilized for one hour in an autoclav at $15 \mathrm{lbs}$. pressure. These should be marked so that it can be determined that they have neither gained nor lost water during or subsequent to sterilization. Or the water may be sterilized in bulk, if kept in a properly guarded container, and subsequently measured directly into dilution bottles with sterilized pipettes. 
" The dilution bottles should have glass stoppers or some other type of closing that makes shaking possible. Cotton plugs are unsatisfactory because the dilution water will soak into the cotton.

" Straight-sided pipettes graduated to deliver between two marks are best, but pipettes marked to deliver may be used if care is taken that the points are not broker, and the tube is completely emptied.

"In making dilutions the original sample and each dilution bottle shall be shaken 25 times, each shake being an up-and-down motion with an excursion of about one foot. After the final dilution fill a pipette to the mark and allow the contents to run into an empty Petri dish, the end of the pipette touching the bottom of the dish as the liquid runs out. If the pipette is one that delivers 1 c.c., be sure that the last drop is carried into the Petri dish. (Pipettes should be placed immediately in water after using to make subsequent cleaning easier.)"

Plating. - "The agar in the flasks (or test tubes) shall be melted in boiling water or steam and after melting should be cooled to $45^{\circ} \mathrm{C}$. before using.

"Pour 10 c.c. of the melted agar in each inoculated Petri dish, and by a gentle rotary motion thoroughly mix the agar and the diluted milk. As nearly as possible the same amount of agar should be poured into each Petri dish so that the depth of the agar in all be uniform. If desired, 10 c.c. may be measured out from the flask with a sterile pipette.

"After dilution of the milk not more than half an hour should elapse before the agar is poured into the Petri dishes.

"After the agar has thoroughly hardened place the Petri dishes in an incubating oven, inverted, in order to 
reduce the danger of spreaders. While clay tops of Petri dishes are useful for some purposes they are not recognized in the standard methods."

Incubation.- " Only one period of incubation and one temperature is regarded as standard, 48 hours at $37.5^{\circ} \mathrm{C}$. In crowded incubators ventilation should be provided."

Counting. - "If, among the different dilutions, there are plates containing from $\mathbf{3 0}$ to $\mathbf{3 0 0}$ colonies these should be counted, and the number, multiplied by the dilution, be reported as the final count. All colonies on such plates should be counted and the numbers averaged. If there are no plates within these limits the one that comes nearest to $\mathbf{3 0 0}$ is to be counted. No plate that contains less than twenty colonies shall be counted, unless it happens that there are no plates with a larger number of colonies, or unless the numbers in the plates check with other dilutions. If the number of colonies on the plate to be counted is over 300, a part of the plate may be counted, and the whole plate averaged.

"Counting shall be done with a lens, magnifying $21 / 2$ diameters (or what the opticians call a $3 \frac{1}{2}+$ lens). Nearsighted persons should use their glasses in counting, but farsighted persons should remove them. In case it is doubtful whether certain objects are colonies or dirt specks they should be examined with a compound microscope."

Reports.- "In making reports it must be borne in mind that with high numbers obtained by the routine method only an approximation to accuracy can be obtained. Only the left-hand figures of the final numbers are of significance. It is best, therefore, to report only the two left-hand figures of the results in order to avoid 
an unwarranted impression of accuracy. For example, when the numbers are in millions no figures smaller than the millions have any significance in the routine analysis of milk. In making the report raise the number to the next highest round number, but never lower it.

"In no case shall the count of a single plate be regarded as sufficient for the purpose of grading milk. If a single sample of milk only is to be tested there should be at least three plates counted before a report is made."

\section{MICROSCOPIC METHOD}

The apparatus required for this method consists of a microscope, a supply of ordinary glass slides, and a straight capillary pipette marked to deliver $1 / 100$ c.c., with the graduation mark $1 \frac{1 / 2}{2}$ to $2 \frac{1}{2}$ inches from the tip. The calibration should be tested by weighing on chemical balances the quantity of milk delivered when the pipette is filled to the mark. One pipette may be used for a number of samples of milk provided it is kept clean. This may be done by rinsing the interior with clean water after each sample and wiping the exterior with a clean towel.

Preparation of Smears._- One one-hundredth c.c. of milk or cream is deposited upon a clean glass slide by means of the pipette above described. By the use of a clean stiff needle this drop of milk is spread over an area of one square centimetre. This may be most conveniently done by placing the slide upon any glass or paper ruled into areas one centimetre square. These marks showing through the glass serve as guides. After uniform spreading the preparation is dried in a warm place upon a level surface. In order to prevent noticeable growth this drying must be accomplished within 
five to ten minutes; but excessive heat must be avoided or the dry films may crack and peel from the slides in later handling.

"After drying the slides are to be dipped in xylol (gasoline may be used) for one minute, then drained and the slides dried. They are then immersed in 90 per cent. grain or denatured alcohol for one minute or more and then transferred to a fresh aqueous solution of methylene blue. Old or unfiltered stains are to be avoided, as they may contain troublesome precipitates. The slides remain in this solution from five seconds to one minute or longer, depending upon the eff ect desired, and are then rinsed in water to remove the surplus stain, and decolorized in alcohol. The decolorization takes several seconds to a minute, during which time the slides must be under observation in order that the decolorization may not proceed too far before they are removed from the alcohol. When properly decolorized the general background of the film should show a faint blue tint. Poorly stained slides may be decolorized and restained as many times as necessary without any apparent injury. After drying, the slides may be examined at once, or they may be filed away and preserved for further reference."

Standardization of the Microscope.- "The microscope to be used must be adjusted in such a way that each field of the microscope covers a certain known fraction of the total square centimetre's area. This procedure is simple with the proper materials at hand. The microscope should have a $1.9 \mathrm{~mm}$. ( $1 /{ }_{12}$ inch) oil immersion objective, and an ocular giving approximately the field desired, and should preferably be fitted with a mechanical stage. To standardize the microscope, place upon the stage a stage micrometer, and by the selection 
of oculars or adjusting the draw tube, or both, bring the diameter of the whole microscopic field to $.205 \mathrm{~mm}$. When so adjusted the microscopic field will cover almost exactly $1 / 300,000$ of a cubic centimetre of the milk (actually 1/302840). This means that if the bacteria in one field only are counted the number should be multiplied by 300,000 to give the total number in a cubic centimetre. If the bacteria in a hundred fields are to be counted the total should of course be multiplied by 3000.

"Inasmuch as it is difficult to count bacteria lying near the margin of the microscopic field, it is much better to have an eyepiece micrometer with a circular ruling $8 \mathrm{~mm}$. in diameter and divided into quadrants. This will give, in the microscopic field, a smaller area within which the bacteria may be seen most sharply, and which may be more easily counted. Such eyepiece micrometers are now manufactured by laboratory supply houses and may be easily obtained. In the use of this eyepiece micrometer the inner circle, by the adjustment of the draw tube, should be made to cover a circle with a diameter of $.146 \mathrm{~mm}$. In this case this inner circle will cover $1 / 600,000$ of a cubic centimetre of milk, meaning, of course, that the number of bacteria in a single field should be multiplied by 600,000 , or, if a hundred fields are counted, by 6000 , to obtain the number per cubic centimetre.

"The number of microscopic fields to be counted will depend somewhat upon the kind of data that is desired. If this method is to be used simply for the purpose of dividing milk into grades, it will in most cases be unnecessary to do the actual counting, since a Grade A milk will show field after field without any bacteria at 
all, while a Grade $\mathrm{C}$ milk will show the field crowded with bacteria. In all doubtful cases, however, counting should be done, and there should never be less than thirty fields counted in order to have reliable results. Counting thirty fields is not so tedious a task as it would seem to be, since in ordinary milk the number of bacteria in each field is small, and the counting may be done very rapidly."

Counting.- "Counting the bacteria in such a smear may be done in two ways: 1 . The number of groups of one or more bacteria present. 2. The number of individuals. The second, of course, is really the correct count of the number of bacteria, but the former will give a count much closer to that obtained by the plate count, since the colonies upon the plate represent groups of bacteria rather than individuals, each group growing into a single colony only. Extensive tests have shown that there is a fair correspondence between the number of groups reported by experienced observers and the number of colonies that may grow in plates made from the same milk, although there are occasionally discrepancies of considerable extent. These discrepancies are caused by variations in judgment as to what constitutes a group, variations in the extent to which groups break up in the dilution waters when the smears are made, and the presence of dead bacteria or of bacteria which do not grow on the plates. Some experience is needed by the microscopist in determining just what should be counted. In high-grade milks an inexperienced person is apt to fail to recognize differences between bacteria and other minute objects. This results as a rule in an overicount by inexperienced men. In milk containing many readily recognizable bacteria in each field the in- 
experienced man is apt to overlook some of them, giving an undercount. These difficulties are overcome, however, by training and experience.

COMPARISON OF RESULTS OBTAINED BY THE TWO METHODS

"It must be recognized that the results obtained from the microscopic record give a closer approximation to the actual number of bacteria present in the milk than those obtained by the plate method, since the plate method will count as one either a single bacterium or a group which may sometimes contain a hundred or even more individuals. Inasmuch, however, as the plate count has become a method of analysis that is well known and commonly applied, it becomes desirable to know as closely as possible what relations there may be between the plate count and the microscopic count. Experience has shown that the count of individual bacteria is ordinarily 1.5 to 8 times as great as the plate count, the ratio between the two being largely dependent upon the size of the clumps of bacteria present. Where the bacteria are mostly isolated, the ratio of the two counts would be much closer than where there are present long chains of streptococci or masses of cocci. After one has had a little experience in counting clumps it is found that the number of groups shown by the microscope agrees fairly well with the number of colonies shown by the plate count, though even here there are occasionally discrepancies, due among other things to the appearance in the microscope of kinds of bacteria which fail to grow in the culture media used in making plates. In all cases, however, the direct count of raw milk will give a much closer approximation to the actual numbers of bacteria than the plate count. In view of these facts it is difficult to interpret one count in terms 
of the other; but a few suggestions will give a fairly satisfactory idea as to how the two may be related.

"Grade A raw milk, which should have less than 100,000 bacteria per c.c., will not show more than three to four small clumps of bacteria for each $\mathbf{3 0}$ fields of the microscope where the diameter of the fields is $.205 \mathrm{~mm}$. Such milk also ought not to contain more than 500,000 individual bacteria per c.c. when counted by the microscope. For Grade A pasteurized milk (which should have less than 200,000 per c.c. by the plate count before pasteurization) the microscope should not show more than six to eight clumps per $\mathbf{3 0}$ microscopic fields, and not more than $1,000,000$ individual bacteria when counted with the microscope.

"Grade B milk, which is supposed not to have more than 1,000,000 bacteria before pasteurization, when counted by the plating method, should not show more than 20 individual bacteria per field, where the diameter of the fields is $.205 \mathrm{~mm}$., and not more than three to four groups of bacteria per field.

"While the above relation between the plate count and the microscopic counts cannot be relied upon as having a very great amount of accuracy, it will serve to give a general idea of the ratio between the two under ordinary conditions, and may serve as a guide in the use of the direct microscopic method."

\section{EXAMINATION FOR STREPTOCOCCI}

When long-chain streptococci are found in milk sediment in association with an excess of leucocytes and the latter cells are clumped together and consist largely of the polymorphonuclear type, there need be no hesitancy in concluding that the streptococci are pathogenic and 
that the milk under examination contains the secretion of a cow affected with catarrhal mastitis.

If the plates prepared from a sample of herd milk contain a large number of extremely minute brownish colonies, which upon microscopic examination are found to consist of streptococci in rather long chains, an examination of the herd from which the milk came will result in the discovery of one or more cows affected with catarrhal mastitis. To examine microscopically, place one of the colonies in a drop of water on a glass slide and spread by a gentle rotary motion of the platinum needle, beginning at the centre and working outward; dry, fix by heat and stain with methylene blue. The chains of Streptococcus lacticus are shorter than those of the streptococci of mastitis, rarely containing more than 6 or 8 cocci, and the individual cocci are arranged as diplococci. (See Figs. 5 and 6.)

The method of examination for streptococci recommended by the Laboratory Section of the American Public Health Association is as follows:

"Where streptococci, diplococci, or cocci are found in the sediment, and the plate from the same sample contains colonies resembling streptococci colonies, these colonies may be grown in bouillon to see if chains will develop.

"First make and record an estimate of the number of such colonies present, then transfer from 10 to 50 of them to bouillon and grow for 15 to 24 hours at $37^{\circ} \mathrm{C}$. To examine the bouillon culture, spread a loopful on a glass slide, fix with heat, fix with alcohol while slide is still quite hot, stain with methylene blue, wash immediately, dry and examine.

"A milk should not be condemned because a few chains are found together with large numbers of other 
microscopic organisms in a bouillon culture, but it is safer to exclude a milk from the market when these three tests agree:

"1. Microscopic examination of the sediment shows streptococci, diplococci, or cocci.

"2. The plate from the same sample shows colonies resembling streptococci colonies exceeding a count of 100,000 to a cubic centimetre.

"3. The bouillon culture from these colonies shows long-chain streptococci alone or in great excess compared with the other bacteria present.

"Milk showing in the stained sediment both abundance of long-chain streptococci and pus should be condemned as unsafe."

The bouillon used in this examination may be prepared as follows:

"Infuse 500 g. finely chopped lean meat 24 hours with 1,000 c.c. distilled water in refrigerator; restore loss by evaporation; strain infusion through cotton flannel." (Or, dissolve $5 \mathrm{~g}$. of beef extract, preferably Liebig's, in 1,000 c.c. distilled water.)

" Add 1 per cent. peptone. Warm on water bath, stirring until peptone is dissolved.

" Heat over boiling water or steam bath thirty minutes. Restore loss by evaporation.

"Titrate, adjust reaction to +1 per cent. by adding normal sodium hydrate.

"Boil two minutes over a free flame, constantly stirring. Restore loss by evaporation.

"Filter through absorbent cotton, passing the liquid through until clear. Titrate and record final reaction. Tube, using 10 c.c. to each tube. Sterilize." 
The presumptive tests for Bacillus coli do not have the same value in milk examination as in water analysis, because it is practically impossible to obtain milk from the cow, even under good dairy conditions, without it being infected to some extent with colon bacilli from the intestines of the animal. The detection of this organism in milk is therefore of little value, except that when it is present in large numbers it is an evidence of uncleanliness and usually an indication of gross fecal contamination.

One of the presumptive tests for Bacillus coli in milk approved by the Laboratory Section of the American Public Health Association is made as follows: "1 c.c. of a 1 to 1,000 dilution of milk is placed in ordinary bile containing 1 per cent. lactose in a fermentation tube and allowed to stand at $37^{\circ} \mathrm{C}$. for $\mathbf{7 2}$ hours, at the end of which time, if there is more than 15 per cent. gas, plates are made, colonies isolated and run through species tests."

The fermentation test described on page 278 is a simple and convenient method of detecting the presence of an excessive number of coli or other gas-forming organisms in milk.

\section{EXAMINATION FOR TUBERCLE BACILLI}

The method recommended by the Laboratory Section of the American Public Health Association is as follows:

"Pint or quart samples of milk should be obtained, kept well iced, and delivered to the laboratory as soon as possible. The milk and cream should be well mixed by shaking vigorously. 50 c.c. of the mixed milk are then transferred to a large centrifuge flask and 100 c.c. of sterile water added. Centrifuge for one hour at 2,000 
revolutions per minute. The milk is diluted with twice its volume of water with the idea that it will decrease the specific gravity of the milk and so permit of the easier sedimentation of the tubercle bacilli. Guinea pigs are then inoculated, subcutaneously in the belly wall, with 5 c.c. of the sediment thus obtained. The guinea pigs not dying in at least two months are chloroformed, after being tested with tuberculin, and careful autopsies made. Smears, cultures and sections are made from the various organs of the animals that show any change from the normal. The smears are stained with carbol fuchsin and examined for acid-fast bacilli.

"Cultures are made on glycerinized potato and glycerine agar to rule out Rabinowitch's quick growing acidfast butter bacillus.

"Sections are stained with carbol fuchsin for tubercle bacilli and also with hæmatin and eosin for histological appearances.

"Tuberculous guinea pigs may be differentiated from nontuberculous by giving sufficient crude tuberculin (2 c.c.) subcutaneously to cause the death of the tuberculous animals in twenty-four hours.

"It is of course understood that the examination of milk for tubercle bacilli is by the very nature of the test limited. For the control of this disease in cattle we must rely upon the tuberculin test."

MicroscopicMethod-Some of the sediment obtained by centrifugalizing the milk is spread thinly on a glass slide, fixed by heating, stained with carbol fuchsin, decolorized in acid alcohol and counter-stained with methylene blue. If small flakes or clots are present in the milk, one of these is spread on the slide and treated in the same manner. The carbol-fuchsin solution is prepared by dissolv- 
ing 1 gramme of fuchsin in 10 c.c. of alcohol and 100 c.c. of a 5 per cent. solution of phenol in water, and then filtering the solution. The acid alcohol is prepared by mixing 5 c.c. of nitric or one of the other mineral acids with 95 c.c. of alcohol. After the smear on the slide has been fixed, it is flooded with carbol fuchsin and the slide is held over a Bunsen flame and the stain kept steaming for 3 minutes. The slide is then rinsed with water and the preparation treated with the acid alcohol until the red color disappears. Next, the acid alcohol is rinsed off with water and the preparation is stained for $\mathbf{3}$ minutes with methylene blue, after which the slide is washed with water, dried, and examined with the 1/12 oil immersion objective. Any tubercle bacilli present will be stained red; other organisms will be stained blue. While the presence of tubercle bacilli may be accepted as proof that the cow from which the milk came is infected with tuberculosis, failure to find these organisms cannot be regarded as positive evidence that the animal is not tuberculous. Tubercle bacilli may be present in small numbers and escape detection on microscopic examination. The so-called acid-fast organisms are also stained red by carbol fuchsin. They may be present in milk and butter, but, apparently, they usually enter the milk after it is drawn from the udder. Jensen is of the opinion that if precautions are taken to prevent contamination of the milk sample when it is drawn from the udder, these organisms will very rarely cause errors in diagnosis.

Antiformin Method.-Take 5 c.c. of the milk to be examined and mix it with 5 c.c. of absolute alcohol, 5 c.c. of ether, $\mathbf{1 0}$ c.c. of a $\mathbf{2 5}$ per cent. solution of antiformin and 25 c.c. of normal saline solution. Place in an incu- 
bator for at least one-half hour. Centrifugalize, prepare a slide from the sediment, and stain as described for the microscopic method.

\section{FERMENTATION TEST}

The fermentation test has been in use in cheese factories for a long time to detect milk which is unsuitable for cheese-making. It can be used in milk control work to discover the presence of the more objectionable milk bacteria, such as the gas-formers and peptonizers, and thus ascertain what form of decomposition the milk is likely to undergo with age, especially if improperly cared for. It is also of assistance in determining the source of excessive bacterial contamination.

The test is very simple and does not require any special apparatus. In cheese factories, bottles holding from 120 to 140 c.c. or test tubes of 40 to 50 c.c. capacity are used for the milk samples. After the milk is introduced, they are closed with a rubber stopper and are held at a temperature of 37 to $38^{\circ} \mathrm{C}$. in a water bath. In a laboratory, it is more convenient to use the test tubes ordinarily used for bacteriological cultures and to place the tubes in an incubator after the milk has been placed in them.

The test tubes are washed and cleansed in the usual manner, plugged with cotton and sterilized by heating in a hot-air sterilizer for $2 \frac{1}{2}$ hours at 150 to $160^{\circ} \mathrm{C}$. It is important that the tubes be sterilized, since any organisms in the tubes will develop in the milk and may influence the result. Each tube is numbered with a paraffine pencil to correspond with the sample of milk and is then filled with milk to within a finger's breadth of the bottom of the cotton plug, closed with the cotton plug and placed in the incubator. In transferring the milk from the ves- 
sel in which it was collected to the test tube, the necessary precautions should be observed to prevent contamination.

Twelve hours after they are placed in the incubator, the samples are examined. If the milk is normal, fresh and of good quality, there will be no change apparent except perhaps a clean, sour odor. The beginning of fermentation or curdling is indicated by an upward bulging of the cream layer and the presence of a greenish layer beneath it. If there is no change at this time, the samples are to be replaced in the incubator and observed again in twelve hours, and subsequently at twelve-hour periods if necessary. If curdling does not take place after fortyeight hours, the reaction of the milk should be taken and tests made for preservatives. When the milk curdles, the time of curdling and the character of the curd are to be noted. The time of curdling depends upon the number of bacteria present which are not inert, while the character of the curd depends upon the kind of bacteria which predominate. The types of curds, the symbols by which they are recorded, and their indications are as follows:

1. Jelly-like Curd.- $\mathbf{J}_{1}$, solid, smooth, white, jellylike curd, with no fluid. $\mathbf{J}_{2}$, curd of same type, but showing a few furrows or gas bubbles. $J_{3}$, curd same, but showing more furrows and gas bubbles and also cracks, with some fluid. The jelly-like curd is produced when the acid-forming bacteria predominate, and if the number of bacteria is excessive it usually indicates that the milk vessels or utensils are unclean, or that the milk is old or has not been kept under proper conditions.

2. Peptonized Curd.-The curd may be firm, jellylike, with ragged surfaces, or it may be soft, flocculent or "mushy," associated in either case with more or less fluid. $\mathbf{P}_{1}$, the amount of fluid is small in proportion to 
the size of the curd. $\mathbf{P}_{2}$, increased amount of fluid, less curd. $\mathbf{P}_{3}$, amount of fluid large in proportion to the size of the curd. This type of curd is produced when a large proportion of peptonizing bacteria are present in the milk. When the number of bacteria is large, it is usually an indication that the milk has been contaminated with dust from hay, fodder or soil, or that a suppurative condition is present in the herd. When milk is produced under good conditions and is kept cool, the peptonizing bacteria (udder cocci) will predominate but the total number of bacteria will be small.

3. Gaseous Curd.-A white, jelly-like curd containing gas bubbles and, when gas has been formed in large quantity, presenting a sponge-like appearance. More or less fluid is present and this may also contain gas bubbles. $\mathbf{G}_{1}$, a few gas bubbles in the cream layer or in the curd. $\mathbf{G}_{2}$, gas bubbles numerous in the cream and curd; gas bubbles may also be present in the fluid. $\mathbf{G}_{3}$, curd sponge-like, containing many gas bubbles; may be split and a portion driven to the top; gas bubbles in fluid. The gaseous curd is produced when a large percentage of gas-forming bacteria is present and is usually an indication that the milk has been contaminated with an excessive amount of manure. It may also occur when polluted water is used to wash the milk vessels and utensils.

4. "Flaky" or F'locculent Curd.-Curd in flakes or flocculi, associated with a turbid fluid, which may be whitish, yellowish, or otherwise discolored. $\mathrm{Fl}_{1}$, curd in fine flakes or partially homogeneous. $\mathrm{Fl}_{2}$, large flakes and considerable fluid. $\mathrm{Fl}_{3}$, large flakes, torn, with white or discolored fluid. This type of curd is produced when saccharomyces which ferment lactose are present in large numbers. The casein is permeated with fine gas bubbles 
at the moment of precipitation, which causes it to be broken up into flakes; the fluid is turbid because of the movement produced by the gas developed (O. Jensen).

\section{ESTIMATION OF THE NUMBER OF LEUCOCYTES}

There are a number of methods for determining the leucocyte content of milk, each having a different limit for normal milk. In several, the milk is centrifugalized, a portion of the sediment is spread on a glass slide, fixed, and stained, and the number of leucocytes in the field of the $1 / 12$ oil immersion objective is counted. In others, the leucocytes in a measured volume of sediment or milk are counted or the quantity of sediment in a definite volume of milk is measured. Of these methods, those most commonly used are the following:

Stokes' Test.-10 c.c. of milk is placed in a sediment tube and centrifugalized for $\mathbf{1 0}$ minutes, after which the cream and separated milk are poured off. A platinum loopful of the sediment is spread on a glass slide over an area of 1 square centimetre, dried in the air, fixed in the flame, and stained with methylene blue for 2 or 3 minutes. The specimen is then placed under the microscope and examined with the 1/12 oil immersion objective. The number of cells in the field of vision are counted. The leucocytes in $\mathbf{1 0}$ fields in different parts of the preparation are counted and the average per field determined. The limit for normal milk is $\mathbf{1 0}$ leucocytes to the field.

Stervart's Test.-Special tubes, closed with a rubber stopper at the bottom, are used for this test, and a special centrifuge head is also required. One c.c. of milk is placed in the tube and centrifugalized for ten minutes. This throws the sediment down on the upper surface of the rubber stopper at the bottom of the tube. The stop- 
per is removed, and the sediment spread on a glass slide by rubbing the stopper over an area of 1 square centimetre. The preparation is dried in the air, stained 2 minutes with Jenner's blood stain and examined under the microscope with the 1/12 oil-immersion objective and a No. 3 ocular. The leucocytes in $\mathbf{1 0}$ fields are counted. An average of 23 cells to the field is the limit for normal milk. If the average number of cells to the field is multiplied by 4400 the approximate number of cells per c.c. is obtained.

Doane-Buckley Method.-10 c.c. of milk is centrifugalized for $\mathbf{1 0}$ minutes in a graduated sediment tube, after which the cream and separated milk is drawn off with a pipette down to the 1 c.c. mark. A drop of saturated alcoholic solution of methylene blue is mixed with the remaining portion and the mixture is allowed to stand one minute to stain the cells. One drop of this mixture is placed in a Thoma-Zeiss blood-counting apparatus and the number of leucocytes per c.c. determined. The limit for normal milk is $\mathbf{5 0 0 , 0 0 0 ~ p e r ~ c . c . ~}$

Trommsdorff Test.-For this test a special sediment tube is used which is drawn out at the lower end into a small capillary tube with twenty graduations, each graduation representing 0.01 per cent. 10 c.c. of milk is placed in the tube and centrifugalized for 10 minutes. The volume and color of the sediment in the capillary tube are then noted. The limit for sediment in milk from individual cows in normal condition is $\mathbf{0 . 1}$ per cent. and the color should be white or grayish white. If the sediment exceeds this amount and is of a yellowish-color, the presence of mastitis secretion is indicated and the sediment should then be examined microscopically to determine whether it consists largely of leucocytes or of débris 
and if streptococci are present. In fresh cows, the sediment is usually of a grayish-white or white color and ordinarily does not exceed 0.08 per cent; sometimes the sediment is red, which is an indication of the presence of red blood cells.

In all of these tests the kind of leucocytes should receive attention as well as the number. A preponderance of polymorphonuclear leucocytes is very significant, since in mastitis three-fourths and more of the cells are of this type. The clumping or grouping of the cells is also characteristic of milk containing mastitis secretion. There is an increased number of epithelial cells in the milk of cows affected with mastitis; in catarrh of the milk cistern, nests of elongated epithelial cells may be observed in the sediment.

When an excessive number of leucocytes is found in market milk, with a preponderance of polymorphonuclear cells showing the characteristic clumping or grouping, an examination of the herd from which the milk came will usually disclose the presence of

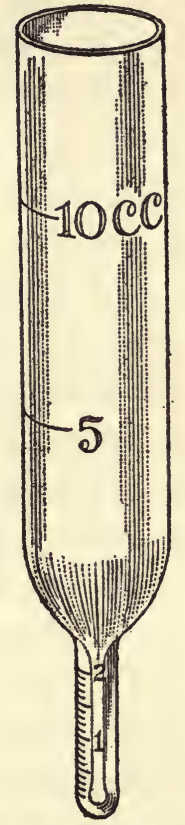

Fra. 39.-Sediment tube used in the Trommsdorf test, showing graduations in the capillary extension at the bottom. mastitis or other suppurative condition. In such cases, however, it must be remembered that leucocytes are insreased in number in the milk at the beginning and near the end of lactation and following incomplete or delayed milking. Heating milk to $60^{\circ} \mathrm{C}$. $\left(140^{\circ} \mathrm{F}\right.$. $)$ or above also increases the number of leucocytes in the sediment. When the number of leucocytes in market milk falls 
within the limits set for normal milk, the possible presence of mastitis secretion is not excluded.

The presence of numerous streptococci in connection with an excess of leucocytes is strong evidence that the milk contains secretion from an inflamed udder. Milk may contain non-pathogenic (Streptococcus lacticus) as well as pathogenic streptococci but, as was first pointed out by Bergy, the streptococci may be regarded as pathogenic when they are associated with a large number of polymorphonuclear leucocytes, especially if they are in long chains. The presence of cocci, diplococci, or short chains within the cells is also significant. Furthermore, the pathogenic streptococci usually form longer chains than the non-pathogenic, chains of Streptococcus lacticus rarely containing more than 6 or 8 organisms. (See Figs. 5 and 6). According to Ernst, the mastitis streptococci can be recognized by the shape of the individual cocci and the length of the chain. (See page 53.)

The leucocyte tests are more reliable for individual milk than for market milk. In comparisons of the leucocyte tests with the catalase test in the examination of individual milk to discover evidence of mastitis, the catalase test has proven the more accurate.

\section{BOILING TEST}

A small quantity of milk is placed in a vessel and boiled, after which it is examined for flakes or curds. In the laboratory, about $\mathbf{1 0}$ to $\mathbf{1 5}$ c.c. of milk is placed in a test tube, which is then held over a Bunsen flame until the milk boils. Fresh, normal market milk will not curdle. When curdling occurs, it indicates that the milk has undergone excessive acid fermentation, either because it is stale, or was produced under unclean conditions, or was 
not properly cooled and cared for. When tested in this manner, milk will curdle before a sour taste is apparent and several hours before it will curdle spontaneously. If boric acid has been added to the milk as a preservative this will increase the acidity and influence the test. Salicylic acid generally has no influence because it is not usually added in sufficient quantity.

Milk also curdles when boiled when there is an excess of albumin or globulin present. In normal milk, albumin and globulin are not present in sufficient amount to make curdling visible when the milk is boiled. The udder secretion from individual cows will curdle on boiling for two to four days after parturition. Boiling will also curdle milk from cows affected with inflammation of the udder, cowpox, and nymphomania. During ostrum the milk sometimes curdles when boiled. It is necessary to test the milk of the individual cow to obtain a positive reaction in these cases. If the milk from the affected cow is mixed with the milk from other cows in the herd, the albumin or globulin may be so diluted that curdling will not be apparent.

\section{ALCOHOL TEST}

In applying the alcohol test, exactly equal quantities by volume of milk and 68 per cent. alcohol are mixed together, after which the mixture is examined for flakes or curds. The flakes may be quite small and must be looked for carefully. The test is most conveniently made with a test tube marked for 5 c.c. and 10 c.c. The tube is filled to the 5 c.c. mark with 68 per cent. alcohol, and to the 10 c.c. mark with milk, and the two fluids are then mixed by shaking. Milk should not be tested when cold, because at low temperatures casein has a tendency to clump and form flakes. The flakes of fat formed when milk is 
agitated must not be mistaken for curds or flakes resulting from the alcohol reaction.

The 68 per cent. alcohol is made by mixing 68 parts of absolute alcohol with 32 parts of distilled water. The alcohol should be neutral. This can be determined by adding a few drops of phenolphthalein solution to a small quantity of the alcohol and then running in a drop of tenth-normal sodium hydroxide solution. If the alcohol is neutral the mixture will assume a permanent pink color.

Fresh normal market milk will not curdle when tested in this manner. Milk which has undergone acid fermentation, or which has been acted upon by the rennetlike ferment produced by certain species of bacteria, or which has undergone a combined acid and rennet fermentation, will curdle when these processes have operated to a certain extent. A positive reaction therefore results when the milk has undergone a certain degree of bacterial decomposition and is an indication that the milk is old, or that it was produced under unclean conditions, or that it was not properly cooled and cared for.

The milk of individual cows will give a positive reaction for from four to twelve days after parturition and near the end of lactation. For a rather long time after abortion, the milk will also give a positive reaction. Milk from cows with diseased udders will react positively before any clinical symptoms are apparent and also for a time after the disease has clinically healed. Milk from cows affected with diseases or injuries of the genital tract, diseases of the digestive tract, or advanced tuberculosis will also usually give a positive reaction to the alcohol test, but not always. It appears that a positive reaction occurs in these cases only when pathological products are 
absorbed from the diseased area and eliminated, in part at least, through the udder. While a negative reaction may not always indicate the entire absence of disease, the presence of any diseased condition which affects the udder directly or indirectly is indicated by a positive reaction, excluding, of course, cows which are "fresh," near the end of lactation, in heat, or which have recently aborted.

The alcohol test is a more delicate test for bacterial decomposition and for the presence of inflammatory and other pathological products than the boiling test and will give a positive reaction when the boiling test is negative.

\section{CATALASE TEST}

The amount of catalase in milk is measured by the amount of oxygen which is separated when a measured quantity of hydrogen peroxide is added to a certain quantity of milk. Different forms of apparatus are used for collecting and measuring the oxygen, the one most commonly used being the Gerber-Lobeck apparatus.

The quantity of oxygen separated will depend not only on the amount of catalase in the milk, but also upon the amount of hydrogen peroxide added. The quantity of oxygen separated increases with the amount of hydrogen peroxide added up to a certain point, but if hydrogen peroxide is present in excess of this amount it will exert a depressing effect upon the ferment. For this reason it is necessary to standardize the hydrogen peroxide solution used, and since the solution is unstable it must be standardized from time to time.

A 1 per cent. solution of hydrogen peroxide is used in the test. The ordinary preparations of hydrogen peroxide are $\mathbf{3}$ per cent. solutions and must therefore be 


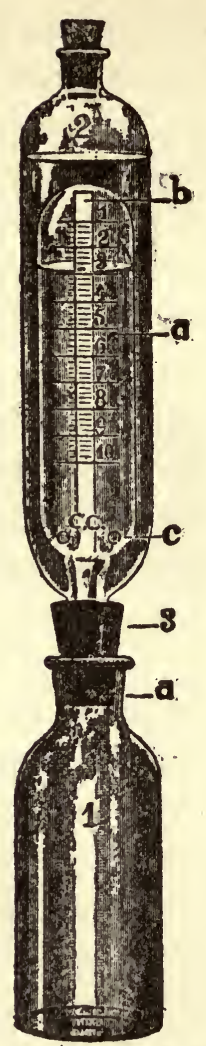

Fia. 40.-Gerber-Lobeck catalase a pparatus. 1. Bottle with perforation in neck at $a$. 2. Volumeter, showing $(a)$ the middle tube, with scale; (b) theinner tube, through which the oxygen ascends from the bottle to the top of the middle tube, and $(c)$ the openings through which the water escapes from the middle to the outer tube. In the illustration, oxygen collected at the top of the middle tube has depressed the water to the 3 c.o. mark and elevated it a corresponding degree in the outer tube. (Courtesy Cornell Veterinarian.)

Example: diluted with twice the quantity of water to prepare a 1 per cent. solution. Distilled water or well-boiled and filtered water should be used. For example: 100 c.c. hydrogen peroxide, 200 c.c. distilled water. The solution should be standardized by titration with a tenth-normal potassium permanganate solution, as follows :

Ten c.c. of the hydrogen peroxide solution is mixed with 90 c.c. of distilled or boiled water. Of this solution, 10 c.c. is placed in a beaker with 10 c.c. of dilute sulphuric acid. The dilute sulphuric acid is prepared by adding 400 c.c. of distilled water to 100 c.c. of sulphuric acid with a specific gravity of 1.82 to 1.825 . About 5 c.c. of the tenth-normal solution of potassium permanganate is run into the beaker from a burette and it is then added slowly until the solution takes on a pale violet color which remains after stirring. About 6 c.c. will be required for a 1 per cent. solution of hydrogen peroxide. Each c.c. of the tenth-normal potassium permanganate solution is equal to 0.0017008 gram hydrogen peroxide. per cent. hydrogen peroxide.

The hydrogen peroxide solution should be kept in an 
amber colored bottle, well stoppered and in a cool place. High temperatures break up the compound. The bottle should be closed immediately after being opened to draw off any of the solution. The solution must be tested by titration from time to time in order to insure accurate results.

To overcome the inconvenience of frequent tests of the hydrogen peroxide solution, the N. Gerber Co., of Leipsig, Germany, has prepared a tablet containing the hydrogen peroxide in more stable form. One of these tablets dissolved in 5 c.c. of water makes a 1 per cent. solution of hydrogen peroxide. (It has also been established by extensive experiments that one of these tablets added to 10 c.c. of milk will give the same result as 3 c.c. of a 1 per cent. hydrogen peroxide solution in 9 c.c. of milk).

The test is made as follows: 1. The bottles must be well cleaned and sterilized by boiling for 15 minutes before using. The use of water containing calcium must be avoided. If not used at once the bottles are to be tightly corked with rubber stoppers, which are also to be sterilized by boiling. The bottles may be closed with cotton plugs and sterilized in a hot-air sterilizer. Pipettes should be sterilized before beginning a series of tests. The pipette used for measuring the milk should be washed out with cold water and then sterilized by filling it with boiling water after each sample of milk is measured.

2. Three c.c. of a 1 per cent. solution of hydrogen peroxide is placed in the bottle; then 9 c.c. of the milk to be tested is added. The bottle is numbered to correspond with the sample of milk. In testing individual milk, it is recommended that the sample be taken from the entire 
quantity of milk obtained at a milking, or from the total quantity obtained from each quarter, if it is desired to test each quarter separately; but when this is not convenient, 50 to 100 c.c. of milk may be drawn from each quarter directly into a sterile sample bottle, after discarding the first three expressions from each teat. In either case, the sample should be thoroughly mixed before the amount required for the test is drawn off.

3. The volumeter, properly filled with water free from air bubbles, is closed at the top with a rubber stopper and is then inserted into the perforated stopper of the bottle. The perforated stopper must be forced down sufficiently to close the small hole in the neck of the bottle. The fluids are mixed by gently whirling the bottle, care being taken not to wet the stopper.

4. The apparatus is set aside at a temperature of 20 to $25^{\circ} \mathrm{C}$. ; in winter a water bath is necessary, but only the bottle should be placed in the water. The rubber stopper in the upper end of the volumeter should be removed in order to avoid any counter-pressure against the water being forced from the middle chamber of the volumeter to the outer by the pressure of the oxygen separated from the hydrogen peroxide in the bottle. The bottle is then permitted to stand for two hours, when the amount of oxygen is read off.

5. The amount of oxygen separated is indicated by the extent to which the water in the inner tube of the volumeter has been forced downward. Before taking the reading as final, the bottle should be gently whirled until the volume of oxygen remains constant. Without such agitation, some of the gas may remain in the bottle, adherent to the fluid, and the reading will not give the 
correct result. Increases of 0.3 to $\mathbf{I}$ c.c. have been observed after agitation.

6. After the reading is taken, the volumeter is disconnected from the bottle, the stopper inserted in the top, and the water forced from the outer to the middle tube by pressure on the stopper until the two columns of water are level with each other. The volumeter is then ready to be used again. The bottle is emptied and cleaned and sterilized for the next test.

Milk from one or several cows in normal condition, tested within three hours after being drawn from the udder, will not show over 3 c.c. of oxygen at the end of the second hour. If the milk is not tested within three hours, the oxygen reading will be in excess of this figure, because the catalase in the milk at the time it was secreted will have been added to by that produced by the bacteria in the milk. According to Faitelowitz and others, if 2 per cent. of chloroform is added to the milk the power or activity of the catalase existing at the time is not affected, while the secretion of catalase by bacteria is prevented.

Certain physiological conditions cause an increase in the catalase. Colostrum, milk for 4 to 5 days up to $\mathbf{3}$ weeks after calving, and milk from "strippers" yielding only a quart or less a day give a higher oxygen reading than is normal for milk at other stages of lactation. The oxygen reading is also increased after sudden or pronounced changes in feed, following incomplete milking and stasis of milk, and sometimes in œestrum when the cow is nervous and excitable.

In disease of the udder, when individual milk is tested, the oxygen reading is above normal before any clinical symptoms are apparent and before there are any visible changes in the appearance of the milk. The reading 
continues high for a time after the clinical symptoms have disappeared. The increase of catalase in mastitis is not always due to the bacteria present. Koning has demonstrated that the streptococci of mastitis do not produce catalase, but that the toxins they excrete irritate the gland tissue and cause an increased transudation of blood serum and emigration of leucocytes, thus increasing the catalase in the milk. The catalase may also be increased in purely traumatic or non-bacterial mastitis. When only one quarter of an udder is visibly diseased, the milk from the other quarters which are apparently healthy may show a high catalase reaction. The catalase test cannot be relied upon to discover mastitis when mixed milk is examined. Mixed milk containing 5 per cent. of milk from a diseased udder will show a high oxygen reading, but if the dilution is greater than this there will be nothing abnormal in the reaction (Gerber).

In general disease, and when disease is present in other organs than the udder, the oxygen reading of individual milk is usually, but not always, high. In these conditions, according to Mogendorff, the catalase in the milk is increased when the udder assists in the elimination of the products of disease, the toxins or other diseaseproducts irritating the gland tissue and causing an unusual amount of blood serum and leucocytes to pass over into the milk. The presence of pathological processes in the.body is often indicated by an increase in the catalase in the milk before they are manifested by clinical symptoms, while in diseases in which resolution is not complete the catalase may be increased in the milk after all clinical symptoms have disappeared. As a rule, there is an increase of catalase in the milk in all diseases accompanied by a high fever; when non-encapsulated purulent areas 
are present in the body, as in traumatic pericarditis, abscesses, furunculosis, panaritium; in diseases of the digestive apparatus such as gastro-intestinal catarrh, constipation, tympanites, enteritis, etc.; when the organs of elimination are affected, as in icterus, interference with the excretion of urine, constipation; in acute and chronic inflammation of the uterus; in peritonitis, and in advanced tuberculosis, even when the udder is free from the disease. The catalase will also be increased in the milk of all cows reacting to tuberculin for several days after the injection.

Whether a high catalase reaction is due to disease in the udder or to disease in another part of the body may be determined by centrifugalizing the milk and examining the sediment. If the disease is in the udder, leucocytes will be present in excess of the usual number. Gratz and Náray observed that when the oxygen reading is high in the milk of cows which have recently "freshened," the sediment, as obtained by the Trommsdorff method, may be low in volume but of a red color, the high catalase reaction being due to the presence of red blood cells. For a time following parturition, red blood cells may enter the milk by diapedesis or by rupture of blood vessels. They therefore regard it as necessary to examine the sediment before deciding as to the cause of a high catalase reaction.

Fresh market milk from cows in normal condition, which has been properly cooled and cared for, should never show over 4 c.c. of oxygen at the end of the second hour (Gerber). When market milk shows a higher oxygen reading, the indication is that the original bacterial contamination has been excessive, or that the milk is old, or that it may have pathological milk or colostrum mixed with it. A large amount of gas $\left(\mathrm{CO}_{2}\right)$ will be 
separated if sodium bicarbonate has been used as a preservative. The catalase test is not as suitable for the examination of market milk as some of the other methods, but it is one of the most delicate tests for detecting pathological conditions when individual milk is examined.

\section{REDUCTASE TEST}

In this test, methylene blue solution and milk are mixed together and the amount of reductase present, or the reduction power, is indicated by the length of time required for the blue color to disappear. Different preparations of methylene blue vary in composition and it is therefore recommended that Merck's B extra methylene blue be always used. The solution is prepared as follows: methylene blue is added to absolute alcohol to saturation; 5 c.c. of this saturated alcoholic solution is then added to 195 c.c. of sterile distilled water; this is the solution used in making the test. The saturated alcoholic solution is rather unstable, and Barthel and O. Jensen therefore recommend that the test solution be made with tablets of Merck's B extra methylene blue prepared by Blauenfeld and Trede, of Copenhagen, Denmark. One tablet is dissolved in 200 c.c. of sterile distilled water. The solution will keep two weeks. When milk is tested with the tablet solution, the reduction time will be shorter than when it is tested with the solution made from the saturated alcoholic solution, because the tablet solution contains less methylene blue.

Ordinary test tubes are used in making the test. These should be cleaned, plugged with cotton and sterilized. The pipettes used in measuring the milk and the methlyene blue solution should also be cleaned and sterilized. After each sample of milk is measured, the pipette used for this purpose should be rinsed with cold water 
and sterilized by drawing boiling water into it several times.

The test is made as follows: The milk to be tested is heated to a temperature of 45 to $48^{\circ} \mathrm{C}$. (113 to $118^{\circ} \mathrm{F}$.) ; $1 / 2$ c.c. of the methylene blue solution is placed in the test tube and 20 c.c. of the milk is added. The test tube is closed with the cotton plug, placed in a water bath or incubator at 38 to $39^{\circ} \mathrm{C}$. (100.4 to $102^{\circ} \mathrm{F}$.), and observed at frequent intervals to note the time of decolorization. If the methylene blue solution is placed in the tube first and the milk afterward, the two fluids will be thoroughly mixed and there will be no opportunity for a part of the methylene blue solution to be absorbed by the cotton plug. It is not necessary to cover the mixture with a layer of paraffine oil, as was formerly recommended, because the difference in reduction time caused by the exclusion of oxygen is not sufficient to be taken into consideration in routine milk testing.

Several investigators have compared the reduction time of market milk with the number of bacteria as determined by the plate method. O. Jensen, using a test solution prepared from a saturated alcoholic solution of methylene blue, found the relations to be as follows:

1. Decolorization in 7 hours or over, $\mathbf{1 0 0 , 0 0 0}$ bacteria per c.c.

2. Decolorization in from 2 to 7 hours, 100,000 to 300,000 bacteria per c.c.

3. Decolorization in from $1 / 4$ to 2 hours, 300,000 to $20,000,000$ bacteria per c.c.

4. Decolorization in less than $1 / 4$ hour, $49,000,000$ to $264,000,000$ bacteria per c.c.

In testing market milk with methylene blue solution prepared from tablets, $O$. Jensen and Barthel found the 
reduction time and the number of bacteria per c.c. to compare as follows:

1. Decolorization in $5 \frac{1}{2}$ hours or over, less than 500,000 bacteria per c.c.

2. Decolorization in from 2 to $5 \frac{1}{2} 2$ hours, 500,000 to $4,000,000$ bacteria per c.c.

3. Decolorization in from 20 minutes to 2 hours, $4,000,000$ to $20,000,000$ bacteria per c.c.

4. Decolorization in 20 minutes or less, over 20,000,000 bacteria per c.c.

These figures do not apply to milk that has been heated.

The reduction time of market milk agrees in a general way with the number of bacteria contained in the milk and is a very good index to the "keeping qualities", or stability of milk. The reductase test is not to be depended upon to detect pathological milk. While mastitis milk usually decolorizes in a shorter time than normal milk, this does not occur in all cases.

O. Jensen has combined the reductase test with the fermentation test.

\section{FERMENTATION-REDUCTASE TEST}

This is a combination of the fermentation and reductase tests which was first proposed by O. Jensen. One-half c.c. of methylene blue solution is placed in a test tube with 20 c.c. of milk, the tube is placed in an incubator and kept under observation until decolorization occurs, as in the reductase test. In addition, the test tube is kept in the incubator until curdling occurs, and the type of curd is then noted. Methylene blue in large quantity inhibits the development of bacteria, especially the lactic acid bacteria, but in the quantity used in this test the effect is practically negligible. 
A quickly reducing milk very frequently produces a good curd (jelly-like) because in milk rich in bacteria the lactic acid bacteria are often so numerous that they inhibit the growth of the other species. But a milk may reduce quickly and at the same time produce a bad curd (gaseous or peptonized) ; such milk is extremely objectionable. On the other hand, a slowly reducing milk may produce a peptonized curd. This is because milk produced under cleanly conditions is exposed to a comparatively slight bacterial contamination and the udder cocci consequently predominate. When such milk is kept at a low temperature the peptonizing bacteria (udder cocci) will develop more rapidly than the others and it will contain few lactic acid bacteria. For these reasons, it has been recommended by Barthel and O. Jensen that milk with a reduction time of $5 \frac{1}{2}$ hours or over should not be condemned as bad on account of a peptonized curd.

\section{DIASTASE TEST}

Koning devised a method for the quantitative determination of diastase. The reagents used are a solution of starch and a solution of iodine. The starch solution is prepared by adding 1 gramme of soluble starch to 100 c.c. of sterile distilled water, warming, and shaking the mixture to bring about solution. The iodine solution is prepared by dissolving 1 gramme of iodine and 2 grammes of potassium iodide in $\mathbf{3 0 0}$ c.c. of distilled water. The test is made as follows:

Ten c.c. of milk is placed in each of five test tubes. 0.05 c.c. of the starch solution is added to the first tube, 0.1 c.c. to the second, 0.2 c.c. to the third, 0.25 c.c. to the fourth and 0.3 c.c. to the fifth. The tubes are placed in a water bath at $45^{\circ} \mathrm{C}$. for 30 minutes, after which 1 c.c. of the iodine solution is added to each tube. If all of the 
starch has been digested the mixture in the tube assumes a citron-yellow color; if any starch remains a blue color will appear. According to Koning, normal milk will digest the starch in the first two or the first three tubes; a higher diastatic power indicates mastitis, while a lower indicates old milk. Others report that the diastatic power of milk from cows affected with mastitis is very variable and that the diastase test cannot therefore be depended upon to discover mastitis milk. The diastatic power is also increased in the colostral period and near the end of lactation. One observer affirms that the diastase in milk is decreased when the ration is rich in carbohydrates.

\section{TESTS FOR HEATED MILK}

Two tests are used to determine whether or not milk has been heated to $80^{\circ} \mathrm{C}$. $\left(176^{\circ} \mathrm{F}\right.$.) or above. They are as follows:

Storch's Test. -5 c.c. of milk or cream is placed in a test tube, 1 drop of $\mathbf{0 . 2}$ per cent. solution of hydrogen peroxide containing 0.1 per cent. of sulphuric acid, and 2 drops of a 2 per cent. solution of paraphenyldiamin are added, and the mixture is shaken. If the mixture assumes an indigo blue or violet color immediately, it has not been heated at all or not higher than $78^{\circ} \mathrm{C}$. $\left(172.5^{\circ}\right.$ F.) ; if it becomes a light bluish-gray within a half minute, it has been heated to between 79 and $80^{\circ} \mathrm{C}$. $\left(174.2^{\circ}\right.$ to $176^{\circ} \mathrm{F}$.) ; if it remains white, it has been heated to at least $80^{\circ} \mathrm{C} .\left(176^{\circ} \mathrm{F}\right.$.). Raw whey gives a violet or reddish-brown color.

Arnold's Guaiac Test.-A small quantity of milk is placed in a test tube and a little tincture of guaiac is run down the side of the tube drop by drop so that it will not mix with the milk but form a layer on top of the milk. If the milk is raw or has not been heated to $80^{\circ} \mathrm{C}$. 
$\left(176^{\circ} \mathrm{F}.\right)$, a blue ring is formed at the point of contact of the two fluids. If the milk has been heated to $80^{\circ} \mathrm{C}$. $\left(176^{\circ} \mathrm{F}\right.$.) or above, no color change occurs. The guaiacwood tincture is more reliable than the guaiac-resin tincture of the U.S. Pharmacopœia. The addition of a few drops of a weak aqueous solution of hydrogen peroxide after the tincture of guaiac has been run into the test tube increases the reliability and sharpness of the test (Zinc), although if the guaiac tincture is "ripe," a change which takes place with age, the hydrogen peroxide is not necessary. When the test is made with the tincture alone, the activity of the latter should be tested against known raw milk. If the hydrogen peroxide is added to the milk before the guaiac tincture, or if too much is added, the reaction will be retarded or suppressed.

When milk is strongly acid it will not give the color reaction at all, or the reaction will be faint or delayed. Lime water should be added to such milk and to buttermilk before testing. Cold milk may not react at all or very slowly. An excess of hydrogen peroxide will prevent the reaction. Heated milk to which formalin has been added will give a color reaction to the Storch test like raw milk, but formalin has no influence on the guaiac test when it is present in the quantity used to preserve milk. The guaiac test is also not affected by sodium bicarbonate, borax, boric acid, and salicylic acid, but the presence of potassium bichromate causes heated milk to react like raw milk and intensifies the color reaction of raw milk.

\section{EXAMINATION FOR DIRT}

The milk is filtered through small cotton discs and the larger particles of dirt present are collected on the surface of the disc. There are several different forms of 
apparatus for making this test. In some the milk is permitted to flow through the filter by gravity, while in the others it is forced through by air pressure from a rubber bulb. According to the quantity of dirt collected on the cotton disc the milk is classed as good, medium, fair, and bad. The dises are sometimes dried and mailed to the producer for his examination. There is no direct relation between the quantity of dirt collected on the cotton disc and the bacterial content. Milk which would be classed as good according to this test may have a high bacterial content and vice versa. Furthermore, milk produced under unclean conditions will test "good" by this test if it is well strained beforehand.

Another method of testing for dirt is to place the milk in a conical glass, or in a vessel with a narrow tube at the bottom, and measure the volume of sediment which settles to the bottom after a certain period; or the milk may be centrifugalized and the sediment measured.

The visible dirt in milk consists principally of particles of feed and litter, manure, hairs, dandruff and dust.

\section{TEST FOR LACTOSE}

Glage has devised a simple test for lactose which may be applied to samples of individual cow's milk or to samples of milk from the different quarters of the udder. It is made as follows: Place 3 c.c. of milk and 3 c.c. of a 15 per cent. solution of potassium hydroxide in a test tube, boil thoroughly and let stand for 10 minutes. When the milk contains the normal amount of lactose the mixture at first becomes pale yellow during the boiling, changing quickly to dark yellow, to orange, and then to brown; after standing the color of the mixture becomes coffee-brown or red-brown. If the quantity of lactose is 


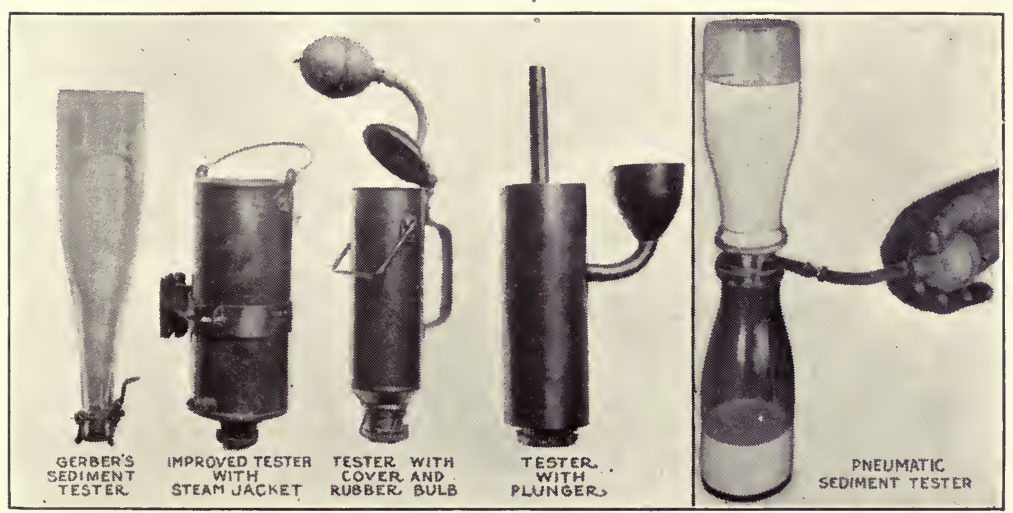

FIG. 41.-Various types of dirt testers (Wisconsin Exp. Station Cir. No. 41). 

below normal the color remains yellow or orange. When the color becomes yellowish-brown the condition of the milk must be regarded as doubtful. The presence of a large amount of fat is likely to interfere with the reaction and it is therefore best to remove the fat from the milk before applying the test. Milk sugar is decreased in quantity and is sometimes entirely absent in inflammation of the udder. It is also reduced in quantity during the colostral period and toward the end of lactation; exercise sometimes decreases it. It is present in greatest amount in the middle of a milking and lowest at the beginning and end. Fresh market milk will always give a normal reaction to this test.

\section{EXAMINATION FOR COLORING MATTERS}

When the yellow color of milk is natural it is largely confined to the cream, and if opportunity is given for the cream to rise the milk beneath it has a bluish tinge. But when the yellow color is artificial not only the cream but the milk beneath it is of the same color. Artificial coloring matters are sometimes added to milk to give it a rich color when it has been adulterated with water. Annatto, also called arnatto and annotto; analin orange, an azo-dye, and caramel are the substances most frequently used. Leach recommends the following procedure for the detection of artificial coloring:

Place 150 c.c. of milk in a casserole, add a little acetic acid and heat until curdling occurs. Gather the curd together with a glass rod and pour off the whey, or separate by filtration. Macerate the curd with ether in a stoppered bottle for several hours. Evaporate the ether extract on a water bath, add sufficient sodium hydroxide to the residue to make it alkaline and pour the mixture 
upon a small wet filter, wash the fat off the surface with tap water and dry the filter. If the filter paper is colored orange the presence of annatto is indicated. The application of stannous chloride will change the color to a characteristic pink if annatto is present.

If the curd is colorless after it has been extracted with ether no other coloring matter is present. If it is orange or brownish the presence of analin orange or caramel is indicated. The curd is then shaken in a test tube with concentrated hydrochloric acid. If the solution immediately turns pink the presence of analin orange is indicated. If it slowly turns blue, this points to the presence of caramel and the following test should be applied: About 120 c.c. of the milk and an equal quantity of alcohol are mixed together and filtered. A small quantity of subacetate of lead is added to the filtrate and the precipitate produced is collected on a small paper filter which is dried in an atmosphere free from hydrogen sulphide. If caramel is present the precipitate is of a dark brown color. If no caramel is present the precipitate will be white or straw color. 


\section{APPENDIX}

\section{METHODS 'AND STANDARDS FOR THE PRODUC- TION AND DISTRIBUTION OF "CERTIFIED MILK" 1}

Adopted by the American Association of Medical Milk Commissions, May 1, 1912.

Certified milk is the product of dairies operated in accordance with accepted rules and regulations formulated by authorized medical milk commissions to insure its purity and adaptability for infants and invalids.

The need for such a milk was experienced primarily by those engaged in the conservation of the life and health of infants. As a result there was formulated in 1892 a plan whereby certified milk would be produced by a dairyman under the control of a medical milk commission designated by a representative medical society.

1 At the fifth annual meeting of the American Association of Medical Milk Commissions, held in Philadelphia, May 25, 1911, a committee was appointed to revise the manual of working methods and standards for the guidance of medical milk commissions in the supervision of the production and distribution of certified milk. The committee consisted of Dr. J. W. Kerr (chairman), Dr. S. McC. Hamill, and Dr. Henry L. Coit. This, their report, was adopted at the sixth annual meeting, held at Louisville, Kentucky, May 1, 1912, as the working methods and standards of the association. The association recommends them to component commissions as ideal and to be as closely approximated as possible. The report includes a statement concerning the certified milk movement, as well as the revised methods and standards, and is published for the information of those interested in the improvement of public milk supplies.

Reprint from the Public Health Reports, vol. xxvii, No. 24, June 14, 1912. 
The first rules designed for this purpose were those contained in an agreement entered into by a medical milk commission and the dairyman concerned. ${ }^{2}$

The rules contained in the original agreement mentioned represented the essential requirements for the production of certified milk. Following this precedent, other commissions were organized, which, in 1906, became federated into a national association known as the American Association of Medical Milk Commissions.

A fundamental object of this Association was to bring about the uniformity of standards and their perfection. This result has been reached by the adoption from time to time of definite standards relating to the veterinary inspection of herds and farms, the medical inspection of employees handling the milk, and the bacteriological and chemical examinations as to quality and purity. The requirements with respect to these four topics have been previously reported upon by committees and adopted by the Association, and at its last annual meeting provision was made for their further revision and amplification.

\section{ORGANIZATION OF MEDICAL MILK COMMISSIONS}

The Medical Milk Commission is appointed by a representative medical society, and acts under its auspices and for it, to encourage the production of milk of the highest possible standards of purity. No commission should be considered as certifying milk that does not conform to the standards adopted from time to time by the Association of Medical Milk Commissions. The commission should include at least five members or a number sufficient to become responsible for and to carry on the following divisions of work; (a) The hygiene of the dairy, as it relates to the production and distribution of the milk; $(b)$ the veterinary supervision of the herd; $(c)$ the medical supervision of the employees; $(d)$ the chemical and bacteriological examinations of the milk.

2 Bul. 56, Hygienic Laboratory, Public Health and Marine Hospital Service, p. 615. 


\section{DUTIES OF THE COMMISSION}

After its organization the commission should designate a veterinarian, a physician, a chemist, and a bacteriologist to enforce its methods and standards, which shall be the prevailing methods and standards of the American Association of Medical Milk Commissions, and these officers should be required to render regular reports of their inspections and examinations. A uniform written agreement should then be entered into with any dairyman who is desirous of undertaking the production of certified milk and the investigation of whose plant shows it to be properly equipped for such purpose. Such agreement shall require the observance of the methods and standards hereinafter mentioned.

Upon receipt of favorable reports from the several experts and committees which have made the investigations, the dairyman should be authorized, in accordance with the terms of the agreement, to employ the term " Certified Milk," and he shall be required to attach to all containers of any character used in distributing the milk produced under the agreement a certificate or seal bearing the term "Certified Milk," the name of the medical milk commission certifying it, and the day or date of production of the milk contained therein.

\section{HYGIENE OF THE DAIRY}

\section{Under the Supervision and Control of the Veterinarian}

1. Pastures or Paddocks.-Pastures or paddocks to which the cows have access shall be free from marshes or stagnant pools, crossed by no stream which might become dangerously contaminated, at sufficient distances from offensive conditions to suffer no bad effects from them, and shall be free from plants which affect the milk deleteriously.

2. Surroundings of Buildings.- The surroundings of all buildings shall be kept clean and free from accumulations of dirt, rubbish, decayed vegetable or animal matter or animal waste, and the stable yard shall be well drained.

3. Location of Buildings. - Buildings in which certified milk is produced and handled shall be so located as to insure proper 
shelter and good drainage, and at sufficient distance from other buildings, dusty roads, cultivated and dusty fields, and all other possible sources of contamination; provided, in the case of unavoidable proximity to dusty roads or fields, the exposed side shall be screened with cheese cloth.

4. Construction of Stables. - The stables shall be constructed so as to facilitate the prompt and easy removal of waste products. The floors and platforms shall be made of cement or other non-absorbent material, and the gutters of cement only. The floors shall be properly graded and drained, and the manure gutters shall be from six to eight inches deep and so placed in relation to the platform that all manure will drop into them.

5. The inside surface of the walls and all interior construction shall be smooth, with tight joints, and shall be capable of shedding water. The ceiling shall be of smooth material and dust-tight. All horizontal and slanting surfaces which might harbor dust shall be avoided.

6. Drinking and Feed Troughs.-Drinking troughs or basins shall be drained and cleaned each day, and feed troughs and mixing floors shall be kept in a clean and sanitary condition.

7. Stanchions.-Stanchions when used shall be constructed of iron pipes or hardwood, and throat latches shall be provided to prevent the cows from lying down between the time of cleaning and the time of milking.

8. Ventilation. - The cow stables shall be provided with adequate ventilation either by means of some approved artificial device, or by the substitution of cheesecloth for glass in the windows, each cow to be provided with a minimum of 600 cubic feet of air space.

9. Windores.-A sufficient number of windows shall be installed and so distributed as to provide satisfactory light and a maximum of sunshine; two feet square of window area to each 600 cubic feet of air space to represent the minimum. The coverings of such windows shall be kept free from dust and dirt.

10. Exclusion of Flies, etc.-All necessary measures should be taken to prevent the entrance of flies and other insects, and rats and other vermin into all the buildings.

11. Exclusion of Animals from the Herd.-No horses, hogs, 
dogs, or other animals or fowls shall be allowed to come in contact with the certified herd, either in the stables or elsewhere.

12. Bedding. - No dusty or mouldy hay or straw, bedding from horse stalls, or other unclean materials shall be used for bedding the cows. Only bedding which is clean, dry, and absorbent may be used, preferably shavings or straw.

13. Cleaning Stable and Disposal of Manure.-Soiled bedding and manure shall be removed at least twice daily, and the floors shall be swept and kept free from refuse. Such cleaning shall be done at least one hour before the milking time. Manure, when removed, shall be drawn to the field or temporarily stored in containers so screened as to exclude flies. Manure shall not be even temporarily stored within 300 feet of the barn or dairy building.

14. Cleaning of Cores.-Each cow in the herd shall be groomed daily, and no manure, mud, or filth shall be allowed to remain upon her during milking; for cleaning, a vacuum apparatus is recommended.

15. Clipping.-Long hairs shall be clipped from the udder and flanks of the cow, and from the tail above the brush. The hair on the tail shall be cut so that the brush may be well above the ground.

16. Cleaning of Udders. - The udders and teats of the cow shall be cleaned before milking; they shall be washed with a cloth and water, and wiped dry with another clean sterilized clotha separate cloth for drying each cow.

17. Feeding.-All foodstuffs shall be kept in an apartment separate from and not directly communicating with the cow barn. They shall be brought into the barn only immediately before the feeding hour, which shall follow the milking.

18. Only those foods shall be used which consist of fresh, palatable, or nutritious materials, such as will not injure the health of the cows or unfavorably affect the taste or character of the milk. Any dirty or mouldy food or food in a state of decomposition or putrefaction shall not be given.

19. A well-balanced ration shall be used, and all changes of food shall be made slowly. The first few feedings of grass, 
alfalfa, ensilage, green corn, or other green feeds shall be given in small rations and increased gradually to full ration.

20. Exercise.-All dairy cows shall be turned out for exercise at least two hours in each twenty-four in suitable weather. Exercise yards shall be kept free from manure and other filth.

21. Washing of Hands.-Conveniently located facilities shall be provided for the milkers to wash in before and during milking.

22. The hands of the milkers shall be thoroughly washed with soap, water, and brush, and carefully dried on a clean towel immediately before milking. The hands of the milkers shall be rinsed with clean water and carefully dried before milking each cow. The practice of moistening the hands with milk is forbidden.

23. Milking Clothes.-Clean overalls, jumper, and cap shall be worn during milking. They shall be washed or sterilized each day and used for no other purpose, and when not in use they shall be kept in a clean place, protected from dust and dirt.

24. Things to be Avoided by Milkers.-While engaged about the dairy or in handling the milk, employees shall not use tobacco nor intoxicating liquors. They shall keep their fingers away from their nose and mouth, and no milker shall permit his hands, fingers, lips, or tongue to come in contact with milk intended for sale.

25. During milking the milkers shall be careful not to touch anything but the clean top of the milking stool, the milk pail and the cow's teats.

26. Milkers are forbidden to spit upon the walls or floors of stables, or upon the walls or floors of milk houses, or into the water used for cooling the milk or washing the utensils.

2\%. Fore-Milk. - The first streams from each teat shall be rejected, as this fore-milk contains large numbers of bacteria. Such milk shall be collected into a separate vessel and not milked onto the floor or into the gutters. The milking shall be done rapidly and quietly, and the cows shall be treated kindly.

28. Milk and Calving Period.-Milk from all cows shall be excluded for a period of forty-five days before and seven days after parturition. 
29. Bloody and Stringy Milk.-If milk from any cow is bloody and stringy, or of unnatural appearance, the milk from that cow shall be rejected and the cow isolated from the herd until the cause of such abnormal appearance has been determined and removed, especial attention being given in the meantime to the feeding or to possible injuries. If dirt gets into the pail, the milk shall be discarded and the pail washed before it is used.

30. Make-up of Herd.-No cows except those receiving the same supervision and care as the certified herd shall be kept in the same barn or brought in contact with them.

31. Employees Other Than Milkers.-The requirements for milkers, relative to garments and cleaning of hands, shall apply to all other persons handling the milk, and children unattended by adults shall not be allowed in the dairy nor in the stable during milking.

32. Straining and Strainers.-Promptly after the milk is drawn it shall be removed from the stable to a clean room and then emptied from the milk pail to the can, being strained through strainers made of a double layer of finely meshed cheesecloth or absorbent cotton thoroughly sterilized. Several strainers shall be provided for each milking in order that they may be frequently changed.

33. Dairy Building.-A dairy building shall be provided which shall be located at a distance from the stable and dwelling prescribed by the local commission, and there shall be no hog-pen, privy, or manure pile at a higher level or within 300 feet of it.

34. The dairy building shall be kept clean and shall not be used for purposes other than the handling and storing of milk and milk utensils. It shall be provided with light and ventilation, and the floors shall be graded and water-tight.

35. The dairy building shall be well lighted and screened, and drained through well-trapped pipes. No animals shall be allowed therein. No part of the dairy building shall be used for dwelling or lodging purposes, and the bottling room shall be used for no other purpose than to provide a place for clean milk utensils and for handling the milk. During bottling this room shall be entered only by persons employed therein. The 
bottling room shall be kept scrupulously clean and free from odors.

36. Temperature of Milk.-Proper cooling to reduce the temperature to $45^{\circ} \mathrm{F}$. shall be used, and aërators shall be so situated that they can be protected from flies, dust, and odors. The milk shall be cooled immediately after being milked, and maintained at a temperature between $35^{\circ}$ and $45^{\circ} \mathrm{F}$. until delivered to the consumer.

37. Sealing of Bottles.-Milk, after being cooled and bottled, shall be immediately sealed in a manner satisfactory to the commission, but such seal shall include a sterile hood which completely covers the lip of the bottle.

38. Cleaning and Sterilizing of Bottles.-The dairy building shall be provided with approved apparatus for the cleansing and sterilizing of all bottles and utensils used in milk production. All bottles and utensils shall be thoroughly cleaned by hot water and sal soda, or equally pure agent, rinsed until the cleaning water is thoroughly removed, then exposed to live steam or boiling water at least twenty minutes, and then kept inverted until used, in a place free from dust and other contaminating materials.

39. Utensils.-All utensils shall be so constructed as to be easily cleaned. The milk pail should preferably have an elliptical opening five by seven inches in diameter. The cover of this pail should be so convex as to make the entire interior of the pail visible and accessible for cleaning. The pail shall be made of heavy seamless tin, and with seams which are flushed and made smooth by solder. Wooden pails, galvanized-iron pails, or pails made of rough, porous materials, are forbidden. All utensils used in milking shall be kept in good repair.

40. Water Supply.-The entire water supply shall be absolutely free from contamination, and shall be sufficient for all dairy purposes. It shall be protected against flood or surface drainage, and shall be conveniently situated in relation to the milk house.

41. Privies, etc., in Relation to Water Supply.-Privies, pig-pens, manure piles, and all other possible sources of contamination shall be so situated on the farm as to render im- 
possible the contamination of the water supply, and shall be so protected by use of screens and other measures as to prevent their becoming breeding grounds for flies.

42. Toilet Rooms. - Toilet facilities for the milkers shall be provided and located outside of the stable or milk house. These toilets shall be properly screened, shall be kept clean, and shall be accessible to wash basins, water, nail brush, soap, and towels, and the milkers shall be required to wash and dry their hands immediately after leaving the toilet room.

\section{TRANSPORTATION}

43. In transit, the milk packages shall be kept free from dust and dirt. The wagon, trays, and crates shall be kept scrupulously clean. No bottles shall be collected from houses in which communicable diseases prevail, unless a separate wagon is used and under conditions prescribed by the department of health and the medical milk commission.

44. All certified milk shall reach the consumer within thirty hours after milking.

VETERINARY SUPERVISION OF THE HERD

45. Tuberculin Test.-The herd shall be free from tuberculosis, as shown by the proper application of the tuberculin test. The test shall be applied in accordance with the rules and regulations of the United States Government, and all reactors shall be removed immediately from the farm. ${ }^{3}$

46. No new animals shall be admitted to the herd without first having passed a satisfactory tuberculin test, made in accordance with the rules and regulations mentioned; the tuberculin to be obtained and applied only by the official veterinarian of the commission.

4\%. Immediately following the application of the tuberculin test to a herd for the purpose of eliminating tuberculous cattle, the cow stable and exercising yards shall be disinfected by the veterinary inspector in accordance with the rules and regulations of the United States Government. ${ }^{3}$

${ }^{3}$ See circular of Instructions issued by the Bureau of Animal Industry for making tuberculin tests and for disinfection of premises. 
48. A second tuberculin test shall follow each primary test after an interval of six months, and shall be applied in accordance with the rules and regulations mentioned. Thereafter, tuberculin tests shall be reapplied annually, but it is recommended that the retests be applied semi-annually.

49. Identification of Cores.-Each dairy cow in each of the certified herds shall be labeled or tagged with a number or mark which will permanently identify her.

50. Herd-book Record.-Each cow in the herd shall be registered in a herd book, which register shall be accurately kept so that her entrance and departure from the herd and her tuberculin testing can be identified.

51. A copy of this herd-book record shall be kept in the hands of the veterinarian of the medical milk commission under which the dairy farm is operating, and the veterinarian shall be made responsible for the accuracy of this record.

52. Dates of Tuberculin Tests.-The dates of the annual tuberculin tests shall be definitely arranged by the medical milk commission, and all of the results of such tests shall be recorded by the veterinarian and regularly reported to the secretary of the medical milk commission issuing the certificate.

53. The results of all tuberculin tests shall be kept on file by each medical milk commission, and a copy of all such tests shall be made available to the American Association of Medical Milk Commissions for statistical purposes.

54. The proper designated officers of the American Association of Medical Milk Commissions should receive copies of reports of all of the annual, semiannual, and other official tuberculin tests which are made, and keep copies of the same on file and compile them annually for the use of the association.

55. Disposition of Cores Sick with Diseases Other Than Tuberculosis.-Cows having rheumatism, leucorrhœa, inflammation of the uterus, severe diarrhœa, or disease of the udder, or cows that from any other cause may be a menace to the herd, shall be removed from the herd, placed in a building separate from that which may be used for the isolation of cows with tuberculosis, unless such building has been properly disinfected since it was last used for this purpose. The milk from such cows 
shall not be used, nor shall the cows be restored to the herd until permission has been given by the veterinary inspector after a careful physical examination.

56. Notification of Veterinary Inspector.-In the event of the occurrence of any of the diseases just described between the visits of the veterinary inspector, or if at any time a number of cows become sick at one time in such a way as to suggest the outbreak of a contagious disease or poisoning, it shall be the duty of the dairyman to withdraw such sickened cattle from the herd, to destroy their milk, and to notify the veterinary inspector by telegraph or telephone immediately.

5\%. Emaciated Cores.-Cows that are emaciated from chronic diseases or from any cause that in the opinion of the veterinary inspector may endanger the quality of the milk, shall be removed from the herd.

\section{BACTERIOLOGICAL STANDARDS}

58. Bacterial Counts.-Certified milk shall contain less than 10,000 bacteria per cubic centimetre when delivered. In case a count exceeding 10,000 bacteria per cubic centimetre is found, daily counts shall be made, and if normal counts are not restored within ten days the certificate shall be suspended.

59. Bacterial counts shall be made at least once a week.

60. Collection of Samples.-The samples to be examined shall be obtained from milk as offered for sale, and shall be taken by a representative of the milk commission. The samples shall be received in the original packages, in properly iced containers, and they shall be so kept until examined, so as to limit as far as possible changes in their bacterial content.

61. For the purpose of ascertaining the temperature, a separate original package shall be used, and the temperature taken at the time of collecting the sample, using for the purpose a standardized thermometer graduated in the centigrade scale.

62. Interval Between Milking and Plating.-The examinations shall be made as soon after collection of the samples as possible, and in no case shall the interval between milking and plating the samples be longer than forty hours.

63. Plating.-The packages shall be opened with aseptic 
precautions after the milk has been thoroughly mixed by vigorously reversing and shaking the container twenty-five times.

64. Two plates at least shall be made for each sample of milk, and there shall also be made a control of each lot of medium and apparatus used at each testing. The plates shall be grown at $37^{\circ} \mathrm{C}$. for forty-eight hours.

65. In making the plates there shall be used agaragar media containing 1.5 per cent. agar and giving a reaction of 1.0 to phenolphthalein.

[The method recommended by a committee of the American Public Health Association for the making of the medium is to be followed (see page 262), modified, however, as to the agar content and reaction to conform to the requirements specified in section 65.]

66. Samples of milk for plating shall be diluted in the proportion of 1 part of milk to 99 parts of sterile water; shake 25 times and plate 1 c.c. of the solution.

[The recommendations of the committee of the American Public Health Association in regard to plating are to be followed (see page 265).]

6\%. Determination of Taste and Odor of Milk.-After the plates have been prepared and placed in the incubator, the taste and odor of the milk shall be determined after warming the milk to $100^{\circ} \mathrm{F}^{4}$

68. Counts. - The total number of colonies on each plate should be counted, and the results expressed in multiples of the dilution factor. Colonies too small to be'seen with the naked eye or with slight magnification shall not be considered in the count.

69. Records of Bacteriologic Tests.-The results of all bacterial tests shall be kept on file by the secretary of each commission, copies of which should be made available annually for the use of the American Association of Medical Milk Commissions.

${ }^{4}$ Should it be deemed desirable and necessary to conduct tests for sediment, the presence of special bacteria, or the number of leucocytes, the methods adopted by the committee of the American Public Health Association should be followed. 


\section{CHEMICAL STANDARDS AND METHODS}

The methods that must be followed in carrying out the chemical investigations essential to the protection of certified milk are so complicated that in order to keep the fees of the chemist at a reasonable figure there must be eliminated from the examination those procedures which, whilst they might be helpful and interesting, are in no sense necessary.

For this reason the determination of the water, the total solids, and the milk sugar is not required as a part of the routine examination.

70. The chemical analyses shall be made by a competent chemist designated by the medical milk commission.

71. Method of Obtaining Samples.-The samples to be examined by the chemist shall have been examined previously by the bacteriologist designated by the medical milk commission as to temperature, odor, taste, and bacterial content.

72. Fat Standards. - The fat standard for certified milk shall be 4 per cent., with a permissible range of variation of from 3.5 to 4.5 per cent.

73. The fat standard for certified cream shall be not less than 18 per cent.

74. If it is desired to sell higher fat-percentage milks or creams as certified milks or creams, the range of variation for such milks shall be $\mathbf{0 . 5}$ per cent. on either side of the advertised percentage and the range of variations for such creams shall be 2 per cent. on either side of the advertised percentage.

75. The fat content of certified milks and creams shall be determined at least once each month.

76. The methods recommended for this purpose are the Babcock (a), the Leffmann-Beam (b), and the Gerber (c). (See pages 233 to 239.)

7\%. Before condemning samples of milk which have fallen outside the limits allowed, the chemist shall have determined, by control ether extractions, that his apparatus and his technic are reliable.

78. Protein Standard.-The protein standard for certified milk shall be 3.50 per cent., with a permissible range of variation of from 3 to 4 per cent. 
79. The protein standard for certified cream shall correspond to the protein standard for certified milk.

80. The protein content shall be determined only when any special consideration seems to the medical milk commission to make it desirable.

81. It shall be determined by the $\mathrm{Kj}$ jeldahl method, using the Gunning or some other reliable modification, and employing the factor 6.25 in reckoning the protein from the nitrogen.

Kjeldahl Method.-Five cubic centimetres are measured carefully into a flat-bottom 800 c.c. Jena flask, 20 c.c. of concentrated sulphuric acid (C. P.; sp. gr., 1.84) are added, and 0.7 gramme of mercuric oxide (or its equivalent in metallic mercury); the mixture is then heated over direct flame until it is straw-colored or perfectly white; a few crystals of potassium permanganate are now added till the color of the liquid remains: green. All the nitrogen in the milk has then been converted into the form of ammonium sulphate. After cooling, 200 c.c. of ammonia-free distilled water are added, 20 c.c. of a solution of potassium sulphide (containing 40 grammes sulphide per litre), and a fraction of a gramme of powdered zinc. A quantity of semi-normal $\mathrm{HCl}$ solution more than sufficient to neutralize the ammonia obtained in the oxidation of the milk is now carefully measured out from a delicate burette (divided into 1/20 c.c.) into an Erlenmeyer flask and the flask connected with a distillation apparatus. At the other end the Jena flask containing the watery solution of the ammonium sulphate is connected, after adding 50 c.c. of a concentrated soda solution ( 1 pound "pure potash" dissolved in 500 c.c. of distilled water and allowed to settle); the contents of the Jena flask are now heated to boiling, and the distillation is continued for 40 minutes to an hour, until all ammonia has been distilled over.

The excess of acid in the Erlenmeyer receiving flask is then accurately titrated back by means of a tenth-normal standard ammonia solution, using a cochineal solution as an indicator. From the amount of acid used the per cent. of nitrogen is obtained; and from it the per cent. of casein and albumen in the milk by multiplying by 6.25. The amount of nitrogen contained in the chemicals used is determined by blank experiments and 
deducted from the nitrogen obtained as described. (Farrington and Woll, Testing Milk and Its Products, p. 221.)

82. Coloring Matter and Preservatives.-All certified milks and creams shall be free from adulteration, and coloring matter and preservatives shall not be added thereto.

83. Tests for the detection of added coloring matter shall be applied whenever the color of the milk or cream is such as to arouse suspicion.

Test for Coloring Matter. - The presence of foreign coloring matter in milk is easily shown by shaking 10 c.c. of the milk with an equal quantity of ether; on standing, a clear ether solution will rise to the surface; if artificial coloring matter has been added to the milk, the solution will be yellow colored, the intensity of the color indicating the quantity added; natural fresh milk will give a colorless ether solution. (Testing Milk and Its Products, Farrington and Woll, p. 244.)

84. Tests for the detection of formaldehyde, borax, and boracic acid shall be applied at least once each month. Occasionally application of tests for the detection of salicylic acid, benzoic acid, and the benzoates are also recommended. (See pages 257 to 260 .)

85. Detection of Heated Milk.-Certified milk or cream shall not be subjected to heat unless specially directed by the commission to meet emergencies.

86. Tests to determine whether such milks and creams have been subjected to heat shall be applied at least once each month. (See page 298.)

87. Specific Gravity.-The specific gravity of certified milk shall range from 1.029 to 1.034 .

88. The specific gravity shall be determined at least each month. (See page 228.)

METHODS AND REGULATIONS FOR THE MEDICAL EXAMINATION OF EMPLOYEES, THEIR HEALTH AND PERSONAL HYGIENE

89. A medical officer known as the attending dairy physician shall be elected by the commission, who should reside near the dairy producing certified milk. He shall be a physician in good standing and authorized by law to practice medicine; 
he shall be responsible to the commission and subject to its direction. In case more than one dairy is under the control of the commission and they are in different localities, a separate physician should be designated for employment for the supervision of each dairy.

90. Before any person shall come on the premises to live and remain as an employee, such person, before being engaged in milking or the handling of milk, shall be subjected to a complete physical examination by the attending physician. No person shall be employed who has not been vaccinated recently or who upon examination is found to have a sore throat, or to be suffering from any form of tuberculosis, venereal disease, conjunctivitis, diarrhœa, dysentery, or who has recently had typhoid fever or is proved to be a typhoid carrier, or who has any inflammatory disease of the respiratory tract, or any suppurative process or infectious skin eruption, or any disease of an infectious or contagious nature, or who has recently been associated with children sick with contagious disease.

91. In addition to ordinary habits of personal cleanliness, all milkers shall have well-trimmed hair, wear close-fitting caps, and have clean-shaven faces.

92. When the milkers live upon the premises their dormitories shall be constructed and operated according to plans approved by the commission. A separate bed shall be provided for each milker, and each bed shall be kept supplied with clean bedclothes. Proper bathing facilities shall be provided for all employees on the dairy premises, preferably a shower bath, and frequent bathing shall be enjoined.

93. In case the employees live on the dairy premises, a suitable building shall be provided to be used for the isolation and quarantine of persons under suspicion of having a contagious disease.

The following plan of construction is recommended:

The quarantine building and hospital should be one story high and contain at least two rooms, each with a capacity of about 6000 cubic feet and containing not more than three beds each, the rooms to be separated by a closed partition. The 
doors opening into the rooms should be on opposite sides of the building, and provided with locks. The windows should be barred and the sash should be at least five feet from the ground, and constructed for proper ventilation. The walls should be of a material which will allow proper disinfection. The floor should be of painted or washable wood, preferably of concrete, and so constructed that the floor may be flushed and properly disinfected. Proper heating, lighting, and ventilating facilities should be provided.

94. In the event of any illness of a suspicious nature, the attending physician shall immediately quarantine the suspect, notify the health authorities and the secretary of the commission, and examine each member of the dairy force; and in every inflammatory affection of the nose or throat occurring among the employees of the dairy, in addition to carrying out the above-mentioned program, the attending physician shall take a culture and have it examined at once by a competent bacteriologist approved by the commission. Pending such examination, the affected employee or employees shall be quarantined.

95. It shall be the duty of the secretary, on receiving notice of any suspicious or contagious disease at the dairy, at once to notify the committee having in charge the medical supervision of employees of the dairy farm upon which such disease has developed. On receipt of the notice, this committee shall assume charge of the matter and shall have power to act for the commission as its judgment dictates. As soon as possible thereafter, the committee shall notify the commission, through its secretary, that a special meeting may be called for ultimate consideration and action.

96. When a case of contagious disease is found among the employees of a dairy producing certified milk under the control of a medical milk commission, such employee shall be at once quarantined and as soon as vossible remcved from the plant, and the premises fumigated.

When a case of contagion is found on a certified dairy it is advised that a printed notice of the facts shall be sent to every householder using the milk, giving in detail the precautions taken by the dairyman under the direction of the commission, 
and it is further advised that all milk produced at such dairy shall be heated at $145^{\circ} \mathrm{F}$. for 40 minutes, or $155^{\circ} \mathrm{F}$. for 30 minutes, or $167^{\circ} \mathrm{F}$. for 20 minutes, and immediately cooled to $50^{\circ} \mathrm{F}$. These facts should also be part of the notice, and such heating of the milk should be continued during the accepted period of incubation for such contagious disease.

The following method of fumigation is recommended:

After all windows and doors are closed and the cracks sealed by strips of paper applied with flour paste, and the various articles in the room so hung or placed as to be exposed on all sides, preparations should be made to generate formaldehyde gas by the use of 20 ounces of formaldehyde and 10 ounces of permanganate of potash for every 1000 cubic feet of space to be disinfected.

For mixing the formaldehyde and potassium permanganate a large galvanized-iron pail or cylinder holding at least 20 quarts and having a flared top should be used for mixing therein 20 ounces of formaldehyde and 10 ounces of permanganate. A cylinder at least $\mathbf{5}$ feet high is suggested. The containers should be placed about in the rooms and the necessary quantity of permanganate weighed and placed in them. The formaldehyde solution for each pail should then be measured into a wide-mouthed cup and placed by the pail in which it is to be used.

Although the reaction takes place quickly, by making preparations as advised all of the pails can be "set off" promptly by one person, since there is nothing to do but pour the formaldehyde solution over the permanganate. The rooms should be kept closed for four hours. As there is a slight danger of fire, the reaction should be watched through a window or the pails placed on a noninflammable surface.

97. Following a weekly medical inspection of the employees, a monthly report shall be submitted to the secretary of the medical milk commission, on the same recurring date by the examining visiting physician.

The following schedule, filled out in writing and signed by himself, is recommended as a suitable form for the attending physician's report: 
This is to certify that, on the dates below indicated, official visits were made to the dairy, owned and conducted by of - (indicating town and state), where careful inspections of the dairy employees were made.

(a) Number and dates of visits since last report.

(b) Number of men employed on the plant.

(c) Has a recent epidemic of contagion occurred near the dairy, and what was its nature and extent?

(d) Have any cases of contagious or infectious disease occurred among the men since the last report? -

(e) Disposition of such cases.

(f) What individual sickness has occurred among the men since the last report?

(g) Disposition of such cases.

(h) Number of employees now quarantined for sickness.

(i) Describe the personal hygiene of the men employed for milking when prepared for and during the process of milking.

(j) What facilities are provided for sickness in employees?

(k) General hygienic condition of the dormitories or houses of the employees.

(l) Suggestions for improvement.

$(m)$ What is the hygienic condition of the employees and their surroundings?

(n) How many employees were examined at each of the foregoing visits?

(o) Remarks.

Date, $\longrightarrow$

Attending Physician. 



\section{INDEX}

Abortion, infectious, 116

Acid-forming bacteria, 51

Acidity, determination of, 254

Acidity test with Babcock pipette, 256

Actinomycosis, 102

Adulteration, detection of, 249

Adulteration, determination of

degree of, 246

Aërator, 182

Age of milk, 64

Aggressins, 45

Alcohol test, 285

Alkalies, test for, 260

Anærobic bacteria, 57

Animal-like taste, 28

Anthrax, 100

Antibodies, 42

Antiformin method, 277

Aphthous fever, 96

Arnold's guaiac test, 298

Babcock test, 233

Bacillus abortus 116, 117

aerogenes, 56

bulgaricus, 54,55

coli, 56

Guillebeau, 54

lactis aërogenes, 53, 56

lactimorbi, 104

mesentericus vulgatus, 60

proteus vulgaris, 61

pyogenes, 108

subtilis, 60

typhosus, 121
Bacteria, acid-forming, 51

alkali-forming, 61

anærobic, 57

common-milk, effect of heat on, 209

counting, 260

gas-forming, 55

inert, 61

of milk, 50

pathogenic, effect of heat on, 204

peptonizing, 58

proportion of different

groups, 64:

variations in number and kind, 62

Bactericidal action of milk, 43

Bacterium acidi lactici, 53, 54, 55,56

lactis acidi, 52

Bedding, 178

Benzoic acid, test for, 259

Beet-like taste, 71

Biorization, 222

Bitter milk, 69

Bitter taste, 28, 29, 30

Black scab, 100

Blood in milk, 113

Blue milk, 71

Borax, tests for, 257

Boiling test, 284

Boric acid, tests for, 257

Burnt taste, 30

Burnt taste and odor, 71

Butyric acid bacteria, 57 
Calculation of total solids, 241

Casease bacteria, 58

Casein, 14

Catalase, 38

Catalase test, 287

Catarrhal mastitis, 105

Cells, number of in milk, 34

Cellular content of milk, 34

Certified' milk, 46

methods and standards, 303

Clarification, 175

Clarifier, 175

Cleaning milk vessels, 189

the cows, 166

the stable, method of, 160

Cocci, udder 59

Coli-aerogenes bacteria, 55, 56

Coli, examination for, 275

Color, examination of, 227

Color, of milk, 28

Coloring matters, examination for, 301

Colostrum, bactericidal power, 18

change of to milk, 13

chemical properties, 11

ferments or enzymes, 12 judgment of as food for man, 13

microscopic appearance, 12 reaction, 12

physical properties, 11

Common milk bacteria, 50

Composition of milk, variations, 19

Consistency, examination of, 227

Cooked taste, 30

Coolers, types of, 182

Coolers, conical, 183

corrugated, 183

double-tube, 186

internal, 186
Coolers, regenerative, 219

tubular, 184

Counting bacteria, collection of samples, 260 microscopic method, 267 plate method, 262

Covered-top pail, 172

Cows, examination for cleanliness, 148

for symptoms of disease, 150

Cow fly, 164

Cow-like taste, 66

Cowpox, 97

false, 99

Cows, stage of lactation, 149

Cream layer, 17

line, 17

line, effect of heat on, 213

Cubic air space, 136

Curdling, premature, 68

sour, 15

sweet, 15

Dairy Farm Inspection, 126

Decomposition products, effect of heat on, 210

Diastase, 37

test, 297

Dilution, effect of on infected milk, 73

influence of on tuberculous infection, 86

Diphtheria, 123

bacilli, effects of heat on, 205

Direct infection, 72

Dirt, examination for, 299

Disease, influence of on milk, 72 
Diseases of cattle which may render milk harmful, 104 of c a t $t \mathrm{le}$ transmissible through milk, 73

of man transmissible through milk, 119

Doane-Buckley Method, 282

“Dry" cows, 3 matter, 19

\section{Electricity, 222}

Electrical conductivity of milk, 34

Enteritis, septic or hemorrhagic, 114

Enzymes, 12, 36

bacterial, 37

original 37

eff ect of heat on, 213

Examining milk, methods of, 223

Excretion of medicines through udder, 119

Failure to Sour and "Butter," 70 False cowpox, 99

Farrington's alkaline tablet test, 256

Fat, 16

per cent., determination of, 233

per cent. in total solids, determination of, 246

Feed boils, 100

Feeding, 175

Ferments, bacterial, 37 effect of heat on, 213 original, 37

Fermentation-reductase test, 296

Fermentation test, 278

"Fishy" milk, 67 taste, 29
"Flaky" milk, 107, 109

Fleshy udder, 3

Flies, 161 cow fly, 164 horn fly, 164 house fly, 162 stable fly, 165

Formaldehyde, tests for, 258

Foot and mouth disease, 96

Foul and unpleasant odor and taste, 29

Freezing point of milk, 33

"Fresh" cows, 4

Fritzmann's Method, 248

Furunculosis of the udder, 99

Gas-forming bacteria, 55

Gerber test, 237

Germicidal action of milk, 43

Gravimetric method for determination of total solids, 240

Greenish-yellow spots, 71

"Gritty" milk, 68

Hay bacillus, 60

Heated milk, tests for, 298

Holder and pasteurizer combined, 220

Holding tank, 219

Homogenized milk, 17

Horn fly, 164

House fly, 162

Ice, quantity required, 187

Indigestion, 114

Inert bacteria, 61

Infection, direct, 72

secondary, 72

Inflammation of the udder, 104

Influence of disease on milk, 72

Immune bodies, 42 
Inspection of dairy farms, 126

Interstitial mastitis, 109

Intestinal tuberculosis, diagnosis of, 95

Involution, 2

Lactalbumin, 16

Lactation, physiology of, 1 stages of, 3

Lactoglobulin, 16

Lactometer, Quevenne's, 228

Lactose, 18

test for, 301

Lactoscope test, 239

Leach's test, 259

Legal standards, 23, 24, 25

Leucocytes, estimation of number, 281

"Letting down," 7

Litmus test, 254

Malt-like taste and odor, 71

Manure-like odor, 30

Mann's acidity test, 254

Market milk, classes or grades

$$
\text { of, } 45
$$

composition of, 22

frequency of tubercle bacilli in, 73

prevention of contamination

Mastitis, 104 with tubercle bacilli, 90

catarrhal, 105

interstitial, 109

milk, harmful properties of, 110

parenchymatous, 108

tuberculous, 81, 93

Medicines, excretion through udder, 119

Metritis, septic, 115
Milk, opacity of, 18

biological properties, 36

cellular content, 34

chemical properties, 14

color, 28

defects, 66

electrical conductivity, 34

ferments or enzymes, 36

freezing point, 33

odor and taste of, 28

pails, types of, 172

physical properties, 28

reaction, 26

refraction, 32

secretion, phases of, 6

first phase, 6 second phase, 7

sickness, 104

solids, 19

specific gravity of, 30

surface tension, 33

Milk house, apparatus, 182

construction, 181

location, 180

water supply, 193

Milk vessels, methods of cleaning, 183

sterilization of, 190

viscosity, 33

Milking machines, methods of cleaning, 192

Milking, methods of, 168

Nauseating taste, 30

Nitrates and nitrites, tests for, 247

Nutritive properties, effect of heat on, 211

Odor, examination of, 227

Odor and taste of milk, 28 
Odors, absorption of by milk, 29

CEdema of the udder, 113

Oily taste, 30

Opacity of milk, 18

Open Tuberculosis, diagnosis of, 94

Orange-colored spots, 71

Original contamination, 63

Ozone, 222

Paratyphoid fever, 123

Parenchymatous mastitis, 108

Pasteurization, 203

"flash" process, 214 continuous process, 214

"holder" process, 214

in final container, 214

methods of, 214

principles of, 204

summary of effects of, 213

Pasteurizers, types of, 215

Peptonizing bacteria, 58

Peroxydase, 38

Peter's test, 259

Physiology of milk secretion, 1

Potato bacillus, 60

Premature curdling, 68

Preservatives, tests for, 257

Rabies, 101

Rancid milk, 67

odor and taste, 30

taste, 28

Reaction, determination of, 254

of colostrum, 12

of milk, 26

Red milk, 71

Reductase, 39

test, 294
Refractive index, 32

Refraction number, determination of, 250

Regenerative cooler, 219

Remont's test, 259

Retained placenta, 116

Retarder, 220

Richmond's test, 258

"Ropy" milk, 69

Rosolic acid test, 260

Salicylic acid, test for, 259

Salts, 19

Salty, cow-like taste, 66 taste, 28

Samples, collecting, 223

individual, 226

mixing, 226

preserving, 224

stable or herd, 225

"Sandy " milk, 68

Scarlet fever, 125

Score cards, 197

Secondary infection, 72

Secretion of milk, first phase, 6 phases of, 6

physiology, 1 second phase, 7

Septic sore throat, 124

Slow-creaming milk, 67

"Soapy" taste, 70

Solid's, determination of, 240

by automatic reckoner, 245

by calculation, 241

Gravimetric method, 240

determination of specific gravity of, 246

Solids not fat, 19

determination of, 245

Sore throat, septic, 124 
Sour curdling, 15

odor and taste, 30

Soxhlet's test, 247

Specific gravity, determination

$$
\begin{gathered}
\text { of, } 228 \\
\text { of milk, } 30
\end{gathered}
$$

of milk solids, determination of, 246

Spoiled feed, effects of on milk, 114

Stable, ceiling, 139

drop, 144

exposure, 129

exterior, 129

feed trough, 143

floor of stall, 144

gutter, 144

interior construction, 139

light, 146

location, 129

manger, 143

odor of air, 131

platform, 140

ties, 145

type, 129

walls, 139

stall divisions, 145

stanchions, 14.5

surroundings, 130

Stable fly, 165

Stable-like odor and taste, 29, 30 taste, 71

Stable practices, 159

bedding, 178

cleaning the cows, 166

cleaning the stable, 160

feeding, 175

milking, 168

time required, 179

Stages of lactation, 3
Stalls, arrangement of, 145

hospital and maternity, 146

Standards, legal, for milk and cream, 23, 24, 25

Staphylococcus pyogenes, 59

Sterilization of milk vessels, 190

Stewart's test, 281

Stokes' test, 281

Storch's test, 298

Strainers, 173

Streptococci, examination for, 272

of mastitis, 53

Streptococcus lacticus, $52,54,55$ pyogenes, eff ect of heat on, 205

Stringy milk, 69

"Strippers," 5

Structure of udder, 1

Surface tension of milk, 33

Sweet curdling, 15

Taste, effect of heat on, 213

examination of, 227

and odor of milk, 28

Temperature, eff ect on growth of bacteria, 63

Total solids, 19

determination of, 240

Toxins, 44

Trembles, 104

Trommsdorff test, 282

Tubercle bacilli,

from cattle, virulence of, for man, 75

conditions under which milk is infected with, 81

eff ect of heat on, 205

examination for, 275 
Tubercle bacilli, frequency of in market milk, 73

human type, in milk, 125

influence of dilution on, 86

prevention of contamination of market milk with, 90

Tuberculosis, intestinal, diagnosis of, 95

open, diagnosis of, 94

of the udder, diagnosis of, 94

uterine, diagnosis of, 95

Turmeric test, 258

Turnip-like taste, 71

Typhoid fever, 121

bacilli, effects of heat on, 205

Toxins, eff ect of heat on, 210

Unclean taste, 30

Udder cocci, 59

diagnosis of tuberculosis of, 94

fleshy, 3
Udder, inflammation of, 104 œdema of, 113 structure of, 1

Uitra-violet rays, 222

Uterus, diagnosis of tuberculosis of, 95

Variations in composition of milk, 19 causes of, 20

Ventilation, 132 cloth method, 135

King system, 132

Villier's and Fayolles' test, 257

Virulence of tubercle bacilli from cattle for man, 75

Viscid milk, 69

Viscosity of milk, 33

Violet-colored spots, 71

Water, 19 supply, 193

Westphal balance, 229

Yellow spots, 71

Yellowish-green milk, 71

Yellowish-green spots, 71 




THIS BOOK IS DUE ON THE LAST DATE STAMPED BELOW

AN INITIAL FINE OF 25 CENTS WILL BE ASSESSED FOR FAILURE TO RETURN THIS BOOK ON THE DATE DUE. THE PENALTY WILL INCREASE TO 50 CENTS ON THE FOURTH DAY AND TO \$1.00 ON THE SEVENTH DAY OVERDUE.

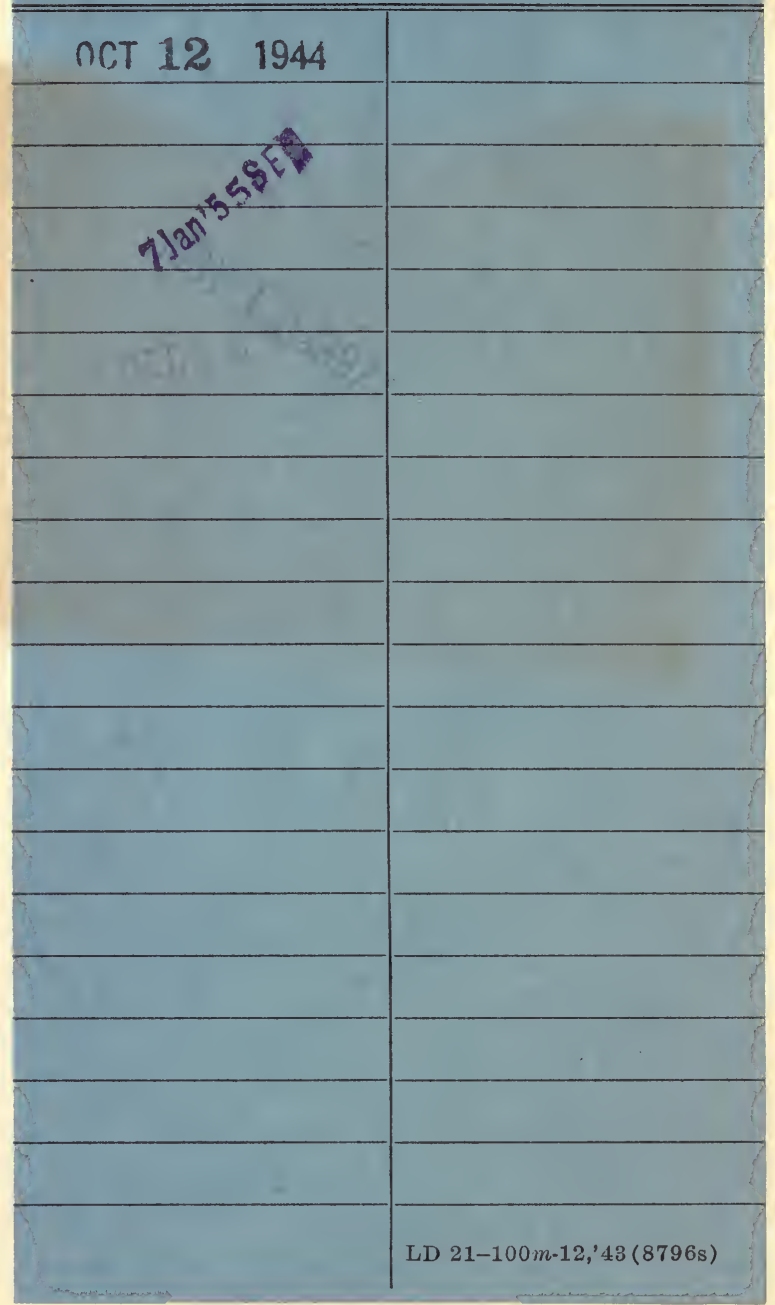


